\title{
Consecuencias de las modificaciones en la escorrentía y temperatura, relacionadas con los cambios globales, sobre el biofilm de sistemas lóticos pampeanos
}

\section{Lic. Joaquín Cochero}

Directora: Dra. Nora Gómez

Trabajo de tesis para optar al título de Doctor en Ciencias Naturales

Instituto de Limnología "Dr. Raúl A. Ringuelet"

CONICET - FCNYM - UNLP

2013 


\section{Agradecimientos}

A Mamá, Papá, Fran y Grego; por todo el apoyo a lo largo de todos estos años, por preocuparse y seguir mi carrera de cerca, iijlos adoro!!!

A Nico; por ser el hermano postizo incondicional

A Nora; por su excelente dirección, paciencia y por todas las oportunidades que me da para aprender

A Male; por el apoyo y por siempre estar ofreciendo ayuda a su primer co-becario!

A Belu; por soportarme en este último tramo y alegrar todos mis días

A Vane y Ana; por el apoyo y la risas

A Ale; por compartir los momentos gamer diarios que me dan aire fresco

A Maxi; por el aguante y las cervezas

A Delia y Vicky; por los mates!

A los amigos, Fanello, Javi, Lara, Damián, Dani, Dino, Carrión; que me han tenido tanta paciencia y que, a pesar de mis colgadas, me siguen invitando a las juntadas

A los "compas" del ILPLA, Cristian, Euge, Pacha, Caro, Estefi, Palito; por el día a día!

A los investigadores y técnicos que siempre me han ofrecido una mano cuando la necesité: Carlos Bonetto, Alejandro Mariñelarena, Jorge Donadelli, Alberto Rodrigues Capítulo, Adonis Giorgi, Anna Romaní

A los jurados de esta tesis, Dra. Verónica Díaz Villanueva, Dra. María Adela Casco y Dr. Adonis Giorgi; por sus aportes, correcciones y sugerencias

A la secretaría de posgrado de la FCNyM por su labor

Al Consejo Nacional de Investigaciones Científicas y Técnicas por el financiamiento

A los proyectos que financiaron las experiencias: Proyecto GLOBRIO de la Fundación BBVA (Dir.: Dr. Sergi Sabater), Proyecto CONICET PIP 296 (Dir.: Dra. Nora Gómez) 
RESUMEN

ABSTRACT

CAPÍTULO 1

Introducción

1.1 Efecto de los cambios globales en los sistemas lóticos 10

1.2 Los arroyos pampeanos 15

$\begin{array}{ll}1.3 & \text { Los biofilms } \\ & 17\end{array}$

1.3.1 El rol de los biofilms en los arroyos 20

1.3.2 Factores que influencian el desarrollo de los biofilms 21

\section{CAPÍTULO 2}

Objetivos, hipótesis y diseño experimental

$\begin{array}{llr}2.1 & \text { Objetivos generales } & 34\end{array}$

$\begin{array}{lll}2.2 & \text { Objetivos particulares } & 34\end{array}$

$\begin{array}{ll}2.3 \text { Hipótesis } & 35\end{array}$

2.4 Diseños experimentales $\quad 36$

2.4.1 El diseño BACIPS (Before-After/Control-Impact Paired Series) 36

2.4.2 El diseño factorial 40

\section{CAPÍTULO 3}

Metodologías

3.1 Materiales y métodos

3.1.1 Recolección del biofilm epipélico $\quad 42$

3.1.2 Parámetros físico-químicos $\quad 43$

3.1.3 Composición del biofilm $\quad 46$

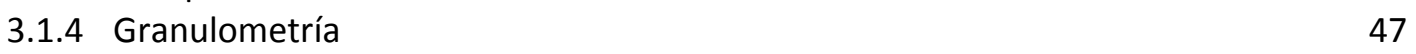

$\begin{array}{lll}3.1 .5 & \text { Biomasa de productores primarios } & 49\end{array}$

$\begin{array}{ll}3.1 .6 & \text { Densidad y biomasa bacteriana }\end{array}$

3.1.7 Actividad respiratoria del biofilm $\quad 52$

3.1.8 Carbohidratos totales $\quad 54$

3.1.9 Actividades enzimáticas extracelulares 55

3.1.10 Peso seco libre de cenizas (PSLC) 57

3.1.11 Índice Autotrófico (IA), riqueza e Índice de diversidad de Shannon (H) 57

3.2 Diseño de canales artificiales para el estudio de los biofilms 58

$\begin{array}{lll}3.2 .1 & \text { Antecedentes } & 58\end{array}$

$\begin{array}{lll}3.2 .2 & \text { Ventajas y limitaciones } & 60\end{array}$

$\begin{array}{lll}3.2 .3 & \text { Consideraciones para su construcción } & 61\end{array}$

3.2.4 El sustrato y su colonización $\quad 62$

3.2.5 Hidrodinámica $\quad 66$

$\begin{array}{llr}3.3 & \text { Análisis estadísticos } & 69\end{array}$

$\begin{array}{lll}3.4 & \text { Medidas estadísticas del efecto biológico } & 71\end{array}$ 
Efectos de la adición experimental de nutrientes sobre los biofilms epipélicos de arroyos pampeanos

$\begin{array}{lll}4.1 & \text { Introducción } & 73\end{array}$

$\begin{array}{lll}4.2 & \text { Objetivos e hipótesis } & 74\end{array}$

4.3 Materiales y métodos $\quad 75$

$\begin{array}{lll}\text { 4.3.1 Diseño experimental } & 75\end{array}$

$\begin{array}{lll}\text { 4.3.2 Sitio de estudio } & 76\end{array}$

$\begin{array}{lll}\text { 4.3.3 Variables medidas } & 78\end{array}$

$\begin{array}{ll}\text { 4.3.4 Análisis estadísticos } & 79\end{array}$

$\begin{array}{llr}\mathbf{4} .4 & \text { Resultados } & \mathbf{8 0}\end{array}$

4.4.1 Parámetros físico-químicos $\quad 80$

4.4.2 Densidad y biomasa bacteriana 84

$\begin{array}{lll}\text { 4.4.3 Biomasa algal } & 85\end{array}$

4.4.4 Actividades enzimáticas extracelulares 86

$\begin{array}{ll}4.5 & \text { Discusión y conclusiones }\end{array}$

\section{CAPÍTULO 5}

El efecto simultáneo del incremento de nutrientes, temperatura, turbidez y velocidad de la corriente en biofilms. Ensayos de laboratorio.

$\begin{array}{lll}5.1 & \text { Introducción } & 96\end{array}$

5.2 Objetivos e hipótesis 96

5.3 Materiales y métodos $\quad 97$

$\begin{array}{lll}\text { 5.3.1 Diseño experimental } & 100\end{array}$

$\begin{array}{ll}\text { 5.3.2 Manipulación experimental de variables } & 101\end{array}$

$\begin{array}{ll}\text { 5.3.3 Variables medidas } & 103\end{array}$

$\begin{array}{ll}\text { 5.3.4 Análisis estadísticos } & 104\end{array}$

$\begin{array}{lll}5.4 & \text { Resultados } & 105\end{array}$

$\begin{array}{lll}\text { 5.4.1 Parámetros físico-químicos } & 105\end{array}$

$\begin{array}{ll}\text { 5.4.2 Variables hidrodinámicas } & 109\end{array}$

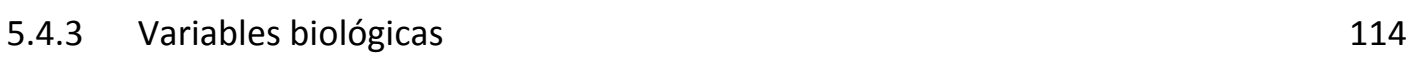

$\begin{array}{lll}\text { 5.4.3.a } & \text { Biomasa bacteriana } & 114\end{array}$

$\begin{array}{lll}\text { 5.4.3.b Biomasa algal } & 116\end{array}$

$\begin{array}{lll}\text { 5.4.3.c Peso seco libre de cenizas (PSLC) } & 118\end{array}$

$\begin{array}{ll}\text { 5.4.3.d Índice autotrófico } & 120\end{array}$

$\begin{array}{ll}\text { 5.4.3.e } & \text { Actividad respiratoria del biofilm } \\ & 121\end{array}$

$\begin{array}{ll}\text { 5.4.3.f Carbohidratos totales } & 124\end{array}$

$\begin{array}{ll}\text { 5.4.3.g Descriptores taxonómicos del biofilm } & 127\end{array}$

5.4.3.h Análisis de las características ecológicas de las diatomeas $\quad 127$

5.4.3.h.i Metabolismo de consumo del nitrógeno 134

5.4.3.h.ii Saprobiedad 136

5.4.3.h.iii Estado trófico 138

$\begin{array}{ll}5.5 \text { Discusión y conclusiones } & 142\end{array}$

\begin{tabular}{lr} 
CONSIDERACIONES FINALES & 147 \\
\hline
\end{tabular}

BIBLIOGRAFÍA $\quad 157$ 


\section{RESUMEN}

Los ríos están amenazados por presiones socioeconómicas que alteran los usos del suelo y el clima degradando las condiciones ambientales, por ende afectando la calidad del agua y la hidrología de estos ecosistemas. Aproximadamente el $40 \%$ de la superficie terrestre está ocupada por cultivos y pasturas, y el uso de fertilizantes que contienen fósforo y nitrógeno se ha incrementado entre dos y siete veces respectivamente en los últimos 40 años. Estos cambios forman parte de lo que se conoce como "cambios globales", cuya definición abarca la combinación de cambios climáticos (tales como alteración de los patrones de precipitación y temperatura, variaciones en el $\mathrm{CO}_{2}$ atmosférico, etc.), y de cambios en el uso de la tierra (como el aumento en el uso de fertilizantes, aumento de la urbanización, etc.). Por lo tanto es esperable de acuerdo con los futuros escenarios de cambios climáticos que los cursos de agua sufran cambios de distinta magnitud, dependiendo el área del planeta que se analice. En el caso de la región pampeana estos incluirían de acuerdo con los pronósticos aumentos en la escorrentía y temperatura que acarrearán aumentos de nutrientes, sólidos en suspensión y de la velocidad de la corriente. De acuerdo con los descriptores analizados en las experiencias in situ y ex situ realizadas en esta tesis, fue posible comprobar algunos de los efectos pertinentes a estas problemáticas en sistemas lóticos pampeanos. En esta tesis se focalizó el interés en el desarrollo y las características del biofilm epipélico, que recubre los sedimentos finos del lecho de los cursos de agua pampeanos. Esta microcomunidad está modulada por muchos factores, entre los que se incluyen las concentraciones de nutrientes inorgánicos, la luz, temperatura, el sustrato, la herbivoría, la velocidad de la corriente y las características de las partículas transportadas por el flujo, entre otros. Por lo tanto, las presiones originadas por los cambios globales pueden tener efectos significativos sobre el desarrollo de este tipo de biofilm.

El objetivo general de la presente tesis fue estudiar los cambios en la estructura y funcionamiento de los biofilms epipélicos de cursos de agua de la llanura pampeana expuestos a las consecuencias relacionadas con algunos de los efectos de los cambios globales. Para esto se realizaron experiencias in situ y ex situ con la finalidad de contrastar hipótesis vinculadas al incremento de nutrientes, temperatura, turbidez y velocidad de la corriente, como algunas de las variables que podrán ser afectadas en el marco de estos cambios. 
Para cumplir esta finalidad se realizó una experiencia de adición de nutrientes en campo y dos experiencias de laboratorio en canales artificiales.

La experiencia de adición experimental de nutrientes (fósforo y nitrógeno) se realizó en un tramo de un arroyo pampeano (denominado tramo Impacto), y se comparó con un tramo del mismo arroyo sin modificar (denominado tramo Control). Ambos tramos fueron muestreados por 9 meses previamente a la adición experimental de nutrientes y durante 12 meses durante la adición continua de nutrientes.

En esta experiencia, llevada a cabo en el Arroyo "La Choza" de la localidad de Luján, se estudiaron las variaciones en las biomasas algales y bacterianas y la producción de enzimas relacionadas con la degradación de materia orgánica ( $\beta$-glucosidasa) y con la adquisición de nutrientes (fosfatasa). Para esta fertilización se buscó generar un enriquecimiento moderado, triplicando los niveles basales del arroyo de fósforo y nitrógeno, para lo que se adicionó fertilizante de uso comercial (Nitrofoska Azul ${ }^{\circledR} 12 \% \mathrm{P}, 12 \% \mathrm{~N}$ ).

Entre los resultados obtenidos, se observó un aumento progresivo de la biomasa algal seguido por aumentos graduales de la biomasa bacteriana. Esto sugiere que las bacterias basan su consumo preferentemente en los productos autotróficos (ej.: carbono) mientras que el consumo de nutrientes inorgánicos tanto como para algas como para bacterias es reducido. Por otro lado, la falta de respuesta de las enzimas analizadas a la adición de nutrientes, y su baja concentración en el arroyo, demuestran que el biofilm no es estimulado por estas condiciones para producirlas. Esto es consistente con los arroyos donde los nutrientes no son limitantes, y su adquisición resulta simplificada.

Las dos experiencias en laboratorio se llevaron a cabo empleando canales artificiales. Una se realizó con un biofilm proveniente de un arroyo con bajo impacto antropogénico (valores promedio de Fósforo Reactivo Soluble (PRD) 0,37 $\mathrm{mgL}^{-1}$; Nitrógeno Inorgánico Disuelto (NID) 0,22 $\mathrm{mgL}^{-1}, \mathrm{DBO}_{5} 6 \mathrm{mgL}^{-1}$, DQO $15 \mathrm{mgL}^{-1}, \mathrm{OD} 7,70 \mathrm{mgL}^{-1}$ ) y otra con uno procedente de un arroyo con alto impacto antropogénico (valores promedio de PRS 2,24 $\mathrm{mgL}^{-1}$; NID 1,85 $\mathrm{mgL}^{-1}$,

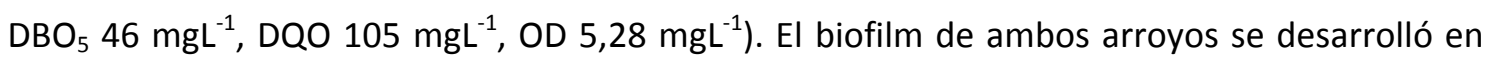
los canales y se les aplicó dos tipos de tratamientos (TB: tratamiento bajo y TA: tratamiento alto). Estos consistieron en incrementar los nutrientes en el agua (fósforo y nitrógeno), la turbidez, la velocidad de la corriente y la temperatura de acuerdo con las predicciones planteadas en los escenarios de cambio global. El tratamiento TA recibió un mayor incremento de esas variables que el tratamiento TB, y ambos tratamientos fueron comparados con canales 
control (C). Cada tratamiento y control fue realizado por triplicado, y el agua de los canales artificiales fue provista por el mismo arroyo de donde se colectaron los biofilms.

Las experiencias de laboratorio presentadas en esta tesis trataron de demostrar que el efecto combinado del aumento de la velocidad de la corriente, nutrientes, turbidez y temperatura, favorecen un mayor desarrollo y actividad en la comunidad biológica. Los principales resultados evidencian que la composición de especies del biofilm es alterada cuando es expuesta a los efectos simultáneos de estos cuatro estresores asociados a los cambios globales en la llanura pampeana. La disminución de especies de diatomeas oligotróficas y oligosaprobicas en el experimento con biofilms del arroyo con bajo impacto antropogénico indica que el ensamble es afectado por los tratamientos. En esa misma experiencia, la diversidad y la riqueza específica disminuyeron en los tratamientos más intensos del experimento, sugiriendo que dicha comunidad es más sensible que la desarrollada en el experimento con biofilms del arroyo mas impactado. Sin embargo, otras variables estructurales y metabólicas que caracterizan el biofilm en general - tales como el contenido de clorofila "a", la biomasa bacteriana, los carbohidratos totales y el peso seco libre de cenizasno evidenciaron diferencias significativas a causa de los estresores estudiados.

Hay que considerar que las pequeñas variaciones debidas a los tratamientos pueden ser importantes para la escala de tiempo empleada, e incluso la estructura de las comunidades fue alterada hasta la significancia estadística. Por ejemplo, las proporciones de especies de diatomeas, al ser clasificadas por su consumo del nitrógeno, saprobiedad y estado trófico, sufrieron pequeñas modificaciones en el corto plazo de las experiencias. Estos cambios estructurales en estas comunidades fueron mayores en aquella que provenía de un arroyo con un menor impacto antropogénico, como es esperable a comunidades menos tolerantes.

Estos cambios parecen sutiles, pero resultan amplios si se considera la escala temporal y espacial utilizada. Los cambios globales ejercen sus efectos a escalas temporales y espaciales mucho mayores a las utilizadas en estos ensayos, y la cantidad de variables a considerar para su estudio apropiado es muy vasta. Pero es mediante el estudio a escalas pequeñas que se puede llegar a una mejor comprensión de la dinámica interna de esta microcomunidad y de los efectos que tienen las variables que influencian su desarrollo.

De acuerdo con los resultados obtenidos en esta tesis es posible reconocer que los arroyos pampeanos demuestran una resistencia al cambio que se manifiesta a través de respuestas diferidas o de pequeños cambios visibles a diferentes escalas. 
En síntesis, la mayor parte de las hipótesis planteadas en esta tesis fueron rechazadas. Por lo cual el efecto de los enriquecimientos con nutrientes puede ser menos predecible en sistemas con altas concentraciones basales de nutrientes, como es el caso de los arroyos pampeanos, naturalmente enriquecidos. Referencias bibliográficas acreditan que estos arroyos muestran una red trófica muy compleja y compartimentalizada, y esa complejidad sería una de las causas que amortiguarían la transferencia potencial de los efectos de las adiciones de nutrientes.

Estos resultados indican que el amplio rango de medidas que pueden reducir los efectos de la eutrofización en arroyos debería incluir la planificación de los usos del suelo, particularmente los usos urbanos y agrícolas, reconocidos como las principales fuentes de nutrientes que pueden ingresar a los arroyos. 


\section{ABSTRACT}

Rivers and streams throughout the world are being threatened by socioeconomic pressures that alter the land uses and climate, degrading environmental conditions and hence affecting their water quality and hydrology. Approximately $40 \%$ of the entire surface of the planet is covered with crops and pastures, and the usage of fertilizers containing phosphorous and nitrogen have increased between two and seven times respectively in the last 40 years. These changes are part of what are known as "global changes", which definition comprises both climatic changes (such as the altering of precipitation patterns and temperature, variations in atmospheric $\mathrm{CO}_{2}$, etc.), and land use changes (such as increases in urbanization and fertilizer use, etc.). It is expected that, according to the scenarios for future climate changes, water courses are affected in different degrees by global changes, depending on the area of the planet that is analyzed. According to the descriptors studied in the in situ and ex situ experiments conducted in this thesis manuscript, it was possible to confirm some alterations pertinent to these issues in the lotic pampean streams. In this research the focus was in the development and characteristics of the epipelic bioifilm, that covers fine sediments in the streambed of pampean rivers and streams. This microcomunity is shaped by many factors, including the concentration of inorganic nutrients, light, temperature, the characteristics of the substrate, the influence of herbivores, the current velocity and the characteristics of the particles that are being transported by the water flow, among others. Therefore, the pressures generated by the global changes might have significant effects on the development of the streams biofilms.

The general objective of this thesis manuscript was to study the changes in structure and functioning of the epipelic biofilms in the pampean streams exposed to the consequences related to some of the effects of the global changes. To achieve this, both in situ and ex situ experiments were conducted to test the hypotheses linked to increases of inorganic nutrients, temperature, turbidity and water velocity, since those variables might be affected by these global changes.

The experiments consisted of an in situ nutrient addition in a stream, and two ex situ experiments in artificial streams in the laboratory. 
The nutrient addition experiment (phosphorous and nitrogen) was carried out in a pampean stream reach (labeled Impact), which was compared to a similar upstream reach left unmodified (labeled Control). Both reaches were sampled for 9 months prior to a continuous nutrient addition in the Impact reach, which lasted another 12 months.

In this experiment, which took place in "La Choza" stream near the city of Luján, the variations of the algal and bacterial biomasses were studied, along with their production of extracellular enzymes related to the degrading of organic matter ( $\beta$-glucosidase) and nutrient acquisition (phosphatase). The objective of the nutrient addition was to generate a moderate increase in inorganic nutrients, tripling the levels of phosphorous and nitrogen in the stream by using of commercial use fertilizer (Nitrofoska Azul ${ }^{\circledR} 12 \% \mathrm{P}, 12 \% \mathrm{~N}$ ).

The results showed a steady increase in algal biomass followed by gradual increases in the bacterial biomass. This suggests that the heterotrophic community bases its consumption in autotrophic products, while the consumption of inorganic nutrients by both communities is reduced. On the other hand, the lack of response to the nutrient addition exhibited by the enzymes, and their low concentration in the stream water, suggest that the biofilm is not stimulated to produce them under these conditions. This is consistent with streams where nutrients are not limited, and their acquisition is simplified.

The two laboratory experiments were carried out employing artificial streams. One experiment was conducted using a biofilm that came from a stream with low anthropogenic impact (SRP $0.37 \mathrm{mgL}^{-1}$; DIN $0.22 \mathrm{mgL}^{-1}, \mathrm{BOD}_{5} 6 \mathrm{mgL}^{-1}, \mathrm{COD} 15 \mathrm{mgL}^{-1}$, DO $7.70 \mathrm{mgL}^{-1}$ ) and the other experiment was conducted using a biofilm that came from a stream with high anthropogenic impact (SPR $2.24 \mathrm{mgL}^{-1}$; DIN $1.85 \mathrm{mgL}^{-1}, \mathrm{BOD}_{5} 46 \mathrm{mgL}^{-1}$, COD $105 \mathrm{mgL}^{-1}$, DO 5.28 $\left.\mathrm{mgL}^{-1}\right)$. The biofilms from both streams were developed in the artificial streams, and two treatments were applied (TB: low and TA: high). These treatments consisted in increased inorganic nutrients (phosphorous and nitrogen), turbidity, water velocity and temperature, according to the predictions considered for the global change scenarios. The TA treatment received a higher increase in those variables that the TB treatment and both treatments were compared to control streams (C). All treatments and control streams were replicated, and the water that circulated through the artificial streams was provided by the same stream from which the biofilms were collected. 
The laboratory experiments in this thesis manuscript tried to prove that the combined effect of the increase in water velocity, nutrients, turbidity and temperature favored the development and activity of the biological community. The main results evidence that the species composition of the biofilm is altered when exposed simultaneously to these four stressors associated with global changes in the Pampean plain. A diminish in the oligotrophic and oligosaprobic diatoms in the experiment that used a biofilm from a stream with a low anthropogenic impact indicates that the assemblage is affected by the treatments. In that same experiment, the diversity and species richness decreased in the high treatments, suggesting that the community is more sensitive than the community that develops in a highly impacted stream. However, other structural and metabolic variables that characterize the biofilm in general - such as the ash-free dry weight, the chlorophyll "a" concentration, the bacterial biomass and the total carbohydrates - did not evidence significant differences due to the treatments.

It is important to consider that the small variations due to the treatments can be of importance when the time scale is considered, and that even the community structure was altered to a significant level. For instance, the proportion of diatom species, as classified by their nitrogen consumption, saprobity and trophic state, suffered small modifications in the short term of the experiments. These structural changes in these communities were greater in the biofilm that came from a less impacted stream, as it is expected for less tolerant communities.

These changes seem subtle, but can be bigger if both the time scale and spatial scale are considered. Global changes produce their effects in temporal and spatial scales that are much greater than the ones used in these experiments, but the studies at smaller scales can provide a better understanding of the internal dynamics in biofilms and the effects of the interactions between the variables that alter its development.

Although the variations observed in the treatments and controls are small, they can be important if the time frame is considered. For instance, in the biofilm that originated from the stream with low anthropogenic impact, variations linked to the treatments in chlorophyll "a" of up to $5 \%$ and in total respiratory activity up to $6 \%$ were measured, in only six weeks of exposure to the treatments. Although, and that the amount of variables that must be studied is vast,. 
According to the results obtained in this thesis manuscript, it is possible to recognize that the communities in pampean streams show a resistance to change that is manifested through gradual responses or small changes evidenced at different scales.

In summary, most of the proposed hypotheses in this thesis manuscript were rejected. Therefore the effects of nutrient enrichments can be less predictable in ecosystems with higher nutrient concentrations, such as the pampean streams that are naturally enriched. These systems show a very complex and compartmentalized trophic network, and its complexity could buffer the potential transfer of the effects caused by nutrient additions.

These results show that the wide range of measures that can reduce the eutrophication of streams should include the proper planning of the land uses, particularly the urban and agricultural land uses, recognized to be the main sources of nutrients that might enter streams and rivers. 


\section{CAPÍTULO 1}

\section{INTRODUCCIÓN}

"Investigación es lo que hago cuando no sé lo que estoy haciendo" Wernher von Braun 
Los ríos son los sistemas nefríticos de la cuenca y, por tanto, su geoquímica y su biota reflejan lo que sucede en el conjunto del territorio (Margalef 1997). En tal sentido pueden aportar información del estado de conservación y de la "salud" de la cuenca. Además su relevancia social y económica es de gran importancia, ya que representan un servicio natural de primer orden para distintos usos como transporte, provisión de agua para consumo, recepción de efluentes urbanos e industriales, producción de energía y pesca, entre otros.

Los cursos de agua son también lugares donde se concentra una gran parte de la biodiversidad a pesar de la reducida extensión de los ecosistemas de agua dulce (sólo el 0,8\% de la superficie de la Tierra). Naiman \& Décamps (1990) calculan que un 60\% de las especies que pueblan el planeta viven o hacen uso de los ríos y de los bosques de ribera asociados a ellos.

Desde una perspectiva geológica, los ríos han transportado durante millones de años buena parte de los sedimentos que afloran en las orogenias y forman parte del sustrato litológico de las placas continentales. Estos sedimentos provienen de la acción de los agentes erosivos, por lo que los ríos no sólo son cruciales para entender el ciclo hidrológico, sino que su papel está presente desde la orogenia hasta la denudación de los continentes. En este contexto, es interesante destacar que los ríos suelen perdurar más que los lagos, ya que éstos tienden a colmatarse de sedimentos y desaparecer (Sabater \& Elosegui 2009).

La caracterización ecológica de los ríos puede llevarse a cabo sobre la base de su estructura y funcionamiento (Allan \& Castillo 2007). Se entiende por estructura aquellas características del medio abiótico que forman el escenario en el que se desarrolla el ecosistema, y de las comunidades de organismos que constituyen sus actores principales. Por funcionamiento de los ecosistemas se entienden los procesos que ocurren en los mismos, y que están determinados tanto por el medio abiótico como por los organismos.

En el caso de los ecosistemas fluviales, su estructura está ligada a la forma y dimensiones del cauce, a la calidad del agua, a la diversidad de hábitats y a las distintas comunidades biológicas que se establecen en los mismos. Su funcionamiento está ligado a procesos como el transporte y retención de sedimentos, reciclado de nutrientes o materia orgánica, o por la fotosíntesis de algas y otros productores primarios, entre otros ejemplos. 
Los ríos están amenazados por presiones socioeconómicas que degradan las condiciones ambientales alterando los usos del suelo y el clima, por ende afectando la calidad del agua y la hidrología de estos ecosistemas. Aproximadamente el $40 \%$ de la superficie terrestre está ocupada por cultivos y pasturas (Ramankutty \& Foley 1999, Asner et al. 2004, Foley et al. 2005). El uso de fertilizantes que contienen fósforo y nitrógeno ha incrementado entre dos y siete veces respectivamente, y las superficies de tierras cultivadas se han duplicado en los últimos 40 años (Tilman et al. 2001).

Estos cambios conforman parte de lo que se conoce como "cambios globales", cuya definición abarca la combinación de cambios climáticos (tales como alteración de los patrones de precipitación, variaciones en el $\mathrm{CO}_{2}$ atmosférico, etc.), y de cambios en el uso de la tierra (como el aumento en el uso de fertilizantes, aumento de la urbanización, etc.) (Vitousek 1994, Stevenson \& Sabater 2010). Estos cambios globales son forzantes que pueden modificar la estructura y funcionamiento de los ríos y pueden tener impactos muy importantes sobre los recursos de agua dulce, incluyendo cambios en la temperatura, escorrentía, flujos de nutrientes, regímenes de flujos y en la calidad del agua (Firth \& Fisher 1992). Predecir la respuesta de los ríos a los cambios globales es crítico para el manejo de recursos acuáticos, servicios del ecosistema y el bienestar humano (Stevenson \& Sabater 2010).

Los cambios climáticos son evidentes a escalas temporales largas y a nivel ecosistémico, y su origen se encuentra en activa discusión (antropogénico o natural, o ambos) (Stevenson \& Sabater 2010).

El Panel Intergubernamental de Cambio Climático, mediante un Reporte Especial en Escenarios de Emisiones (IPCC 2007), indica que el promedio anual de escorrentía puede incrementarse en un $10-40 \%$ en las latitudes más altas, y decrecer en un $10-30 \%$ en las regiones más secas.

Como las proyecciones climáticas dependen en parte de la actividad humana futura, los modelos climáticos son calculados para distintos escenarios, que contemplan los posibles desarrollos demográficos, socioeconómicos y tecnológicos. El reporte plantea así la existencia de unos cuarenta escenarios posibles que son agrupados en cuatro "familias" (A1, A2, B1 y B2, Tabla 1.1). Estas familias clasifican a los escenarios en base a la heterogeneidad en el desarrollo socioeconómico (con mayor globalización o mayor regionalización) y en base a su enfoque (económico de rápido crecimiento pero con poca consideración del aspecto ambiental o ambiental con el empleo máximo de tecnologías sustentables). 

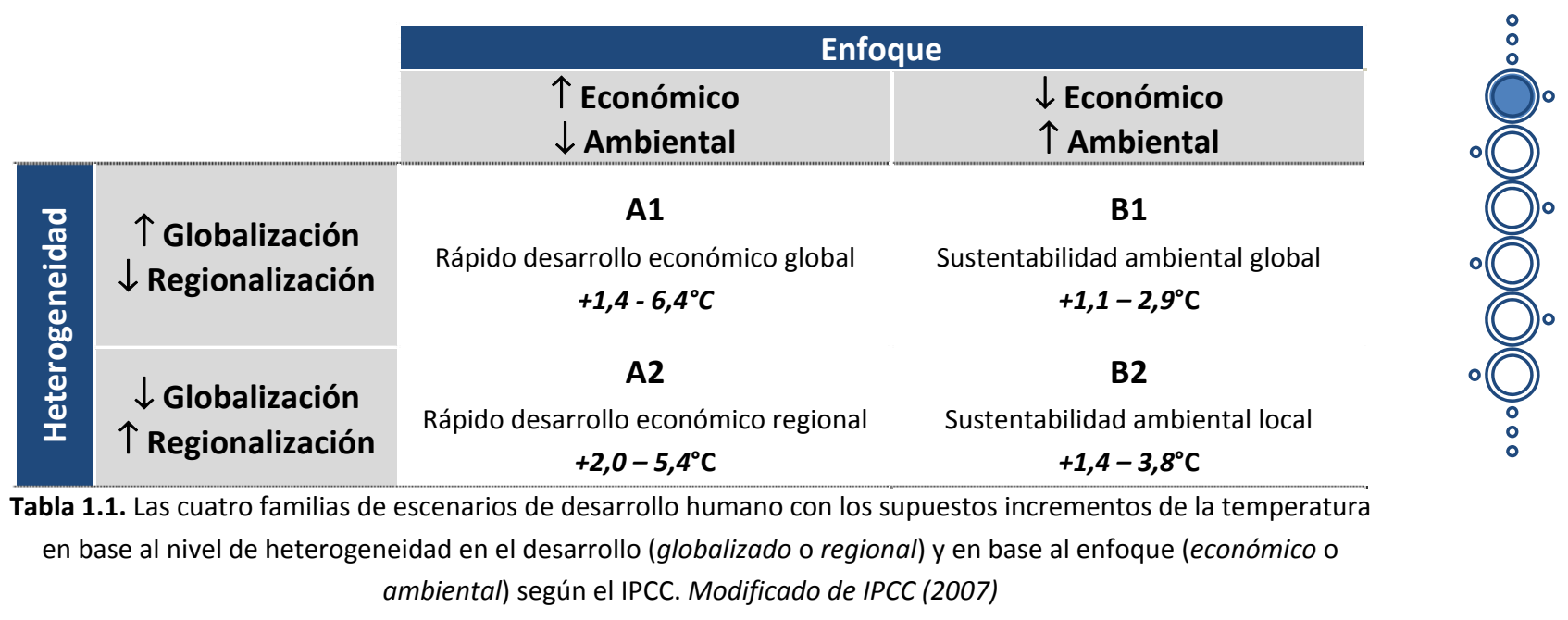

En Argentina, la temperatura media anual se ha incrementado en casi un grado centígrado en el último siglo. La década de los 90 s ha sido la más calurosa en el siglo XX, siendo 1995 el año que registró las mayores temperaturas (Hulme \& Sheard 1999). La tendencia en las precipitaciones anuales a nivel país ha demostrado un aumento del $10 \%$ por siglo, aunque en la Pampa húmeda la precipitación anual se incrementó hasta un 15\% por siglo. La excepción a este aumento ha ocurrido en algunas partes de la cordillera de los Andes donde se ha detectado una disminución en las tendencias de las precipitaciones. Dichos cambios pueden resultar en cambios en los ríos argentinos, tales como modificaciones de caudal o de regímenes de flujo, o modificar la entrada de materiales al cuerpo de agua por escorrentía, entre otras consecuencias.

La intensidad de los efectos de los cuatro escenarios climáticos sobre el clima global dependerá de la sensibilidad del planeta a dichos cambios. EI IPCC junto con la Climatic Research Unit de la Universidad de East Anglia planteó para la Argentina los cuatro escenarios propuestos por el IPCC combinados con tres sensibilidades diferentes (bajo, medio y alto) resultando en un rango de posibilidades que abarcan desde B1-bajo (el escenario con menor emisión de gases de efecto invernadero combinado con la menor sensibilidad) hasta el A2-alto (el escenario con mayor emisión de gases de efecto invernadero combinado con la mayor sensibilidad) (Hulme \& Sheard 1999).

Considerando estas sensibilidades, las predicciones para la región Pampeana muestran un aumento en la temperatura que varía desde los $0.4^{\circ} \mathrm{C}$ hasta los $1.5^{\circ} \mathrm{C}$ para el año 2020, y desde el $0.9^{\circ} \mathrm{C}$ hasta los $4.1^{\circ} \mathrm{C}$ en el año 2080 (Figura 1.1). Con respecto a las precipitaciones, los modelos muestran desde una variación no significativa hasta un $4 \%$ para el año 2020 , y desde un $3 \%$ hasta un $10 \%$ para el año 2080 (Figura 1.2).

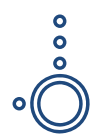


Estos aumentos en la temperatura y las precipitaciones influirán directamente en los sistemas lóticos pampeanos, incrementando la temperatura del agua y su caudal, e indirectamente a través de la escorrentía, incorporando nutrientes procedentes del lavado del suelo como así también materiales en suspensión.

Los cambios en el uso de la tierra, al contrario de los cambios climáticos, se manifiestan a escalas temporales cortas y a niveles locales o regionales, y se relacionan directamente con un origen antropogénico (Watson et al. 2000).

La cantidad de nutrientes que llegan a los sistemas fluviales aumenta año tras año debido a las actividades agrícola-ganaderas inadecuadas, a las plantaciones forestales que reciben fertilizantes, o a las entradas directas desde núcleos urbanos (Meybeck \& Helmer 1989). En consecuencia, estos aumentos de nutrientes van a tener un efecto importante para los sistemas fluviales (Sabater et al. 2003). En esta dinámica de aporte continuo de nutrientes los pequeños cursos fluviales son esenciales para su asimilación y reciclaje (Alexander et al. 2000).

Los productores primarios (algas, macrófitas) y los heterótrofos microbianos (bacterias y hongos) son los primeros en ser afectados por el enriquecimiento de nutrientes, ya que dependen de la disponibilidad de los nutrientes inorgánicos de la columna de agua (Stelzer et al. 2003). 


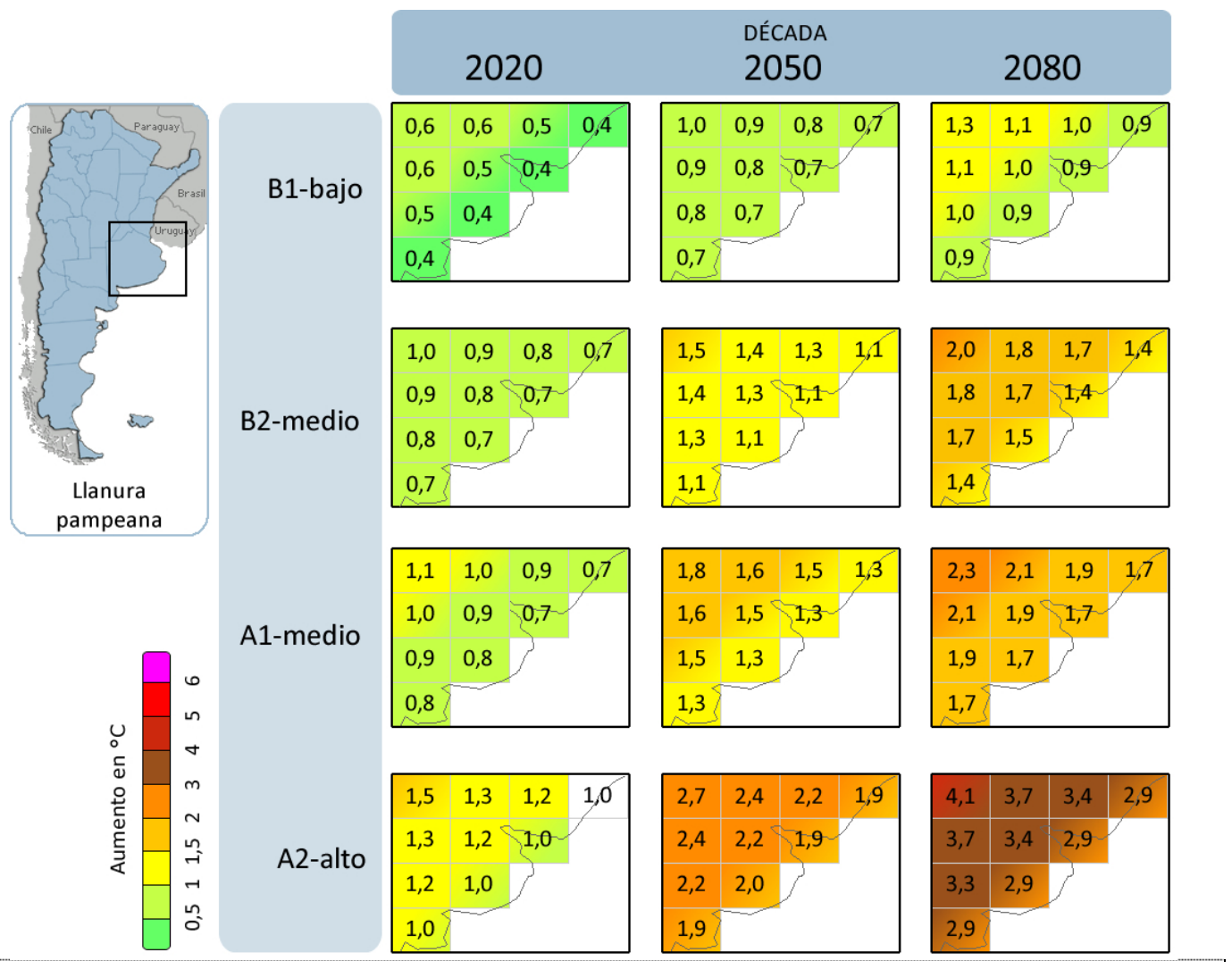

Figura 1.1. Mapas de aumento de la temperatura para la región pampeana en los cuatro escenarios propuestos por el IPCC (B1-bajo; B2-medio; A1-medio; A2-alto), para tres décadas diferentes (2020, 2050, 2080). Cada valor representa un incremento en grados centígrados. (Modificado de Hulme \& Sheard 1999)

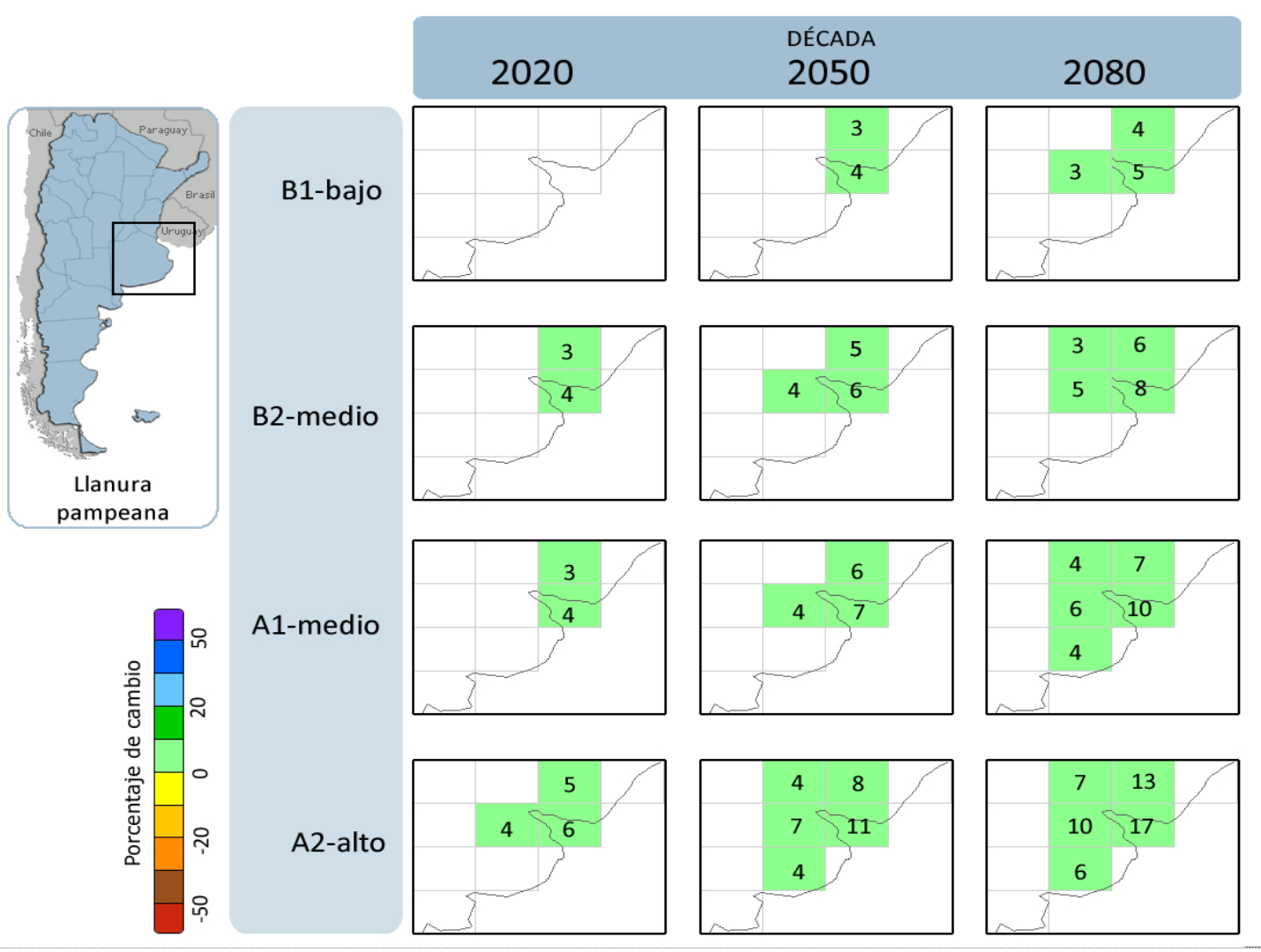

Figura 1.2. Mapas de aumento de las precipitaciones para la región pampeana en los cuatro escenarios propuestos por el IPCC (B1-bajo; B2-medio; A1-medio; A2-alto), en tres décadas diferentes (2020, 2050, 2080). Cada valor representa un incremento de las precipitaciones en porcentaje, y las celdas en blanco indican que no hay modificaciones significativas predichas. (Modificado de Hulme \& Sheard 1999) 
La región pampeana es una superficie de escasa pendiente con sólo una parte muy reducida ocupada por sierras que escasamente superan los $500 \mathrm{msnm}$, pertenecientes al sistema serrano de Tandilia, o los 1200 msnm en el caso del sistema serrano de Ventania. La temperatura media de verano oscila entre los $20-24^{\circ} \mathrm{C}$ y la de invierno entre $7^{\circ} \mathrm{C}-10^{\circ} \mathrm{C}$, siendo la media anual de $18^{\circ} \mathrm{C}$. Las precipitaciones oscilan entre los 800 y $1000 \mathrm{~mm}$ anuales. La fisionomía vegetal dominante es la de la estepa o pseudoestepa de gramíneas, entre las cuales crecen numerosas especies herbáceas y algunos arbustos, existiendo numerosas comunidades edáficas (Cabrera \& Willink 1980).

Dentro de la región pampeana se incluye gran parte de la Provincia de Buenos Aires, que soporta una gran densidad demográfica (16 millones, representando el 39\% de la población total del país) y concentra las mayores actividades industriales, agrícolas y ganaderas, junto con las utilizaciones más intensas de agroquímicos (INDEC 2010). Es por ello que gran parte de los ríos y arroyos de la llanura son impactados por fuentes puntuales de contaminación provenientes de efluentes domésticos e industriales, como así también por fuentes difusas asociadas a los cultivos.

Los arroyos de la llanura pampeana corren por áreas deposicionales, y sus bajas velocidades de corriente generan usualmente un sustrato compuesto por sedimentos finos (limos y arcillas) cubierto por biofilms epipélicos. La vegetación de ribera no tiene un gran desarrollo, estando compuesto principalmente por especies herbáceas, y con ausencia de estratos arbóreos (Giorgi et al. 2005, Feijoó \& Lombardo 2007).

Los niveles de nutrientes en estos arroyos son altos en relación a los encontrados en arroyos forestados (Binkley et al. 2004), aún en sitios expuestos a baja o moderada agricultura y ganadería (Feijoó et al. 1999, Bauer et al. 2002a, b). Las altas concentraciones de nutrientes en sus aguas favorecen el desarrollo de densas comunidades de macrófitas, que pueden proveer fuentes de materia orgánica para los heterótrofos microbianos (Giorgi 1998, Allan \& Castillo 2007)

En estos arroyos la luz que alcanza al sedimento, y por ende al biofilm, puede disminuir como consecuencia de las concentraciones de sólidos en suspensión y por la cubierta de macrófitas, siendo este último factor el más importante que regula la penetración de la 
radiación solar que puede alcanzar el fondo (Giorgi 1998), ya que los sólidos en suspensión suelen incrementarse particularmente después de las lluvias y por períodos no mayores a 48hs.

Dadas las características particulares que poseen estos arroyos, los efectos de los cambios globales pueden ser muy distintos a los esperados para otras ecorregiones de Argentina. Los escenarios muestran que el norte del país incrementará su temperatura a mayor velocidad que en el sur, por lo que las sequías serán más importantes en regiones como Salta y Jujuy. Por otro lado las precipitaciones anuales diferirán entre el este y el oeste del país, disminuyendo en la cordillera, al contrario del aumento planeado para la región Pampeana. Esto generará una reducción en los caudales de los ríos de provincias como Mendoza y San Juan, mientras dicha variable aumentará en los ríos y arroyos pampeanos.

Los cambios que generan estas variables sobre los ecosistemas dulceacuícolas se ve sumado a los efectos por los enriquecimientos con nutrientes, producto del aumento en el uso de fertilizantes, que en los arroyos Pampeanos pueden tener consecuencias menos predecibles al tener sus concentraciones basales altas (Artigas et al. 2013).

En esta tesis se abordarán los efectos sobre el biofilm del enriquecimiento de nutrientes en campo (Capítulo 4) y se exponen resultados de las simulaciones realizadas en laboratorio de incrementos simultáneos de nutrientes, velocidad de la corriente, turbidez y temperatura (Capítulo 5). 
El biofilm es un complejo biológico conformado principalmente por bacterias, hongos, algas y microinvertebrados, incluidos en una matriz de polisacáridos y otros polímeros (Lock 1984).

Los biofilms se desarrollan en un amplio rango de interfaces físicas en los ambientes de agua dulce (Brisou 1995), que incluyen las interfaces agua/biomasa (como en la superficie de algas o macrófitas), y agua/sedimentos inorgánicos (como material particulado, arenas, piedras). Es así que los tipos de biofilms serán denominados acorde al sustrato en el cual se desarrollan: el episammon se desarrolla sobre arenas, el epiliton sobre rocas y piedras, el epipelon sobre limos y arcillas, el epifiton sobre plantas, y el epixilon sobre madera. (Stevenson 1996).

Su composición biológica varía con las condiciones ambientales. En algunos casos son casi en su totalidad bacterianos, mientras que en otros se forman junto con algas (diatomeas, cianofitas) y se desarrollan en comunidades que acumulan una gran biomasa. El epipelon de los ríos y arroyos de la llanura pampeana está generalmente dominado por diatomeas y cianofitas (Gómez \& Licursi 2001, Solari \& Claps 1996, Giorgi et al. 2005, Sierra \& Gómez, 2007).

En general el grado de madurez del biofilm está demostrado por un aumento de la densidad de algas con respecto a la densidad de bacterias, una disminución en el contenido polisacárido y consecuentemente una disminución de la penetración de la luz a las capas más profundas del biofilm (Barranguet 2004). Los biofilms maduros son altamente complejos tanto en diversidad microbiana como en su estructura tridimensional, la cual está determinada mayormente por la arquitectura de la matriz, con canales interconectantes por donde circula el agua. Este flujo de agua es importante para distribuir los nutrientes y el oxígeno disuelto a las distintas partes del biofilm.

El tiempo en que el biofilm llega a sus últimas etapas de colonización y de desarrollo (Figura 1.3) depende primariamente de la comunidad en estudio. La concentración de clorofila "a" suele ser un buen indicador del estado de colonización, ya que su aumento en el tiempo se ajusta a una curva de tipo logística (Figura 1.4, Jenkinson \& Lappin-Scott 2001). Es por ello que en general para los estudios de laboratorio se busca que el biofilm alcance un desarrollo algal homogéneo: en algunas experiencias los tiempos de colonización fueron de unos pocos días (Ricart et al. 2009), mientras que en otras la comunidad se ha desarrollado por completo en un 
término de 7-10 semanas (Stock \& Ward 1989), siendo aceptado en la mayoría de los estudios un tiempo de 25-30 días (Navarro Rodríguez 1998, Admiraal et al. 1999, Muñoz et al. 2001, Real et al. 2003). En estudios de colonización de biofilm en arroyos pampeanos en particular se ha considerado como adecuado un término de seis semanas (Giorgi \& Ferreira, 2000).

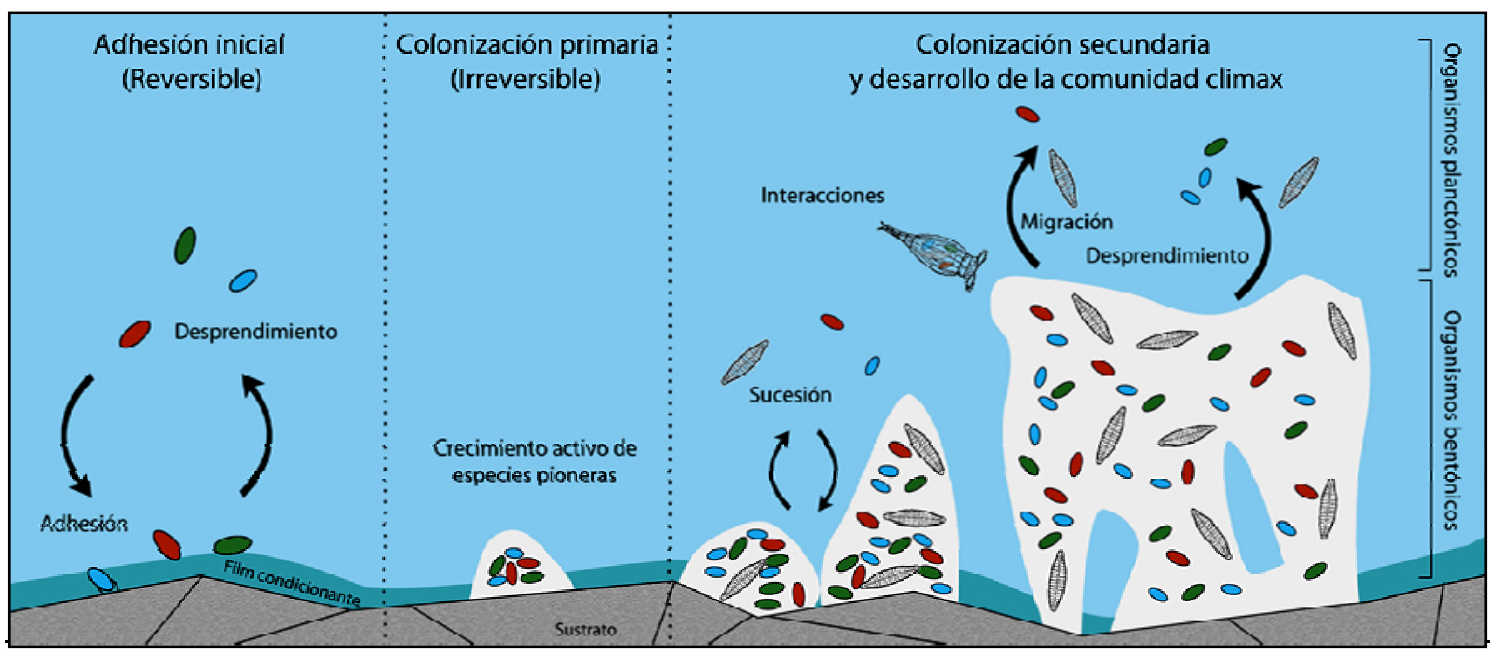

Figura 1.3. Diagrama de la formación del biofilm. Modificado de (Sigee 2005)

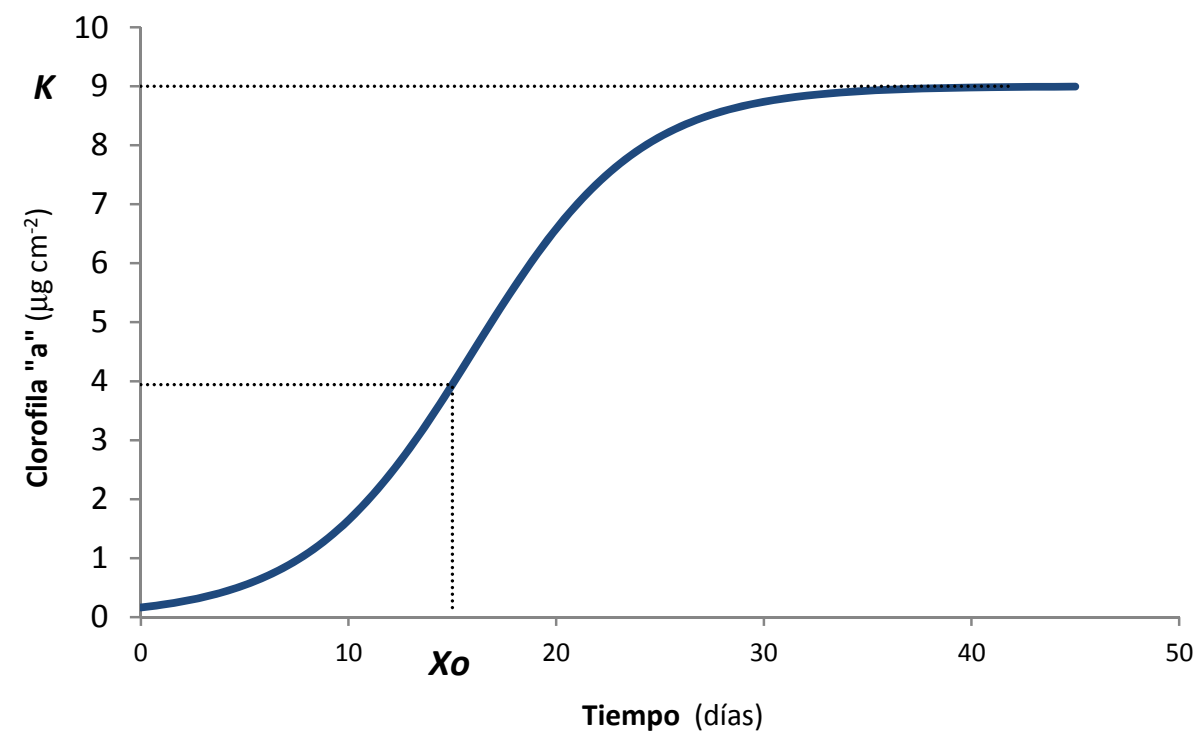

Figura 1.4. Colonización teórica del biofilm según Jenkinson \& Lappin-Scott (2001). $\boldsymbol{K}=$ capacidad de carga; $\boldsymbol{X o}=$ tiempo en alcanzar el crecimiento máximo, mitad de la capacidad de carga

Las funciones ecosistémicas de los biofilms involucradas en su dinámica se incluyen las interacciones entre organismos (por transferencia de genes, quorum sensing, procesos de adhesión específica e interacciones tróficas), la formación y transferencia de biomasa (fijación de carbono por algas, incorporación de otros nutrientes, ingestión de células y material particulado por heterótrofos), la homeostasis (por producción de matriz, control de 
crecimiento poblacional y balances de poblaciones) y las interacciones con el ambiente externo (por absorción de luz y nutrientes y por pérdida y ganancia de células) (Figura 1.5).

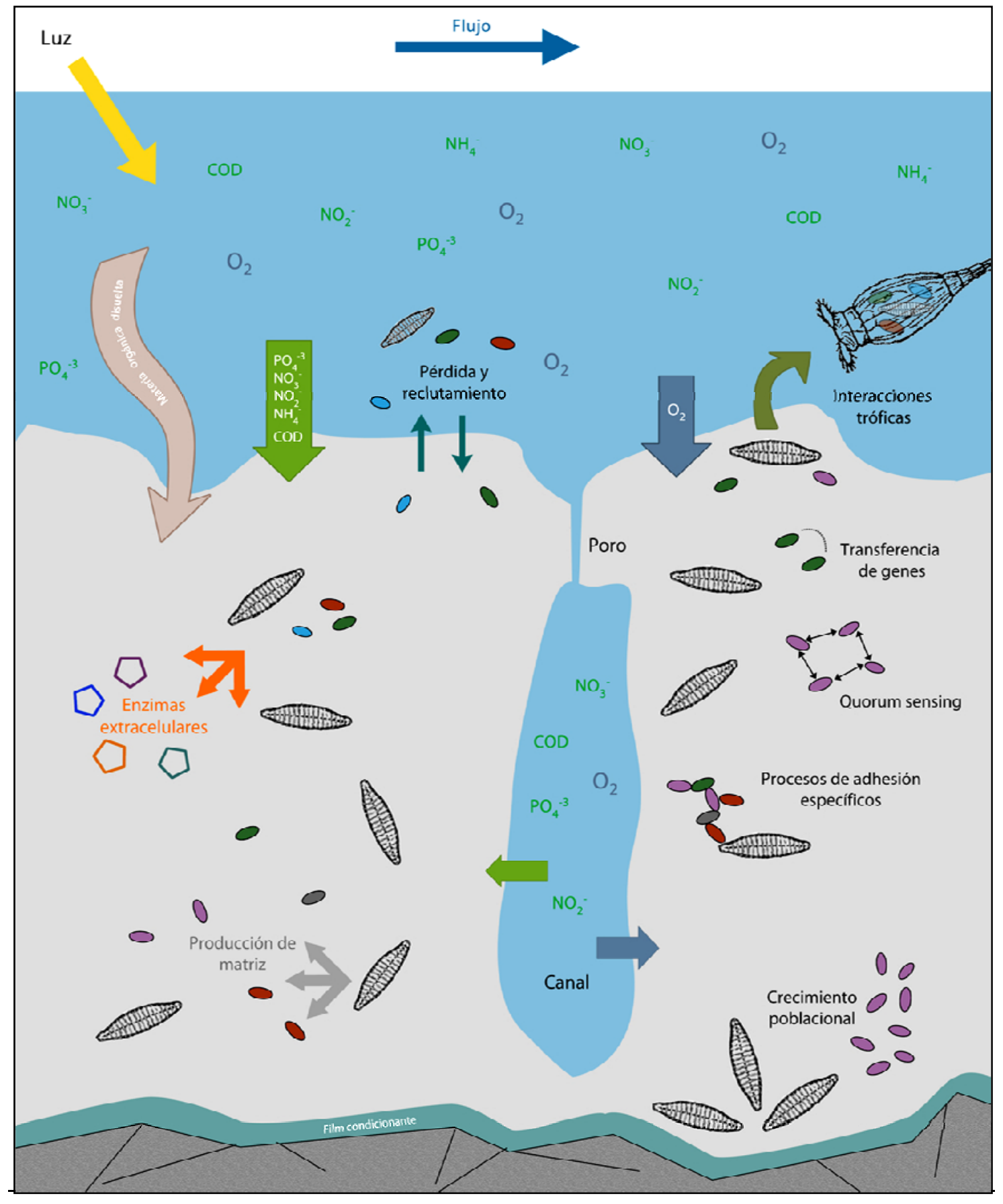

Figura 1.5. Diagrama de la dinámica y funcionamiento de un biofilm mixto (algas, bacterias y hongos). Modificado de Sigee (2005) y Sabater et al. (1993). 
La dinámica y las respuestas de los biofilms proveen un sistema de modelos útiles que permiten interpretar los aspectos fundamentales de las interacciones en las comunidades y de las funciones de los ecosistemas (Allison et al. 2000). Su pequeña escala los hace convenientes para los experimentos tanto de laboratorio como ambientales, y la estrecha proximidad entre los organismos dentro del biofilm conlleva a altos niveles de interacción biológica.

De las comunidades que habitan los ríos y arroyos, los biofilms son los primeros en interactuar con las sustancias disueltas, tales como los nutrientes y la materia orgánica. Ya que los biofilms pueden ser luego utilizados por los consumidores, constituyen un paso obligado en la integración de nutrientes en el ciclo de la materia y energía de los cursos de agua (Allan \& Castillo 2007).

La importancia de los biofilms es mayor en arroyos de bajo orden, donde la comunidad bentónica es la principal responsable por el procesado de la materia orgánica, y su biomasa suele ser más significativa que la biomasa planctónica (Pusch et al. 1998).

El rol de los biofilms en los lechos de los arroyos es importante debido a las varias funciones que cumplen, entre las que se destacan:

- Absorción y retención de materia orgánica particulada y disuelta (Lock 1981, Battin et al. 2003)

- Concentración de nutrientes e intercambio de iones (Hamilton 1987, Freeman \& Lock 1995)

- Protección física contra la erosión (Lock 1993)

- Estabilización del sedimento (Yallop et al. 2000): hay una relación inversa entre las tasas de producción algal y la estabilidad del sedimento, y una relación directa con las tasas de producción bacteriana.

- Adsorción de químicos y contaminantes (ej.: metales pesados)(Shorer \& Eisele 1997)

- Alimento para una fuente importante de organismos (Stevenson 1996) 
El desarrollo y las características de los biofilms en los ecosistemas acuáticos está modulado por muchos factores (resumidos en la Figura 1.6), incluyendo las concentraciones de nutrientes inorgánicos, la luz, temperatura, el sustrato, la herbivoría, la velocidad de la corriente y las características de las partículas transportadas por el flujo (Horner et al. 1990, Stevenson 1996).

Los diversos factores, además, interaccionan entre sí para modular las respuestas del biofilm. Por ejemplo, la incorporación de nutrientes al biofilm no sólo dependerá de las concentraciones de nutrientes inorgánicos en la columna de agua, sino que además estará modulada por la velocidad de la corriente, la temperatura, la luz y la herbivoría (Borchardt 1996). Es por ello que es muy difícil establecer modelos para las distintas variables individuales que afectan el crecimiento de los biofilms que sean validados empíricamente. 


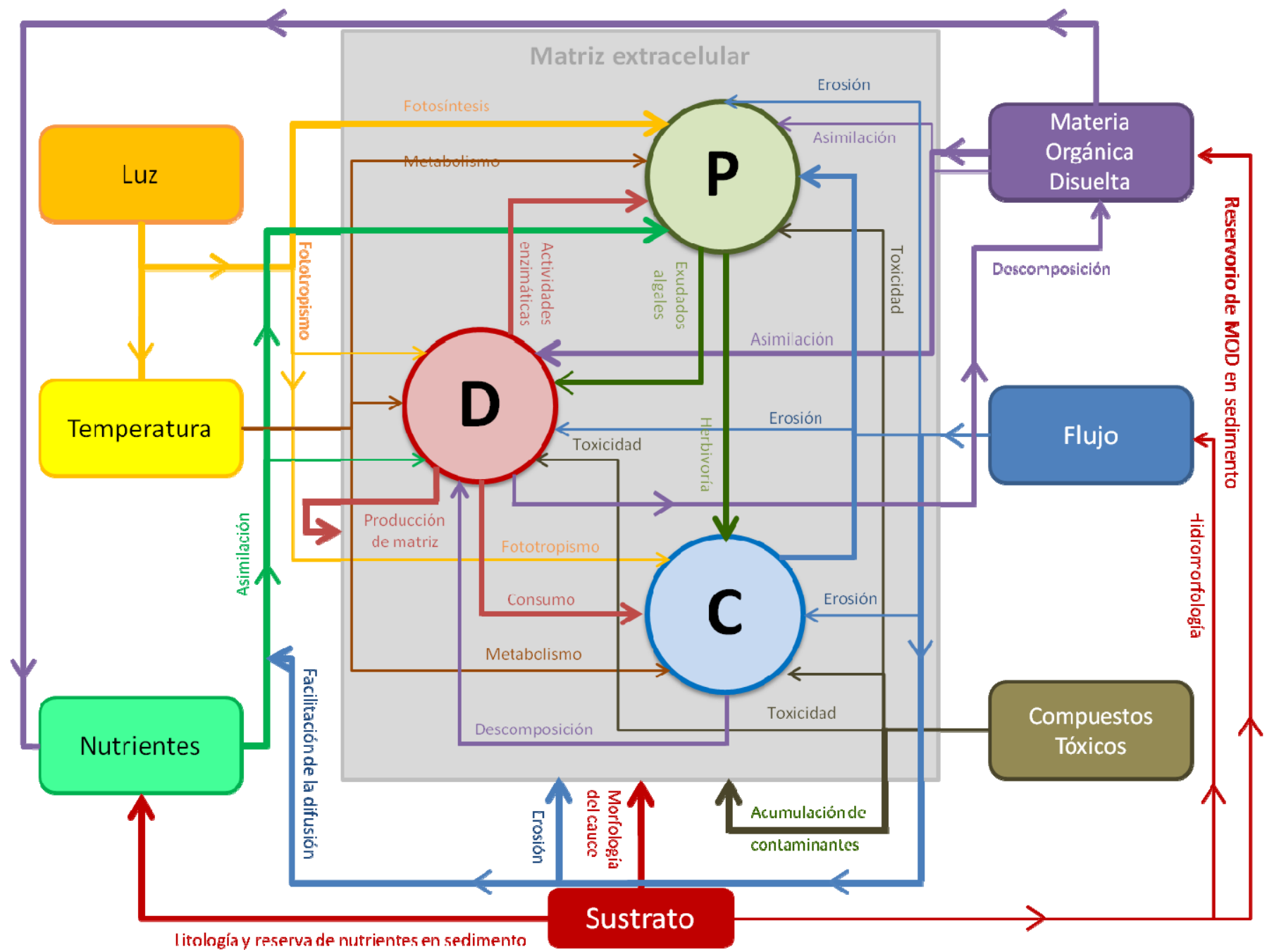

Figura 1.6. Principales factores que afectan el desarrollo del biofilm (Sustrato, Nutrientes, Temperatura, Luz, características del Flujo, Compuestos tóxicos y Materia Orgánica Disuelta), y los compartimentos del mismo adonde ejercen su efecto (Matriz extracelular, $\mathbf{P}=$ productores, $\mathbf{D}=$ descomponedores, $\mathbf{C}=$ consumidores). Flechas de mayor tamaño indican efectos más importantes. 
El nitrógeno inorgánico disuelto (NID) y el fósforo reactivo soluble (PRS) han sido usualmente identificados como los nutrientes claves en la limitación del crecimiento de los biofilms en los arroyos (Borchardt 1996). Mientras mayor es la oferta de nutrientes externa al biofilm, menos importante es el ciclado de nutrientes dentro del biofilm para cumplir con sus demandas biológicas (Mulholland 1996), e incluso el aumento diferencial de los distintos nutrientes resultará en comunidades con mayor o menor relación autotrófica/heterotrófica. EI ciclado de nutrientes dentro del biofilm también puede ser afectado por consumidores externos al biofilm, tales como larvas de insectos y otros macroinvertebrados, ya sea por consumo de algas o por aporte de nutrientes por excretas (ej.: Bronmarck, 1989; Giorgi \& Tiraboschi, 1999; Jones et al., 2002).

Las concentraciones de los diversos nutrientes sobre las algas bentónicas han sido ampliamente estudiados (ver Borchardt 1996 para una revisión), y se han sugerido muchos modelos para su incorporación al biofilm. Los primeros modelos que surgieron eran derivados de la ecuación de Michaelis-Menten para cinética enzimática (como los de Dugdale 1967, Eppley et al 1969, Goering et al. 1973, Paasche 1973, Rhee 1973), o modelos empíricamente derivados del crecimiento bacteriano (Droop 1961, Caperon 1967, Monod 1950). Sin embargo esos modelos no contemplan la capacidad de las algas de acumular nutrientes y tenían muchos problemas de aplicación. Los modelos propuestos luego por Droop (1968), Caperon (1968) y Fuhs (1969) propusieron que el crecimiento era una función de la concentración intracelular del nutriente limitante. La combinación del modelo de Droop y el de Michaelis-Menten crea un modelo de dos etapas (incorporación y utilización), llamado modelo VIS (Variable Internal Stores), que describe la dinámica de la densidad algal y la concentración externa del nutriente en el tiempo (Figura 1.7).

A su vez, los efectos de la luz, la temperatura, la velocidad de la corriente y la herbivoría modulan la incorporación de nutrientes por el biofilm. 

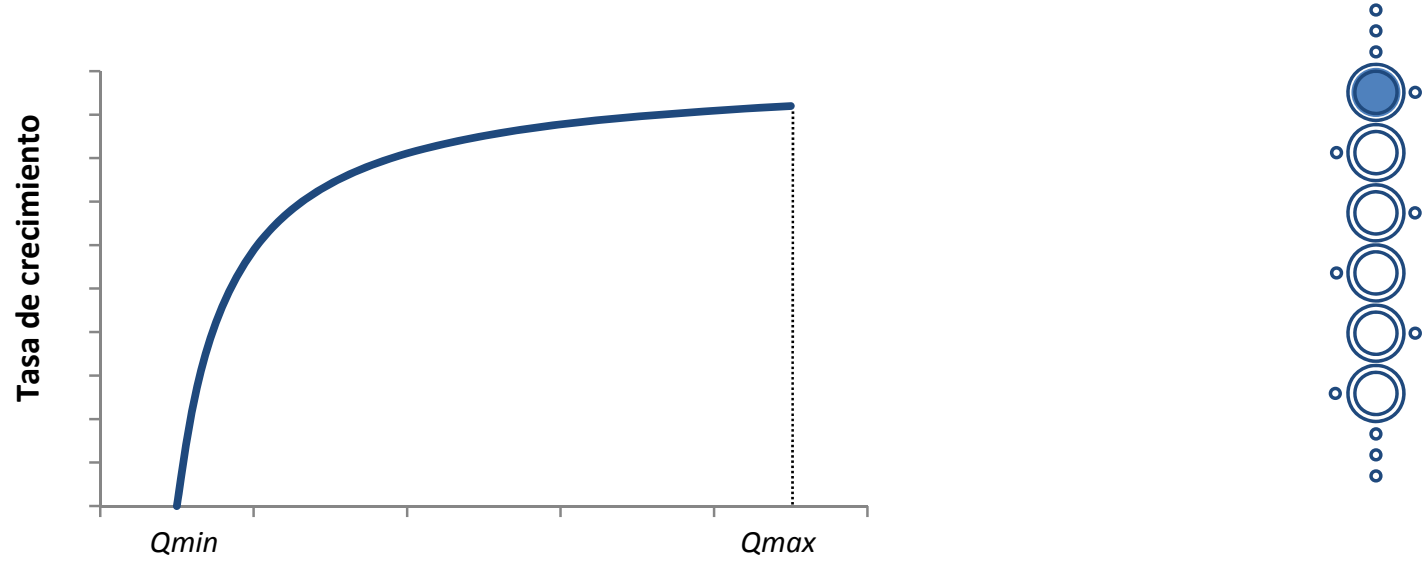

Concentración de nutrientes por célula (Q)

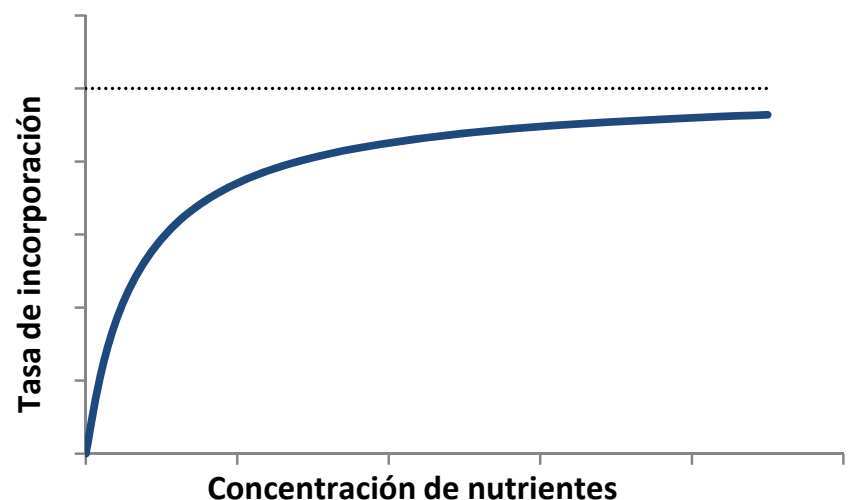

Figura 1.7. El modelo VIS de crecimiento algal, adonde la tasa de crecimiento celular depende de la concentración de nutrientes intracelular $(Q)$ de manera hiperbólica, y la incorporación de nutrientes por las algas responde a la concentración de nutrientes extracelular mediante la función de Michaelis-Menten

\subsection{4.b Las características del sustrato}

Las superficies donde se desarrolla el biofilm provén de una interface para la concentración de partículas cargadas y neutras, y pueden también proveer nutrientes directamente (Bitton \& Marshall 1980).

Mientras que las superficies rugosas son fácilmente colonizables ya que las fuerzas de cizalla están disminuidas y la superficie queda incrementada (Donlan 2002), las cepas de al menos algunas especies parecen colonizar con facilidad las superficies lisas también (Donlan \& Costerton 2002). Otras investigaciones también han demostrado que los microorganismos se adhieren más rápidamente a superficies hidrofóbicas como los plásticos que a las hidrofílicas como el vidrio o los metales (Donlan 2002). 
Asimismo, la productividad primaria autotrófica y la respiración del biofilm béntico son mayores en sistemas con mayor heterogeneidad de sustrato (Cardinale et al. 2002). Por ejemplo, los biofilms epilíticos tienen actividades mayores de peptidasas, y mayores biomasas algales y bacterianas; los biofilms episammicos tienen actividades menores de $\beta$-glucosidasa y fosfatasa, sin cambios significativos en las biomasas algales y bacterianas (Romaní et al. 2004).

La temperatura primariamente afecta el desarrollo de la biomasa del biofilm y su metabolismo a través del control de las tasas de reacción de enzimas. Mientras la temperatura incrementa, la energía cinética de reacción de las moléculas resulta en tasas de reacción más altas hasta el punto donde la tasa de desnaturalización excede los efectos cinéticos. Por lo general, los microorganismos en cultivo tienen una temperatura óptima para su crecimiento cercana a su máximo tolerable (Seaburg et al. 1981) (Figura 1.8).

En el compartimento heterotrófico en particular se ha demostrado que las bacterias acuáticas tienen un óptimo de temperatura para su crecimiento superior al máximo de temperatura ambiental (Boylen \& Brock 1973, Bott 1975, Lovell \& Konopka 1985). Esto sugiere que el incrementar la temperatura ambiente resulta en crecimientos mayores (Peters et al. 1987).

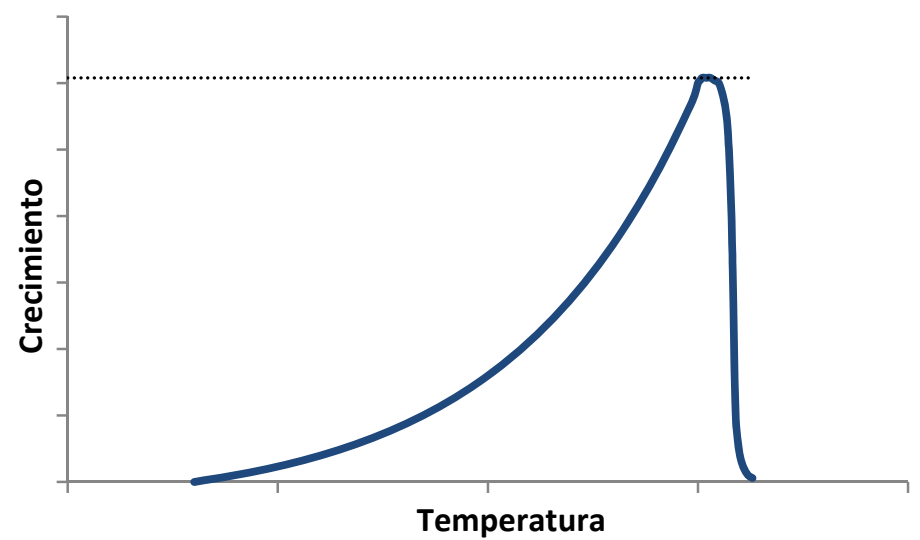

Figura 1.8. Curva de crecimiento de los organismos del biofilm en base a la temperatura de Peters et al. 1987. La línea punteada marca el crecimiento óptimo. 
La luz solar es el factor más importante para el desarrollo del componente autotrófico en los biofilms (von Schiller et al. 2007). Las algas utilizan las radiaciones con longitudes de onda entre 400-700nm, rango denominado como Radiación Fotosintéticamente Activa (cuyas siglas son conocidas como PAR, según su denominación en inglés). Antes de que la luz que irradia a un cuerpo de agua alcance el sustrato debe pasar una variedad de obstáculos, cuyo efecto integrado puede resultar en muy pocos fotones disponibles para la fotosíntesis. Los efectos de la vegetación terrestre, de la atenuación por la columna de agua e incluso la misma atenuación que causa la matriz extracelular del biofilm pueden resultar en una situación limitante para los fotoautótrofos (Hill 1996). Incluso el mismo fitoplancton, que absorbe las mismas longitudes de onda de la luz que utilizan las algas bentónicas, compite con ellas por el recurso, y se espera una relación inversa entre la biomasa fitoplantónica y la biomasa algal bentónica (Hansson 1988).

A su vez, la tasa fotosintética de las algas del biofilm es una función no-lineal de la intensidad lumínica: a bajas irradiancias las tasas fotosintéticas aumentan linealmente con el incremento de la luz; a irradiancias medias, la tasa fotosintética comienza a saturarse (como resultado de la máxima actividad de la ribulosa 1,5-bifosfatocarboxilasa); y a irradiancias altas la tasa fotosintética se mantiene constante o incluso disminuye por fotoinhibición (Hill 1996). Para evaluar las respuestas fotosintéticas de las algas bentónicas se han desarrollado modelos de fotosíntesis-irradiancia (Figura 1.9) que pueden incluir mecanismos de fotoinhibición (como el de Platt et al. 1980) o bien aquellos que no consideran estos mecanismos, como los propuestos por Jassby \& Platt (1976) o por Neale \& Richerson (1987).

A pesar de los variados regímenes de luz a los que están expuestos los biofilms, la mayoría de los estudios de fotosíntesis-irradiancia indican que la fotosaturación ocurre en un rango relativamente estrecho de fotones, desde unos 100 a $400 \mathrm{mE} \mathrm{m}^{-2} \mathrm{~s}^{-1}$ (Hill 1996). 


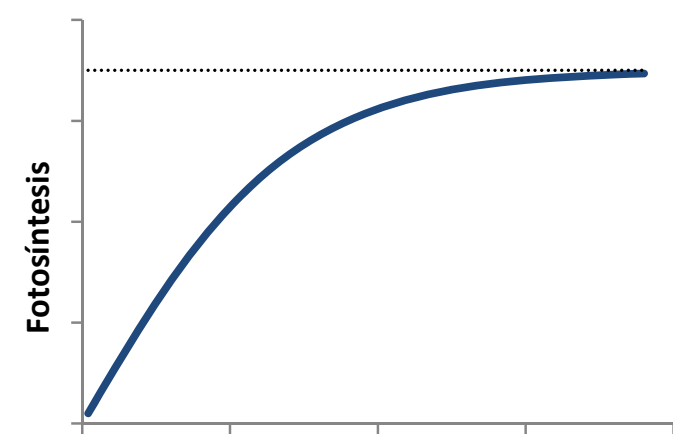

Irradiancia

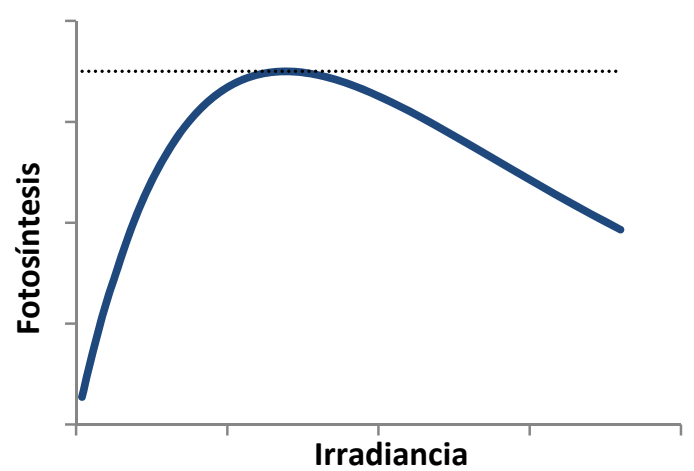

Figura 1.9. Curvas de fotosíntesis-irradiancia en biofilms en modelos sin fotoinhibición, pero con fotosaturación (izquierda) y con fotoinhibición (derecha). La línea punteada marca la producción máxima.

\subsection{4.e $\quad$ La velocidad del flujo}

La velocidad y la dinámica de los flujos son factores que modulan las respuestas de los biofilms. Sin embargo, no hay una relación simple positiva entre la velocidad de la corriente y el metabolismo fitobentónico, los procesos de acumulación o la biomasa. La biomasa algal es mayor en corrientes más rápidas en algunos hábitats (Ball et al. 1969, Horner et al. 1990, Battin et al. 2003), mientras que en otros hábitats la biomasa es mayor en corrientes lentas (Antoine \& Benson-Evans 1982, Stevenson 1984, Uehlinger 1991). Una revisión de la literatura realizada por Stevenson (1996) concluye que las biomasas mayores ocurren en velocidades intermedias en la mayoría de los hábitats (Stevenson 1996, Cap. 11 tabla 1)

Esta relación hiperbólica entre la biomasa del biofilm y la velocidad de la corriente (Figura 1.10) sugiere que hay dos o más fuerzas relacionadas al flujo que afectan la biomasa algal: una que subsidia a bajas velocidades y una que estresa a altas velocidades (Odum et al. 1979).

Es así que a bajas velocidades los incrementos en la velocidad de la corriente estimulan la incorporación de nutrientes, la fotosíntesis, respiración y tasas de reproducción. Y a altas velocidades las fuerzas erosivas causan el desprendimiento de los organismos, generando biofilms con menores biomasas (Battin et al. 2003).

En el rango de velocidad de 0 hasta $50 \mathrm{~cm}^{-1} \mathrm{~s}^{-1}$, se han reportado mayores incrementos de biomasa (y/o productividad) con los incrementos de velocidad, tanto en arroyos como en laboratorio, aunque la velocidad de colonización haya sido más lenta (Whitford \& Schumacher 1964, Mclntire 1968b, Rodgers \& Harey 1976, , Homer \& Welch 1981, Horner Welch \& 
Veenstra 1983, Korte \& Blinn 1983, Stevenson 1983, Welch et al. 1988, Navarro Rodriguez 1998, Leu et al. 1996, Tien et al. 2009). Sin embargo, la biomasa del biofilm ha sido frecuentemente menor en velocidades por encima de los $51 \mathrm{~cm}^{-1} \mathrm{~s}^{-1}$ (Horner \& Welch 1981, Horner et al. 1983).

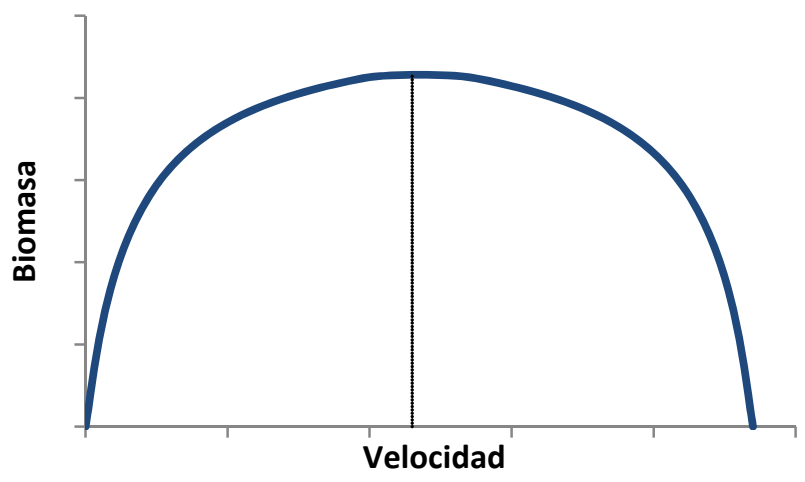

Figura 1.10. Biomasa del biofilm en relación a la velocidad de la corriente. La línea punteada marca la velocidad a la cual las fuerzas abrasivas del flujo empiezan a ser mayores que la incorporación de nutrientes

\subsection{4.f La cantidad y calidad de la materia orgánica}

La fuente, calidad y tipo de materia orgánica disuelta (MOD), así como su cantidad, puede influenciar la abundancia y distribución de las bacterias en ecosistemas acuáticos (Koetsier et al. 1997, Leff et al. 1999, Leff et al. 2000, McNamara \& Leff 2004)

Las bacterias heterotróficas son los principales organismos que utilizan la materia orgánica disuelta en los arroyos (Dahm 1981, Kaplan \& Bott 1983) y la convierten en formas particuladas que pueden ser consumidas por otros organismos (Edwards 1987, Edwards \& Meyer 1987). Es por esto que, por lo general, el aumento en la cantidad de materia orgánica disuelta se corresponde con un aumento en el desarrollo de la biomasa del biofilm (Kaplan \& Bott 1989, Olapade \& Leff 2005), generalmente en su componente bacteriano.

\subsection{4.g La herbivoría}

La herbivoría en biofilms es realizada por organismos unicelulares, como protozoos, o por multicelulares, como pequeños invertebrados. La biomasa del biofilm casi siempre decrece en presencia de herbívoros (Steinman 1996), y suele afectar directamente en mayor medida al componente autotrófico del mismo; incluso los macroinvertebrados pueden tener 
un efecto indirecto positivo sobre la actividad bacteriana a cuestas de la disminución algal en ambientes con bajas concentraciones de nutrientes (Haglund \& Hillebrand 2005).

La interacción entre la forma del crecimiento algal y la morfología del herbívoro ayuda a determinar hasta qué nivel de biomasa va a ser removida (Gregory 1983, Lamberti et al. 1987). Asimismo, también puede haber selectividad en la alimentación de los consumidores que afecten sólo a algunos grupos taxonómicas; esto resultará en diferencias a niveles funcionales, metabólicos y estructurales en los biofilms.

\subsection{4.h Los compuestos ecotoxicológicos}

El estrés químico inorgánico afecta a los biofilms a niveles bioquímicos, celulares, poblacionales y comunitarios. Las algas difieren en su tolerancia al estrés dependiendo de la actividad del químico inorgánico sobre los sitios de unión de la superficie celular. Factores químicos, físicos y biológicos influencian la toxicidad relativa de los químicos inorgánicos sobre el biofilm, y los efectos a nivel comunitario pueden ser muy complejos.

Los efectos de los metales pesados en comunidades microbénticas en arroyos han sido estudiados profusamente, desde las primeras investigaciones de Reese (1937) y Williams \& Mount (1965). Mientras que los materiales orgánicos disueltos y los nutrientes son directamente absorbidos por el biofilm por diferencia del gradiente de concentración, los metales pesados son generalmente adsorbidos sobre la superficie del biofilm como resultado de las interacciones entre los iones del metal y las superficies microbianas cargadas (Jang et al. 2001).

Los compuestos orgánicos tóxicos, como herbicidas, insecticidas, surfactantes, hidrocarburos aromáticos policíclicos (PAH) o bifenilos polihalogenados entre otros, pueden afectar al desarrollo del biofilm. Hay extensos y diversos estudios sobre los efectos de los contaminantes orgánicos sobre el biofilm, con mucha variabilidad en la sensibilidad de los organismos a los tóxicos. Sin embargo, algunas generalizaciones pueden ser formuladas (Hoagland et al. 1996):

1) una variedad de tóxicos orgánicos, particularmente herbicidas, pueden tener efectos dramáticos sobre las comunidades algales bentónicas, a concentraciones tan bajas como de $\mu g \mathrm{~L}^{-1}$ 
2) aunque la biomasa y/o productividad algal pueden no ser afectadas a nivel comunitario, cambios en las composiciones de especies son comunes en respuesta a los tóxicos

3) los efectos sobre las comunidades perifíticas pueden ser directos o indirectos, por lo que bioensayos a nivel de especie y de comunidad son importantes para determinar las respuestas causa-efecto. 


\section{CAPÍTULO 2}

OBJETIVOS, HIPÓTESIS Y DISEÑO EXPERIMENTAL

"La frase más emocionante a oír en la ciencia, la que anuncia nuevos descubrimientos, no es "Eureka!" sino "Eso es curioso..."'” Isaac Asimov 
Como fue detallado en la Introducción, los cambios globales incluyen tanto a los cambios climáticos como a los cambios en los usos de la tierra (Figura 2.1). En la región pampeana las principales presiones que reciben los arroyos, dentro de ese marco teórico, incluyen el aumento de nutrientes (ej.: uso de fertilizantes), el aumento de los sólidos en suspensión y de la velocidad de la corriente (por aumentos en la escorrentía) y un aumento en el promedio de la temperatura atmosférica en la zona (por modificaciones climáticas).

El desarrollo de los biofilms en los ecosistemas acuáticos está modulado por diversos factores que incluyen las concentraciones de nutrientes, la luz, temperatura, el sustrato, la herbivoría, la velocidad de la corriente y las características de las partículas transportadas por el flujo (ver Capítulo 1.3.4. Factores que afectan el desarrollo del biofilm). Las respuestas de los biofilms a estas variables han sido estudiadas de manera independiente (por ejemplo Borchardt 1996, Donlan 2002, Battin et al. 2003, von Schiller et al. 2007), sin embargo son pocos los estudios de los efectos simultáneos de varias variables. Por ejemplo, hay estudios que abordan la relación entre el desarrollo del biofilm en relación a la combinación de nutrientes y luz (por ejemplo Rosemond et al. 1993, Mosisch et al. 2001, von Schiller et al. 2007, entre otros), la relación entre el tipo de sustrato y los nutrientes (Romaní et al. 2004), o la relación entre la velocidad de la corriente, el sedimento en suspensión y la concentración de fósforo (Horner et al. 1990).

Es así que resulta de interés el estudio de los efectos que tienen las variables abióticas relacionadas con los cambios globales sobre los biofilms, y particularmente en la presente investigación los relacionados a sistemas lóticos pampeanos. En tal sentido se plantea el marco conceptual que se visualiza en la Figura 2.1, en el cual se expresan las causas y efectos esperables en los biofilms epipélicos expuestos al aumento de la temperatura, y la intensificación de la escorrentía. 


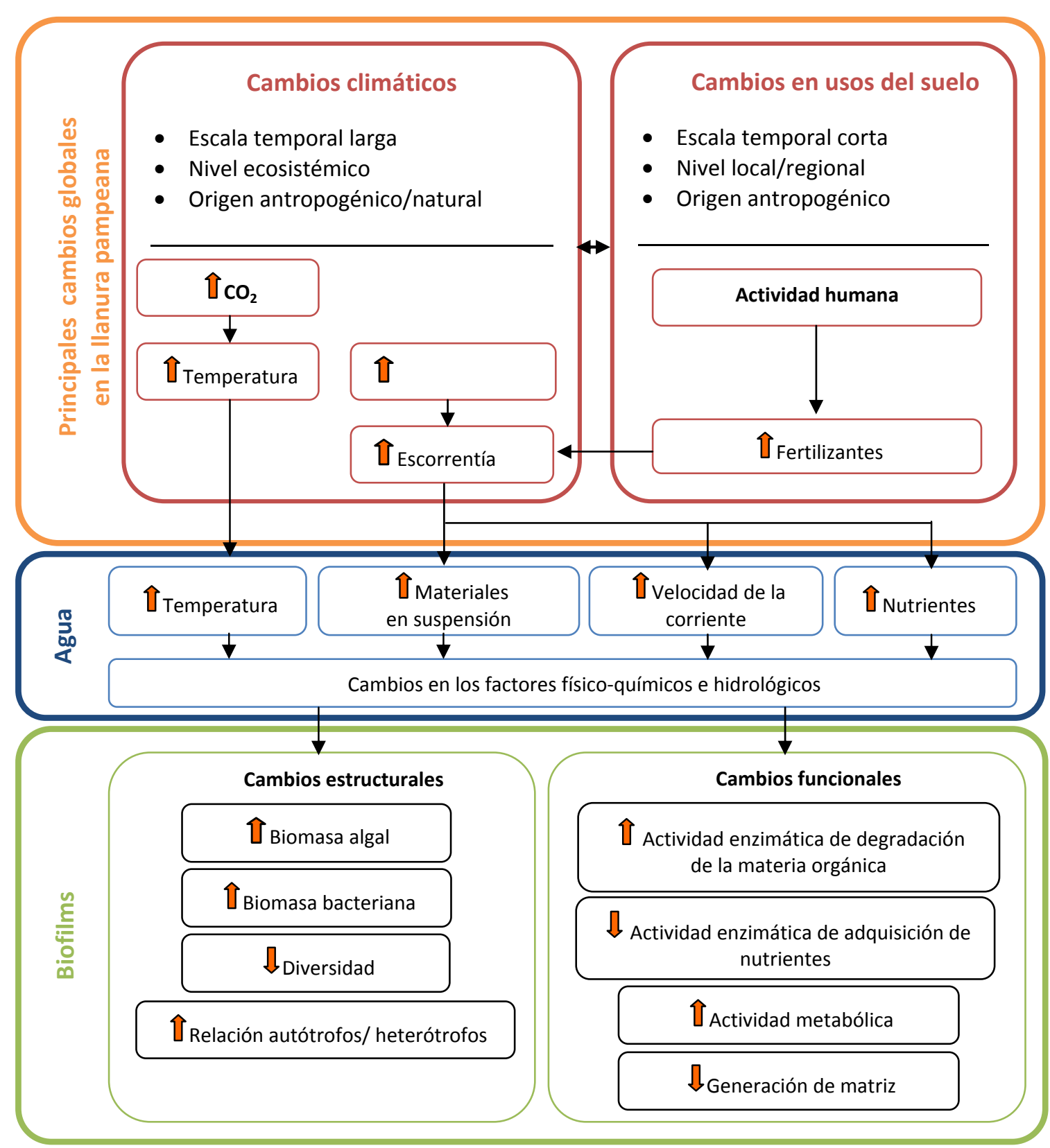

Figura 2.1. Modelo conceptual utilizado en la presente tesis, contemplando los cambios climáticos y los cambios en los usos de la tierra como partes de los cambios globales 
El objetivo general de la presente tesis es estudiar los cambios en la estructura y funcionamiento de los biofilms epipélicos de cursos de agua de la llanura pampeana expuestos a las consecuencias relacionadas con algunos de los efectos de los cambios globales.

Para abordar el objetivo general, se plantearon las siguientes preguntas:

1) ¿Cuál es el efecto de los nutrientes, provenientes de fertilizantes, sobre los biofilms en sistemas naturales?

2) ¿Cuáles son los efectos que pueden tener las presiones relacionadas a los cambios globales (temperatura, nutrientes, escorrentía, etc.) de manera simultánea sobre el biofilm?

3) ¿Cómo se verán afectadas las respuestas del biofilm a dichas presiones como consecuencia de los cambios en la calidad del agua del sistema lótico donde habita?

Para analizar cómo esas presiones afectarán a los biofilms, se plantearon los siguientes objetivos particulares, desarrollados a través de aproximaciones experimentales de campo y laboratorio:

1) Estudiar las respuestas del biofilm epipélico de un arroyo pampeano cuando es expuesto a un incremento en nutrientes inorgánicos (triplicando las concentraciones basales de fósforo y nitrógeno de un arroyo mesotrófico).

2) Evaluar las modificaciones estructurales y funcionales en los biofilms cuando son expuestos a un aumento simultáneo de nutrientes inorgánicos (fósforo y nitrógeno), velocidad de la corriente, turbidez y temperatura.

3) Analizar las diferencias entre las respuestas de los biofilms a dichas variables en arroyos con distintos grados de calidad del agua. 


\section{Efectos de las adiciones de nutrientes. Experiencia in situ}

La hipótesis planteada para la experiencia de adición de nutrientes en campo fue que la estructura y función del biofilm epipélico de arroyos pampeanos es afectada por los nutrientes inorgánicos disponibles en el agua.

Las predicciones de dicha hipótesis fueron que, ante una adición experimental de nutrientes (fósforo y nitrógeno), el biofilm epipélico evidenciará:

a. Un aumento en la biomasa algal y en la biomasa bacteriana.

b. Un aumento en la actividad de las enzimas relacionadas con la degradación de la materia orgánica ( $\beta$-glucosidasa).

c. Una disminución en la actividad de las enzimas involucradas en la adquisición de nutrientes (fosfatasa).

Efecto simultáneo de nutrientes, temperatura, turbidez y velocidad de la corriente. Experiencia ex situ

La principal hipótesis planteada para las experiencias de manipulación en laboratorio fue que la estructura y función del biofilm epipélico de arroyos pampeanos es afectada por múltiples presiones simultáneas relacionadas a los cambios globales, tales como concentración de nutrientes, la temperatura, la velocidad de la corriente y la turbidez. También se hipotetizó que la manera en que el biofilm epipélico de arroyos pampeanos es afectado por dichas presiones depende de la calidad del agua donde se generan, siendo los impactos mayores en arroyos expuestos a un menor impacto antropogénico.

Las predicciones asociadas a estas hipótesis fueron que

1) El incremento simultáneo de la concentración de nutrientes, la temperatura, la velocidad de la corriente y la turbidez, se manifestarán en el biofilm epipélico por:

a. Un aumento en la biomasa total y en la actividad metabólica heterotrófica (respiración). 
b. Una disminución en la diversidad del biofilm y una disminución de la matriz (polisacáridos).

c. Una simplificación en la estructura comunitaria que favorecerá el predominio de la biomasa autotrófica sobre la heterotrófica.

2) Los efectos en los biofilms expuestos al aumento de dichas variables serán mayores en los biofilms provenientes de un arroyo con mejor calidad del agua.

Se entiende por experimento cualquier método racional y coherente para intentar probar que la hipótesis nula lógica sea falsa (Underwood 2007). Para algunos estudios, se puede medir una variable o estudiar un patrón de distribución o de tamaños de organismos. Estos experimentos son llamados mensurativos, para diferenciarlos de los experimentos manipulativos, que involucran cambiar (o manipular) componentes del hábitat o de los organismos para examinar si cambian como fue predicho. Este último tipo de experimento es usualmente utilizado para probar hipótesis sobre los procesos que modifican patrones en la naturaleza (Underwood 2007). En esta tesis se realizaron experimentos manipulativos de campo y laboratorio.

En la presente investigación se utilizaron dos diseños experimentales: un diseño Before-After/Control-Impact Paired Series (BACIPS) para las experiencias de campo, y un diseño factorial ortogonal para las experiencias de laboratorio.

\subsubsection{El diseño BACIPS (Before-After/Control-Impact Paired Series)}

Los propósitos de las evaluaciones de impacto son analizar si un factor de estrés ha cambiado o no el ambiente, evaluar cuáles componentes son afectados, y estimar la magnitud de esos efectos. Para estos fines se suelen utilizar los diseños experimentales BeforeAfter/Control-Impact, o BACl. Hay varios tipos de diseños BACl (resumidos en la tabla 2.1) y, aunque los datos utilizados para interpretar los efectos son muy variados, los métodos de análisis son generalmente muy similares, e involucran la comparación de los sitios potencialmente impactados con sitios control. 
Ya que no es totalmente correcto nombrar al sitio que recibirá el posible efecto como sitio "Impacto", ya que presupone que el impacto va a existir (Underwood 2007), se lo podría llamar "Tratamiento". Sin embargo, se mantendrá el rótulo de sitio Impacto para generar cierta consistencia con las siglas del inglés utilizadas para describir los diseños $\mathrm{BACl}$.

El análisis de los diseños $\mathrm{BACl}$ puede ser complejo. Las aproximaciones para su análisis realizadas por Underwood $(1991,1992,1994)$ describen varias alternativas basadas en modelos ANOVA (Tabla 2.2).

En el presente trabajo se utilizó un diseño BACIPS (Before-After/Control-Impact Paired Series, Stewart-Oaten et al. 1986) para las experiencias de campo. Esta aproximación se basa en comparar el antes con el después en varios muestreos, emparejando en el tiempo el sitio impactado con el sitio control para incorporar al estudio los cambios naturales de ambos sitios (Control-Treatment Pairing, Eberhart 1976).

Sin embargo, esta aproximación tiene dos limitaciones. La primera es que el test asume que los efectos son aditivos, cuando en realidad en muchos sistemas biológicos los efectos son multiplicativos. Esto significa que las diferencias aritméticas entre el control y el impacto suelen ser mayores cuando las densidades específicas son más abundantes que cuando las densidades específicas son escasas (Stewart-Oaten et al. 1986). La segunda es que el análisis asume que no hay una tendencia obvia entre las diferencias entre el sitio control y el sitio impactado en el período antes del impacto. Es decir, el sitio impactado y el sitio control deberían ser similares entre sí antes del impacto.

En el BACIPS el análisis de las interacciones es un poco más complejo que en el diseño tradicional $\mathrm{BACl}$ de Green (1979), adonde la interacción $\mathrm{BAxCl}$ indica la presencia de un impacto. En el BACIPS no sólo importa dicha interacción (Downes et al. 2002) sino también la interacción $\mathrm{ClxT}_{(\mathrm{BA})}$, ya que diferenciaría entre distintos tipos de impacto.

A los fines de facilitar la interpretación de los resultados arrojados por estos análisis en la Tabla 2.3 se exponen las distintas alternativas que pueden suscitarse.

1. Si la interacción $\mathrm{BAxCl}$ es significativa: hay un impacto en el tramo tratado.

a. Si la interacción $\mathrm{ClXT}_{(\mathrm{BA})}$ es también significativa, habrá diferencias entre los tramos y entre los distintos tiempos muestreados

b. Si la interacción $\mathrm{ClxT}_{(\mathrm{BA})}$ es no-significativa habría un impacto instantáneo y sostenido en el tiempo, también llamado impacto press (Underwood 1989, 1991). 
2. Si la interacción $\mathrm{BAxCl}$ no es significativa:

a. Si la interacción $\mathrm{Cl}_{\mathrm{X}} \mathrm{T}_{(\mathrm{BA})}$ es significativa, hay una posibilidad que haya un impacto no sostenido en el tiempo, con un efecto gradual enmascarando la significancia estadística en la primera interacción.

Este tipo de impactos es llamado impacto de pulso (Underwood 1989, 1991).

b. Si la interacción $\mathrm{ClXT}_{(\mathrm{BA})}$ es no-significativa no hay impacto de ningún tipo.

\begin{tabular}{|c|c|c|c|c|c|}
\hline Diseño & Controles & \# Muestreos & Ventajas & Desventajas & Refs. \\
\hline BA & Sin controles & $\begin{array}{l}1 \text { o varios antes } \\
\text { y después }\end{array}$ & - Medida rápida & $\begin{array}{l}\text { - No hay } \\
\text { controles } \\
\text { - Altamente } \\
\text { desacreditado }\end{array}$ & Green (1979) \\
\hline $\mathrm{BACl}$ & 1 & $\begin{array}{l}1 \text { o varios antes } \\
\text { y después, } \\
\text { asincrónicos } \\
\text { entre los sitios }\end{array}$ & $\begin{array}{l}\text { - Hay sitio } \\
\text { control } \\
\text { - Si se hacen } \\
\text { varios muestreos, } \\
\text { hay mayor } \\
\text { robustez } \\
\text { estadística }\end{array}$ & $\begin{array}{l}\text { - Al ser } \\
\text { asincrónicos los } \\
\text { muestreos entre } \\
\text { ambos sitios, son } \\
\text { pseudoréplicas } \\
\text { - Un solo sitio } \\
\text { control }\end{array}$ & Green (1979) \\
\hline BACIPS & 1 & $\begin{array}{l}\text { Varios antes y } \\
\text { después, al } \\
\text { mismo tiempo } \\
\text { entre sitios }\end{array}$ & $\begin{array}{l}\text { - Hay sitio } \\
\text { control } \\
\text { - No hay } \\
\text { pseudoréplicas } \\
\text { - Ampliamente } \\
\text { utilizado }\end{array}$ & $\begin{array}{l}\text { - Un solo sitio } \\
\text { control }\end{array}$ & $\begin{array}{l}\text { Stewart- } \\
\text { Oaten et al. } \\
(1986)\end{array}$ \\
\hline $\begin{array}{l}\text { BACIPS } \\
\text { asimétrico }\end{array}$ & Varios & $\begin{array}{l}\text { Varios antes y } \\
\text { después, al } \\
\text { mismo tiempo } \\
\text { entre sitios }\end{array}$ & $\begin{array}{l}\text { - Hay varios } \\
\text { sitios control, muy } \\
\text { robusto } \\
\text { - No hay } \\
\text { pseudoréplicas }\end{array}$ & $\begin{array}{l}\text { - El esfuerzo que } \\
\text { plantea el } \\
\text { muestreo de varios } \\
\text { sitios control } \\
\text { - Se debe hacer } \\
\text { un promedio de los } \\
\text { valores entre los } \\
\text { controles }\end{array}$ & $\begin{array}{l}\text { Underwood } \\
\text { (1991) }\end{array}$ \\
\hline
\end{tabular}

Tabla 2.1. Resumen de los distintos tipos de diseños experimentales $\mathrm{BACl}$, con sus características, ventajas y desventajas

\begin{tabular}{|c|c|c|c|c|c|c|c|c|}
\hline \multirow[b]{2}{*}{ Fuentes de variación } & \multicolumn{2}{|c|}{ BA } & \multicolumn{2}{|c|}{$\mathrm{BACl}$} & \multirow{2}{*}{$\begin{array}{c}\text { BACIPS } \\
\text { GL }\end{array}$} & \multirow[b]{2}{*}{ F vs. } & \multicolumn{2}{|c|}{ BACIPS asimétrico } \\
\hline & $\mathrm{GL}$ & F vs. & GL & F vs. & & & GL & F vs. \\
\hline Antes vs. Después (BA) & 1 & $T(B A)$ & 1 & & 1 & & 1 & \\
\hline $\begin{array}{l}\text { Control vs. Impacto } \\
\text { (CI) }\end{array}$ & --- & & 1 & & 1 & & L - 1 & \\
\hline Tiempos $\left(T_{(B A)}\right)$ & $2(t-1)$ & & --- & & $2(t-1)$ & & $2(t-1)$ & \\
\hline Interacción $\mathrm{BAxCl}$ & --- & & 1 & Res & 1 & $\mathrm{ClxT}_{\mathrm{BA}}$ & $L-1$ & $\mathrm{Cl}$ \\
\hline Interacción $\mathrm{Clx}_{(\mathrm{BA})}$ & --- & & --- & & $2(t-1)$ & Res & $2(t-1)(L-1)$ & Res \\
\hline Residual & $2 t(n-1)$ & & $4(n-1)$ & & $4 t(n-1)$ & & $2 \mathrm{Lt}(\mathrm{n}-1)$ & \\
\hline Total & $2 t n-1$ & & $4 n-1$ & & $2\left(t_{B}+t_{A}\right)-1$ & & $N-1$ & \\
\hline
\end{tabular}

Tabla 2.2. Tablas de ANOVA para los distintos diseños BACI (Modificada de Underwood 1994). GL = grados de libertad; $F$ vs. = contra lo que se debe comparar los cuadrados medios de esa fuente de variación para evidenciar impactos. 


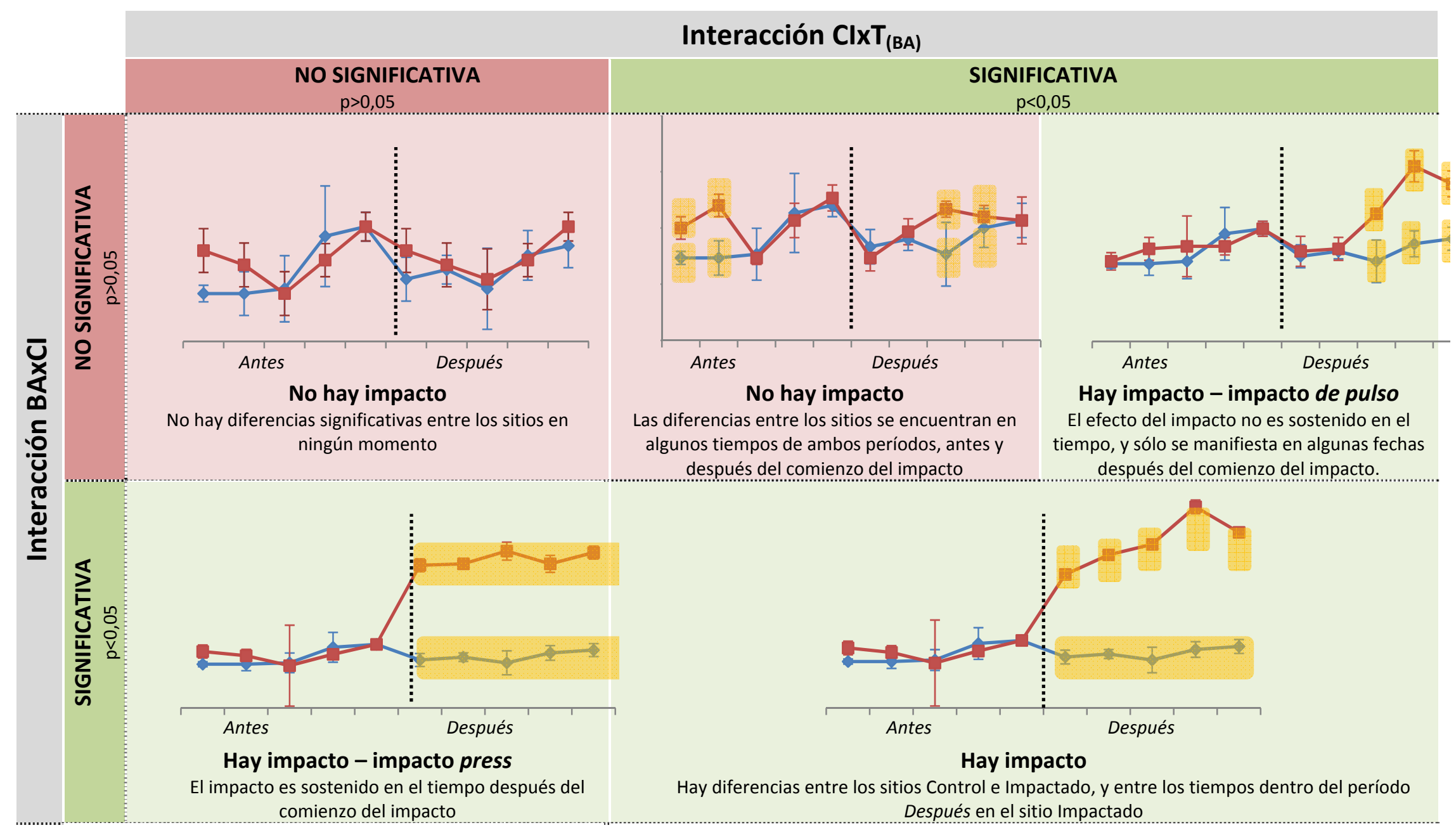

Tabla 2.3. Interpretación de las significancias de las interacciones del BACIPS, con ejemplos hipotéticos. La línea roja es el promedio de la variable en el tramo Impactado, la línea azul es el promedio de la variable en el tramo Control, ambas con sus desvíos estándar. Los rectángulos amarillos y las letras en itálica indican diferencias significativas entre control (letras azules) y tratamiento (letras rojas) para la fecha sobre la cual se encuentran. 
Para las experiencias de laboratorio del presente estudio se utilizaron diseños experimentales factoriales. Los experimentos factoriales son investigaciones en más de un tratamiento experimental examinados simultáneamente (Underwood 2007). Cada tratamiento experimental se considera un factor, con una cantidad de niveles dentro de cada factor.

En general, los experimentos factoriales se diseñan para ser ortogonales. La ortogonalidad es la propiedad de que cada nivel de un factor está presente en el experimento en combinación con todos los niveles de los demás factores. Cuando dos factores en un experimento no son ortogonales entre ellos, deberían ser organizados de tal manera que uno sea muestreado independientemente como un factor anidado, para retener una estructura y un análisis válido. Por ello, si dos factores no son ortogonales entre sí (algunos niveles de uno de los factores no están presentes en todos los niveles del otro factor), las diferencias entre los factores serán confusas (en el sentido estadístico), y el análisis será inválido.

A su vez, hay dos tipos de factores: fijos o al azar. Los factores fijos incluyen todos los niveles relevantes a la hipótesis en el experimento. Los factores al azar incluyen sólo una muestra de los niveles relevantes en la hipótesis elegidos al azar. Es decir, si repetimos un experimento que tuvo un factor al azar, y elegimos cualquier otro nivel de ese factor, deberíamos obtener los mismos resultados y las mismas conclusiones que la primera vez. Eso no pasaría cuando el factor es fijo, adonde si alteramos los niveles del factor, se obtienen diferentes conclusiones ya que provienen de diferentes hipótesis.

Es muy importante definir previamente a los muestreos qué tipo de factores se tienen en el estudio, ya que su definición es una función de la manera en que las hipótesis están planteadas y no una propiedad del análisis (Underwood 2007). En el análisis estadístico en sí, los cuadrados medios de los factores se compararán con los cuadrados medios residuales o con los cuadrados medios de las interacciones, dependiendo del tipo de factor. 


\section{CAPÍTULO 3}

METODOLOGÍAS

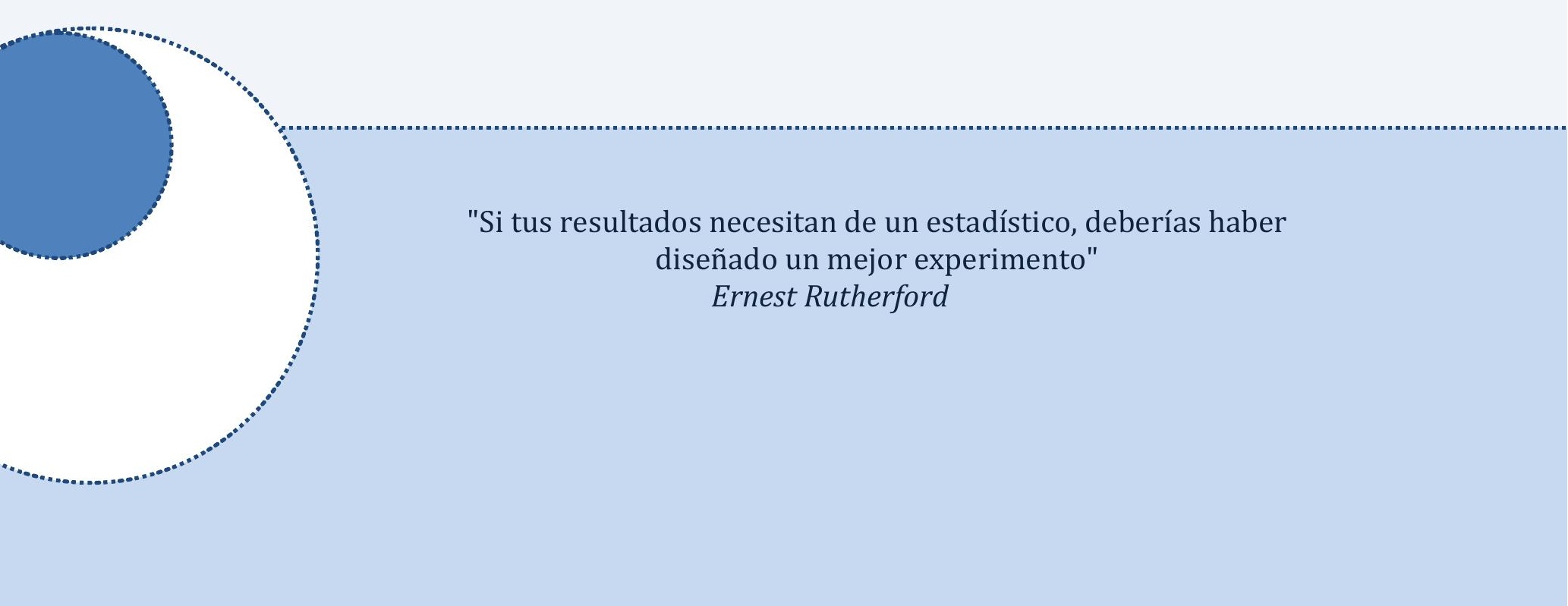


Para la recolección de los primeros $5 \mathrm{~mm}$ del lecho de los arroyos se empleó una pipeta seccionada en su punta, con una propipeta en su otro extremo para asistir con la succión. Así se recolectaron 4mL de biofilm (Gómez \& Licursi 2001, Licursi \& Gómez 2002, Gómez et al. 2009) (Figura 3.1) y se calculó su superficie específica. La superficie específica calculada representa la sumatoria de las superficies de todos los granos del sedimento en un volumen determinado, y permite la conversión entre un volumen de muestra $(4 \mathrm{~mL})$ y su equivalente en superficie, dependiendo de las proporciones de arenas, limos y arcillas que contenga la muestra (ver la sección 3.1.4. Granulometría).

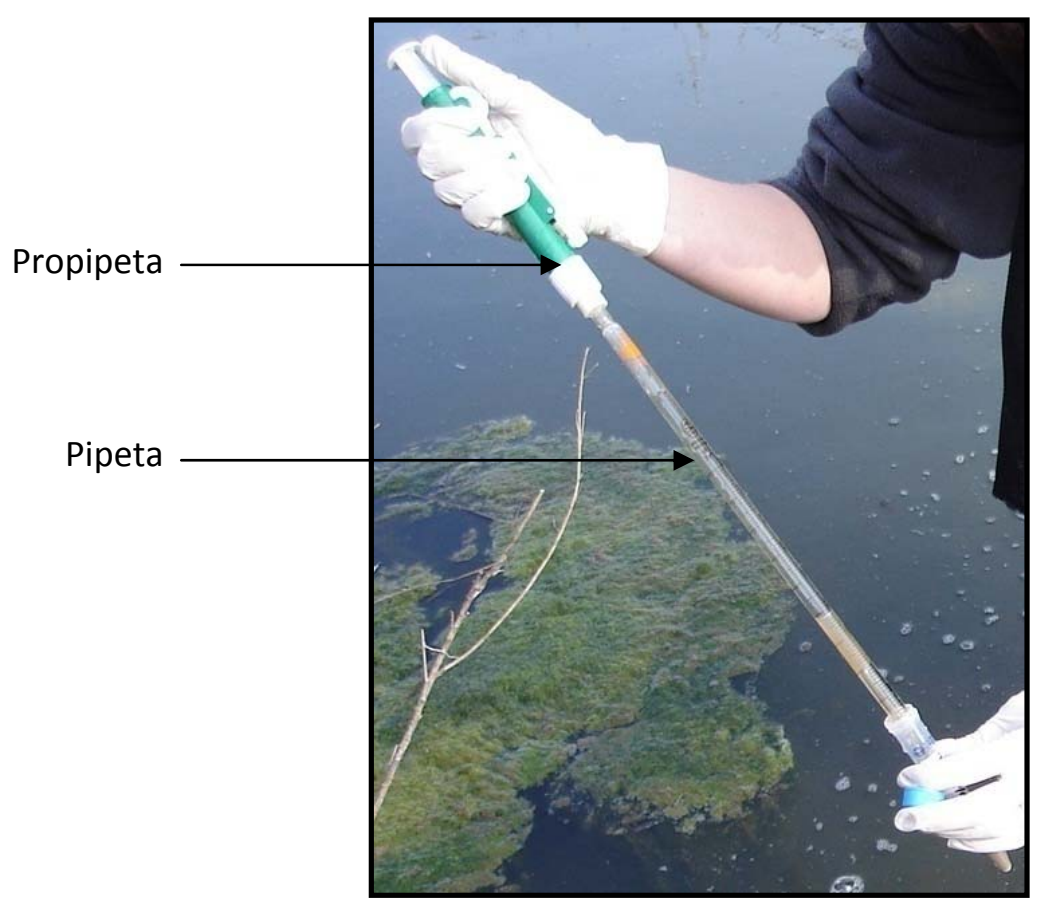

Figura 3.1. Dispositivo de muestreo para biofilms epipélicos. 
El pH, la temperatura, la conductividad y el oxígeno disuelto (OD) fueron medidos con sensores multiparamétricos (HORIBA U10, CONSORT C933).

La Radiación Fotosintéticamente Activa (PAR) fue medida con un sensor de PAR LICOR, y expresada en $\mu \mathrm{mol}$ de fotones $\mathrm{m}^{-2}$ ( $\mu$ Einsteins). El caudal se midió en las experiencias de laboratorio con un caudalímetro Schiltknecht MiniAir20.

Los nutrientes fueron analizados por triplicado mediante técnicas estándar (APHA 1998). Para ello las muestras fueron filtradas por filtros GF/C y congeladas a $-18^{\circ} \mathrm{C}$ hasta su análisis. Se utilizaron dos blancos y cinco estándares duplicados para asegurar curvas de calibración precisas, y se midieron fósforo reactivo soluble (o PRS, $\mathrm{P}-\mathrm{PO}_{4}{ }^{3-}$ ), nitratos $\left(\mathrm{N}-\mathrm{NO}_{3}{ }^{-}\right.$), nitritos $\left(\mathrm{N}-\mathrm{NO}_{2}{ }^{-}\right)$y amonio $\left(\mathrm{N}-\mathrm{NH}_{4}{ }^{+}\right)$. El nitrógeno inorgánico disuelto (NID) se calculó como la suma de nitratos + nitritos + amonio.

\section{Amonio}

Para medir el amonio se utilizaron dos reactivos:

- Reactivo 1: se disolvieron $15 \mathrm{~g}$ de fenol y $0,015 \mathrm{~g}$ de nitroprusiato de sodio en $500 \mathrm{ml}$ de agua destilada-deionizada

- Reactivo 2: se disolvieron $10 \mathrm{~g}$ de $\mathrm{NaOH}$ en $400 \mathrm{~mL}$ de agua deionizada. Se dejó enfriar y se agregó un volumen de lavandina comercial concentrada equivalente a $0,265 \mathrm{~g}$ de cloro disponible. Luego se completó a $500 \mathrm{~mL}$ con agua deionizada.

A $25 \mathrm{~mL}$ de muestra se agregaron $0,5 \mathrm{~mL}$ de cada reactivo consecutivamente. Se colocaron las muestras en un baño termostático durante una hora y se midió la absorbancia a $635 \mathrm{~nm}$ en un espectrofotómetro. 


\section{Nitritos}

Para medir los nitritos se prepararon dos reactivos:

- Reactivo 1: se disolvió $1 \mathrm{~g}$ de sulfanilamida en una mezcla de $60 \mathrm{~mL}$ de agua destilada y $20 \mathrm{~mL}$ de ácido clorhídrico concentrado. Se completó a $100 \mathrm{~mL}$ con agua destilada.

- Reactivo 2: se disolvió 0,1 g de $\mathrm{N}_{1}$ Naftiletilendiamina en $100 \mathrm{~mL}$ de agua destilada.

A $50 \mathrm{~mL}$ de muestra se agregaron $1 \mathrm{~mL}$ del Reactivo 1. Luego de diez minutos se agregó $1 \mathrm{~mL}$ del Reactivo 2. Se midió la absorbancia a 543nm en espectrofotómetro después de los 10 minutos y antes de dos horas.

\section{Nitratos + Nitritos}

Para medir los nitratos + nitritos se utilizaron:

- Reactivo 1: Se disolvió 32g de $\mathrm{NaOH}$ en $1000 \mathrm{~mL}$ de agua destilada.

- Reactivo 2: Se disolvió 0,545 g de sulfato de hidrazina en $1000 \mathrm{~mL}$ de agua destilada.

- Reactivo 3: Se disolvió $0,228 \mathrm{~g}$ de sulfato de cobre en $100 \mathrm{~mL}$ de agua destilada.

- Reactivo 4: Se disolvió 5,1 g de sulfato de zinc en $100 \mathrm{~mL}$ de agua destilada.

- Reactivo reductor: Se mezclaron $160 \mathrm{~mL}$ del Reactivo 2, $2 \mathrm{~mL}$ de Reactivo 3 y 2 $\mathrm{ml}$ de Reactivo 4. Se completó con agua destilada a $200 \mathrm{~mL}$.

A $10 \mathrm{~mL}$ de muestra se le agregó $2 \mathrm{~mL}$ del Reactivo 1 y 2,5 $\mathrm{mL}$ del Reactivo reductor. Después de 30 minutos se agregaron 2 gotas de $\mathrm{HCl} 11 \mathrm{~N}$ y $1 \mathrm{ml}$ de Reactivo 1 utilizado para medir nitritos. Después de 5-10 minutos se agregaron $1 \mathrm{~mL}$ del Reactivo 2 utilizado para medir nitritos. Se midió la absorbancia a 543nm en espectrofotómetro.

\section{Fósforo Reactivo Soluble (PRS)}

Para medir el fósforo reactivo soluble (o PRS) se prepararon los siguientes reactivos:

- Reactivo 1: se disolvió $15 \mathrm{~g}$ de molibdato de amonio en $500 \mathrm{~mL}$ de agua destilada.

- Reactivo 2: se disolvió $140 \mathrm{~mL}$ de $\mathrm{H}_{2} \mathrm{SO}_{4}$ en $900 \mathrm{~mL}$ de agua destilada

- Reactivo 3: se disolvió 54g de ácido ascórbico en $1000 \mathrm{~mL}$ de agua destilada

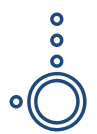


- Reactivo 4: se disolvió $0,34 \mathrm{~g}$ de tartrato de antimonio y potasio en $250 \mathrm{~mL}$ de agua destilada

- Reactivo mezcla: se mezclaron los reactivos 1 a 4 en orden en relación 20:50:20:10

A $25 \mathrm{~mL}$ de muestra se agregaron 2,5mL del Reactivo mezcla. Después de 15 minutos y antes de las tres horas se midió la absorbancia en espectrofotómetro a 885nm. 
Las muestras destinadas al análisis de la composición taxonómica composición fueron fijadas con formol al $4 \%$ y conservadas en envases plásticos. Para la cuantificación de los especímenes se emplearon cámaras de Sedgewick-Rafter que fueron analizadas en un microscopio Olympus BX-51 a 400X (Stevenson \& Bahls 1999).

Para la identificación de diatomeas se emplearon dos submuestras que fueron oxidadas con $\mathrm{H}_{2} \mathrm{O}_{2}$ y sometidas a tres ciclos sucesivos de lavados con agua destilada y centrifugado (3500rpm). Las muestras fueron luego montadas con Naphrax ${ }^{\circledR}$ para su observación en microscopio Olympus BX-51 a 1000X.

La identificación se llevó a cabo con la ayuda de la siguiente bibliografía, según el grupo taxonómico:

- Diatomeas: Patrick \& Reimer (1966, 1975), Krammer \& Lange-Bertalot (1986, 1988, 1991a, 1991b), Lange-Bertalot (1993), Krammer (1992, 2000), Lange-Bertalot \& Moser (1994)

- Cianobacterias: Komárek \& Anagnostidis (1999, 2005), Desikachary (1959)

- Clorofitas: Komárek \& Praha (1983), Streble \& Krauter (1987), Bourrelly (1972)

- Zooplancton: Olivier (1965), Sládecèk (1973), Margalef (1983), Streble \& Krauter (1987), Dou (2000), Coelho-Botelho (2003), de Paggi (2004), Javed (2006)

Las distintas especies de diatomeas fueron clasificadas de acuerdo con sus preferencias metabólicas de nitrógeno (Van Dam et al. 1994, Licursi et al. 2010), por su estado trófico y saprobiedad (Sládecèk 1973, Van Dam et al. 1994, Gómez \& Licursi 2001) 
Los análisis granulométricos se realizaron para caracterizar el tipo de sustrato y para calcular la superficie específica del mismo. El material se separó en tres clases de tallas de grano, según la clasificación propuesta por Folk (1974): arena (diámetro $>62,5 \mu \mathrm{m})$, limo $(62,5$ $\mu \mathrm{m}<$ diámetro $>3,9 \mu \mathrm{m}$ ) y arcilla (diámetro $<3,9 \mu \mathrm{m}$ ). La separación del material grueso (arena) se realizó por tamizado y la de los materiales finos (limos y arcillas) aplicando el principio de Stokes (la velocidad de sedimentación de una partícula es proporcional a su diámetro al cuadrado). Para lograr la separación en las tres clases granulométricas (APHA 1998) se procedió de la siguiente manera:

1. A las muestras homogeneizadas $(4 \mathrm{~mL})$ se les agregó $30 \mathrm{~mL}$ de solución de dispersante (Hexametafosfato de Sodio) de concentración $1 \mathrm{~g} \mathrm{~L}^{-1}$, disponiéndolas en un shaker por 12 horas.

2. Las muestras se dispusieron por un tamiz de $62,5 \mu \mathrm{m}$ de poro, utilizando el mismo dispersante para ayudar su tamizado. El tamizado se efectúo sobre un embudo, y la solución que arrastró el material fino se colectó en una probeta de $1 \mathrm{~L}$. El sedimento retenido en el tamiz fue secado en estufa a $60^{\circ} \mathrm{C}$ y posteriormente pesado; el resultado obtenido correspondió al contenido de la fracción arena.

3. Posteriormente se procedió a enrasar la probeta que contenía el material fino con la solución de dispersante a $1 \mathrm{~L}$ y fue agitada manualmente. A los 20 segundos de finalizada la agitación se extrajeron $20 \mathrm{~mL}$ de mezcla mediante pipeta, a una profundidad de $20 \mathrm{~cm}$ desde la superficie, y se dispusieron en un crisol. El contenido del crisol fue secado en estufa a $60^{\circ} \mathrm{C}$ y pesado, y al valor obtenido se le descontó los 0,02g de la sal del dispersante empleado. El peso final representó el contenido de material fino (limo + arcillas).

4. El remanente de la mezcla en la probeta se dejó sedimentar por 2 horas y se realizó una segunda extracción de $20 \mathrm{~mL}$ de la mezcla por pipeteo, a una profundidad de $10 \mathrm{~cm}$ de la superficie. Este volumen extraído se colocó en otro crisol, y luego de ser secado en estufa a $60^{\circ} \mathrm{C}$ y pesado se le descontaron los $0,02 \mathrm{~g}$ de la sal del dispersante disuelto. El peso final representó el contenido de arcillas en el sedimento. 
5. El tiempo que se debe dejar sedimentar la solución se calculó con la siguiente fórmula:

$$
\boldsymbol{T i e m p o}(\text { minutos })=\frac{\boldsymbol{P}}{1500 * \boldsymbol{K} * \boldsymbol{d}^{2}}
$$

$\mathbf{P}=$ profundidad en $\mathrm{cm}$

$\mathbf{K}=$ constante dependiente de la viscosidad del agua, temperatura, fuerza de gravedad $\mathbf{y}$ densidad de partículas. Para $24^{\circ} \mathrm{C} \mathrm{K}=3,93$;

$\mathrm{d}^{2}=$ diámetro de las partículas en $\mathrm{mm}$, al cuadrado

Al obtener los pesos secos de cada fracción granulométrica (arena, limo y arcilla) se puede calcular la cantidad de granos en cada fracción, con el protocolo de Marxsen and Witzel (1991):

$$
\boldsymbol{N}=-0.14225-(5 \log \mathbf{d} \mathbf{1}+\log \mathrm{d} 2) / 2+\log \boldsymbol{p}
$$

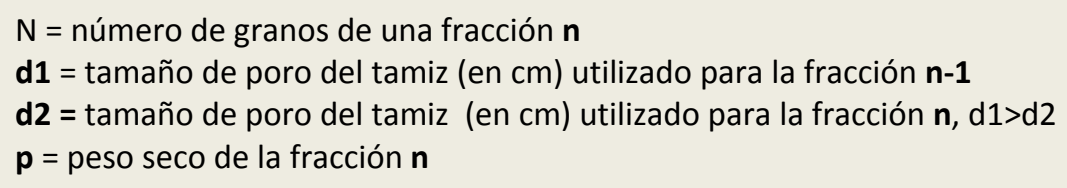

Si para cada fracción se conoce el número de granos $(\mathrm{N})$ y se conoce el diámetro promedio de cada grano ( $r$ ), se puede calcular la superficie específica del sedimento de cada fracción (considerando los granos de arena como esferas de sílice), y así obtener un factor de conversión entre la superficie y el volumen de la muestra.

En esta tesis, este factor se calculó para cada sitio del cual se colectó biofilm y se consideró constante durante su estudio en ese sitio. 
La biomasa algal fue estimada utilizando la concentración de clorofila "a". Para ello se midieron muestras por triplicado según el método espectrofotométrico utilizado por Strickland \& Parsons (1968):

1. Se filtraron las muestras por filtros tipo Whatman GF/C, se secaron y mantuvieron en freezer

$\left(-18^{\circ} \mathrm{C}\right)$ y en silicagel hasta su análisis.

2. Se colocaron los filtros con $3 \mathrm{~mL}$ de acetona $90 \%$ en frascos de vidrio y se dejaron reposar en oscuridad y en la heladera por $12 \mathrm{hs}$.

3. Los frascos se colocaron por 6 minutos en un baño de ultrasonido para favorecer la liberación de la clorofila.

4. Los filtros y el sobrenadante se traspasaron a frascos de centrífuga tipo Falcon de $15 \mathrm{~mL}$. Se machacaron los filtros con una varilla de vidrio esmerilado, y se les agregó otros $5 \mathrm{ml}$ de acetona $90 \%$.

5. Se centrifugó el material por 45 minutos a 3500RPM.

6. Se cuantificó el sobrenadante en un espectrofotómetro en las longitudes de onda $430 \mathrm{~nm}, 630 \mathrm{~nm}, 645 \mathrm{~nm}, 665 \mathrm{~nm}$ y $750 \mathrm{~nm}$, utilizando un blanco de acetona.

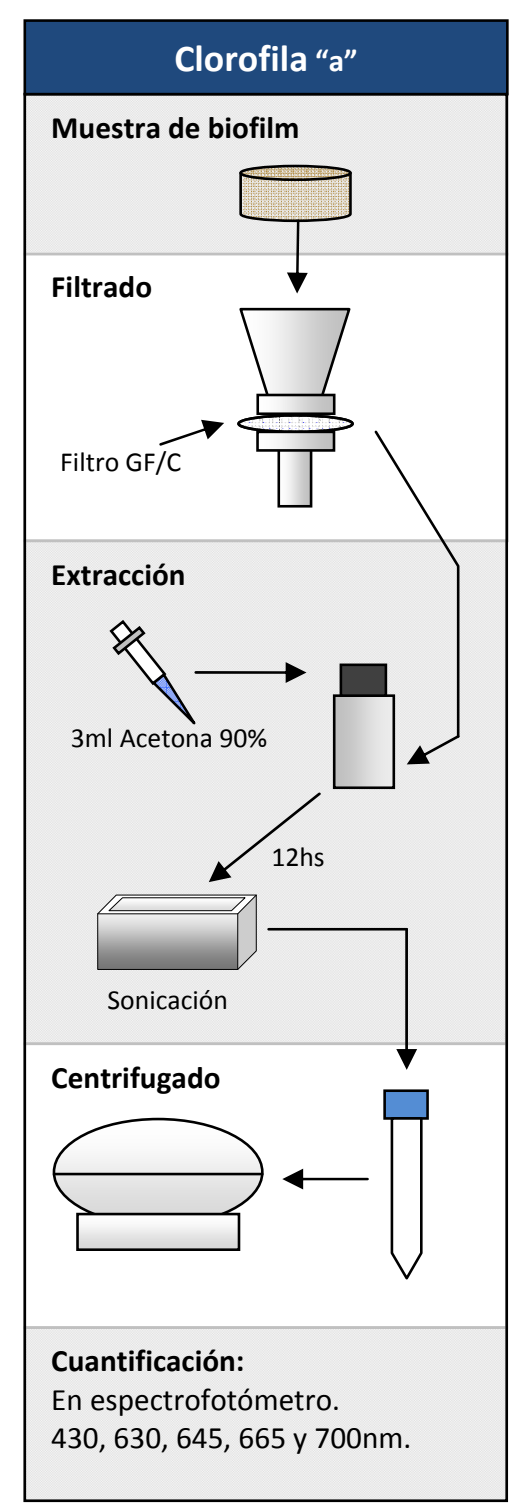

Para el cálculo de la clorofila "a" (en $\mu \mathrm{g} \mathrm{L}^{-1}$ ) se utilizó la siguiente ecuación (Strickland \& Parsons 1968):

$\boldsymbol{C h l}\left(\mu \mathrm{L} \mathrm{L}^{-1}\right)=\frac{11,6\left(\boldsymbol{D \boldsymbol { O } _ { 6 6 5 }}-\boldsymbol{D} \boldsymbol{O}_{750}\right)-1,31\left(\boldsymbol{D \boldsymbol { O } _ { 6 4 5 }}-\boldsymbol{D} \boldsymbol{O}_{750}\right)-0,14\left(\boldsymbol{D \boldsymbol { O } _ { 6 3 0 }}-\boldsymbol{D \boldsymbol { O } _ { 7 5 0 }}\right)}{\left(\frac{\boldsymbol{V} \boldsymbol{E}}{1000}\right) /\left(\frac{\boldsymbol{V} \boldsymbol{F}}{1000}\right)}$

DO: la densidad óptica obtenida para la longitud de onda señalada.

VE: Volumen del extracto, en $\mathrm{mL}$. Para este protocolo es igual a $8 \mathrm{~mL}$.

VF: Volumen filtrado. En este caso, expresa la superficie conocida de la muestra filtrada en $\mathrm{cm}^{2}$. 
Las muestras de bacterias del biofilm fueron colectadas por triplicado en viales de vidrio autoclavados, y fijadas con formol $2 \%$.

El conteo de la densidad y estimación de la biomasa se realizó utilizando métodos de epifluorescencia, que señala los siguientes pasos (Porter \& Feig 1980):

1. Se colocaron las muestras en un baño de ultrasonido en frío, por tres ciclos de dos minutos cada uno.

2. Se diluyeron las muestras unas $20-400$ veces de acuerdo con la cantidad de sedimento que presentaban para facilitar las observaciones en microscopio, hasta un volumen final de $5 \mathrm{~mL}$.

3. Las muestras se tiñeron con $2 \mu \mathrm{g} \cdot \mathrm{mL}^{-1}$ de DAPI (4,6-diamidino-2-fenilindoldihidrocloruro, Sigma D9542) durante 10 minutos.

4. Se filtraron las muestras teñidas por filtros de policarbonato negro de $0,2 \mu \mathrm{m}$ de poro a baja presión de vacío $(180 \mathrm{mmHg})$. Para proteger el filtro negro se le colocó un filtro Whatman GF/C por debajo en la columna de filtración.

5. El filtro se montó colocando una gota de aceite de inmersión de baja fluorescencia en un portaobjetos, y se agregó otra gota de aceite sobre el filtro antes de colocar el cubreobjeto.

6. La observación se realizó en un microscopio

\section{Densidad bacteriana}

Muestra de biofilm

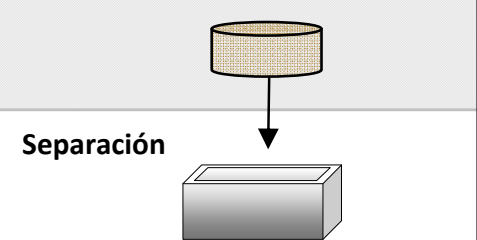

Sonicador

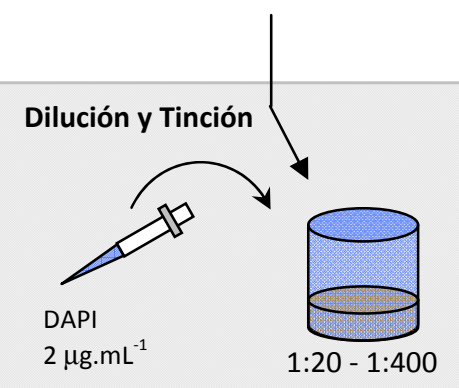

Filtrado

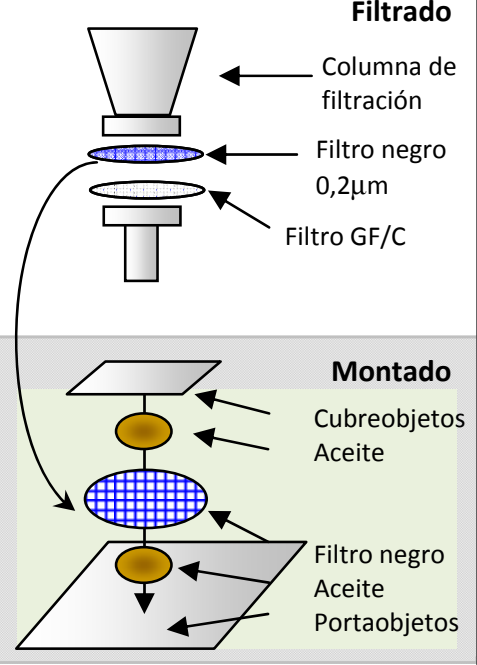

Cuantificación: Microscopio de epifluorescencia $1000 \mathrm{X}$

Olympus BX-51 con epifluorescencia a 1000X, y se contaron 20 campos al azar. 
La densidad bacteriana por superficie (N) fue calculada utilizando la siguiente ecuación:

$$
N=\frac{\boldsymbol{n} *\left(\frac{\boldsymbol{A}}{\boldsymbol{a t}}\right) * d *\left(\frac{V m}{V \boldsymbol{f}}\right)}{S}
$$

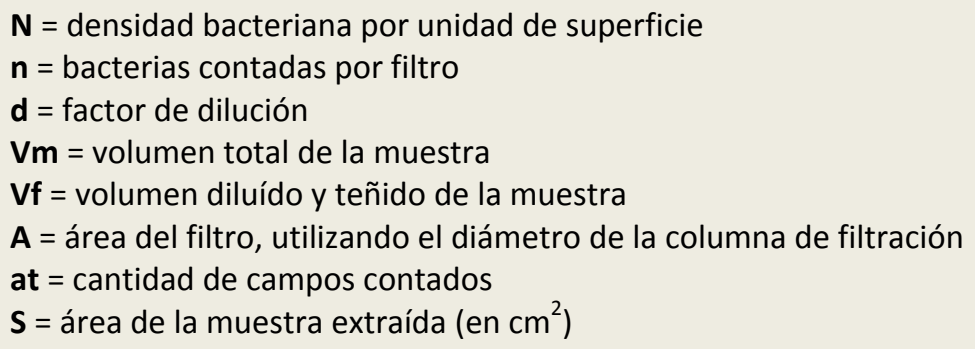

Una vez obtenida la densidad bacteriana, se puede calcular la biomasa bacteriana de dos maneras: aproximando el biovolumen de cada forma celular a una forma geométrica (cocos a esferas, filamentos a cilindros y bacilos a cilindros semiesféricos), o utilizando un factor constante de $0,1 \mu \mathrm{m}^{3}$ por célula (Thiel-Nielsen \& Sondergaard 1998). Para todos los análisis de la presente tesis se utilizó esta segunda opción, asumiendo un volumen constante de $0,1 \mu \mathrm{m}^{3}$ por célula (Romaní et al. 2009).

La biomasa bacteriana de cada muestra se calculó entonces utilizando el biovolumen y la densidad de cada forma bacteriana, utilizando la fórmula alométrica de Norland (Norland 1993):

$$
m=C V^{a}
$$

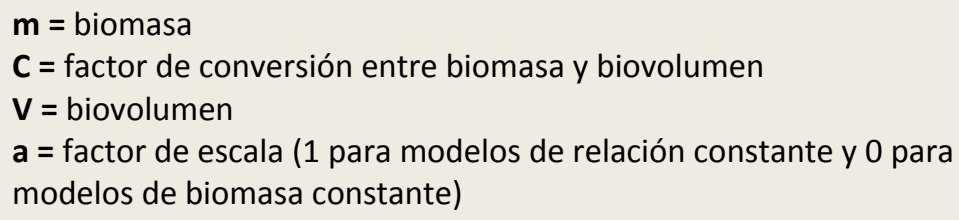

Como factor de conversión (C) se utilizó $2,2 \times 10^{-13} \mathrm{gC} \mu \mathrm{m}^{-3}$, establecido en la mitad de los distintos valores citados en la bibliografía (Bratbak \& Dundas 1984), y como factor de escala se utilizó 0,91 (Norland 1993). 
Para analizar la actividad respiratoria del biofilm se siguió la técnica propuesta por Blenkinsopp \& Lock (1990) la cual emplea el compuesto 2-(p-iodofenil)-3-(p-nitrofenil)-5-fenil cloruro de tetrazolio (INT) que es reducido a lodonitrotetrazolio formazán (INT-Formazan) en la cadena transportadora de electrones, acumulándose en el interior de las células y tiñéndolas de un color rojizo.

La cantidad de INT reducido a INT-Formazan es proporcional a la respiración de los organismos, por lo que sirve como estimación de la respiración de los organismos aeróbicos del biofilm. En células procariotas el INT-Formazan forma unos cristales definidos que pueden ser vistos con microscopio óptico, mientras que en células eucariotas es incorporado difusamente.

Para estimar la respiración total del biofilm mediante INTFormazan se realizó el siguiente ensayo:

1. Se prepararon simultáneamente:

a. Muestras del biofilm epipélico: por duplicado y sin fijadores

b. Muestra control: es una muestra del biofilm que se fijó con formol $2 \%$ unos $30 \mathrm{~min}$ antes del ensayo

c. Blancos: dos blancos de metanol

d. Estándares: de INT-Formazan (Sigma 17375), para obtener una curva de calibración (de 5, 10, 15, 20, 25 y 30

\section{Actividad respiratoria}

Muestra de Biofilm

Preparación
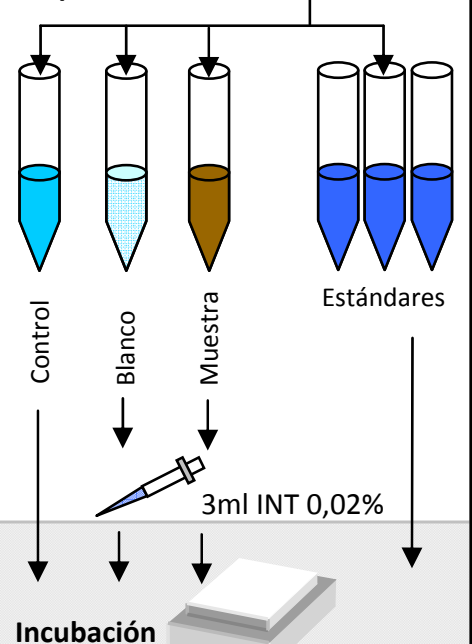

Incubación

Shaker $12 \mathrm{hr}$
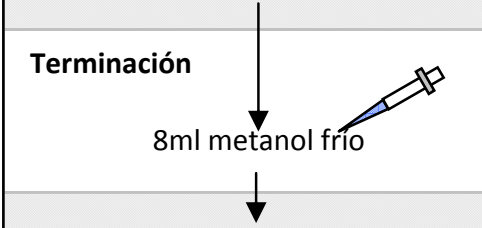

Incubación
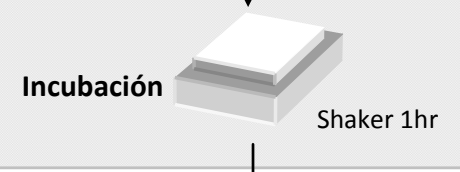

Sonicación

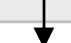

(2)

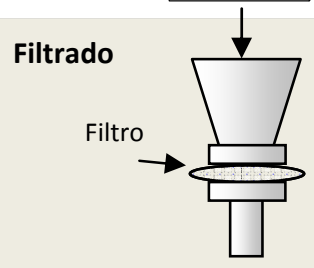

Medición: En espectrofotómetro a $480 \mathrm{~nm}$ $\left.\mu g \cdot \mathrm{mL}^{-1}\right)$

2. A las muestras del biofilm, a la muestra control, a los blancos y a los estándares se les agregó $3 \mathrm{ml}$ de INT 0,02\% y se incubaron en shaker en oscuridad por 10-12hs, a temperatura ambiente.

3. Se les agregó $8 \mathrm{ml}$ de metanol frío $\left(4^{\circ} \mathrm{C}\right.$ en oscuridad), para finalizar la reducción del INT. 
4. Se volvieron a incubar, por una hora, y se sumergieron en un baño de ultrasonido por 2 minutos.

5. Se filtraron las muestras para disminuir su turbidez por filtros Whatman GF/F.

6. Se midió la absorbancia de las muestras filtradas en un espectrofotómetro a $480 \mathrm{~nm}$.

Los valores de absorbancia obtenidos en las muestras de biofilm se les restaron los valores de absorbancia de las muestra control y los valores promedio de los dos blancos. Se generó una curva de calibración de $\mu \mathrm{g} \cdot \mathrm{mL}^{-1}$ a partir de las absorbancias de los estándares, y los valores de absorbancia medidos en las muestras de biofilm fueron referidos a esos estándares. Los volúmenes de cada muestra fueron luego convertidos $\mathrm{a}_{\mathrm{cm}}^{-2}$ utilizando el factor de conversión obtenido en la granulometría, y se expresaron por la cantidad de horas correspondientes a la incubación. 
Para cuantificar los carbohidratos totales presentes en el biofilm se realizaron ensayos fenol-ácido sulfúrico, siguiendo la propuesta de Dubois et al. (1956). Esta técnica considera los carbohidratos totales: los intracelulares, extracelulares (denominados EPS), y los unidos a las partículas. Los pasos a seguir según dicho protocolo son:

1. Se prepararon en simultáneo:

a. Muestras del biofilm: por triplicado y sin fijar

b. Blancos: dos blancos de agua destilada

c. Estándares: de glucosa, para obtener una curva de calibración (de 12, 24, 36, 48, 60, $72,84,96,108$ y $120 \mu \mathrm{g} \cdot \mathrm{mL}^{-1}$ )

2. Se agregaron $5 \mathrm{ml}$ de $\mathrm{H}_{2} \mathrm{SO}_{4} 1 \mathrm{M}$ a cada muestra en un vial de vidrio, y se maceraron con varilla de vidrio esmerilado.

3. Se taparon los tubos individualmente con papel de aluminio y se colocaron en un termobaño a $100^{\circ} \mathrm{C}$ por una hora.

4. Se separó $1 \mathrm{~mL}$ del extracto ácido y se les agregó $1 \mathrm{~mL}$ de fenol al 5\%

5. Se dejaron reposar unos 40 minutos, y se les agregó lentamente $5 \mathrm{~mL}$ de $\mathrm{H}_{2} \mathrm{SO}_{4}$ concentrado (bajo campana para extracción de gases y con

\section{Carbohidratos totales}

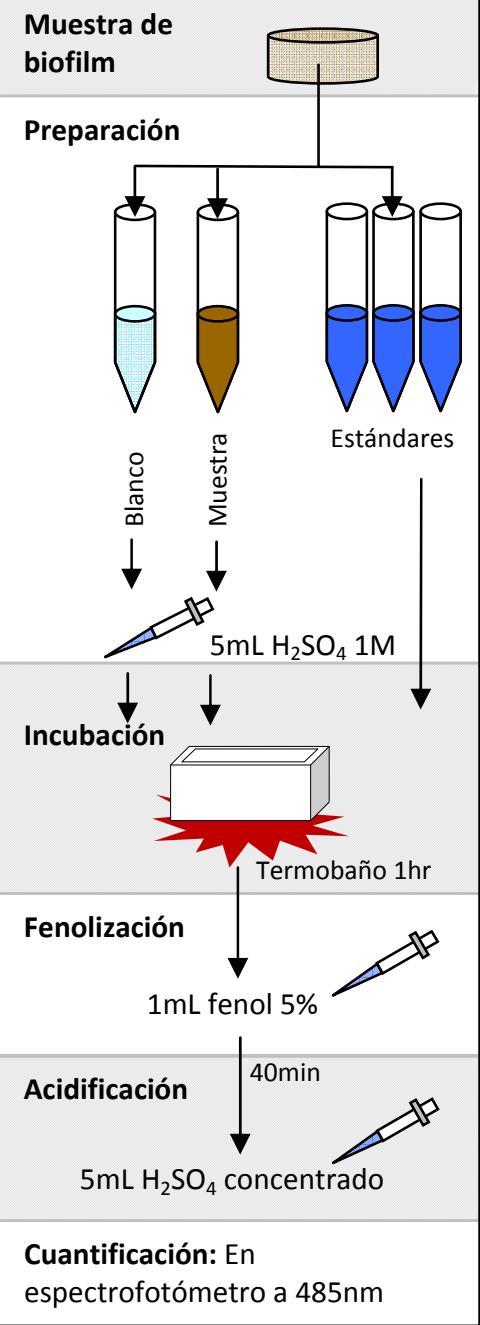
el tubo inclinado).

6. Se dejaron enfriar los tubos y se cuantificaron a $485 \mathrm{~nm}$ en espectrofotómetro, utilizando $\mathrm{H}_{2} \mathrm{SO}_{4} 1 \mathrm{M}$ como blanco.

A las absorbancias medidas en las muestras de biofilm se les restaron las absorbancias medidas en lo blancos. La cuantificación se realizó utilizando los valores obtenidos para la curva de calibración de glucosa como conversión a $\mu \mathrm{g} \cdot \mathrm{mL}^{-1}$. 
La mineralización de nitrógeno y fósforo orgánico y la asimilación de material orgánico disuelta en biofilms es facilitada por las enzimas extracelulares producidas por bacterias, hongos y, en algunos casos, algas (Sinsabaugh et al. 1991b). Estas enzimas están adheridas a la superficie de la célula microbiana (o en el espacio periplásmico en las bacterias Gramnegativas) y reaccionan a sustratos poliméricos afuera de la célula (Chróst 1992). fluorómetro. realizando los siguientes pasos:

Una distinción debe realizarse entre los términos "actividad enzimática extracelular", que refiere no sólo a esas enzimas que están adheridas a la célula, sino también a las que están disueltas y libres en el ambiente (formando parte de la matriz), y el término "ectoenzima" que refiere específicamente a aquellas adheridas a las células.

En la experiencia in situ realizada en esta tesis se midió la actividad de las enzimas extracelulares $\beta$-glucosidasa (EC 3.2.1.21) y fosfatasa (EC 3.1.3.1-2) utilizando sustratos metilumbeliferil (MUF), donde las enzimas pueden reaccionar y emitir fluorescencia que puede ser medida con un

Para el análisis de las enzimas se siguieron los protocolos propuestos por Hoppe (1983) y Chróst (1990),

1. Las muestras fueron colectadas por quintuplicado en viales estériles, y se conservaron en frío y oscuridad hasta ser

Actividades enzimáticas extracelulares

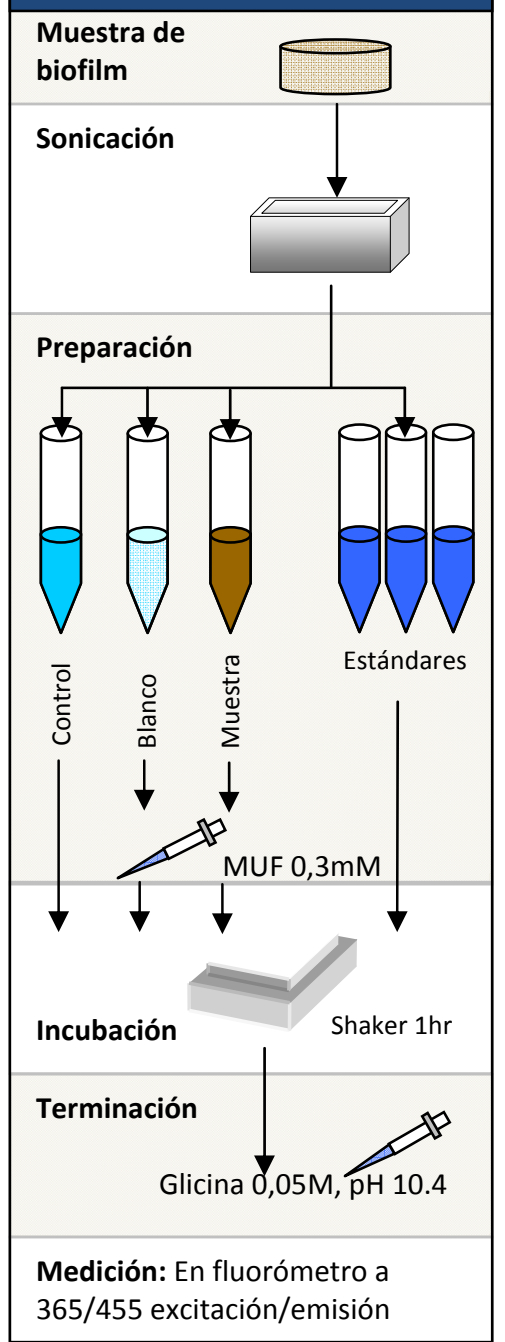
procesadas en el mismo día de la recolección.

2. Las muestras se sumergieron en un baño ultrasónico en dos ciclos de dos minutos cada uno.

3. Se prepararon en simultáneo:

a. Muestras del biofilm: corresponde al sobrenadante de la muestra sonicada 
b. Blancos: con agua Milli-Q y por duplicado

c. Control: una muestra de agua del arroyo

d. Estándares: para cuantificar la fluorescencia se prepararon estándares replicados de concentraciones conocidas de MUF.

4. Se añadieron $2 \mathrm{ml}$ de sustrato artificial MUF a las muestras de biofilm y a los blancos, a concentración de saturación de 0,3mM. La concentración fue determinada previamente realizando un análisis de fluorescencia del sustrato a concentraciones crecientes y ajustando los resultados a una curva hiperbólica de Michaelis-Menten. De esa manera, calculando la constante de saturación $(\mathrm{Km})$ y la velocidad máxima (Vmax) se puede saber la concentración de saturación.

5. Se incubaron las muestras en oscuridad a $20^{\circ} \mathrm{C}$ en un shaker por una hora.

6. Se agregó un tampón de glicina a todas las muestras en una concentración de $0,05 \mathrm{M}$ y $\mathrm{pH}=10,4$, con una proporción $1 / 2 \mathrm{v} / \mathrm{v}$ glicina/muestra.

7. Las muestras fueron centrifugadas por diez minutos para disminuir su turbidez

8. Se midió la fluorescencia a 365/455 excitación/emisión en un fluorómetro con una cubeta de cuarzo de $10 \mathrm{~mm}$.

A las absorbancias medidas en las muestras de biofilm se les restaron las absorbancias medidas en los blancos (para descontar la degradación abiótica del sustrato artificial) y la de los controles (para descontar la fluorescencia natural del agua sin sustrato artificial), y se utilizaron los estándares para obtener la concentración de las enzimas. La actividad enzimática se expresó en nmoles de MUF liberado por hora (tiempo de incubación) por centímetro cuadrado de muestra. 
El peso seco libre de cenizas es una medida de la materia orgánica en una muestra. Se mide como la diferencia de peso de una muestra secada a estufa a $60^{\circ} \mathrm{C}$ y el peso de la misma muestra muflada a $550^{\circ} \mathrm{C}$ por tres horas (APHA 1998). Esta metodología no distingue el origen de la materia orgánica (algal, bacteriano, fúngico, etc.) ni el estado fisiológico de la misma (detritos, material senescente, etc.).

En la presente tesis se analizaron muestras por triplicado utilizando crisoles de porcelana. Para el secado se utilizó una estufa (O.R.L Industria Argentina), y una mufla (O.R.L Industria Argentina).

\subsubsection{1 Índice Autotrófico (IA), riqueza e Índice de diversidad de Shannon (H)}

El índice autotrófico determina la naturaleza trófica del biofilm, y se calculó como el cociente de peso seco libre de cenizas (en $\mathrm{mg} \cdot \mathrm{m}^{-2}$ ) sobre la concentración de clorofila (en $\mathrm{mg} \cdot \mathrm{m}^{-2}$ ) (APHA 1998). Los valores mayores a 200 indican que en el biofilm predominan los heterótrofos (APHA 1998).

Los materiales orgánicos no viables pueden afectar la interpretación de este índice, sin embargo es una medida aproximada para describir cambios en las comunidades del biofilm entre sitios de muestreo.

La riqueza específica expresa el número de especies en una muestra, y el índice de diversidad de Shannon (Shannon \& Weaver 1949) expresa la riqueza de especies y su equitatividad (como se distribuyen los individuos en las especies presentes), y es calculado como:

$$
H=\sum_{i=1}^{n} p i \ln (p i)
$$


Los estudios de las perturbaciones a escalas espacio-temporales pequeñas proveen valiosa información sobre la fisiología y dinámica de las comunidades. Este tipo de aproximación, Ilamada "scale-up" o "bottom-up", busca por medio de observaciones empíricas a pequeña escala determinar posibles asociaciones a escalas mayores (Root \& Schneider 2002).

Un canal artificial, o río artificial, es un canal diseñado para contener un flujo controlado de agua, que luego es utilizado para estudiar alguna propiedad física, química o biológica de los sistemas naturales (Warren \& Davis 1971, Lamberti \& Steinman 1993). Los ríos artificiales simplifican las condiciones naturales de los ecosistemas fluviales, manteniendo sus características de aguas corrientes e incluyendo una parte de la comunidad biológica, y proporcionan la oportunidad de examinar cuestiones científicas que no pueden ser abordadas directamente en estudios de campo (Guasch \& Serra 2009).

Es importante remarcar que las respuestas pueden ser enmascaradas por la variación local o "ruido" a medida que se amplía la escala de estudio, siendo entonces los estudios a pequeña escala insuficientes para interpretar fenómenos a escalas mayores. Sin embargo, diversos estudios han empleado la metodología a pequeña escala para entender el funcionamiento de los compartimentos aislados de los ecosistemas (algunos ejemplos en Tabla 3.1) sentando una base sólida sobre la dinámica de los mismos antes de pretender explicar fenómenos a escalas mayores.

Entre los diversos usos que se les han dado a estos sistemas, se incluyen el análisis de efectos toxicológicos, el análisis de variaciones en las características hidrológicas y lumínicas, el estudio de la dinámica de los nutrientes y de los productores, o el de la bioenergética de poblaciones de invertebrados (Tabla 3.1).

El objetivo científico debe determinar la dimensión y características del sistema de canales utilizado, y el diseño final debe ser fruto del compromiso entre la replicabilidad y el realismo. En general, se considera que las diferencias en las variaciones físicas y químicas ocurridas en los canales deberían mantenerse siempre por debajo del 20\% (Guasch \& Serra 2009). 


\begin{tabular}{|c|c|c|c|c|c|}
\hline Autores & Año & Diseño & Organismos & Variables analizadas & Tipo de experimento \\
\hline Odum \& Hoskin & 1957 & Tubos de vidrios, cerrados & Biofilms & Fósforo, glucosa, velocidad & Metabolismo \\
\hline Lauff \& Cummins & 1964 & $\begin{array}{l}\text { Fibra de vidrio y madera, } \\
\text { cerrados }\end{array}$ & Plecópteros & Tamaño de partícula del sustrato & Comportamiento \\
\hline Whitford et al. & 1964 & Madera, cerrados & Organismos lóticos & Ninguna & Descripción de aparatos \\
\hline McIntire et al. & 1964 & $\begin{array}{l}\text { Madera, parcialmente } \\
\text { cerrados }\end{array}$ & Biofilms & Luz & $\begin{array}{l}\text { Métodos para medir } \\
\text { productividad primaria }\end{array}$ \\
\hline Kevern \& Ball & 1965 & Plástico, cerrados & Biofilms & $\begin{array}{c}\text { Temperatura, luz, velocidad de la corriente, } \\
\text { EDTA }\end{array}$ & Productividad primaria \\
\hline Davis \& Warren & 1965 & $\begin{array}{l}\text { Madera, parcialmente } \\
\text { cerrados }\end{array}$ & Peces, insectos, biofilms & Espectro estacional & Dinámica trófica \\
\hline Phinney \& McIntire & 1965 & Cerrados & Biofilms & Temperatura & Metabolismo \\
\hline Patrick & 1967 & Plástico, abiertos & Diatomeas & Tasa de intercambio, área del sustrato & Estructura comunitaria \\
\hline Brocksen et al. & 1968 & $\begin{array}{l}\text { Madera, parcialmente } \\
\text { cerrados }\end{array}$ & Peces, insectos, algas & Temperatura & Dinámica trófica \\
\hline Mclntire & 1968 & $\begin{array}{l}\text { Madera, parcialmente } \\
\text { cerrados }\end{array}$ & Biofilms & Luz, velocidad de la corriente, temperatura & $\begin{array}{l}\text { Productividad primaria, } \\
\text { estructura comunitaria }\end{array}$ \\
\hline McDiffett & 1970 & Fibra de vidrio y madera & Plecóptero & Ninguna & Bioenergética \\
\hline Rose \& McIntire & 1970 & $\begin{array}{l}\text { Madera, parcialmente } \\
\text { cerrados }\end{array}$ & Biofilms & Dieldrina & Acumulación de pesticida \\
\hline Seim & 1970 & $\begin{array}{l}\text { Madera, parcialmente } \\
\text { cerrados }\end{array}$ & Salmón & Efluente de planta de pasta de celulosa & Productividad secundaria \\
\hline Kehde \& Wilhm & 1972 & Madera, cerrados & Biofilms, gasterópodos & Ninguna & Productividad primaria, pastoreo \\
\hline Horner et al. & 1990 & Metacrilato, cerrados & Biofilms & $\begin{array}{l}\text { Velocidad de la corriente, sedimentos en } \\
\text { suspensión, fósforo }\end{array}$ & $\begin{array}{c}\text { Interacción entre factores } \\
\text { abióticos }\end{array}$ \\
\hline Leu et al. & 1996 & Abierto & Ninguno & Velocidad de la corriente & Transporte de nitrógeno \\
\hline Navarro et al. & 2000 & Metacrilato, abiertos & Biofilms & $\begin{array}{c}\text { Cobre, atrazina, velocidad de la corriente, } \\
\text { herbivoría }\end{array}$ & Estructura comunitaria \\
\hline Muñoz et al. & 2001 & Metacrilato, abiertos & Biofilms, gasterópodos & Atrazina, herbivoría & Alteraciones en la herbivoría \\
\hline Sabater et al. & 2002 & Metacrilato, abiertos & Biofilms & Cobre, velocidad de la corriente & $\begin{array}{l}\text { Toxicidad y estructura } \\
\text { comunitaria }\end{array}$ \\
\hline Gold et al. & 2003 & PVC, cerrados & Diatomeas & Cadmio & Estructura comunitaria \\
\hline Guasch et al. & 2004 & Metacrilato, abiertos & Biofilms & Cobre, fosfato & Sensibilidad a la toxicidad \\
\hline Lehtola et al. & 2006 & Cobre y metacrilato, cerrados & Biofilms & Velocidad de la corriente & $\begin{array}{l}\text { Efectos de la velocidad en dos } \\
\text { tipos de canales }\end{array}$ \\
\hline Ricart et al. & 2009 & Metacrilato, abiertos & Biofilms & Herbicida & Toxicidad de la fenilurea \\
\hline
\end{tabular}

Tabla 3.1. Algunos antecedentes de la utilización de ríos artificiales. 
Esta aproximación, sin embargo, tiene limitaciones. El control de las condiciones ambientales exige simplificar el sistema, hecho que dificulta la extrapolación de los resultados obtenidos a los ecosistemas naturales (Tabla 3.2). Estas limitaciones pueden disminuirse o superarse combinando estudios entre el laboratorio y el campo.

\begin{tabular}{|c|c|}
\hline Ventajas & Limitaciones \\
\hline Control de variables ambientales & Simplificación del ecosistema natural \\
\hline Replicación y significación estadística & $\begin{array}{l}\text { Dificultad para mantener poblaciones o } \\
\text { comunidades parecidas a las naturales }\end{array}$ \\
\hline $\begin{array}{l}\text { Permiten la modificación de las condiciones } \\
\text { ambientales (nutrientes, luz, velocidad del agua, } \\
\text { etc.) y de las interacciones biológicas } \\
\text { (depredación, herbivoría, etc) }\end{array}$ & $\begin{array}{l}\text { Dificultad en reproducir los procesos que } \\
\text { ocurren a escala mayor }\end{array}$ \\
\hline \multirow[t]{2}{*}{$\begin{array}{l}\text { Permiten trabajar con comunidades y analizar } \\
\text { efectos directos e indirectos de los tratamientos }\end{array}$} & $\begin{array}{l}\text { Difícil extrapolación de los resultados obtenidos } \\
\text { a nivel de ecosistema natural }\end{array}$ \\
\hline & $\begin{array}{l}\text { Coste de las instalaciones y de su mantenimiento } \\
\text { Elevado consumo de agua en sistemas abiertos }\end{array}$ \\
\hline
\end{tabular}

Tabla 3.2. Ventajas y limitaciones de la utilización de los arroyos artificiales.

Modificado de Guasch \& Serra (2009) 
Los canales artificiales han sido desarrollados en una gran variedad de formas y tamaños, siendo utilizados para muchos fines. Pueden estar localizados in situ, normalmente a las orillas del arroyo del cual se deriva agua, o bien ex situ, tanto de exterior como de interior. En éstos últimos se pueden ejercer un mayor control sobre las condiciones ambientales (Figura 3.2).

\begin{tabular}{|c|c|c|c|}
\multicolumn{4}{|c|}{ Escala } \\
\hline Ecosistema & \multicolumn{3}{|c|}{ Canal artificial } \\
& In situ & Exterior & Interior \\
\hline $10^{2}-10^{3} \mathrm{mts}$ & $10^{1}-10^{2} \mathrm{mts}$ & $10^{1}-10^{2} \mathrm{mts}$ & $10^{1}-10^{0} \mathrm{mts}$ \\
\hline
\end{tabular}

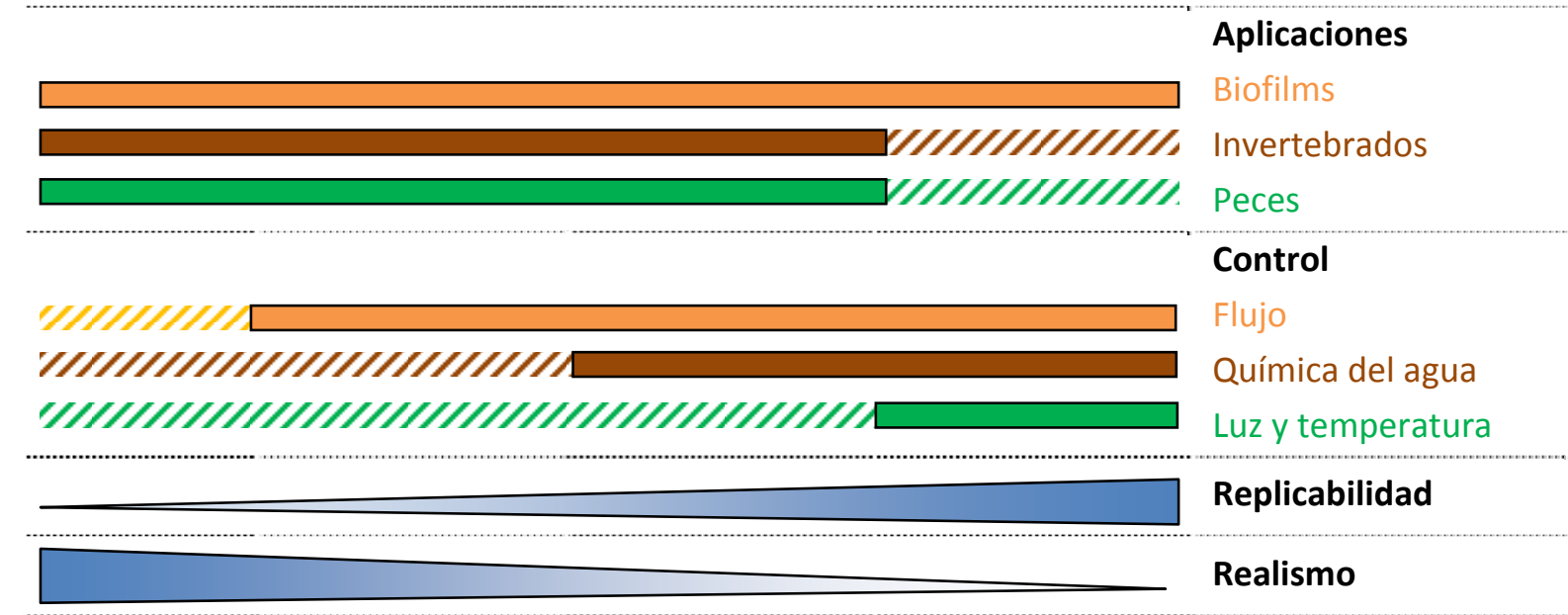

Figura 3.2. Comparación entre los estudios en distintos tipos de canales artificiales y con los estudios ecosistémicos. Modificado de Guasch \& Serra (2009)

Cada canal es la unidad experimental, por lo que las muestras tomadas del mismo canal son consideradas réplicas analíticas, o pseudoreplicas (Guasch \& Serra 2009).

Para estudiar, por ejemplo, los efectos de un único factor, se debe contar con un mínimo de tres canales control y tres canales tratados con ese único factor. Se suele tomar varias réplicas analíticas de un mismo canal con el fin de obtener una muestra más representativa y disminuir la heterogeneidad de los datos para cada réplica, aunque para los análisis estadísticos se debe usar el promedio obtenido de esas réplicas analíticas.

En los ensayos de laboratorio de la presente tesis se utilizaron nueve canales de $1 \mathrm{~m} \mathrm{x}$ $0,15 \mathrm{~m} \times 0,10 \mathrm{~m}$, donde el agua ingresa a través de una rampa inclinada para disminuir su velocidad, y egresa del canal a través de una ranura horizontal (Figuras 3.3 y 3.4). La 
inclinación de la rampa y la forma de la ranura terminal aseguran un flujo laminar y constante a través de todo el canal. Una vez que el agua egresa del canal es colectada en un recipiente plástico desde donde es recirculada hacia la entrada del canal por bombas.

La luz fue provista por lámparas de espectro completo $\left(\mathrm{GE}^{\circledR} \mathrm{E}\right.$-biax Helical, $6500^{\circ} \mathrm{K}$, IRC $82 \%$ ), y el fotoperiodo fue de $10 \mathrm{hs}$ sin luz/14hs con luz, para lograr una radiación fotosintéticamente activa (PAR) de 110-115 $\mu$ Einsteins. Por más que estos valores de PAR son inferiores a los medidos en campo a cielo abierto (PAR en aire $>1000 \mu$ Einsteins), se encuentran dentro de los utilizados en estudios experimentales similares (Horner et al. 1990, Navarro Rodríguez 1998, Gold et al. 2003, Guasch \& Serra 2009, entre otros).

\subsubsection{El sustrato y su colonización}

El sustrato en la base de los canales puede ser básicamente de dos tipos: natural (rocas, gravas, sedimento, materia orgánica, etc.) o artificial (cristal, cerámica, plástico, acrílico). El sustrato artificial proporciona una mayor homogeneidad y simplicidad que el natural, y es recomendable en estudios realizados a escala microbiana. Esto permite que los sustratos artificiales sean de pequeña dimensión (pocos centímetros) para poder tomar un gran número de muestras comparables. Los sustratos naturales incrementan el grado de complejidad del fondo del canal, la variabilidad del flujo y la variedad de procesos que se desarrollan, y así acercarse más a las características de los ríos reales (Guasch \& Serra 2009).

La colonización de los sustratos por los organismos se puede lograr de dos formas, que dependerá del tipo de estudio:

a) Incubar los sustratos del canal en un río durante un período suficiente para que sean colonizados de forma natural, y transferirlos luego a los canales.

b) Inocular directamente los canales. El inoculo se extrae de un río de referencia con características físicas y químicas parecidas a las del sistema de canales utilizados.

La duración de los experimentos puede ser de hasta varios meses, dependiendo del tiempo de respuesta de los organismos estudiados (horas en bacterias, días en algas, semanas en invertebrados y meses para peces), y de la escala de complejidad biológica escogida. 
En los ensayos de laboratorio de la presente tesis se dispusieron como sustrato para los biofilms policubetas de acrílico (Falcon ${ }^{\circledR}$ ) en las que se depositó el sedimento proveniente del arroyo a estudiar, previamente autoclavados para esterilizarlos, generando un sustrato similar al de los arroyos (Figura 3.5). La colonización de los sustratos fue lograda por inoculación utilizando $25 \mathrm{~mL}$ de sedimento procedente de los arroyos al comienzo de la etapa de colonización, la cual duró unas seis semanas. Durante la etapa de colonización se extrajeron muestras regularmente para inspeccionar el desarrollo del mismo con un microscopio óptico (Olympus BX-50).

El agua de los canales provino de los mismos arroyos estudiados previamente filtrada, y un porcentaje del volumen utilizado en los canales fue reemplazado semanalmente para evitar la acumulación de metabolitos secundarios y compensar la posible evapotranspiración. 

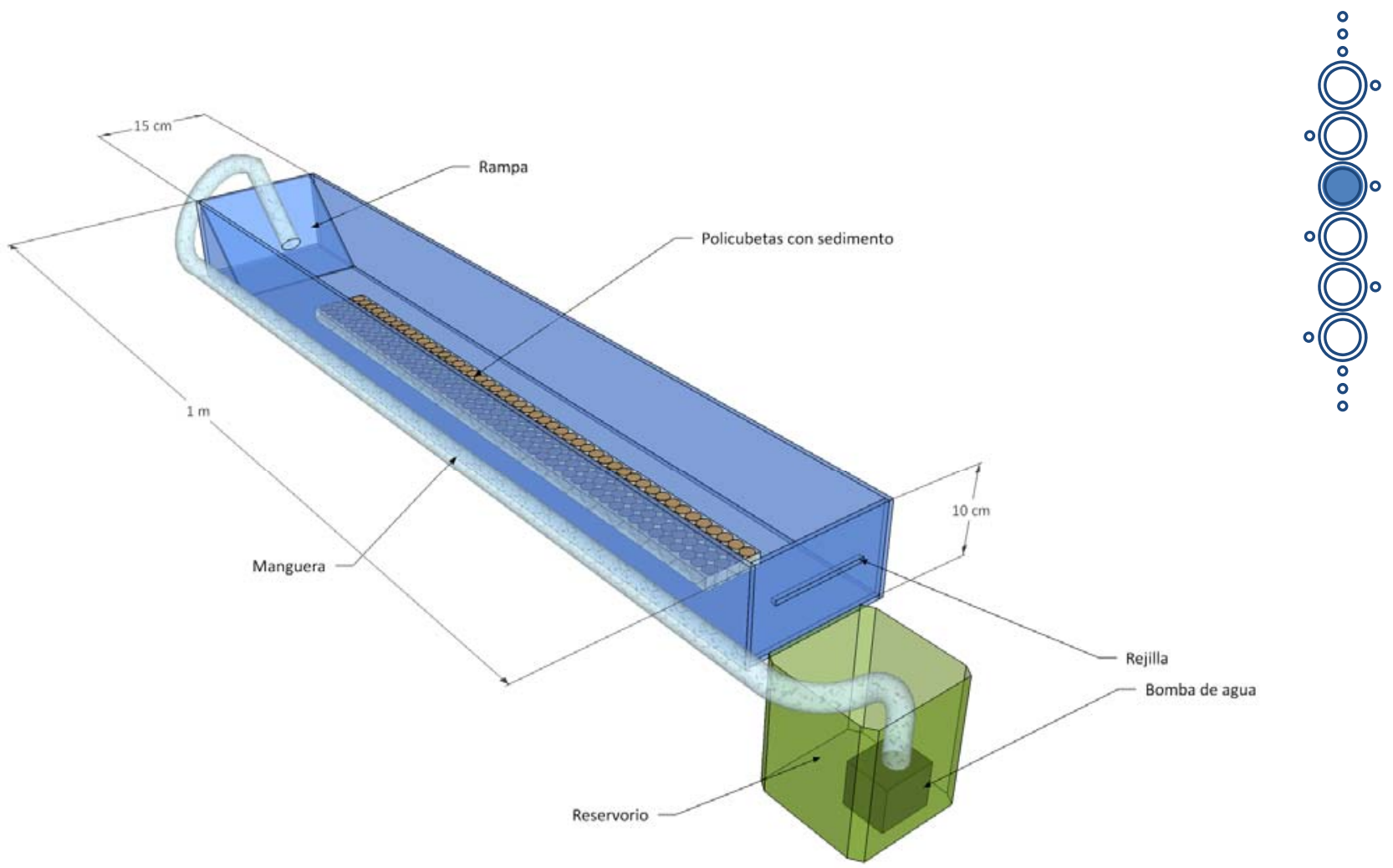

Figura 3.3. Diseño de uno de los canales artificiales utilizados para las experiencias de laboratorio.

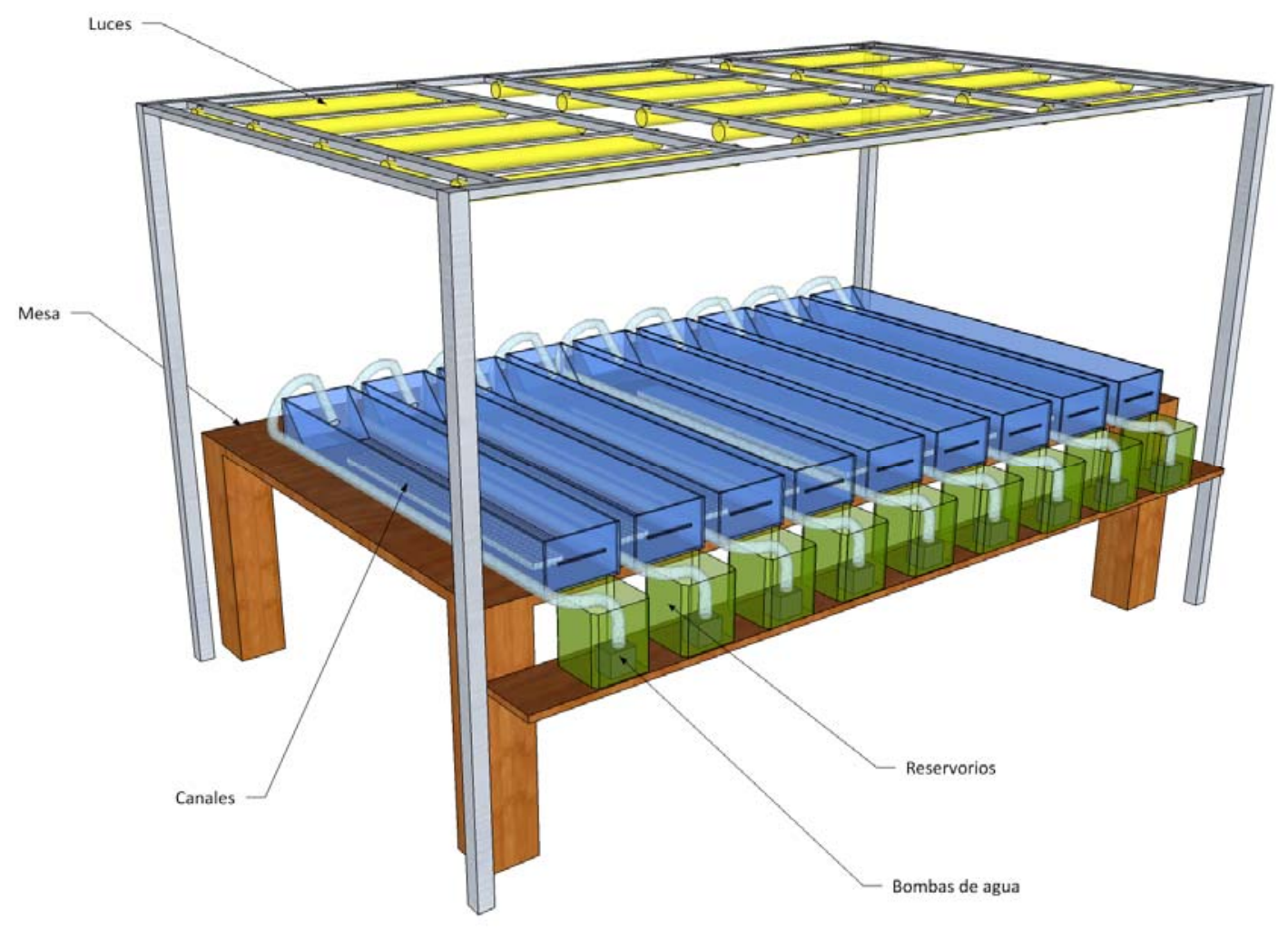

Figura 3.4. Diseño del sistema de canales artificiales utilizados para las experiencias de laboratorio. 

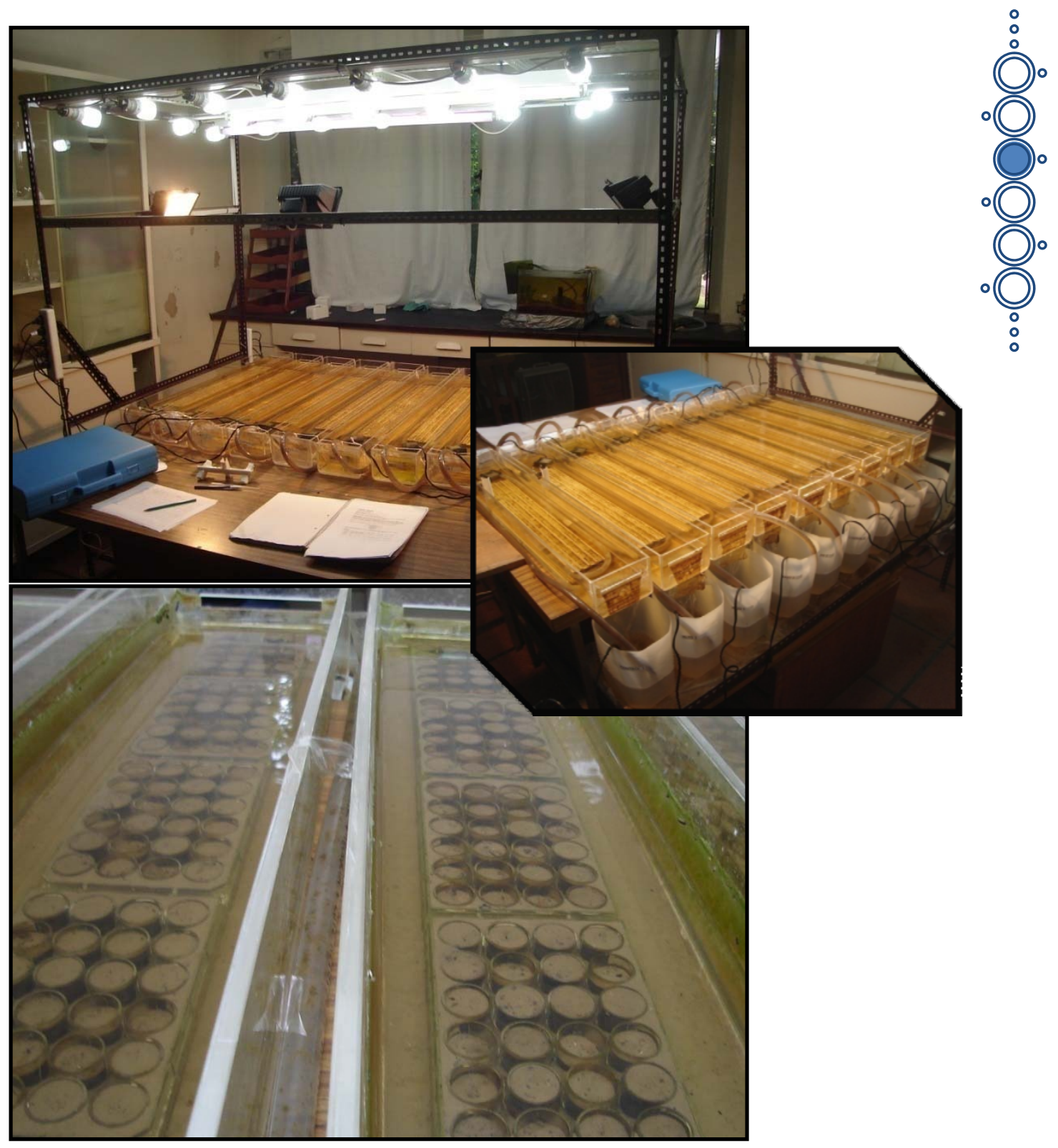

Figura 3.5. Canales artificiales utilizados para las experiencias de laboratorio. Imagen superior: Sistema completo de canales con iluminación. Imagen central: Canales con sus reservorios de agua. Imagen inferior: Policubetas de acrílico conteniendo el sedimento para el desarrollo del biofilm. 
La hidrodinámica es un aspecto importante a la hora de diseñar los canales, ya que se busca mantener que el flujo del agua sea similar al natural.

En el caso de los estudios de biofilms, se pretende que el flujo sea laminar para optimizar el intercambio de sustancias entre el agua y los microorganismos. Entre los parámetros hidrodinámicos que deben ser considerados para que se asemejen al arroyo que se desea simular, Nowell \& Jumars (1987) sugieren el número de Froude, el número de Reynolds, la intensidad de la turbulencia, el grosor de la capa de intercambio (boundary layer) y la rugosidad del lecho. Teniendo en cuenta estas consideraciones, estos parámetros fueron calculados como se detallan a continuación.

\section{Número de Froude (Fr)}

Éste número adimensional expresa la relación entre las fuerzas gravitacionales e inerciales, para determinar la resistencia de un objeto parcialmente sumergido moviéndose a una velocidad específica, y se calcula como:

$$
F \boldsymbol{r}=\frac{U^{2}}{g D}
$$$$
\mathbf{U}=\text { velocidad de la corriente }\left(\mathrm{m} \mathrm{s}^{-1}\right)
$$$$
\mathbf{g}=\text { fuerza gavitatoria }\left(9,8 \mathrm{~m} \mathrm{~s}^{-2}\right)
$$$$
\mathbf{D}=\text { profundidad del agua }(\mathrm{m})
$$

Permite diferenciar entre dos regímenes de flujo: el flujo subcrítico, o lento, con números de Froude menores a la unidad, y donde la información y los efectos del flujo aguas abajo pueden ser transmitidos aguas arriba; y el flujo supercrítico para números de Froude mayores a uno, donde los efectos del flujo sólo se transmiten aguas abajo. 
Expresa la relación entre las fuerzas inerciales y las viscosas, y se calcula como:

$$
\operatorname{Re}=\frac{U L}{v}
$$

$\mathbf{U}=$ velocidad de la corriente $\left(\mathrm{m} \mathrm{s}^{-1}\right)$

$\mathbf{L}=$ distancia que recorre el agua $(\mathrm{m})$

$\mathbf{v}=$ viscosidad cinética del agua $\left(\mathrm{m}^{2} \mathrm{~s}^{-1}\right)$

Ya que la viscosidad cinética del agua puede cambiar muy poco, y que la mayoría de los organismos lóticos tienen preferencias de velocidad de la corriente, se busca generalmente que los arroyos artificiales tengan la mayor longitud posible. El número de Reynolds está involucrado en la aparición de turbulencia y en la determinación del grosor de la capa de intercambio.

El flujo se considera turbulento cuando $\boldsymbol{R e}>4000$, laminar cuando $\boldsymbol{R} \boldsymbol{e} 2300$ y de transición cuando se encuentra entre esos dos límites.

En comparación con el número de Froude, que se suele calcular cuando las fuerzas gravitacionales son predominantes en el flujo, el número de Reynolds se utiliza cuando predominan las fuerzas de viscosidad.

\section{Intensidad de la turbulencia (Tu)}

Ya que los componentes de la velocidad varían en tres dimensiones espaciales, la caracterización completa de la turbulencia es imposible utilizando velocímetros estándares, ya que miden la velocidad en una sola dimensión. La intensidad de la turbulencia expresa las fluctuaciones en la velocidad con respecto a la velocidad media, por lo que, a iguales valores de variación, la intensidad de la turbulencia es menor a mayores números de Reynolds. En canales con un flujo completamente desarrollado, se puede aproximar utilizando el número de Reynolds (Re) con la siguiente fórmula:

$$
\text { Intensidad de Turbulencia }(\%)=\left(0,16 * R e^{-\frac{1}{8}}\right) * 100
$$


Como las capas de intercambio se desarrollan en las paredes de los canales, además de las relacionadas con el fondo, los arroyos artificiales deben ser suficientemente anchos como para minimizar el efecto de las paredes. Para las experimentaciones en laboratorio en la presente tesis los canales de de acrílico tuvieron unas medidas de $1 \mathrm{~m} \times 0,15 \mathrm{~m} \times 0,10 \mathrm{~m}$.

\section{Rugosidad del lecho (Ru)}

Se utiliza para obtener una medida del lecho del arroyo y su interacción con el flujo, y se calcula como:

$$
\boldsymbol{R u}=\frac{\boldsymbol{u}^{\prime} \boldsymbol{d}}{\boldsymbol{v}}
$$

$$
\begin{aligned}
& \mathbf{u}^{\prime}=\text { velocidad de cizalla }\left(\mathrm{m} \mathrm{s}^{-1}\right) \\
& \mathbf{d}=\text { altura o rugosidad de los granos } \\
& \mathbf{v}=\text { viscosidad cinética del agua }\left(\mathrm{m}^{2} \mathrm{~s}^{-1}\right)
\end{aligned}
$$

Cuando $\boldsymbol{R} \boldsymbol{u}$ es menor a tres, las partículas del sustrato se encuentran dentro de la subcapa viscosa de la capa de intercambio, y el flujo se considera hidráulicamente suave. Cuando $\boldsymbol{R u}$ es mayor a 70 , el flujo es hidráulicamente rugoso y no hay una subcapa viscosa continua. Esta condición es la normal en los arroyos y ríos naturales. 
Una de las herramientas más poderosas y versátiles en el diseño de experimentos es la serie de procedimientos conocidos como el análisis de la varianza (ANOVA), que fueron empleados en esta tesis para contrastar los datos obtenidos con datos "control". Estos fueron diseñados para solucionar el problema de las comparaciones entre dos o más poblaciones, y son muy utilizados en los experimentos tanto manipulativos como mensurativos.

Para el análisis de datos en las experiencias de laboratorio se emplearon ANOVA de medidas repetidas (RM ANOVA), para tratar de obtener mayor información de los cambios en el biofilm durante la experiencia. Este análisis fue de dos factores (Tratamiento y Fecha), con medidas repetidas en el factor Fecha (Winer, 1971)

Para que un análisis ANOVA este correctamente realizado debe cumplir, en mayor o menor medida, con tres supuestos básicos, resumidos a continuación en orden de importancia (Barlett 1947, Cochran 1947, Eisenhart 1947, Box 1953, Scheffé 1959, Underwood 1996, 2007):

1. Independencia de los datos: este supuesto es esencial para la realización del ANOVA y depende directamente del diseño experimental.

2. Homogeneidad de varianzas: su falta sólo es seria si una de de las poblaciones tiene una varianza mucho mayor que el resto. Se comprobó en los análisis mediante el test de Cochrane.

3. Normalidad: el ANOVA es muy robusto a la falta de normalidad, incluso cuando las muestras son pequeñas.

Los ANOVA con medidas repetidas requieren que se cumpla, también, el supuesto de esfericidad. Esto asume que las varianzas de las diferencias entre todas las combinaciones de los grupos relacionados son iguales. Para evaluar esto se utilizó el test de esfericidad de Mauchly, y se utilizó la corrección de Greenhouse-Geisser en el caso que no se cumpliese este supuesto (Greenhouse \& Geisser 1959).

Los análisis de varianza detectan las diferencias significativas globales en un experimento, aunque no son capaces de establecer entre cuáles de los grupos que conforman el experimento hay diferencias. Para ello se utilizan las comparaciones múltiples. En esta tesis se utilizó el test a posteriori de Student-Newman-Keuls (o SNK). Este procedimiento es una extensión secuencial de los test de $t$, y es muy utilizado en ecología. 
El análisis SNK tiene una probabilidad excesiva de error tipo I (rechazar la hipótesis nula cuando es en realidad cierta) en algunas circunstancias; es decir, implicaría diferencias significativas entre los grupos de medias cuando en realidad no las hay (Day \& Quinn 1989, Snedecor \& Cochran 1989). Esto empeora cuando las medias de los tratamientos caen en grupos muy separados entre sí. Para solucionar esto, Day \& Quinn (1989) proponen que se ajuste la probabilidad del error tipo I en cada paso de la secuencia del análisis, modificando $\alpha$ de acuerdo con la cantidad de medias que haya en el grupo que se compara. 
Un valor no significativo de probabilidad estadística $(\boldsymbol{p})$ no significa necesariamente que no hay efectos sobre la comunidad (significancia biológica), y es importante estimar el tamaño de dicho efecto (Osenberg et al. 2006).

En la presente tesis se calculó como una medida del tamaño del efecto el valor Etacuadrado ( $\eta 2)$, que indica cuánta variabilidad de la variable dependiente puede ser explicada por la variable independiente. El valor de $\eta^{2}$ se calculó como un cociente de sumas de cuadrados (SS):

$$
\eta^{2}=\frac{\left(S S_{\text {efecto }}\right)}{\left(S S_{\text {total }}\right)}
$$

Este valor es una medida análoga al $r^{2}$ en los análisis de correlación y regresión, y puede ser interpretada de la misma manera. Por ende, un $\eta^{2}=0.246$ significa que el $24,6 \%$ de la variabilidad en la variable dependiente puede ser explicada por la variable independiente. En general se utiliza la regla de Cohen (1992) para interpretar el valor de $\eta^{2}$ obtenido, y se considera un efecto pequeño cuando $\eta^{2} \leq 0,20$, un efecto moderado cuando $0,20>\eta^{2}<0,80$ y un efecto grande cuando $\eta^{2} \geq 0,80$.

Para analizar el tamaño del efecto en las comunidades biológicas en las experiencias de laboratorio se utilizó una variación de Eta-cuadrado denominada Eta-cuadrado generalizado $\left(\eta_{\mathrm{G}}{ }^{2}\right)$ (Olejnik \& Algina, 2003), ya que permite estimar el tamaño del efecto en los diseños ANOVA de repeticiones múltiples (Bakeman, 2005).

$$
\eta \mathbf{G}^{2}=\frac{\left(S S_{A}\right)}{\left(S S_{A}\right)+\left(S S_{S / A}\right)+\left(S S_{B S / A}\right)}
$$

Adonde $\mathrm{A}$ es el factor inter-sujetos (Tratamiento), B es un factor con medidas repetidas (Tiempo) y los sujetos están anidados dentro de los niveles del factor $\mathrm{A}(\mathrm{s} / \mathrm{A})$.

En las tablas presentadas con resultados de los ANOVA en la presente tesis se proporcionarán valores de significancia $(p)$ y valores de $\eta^{2}$ de los factores principales y su interacción, no así los valores de $\eta^{2}$ de los errores. Es por ello que la suma de los porcentajes de $\eta^{2}$ no suman el $100 \%$. 


\section{CAPÍTULO 4}

EFECTOS DE LA ADICIÓN EXPERIMENTAL DE NUTRIENTES SOBRE LOS BIOFILMS EPIPÉLICOS DE ARROYOS

PAMPEANOS

"Las enzimas son unas cosas inventadas por los biólogos para explicar unos procesos que de otra forma requieren que piensen mucho más."

Jerome Lettvin 
El enriquecimiento por nutrientes es una presión global para todos los tipos de ecosistemas acuáticos (UNEP 2007), ya que deriva en incrementos en los productores primarios y en cambios a la comunidad de ecosistemas marinos y dulceacuícolas (Smith 2003). Las crecientes presiones humanas sobre los recursos acuáticos, derivados de cambios en los usos del suelo y los cambios climáticos, pueden alterar los patrones de escorrentía resultando en mayores descargas de agua en los ríos y arroyos (Hulme \& Sheard 1999). Estos efectos pueden resultar en un incremento en el ingreso de nutrientes a los cursos de agua que producirían efectos en cascada en todo el funcionamiento del ecosistema, con grandes consecuencias ecológicas y hasta económicas (Dodds et al. 2009).

En ríos y arroyos, los primeros organismos que reciben y responden directamente a los nutrientes son los productores primarios (algas, macrófitas) y los heterótrofos microbianos (bacterias, hongos) ya que dependen de los nutrientes inorgánicos disponibles en la columna de agua (Stelzer et al. 2003).

La biomasa algal del biofilm está regulada por los nutrientes inorgánicos, que a su vez determinan una mayor disponibilidad de materia orgánica para ser descompuesta por el componente heterotrófico. Para ello, las enzimas extracelulares producidas principalmente por bacterias y hongos y, en algunos casos, por algas (Romaní et al. 2012, Sinsabaugh et al. 1991), convierten moléculas de alto peso molecular a unas de menor peso molecular, que quedan disponibles para los microorganismos (Chróst 1992).

Los efectos de las adiciones de nutrientes en arroyos templados de bajo orden han mostrado diferencias sustanciales en las biomasas algales y bacterianas del biofilm, con mínimos cambios en los grupos animales (Sabater et al. 2011). El enriquecimiento también produjo que las enzimas asociadas con la adquisición de nutrientes (como la fosfatasa) decrecieran, mientras que aquellas relacionadas con el uso y descomposición de material algal (como la peptidasa y la $\beta$-glucosidasa) incrementaran. Resultados similares fueron obtenidos en un río prístino de tundra en una adición de fósforo a largo plazo (Peterson et al. 1993).

Sin embargo, poco se conoce sobre el metabolismo del biofilm en arroyos pampeanos (Vilches 2005, Sierra \& Gómez 2007, Vilches 2011) y particularmente cuando el ingreso de nutrientes constituye una de las principales forzante del sistema. 
El objetivo del estudio expuesto en el presente capítulo fue estudiar la respuesta del biofilm epipélico en un arroyo pampeano sujeto a la adición moderada de nutrientes.

La hipótesis planteada para la experiencia de adición de nutrientes en campo fue que la estructura y función del biofilm epipélico de arroyos pampeanos es afectado por los nutrientes inorgánicos disponibles en el agua.

Las predicciones planteadas para esta experiencia de adición de nutrientes establecen que el biofilm epipélico responderá con:

1. Un aumento de la biomasa algal y de la biomasa bacteriana.

2. Un aumento en la actividad de aquellas enzimas relacionadas con la degradación de la materia orgánica (como la $\beta$-glucosidasa, que degrada polisacáridos)

3. Una disminución en la actividad de aquellas enzimas involucradas con la adquisición de nutrientes (fosfatasa).

Para comprobar las predicciones se midieron los efectos de la adición de nutrientes a largo plazo (un año) en una comunidad epipélica de un arroyo pampeano. Las respuestas de la biomasa algal y bacteriana, y de las actividades enzimáticas ( $\beta$-glucosidasa, fosfatasa) fueron comparadas con un tramo Control localizado aguas arriba del tramo Impacto (con adición de nutrientes). 
Para realizar la manipulación artificial de las concentraciones de nutrientes se realizó un diseño experimental BACIPS (Before-After/Control-Impact Paired Series) con réplicas en el tiempo (descripto en el Capítulo 2. Objetivos e hipótesis)

Se eligieron dos tramos de 100 metros de un arroyo pampeano mesotrófico: un tramo Impacto localizado 5,3 km aguas debajo de un tramo Control, ambos con características hidrológicas y geomorfológicas similares.

Ambos tramos fueron muestreados en seis oportunidades previamente a la adición experimental de nutrientes (Marzo 2007-Noviembre 2007, período Antes) y en once oportunidades durante la adición continua de nutrientes (Diciembre 2007-Diciembre 2008, período Después) (Figura 4.1). La adición consistió en incrementar las concentraciones de Nitrógeno Inorgánico Disuelto (NID) y Fósforo Reactivo Soluble (PRS) unas tres veces en el tramo Impacto en comparación con el tramo Control.

La adición experimental de nutrientes fue realizada utilizando bolsas confeccionadas con red de media sombra que contuvieron fertilizante de uso comercial Nitrofoska Azul ${ }^{\circledast}$ $(12 \% \mathrm{P}, 12 \% \mathrm{~N}, 17 \% \mathrm{~K}, 5 \% \mathrm{Ca}, 2 \% \mathrm{Mg}, 15 \% \mathrm{~S}, 0,2 \% \mathrm{Fe}, 0,02 \% \mathrm{~B}, 0,01 \% \mathrm{Zn}$, trazas de $\mathrm{Cu}, \mathrm{Mn}$ y $\mathrm{Mo})$ distribuidas en el tramo Impacto (Figura 4.2), que permitían la disolución continua del fertilizante en el agua. La adición fue ajustada cada dos semanas, momento en el cual se llevaban a cabo las mediciones físico-químicas en el agua, periodicidad que fue mantenida durante todo el período de estudio. Dependiendo de la concentración de nutrientes analizada en cada fecha, se evaluaba la necesidad de adicionar nuevo fertilizante a las bolsas para mantener los niveles del tramo Impacto de acuerdo con lo pautado para esta experiencia.

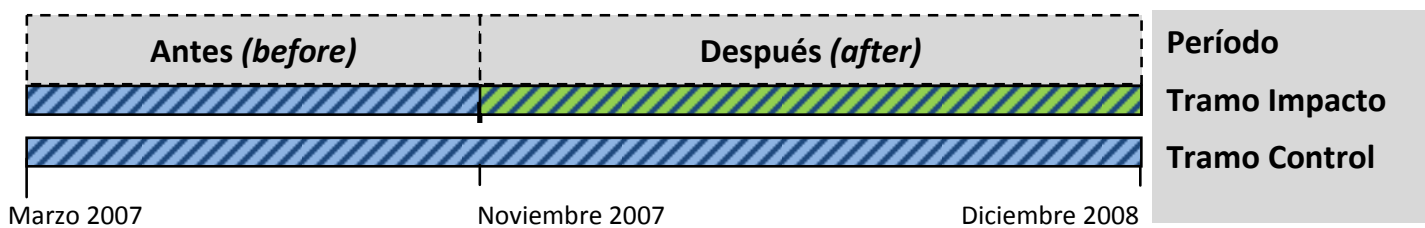

Figura 4.1. Esquema del diseño experimental. La superficie verde indica el agregado de fertilizante al Tramo Impacto. 


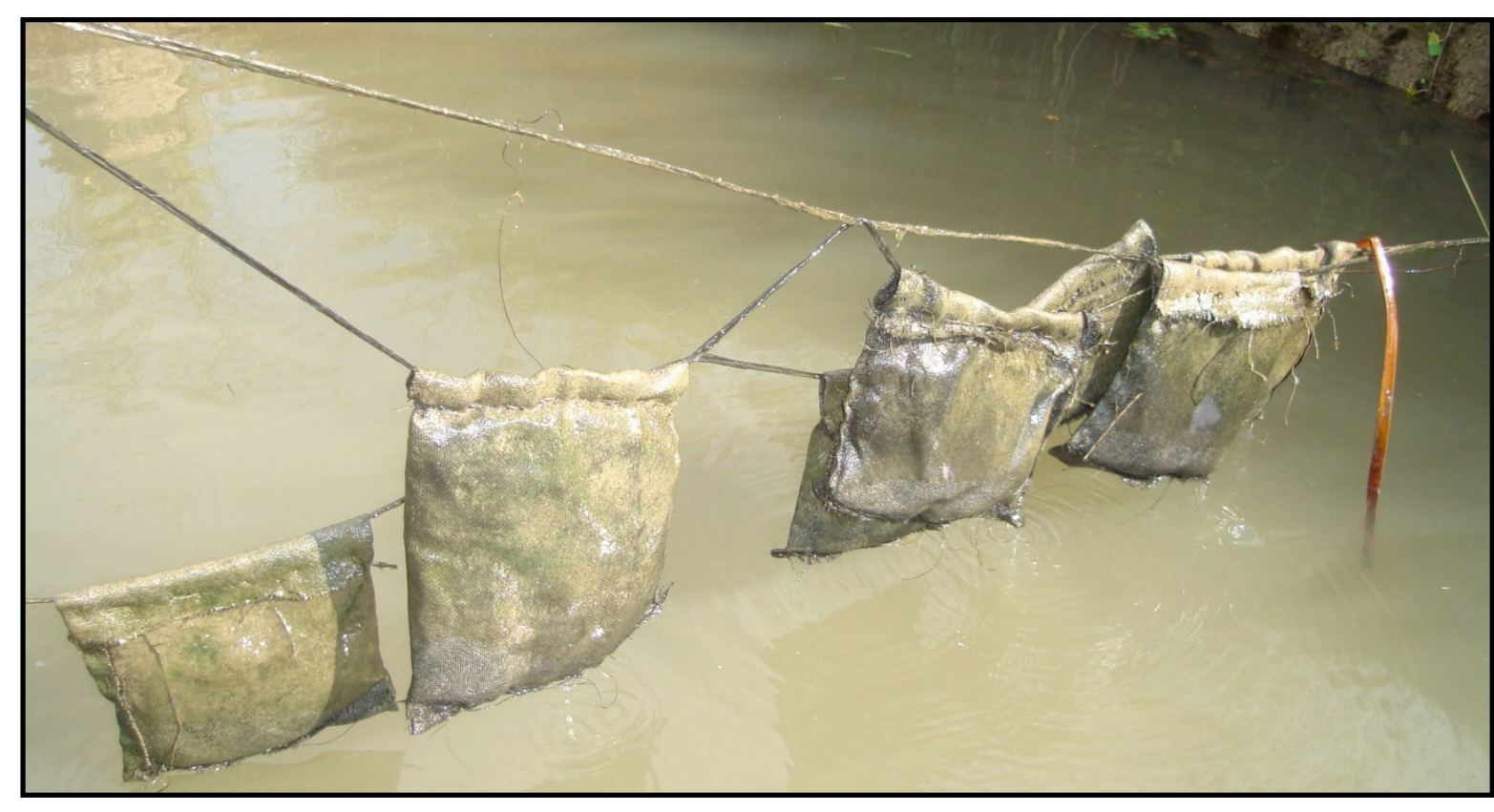

Figura 4.2. Bolsas conteniendo fertilizante en el tramo Impacto del Arroyo La Choza.

\subsubsection{Sitio de estudio}

El arroyo "La Choza" es un arroyo pampeano localizado en la provincia de Buenos Aires cerca de la ciudad de Luján (Figura 4.3). Drena una cuenca de unos $48 \mathrm{~km}^{2}$ sobre depósitos de loess y tosca.

Aunque la vegetación nativa corresponde a la Región Pampeana, con diversas especies de gramíneas, aproximadamente un cuarto de la cuenca está dedicada a la agricultura y un $75 \%$ a la ganadería extensiva.

El clima del área es templado continental, con lluvias promediando los $925 \mathrm{~mm}$ anuales, en primavera y otoño, y unas temperaturas que promedian entre los $10^{\circ} \mathrm{C}$ en julio y los $22^{\circ} \mathrm{C}$ de enero (Cabrera \& Willink 1980).

El lecho del arroyo está compuesto principalmente por carbonato de calcio y depósitos de limos y arcillas (Feijoó \& Lombardo 2007). Contienen naturalmente altos niveles de nutrientes, y escasa vegetación ripariana, lo que favorece que la radiación solar no sea interceptada por obstáculos para alcanzar la superficie del agua (Feijoó \& Lombardo 2007). Como en otros arroyos pampeanos, el desarrollo de macrófitas y del plancton es favorecido especialmente en primavera y verano (Giorgi 1998, Bauer 2009). La turbidez en el agua suele 
ser alta después de las tormentas por la erosión de los horizontes del suelo, ricos en sustancias orgánicas.

Los tramos Control e Impacto fueron localizados en una sección de tercer orden de este curso de agua (Figura 4.3, 4.4).

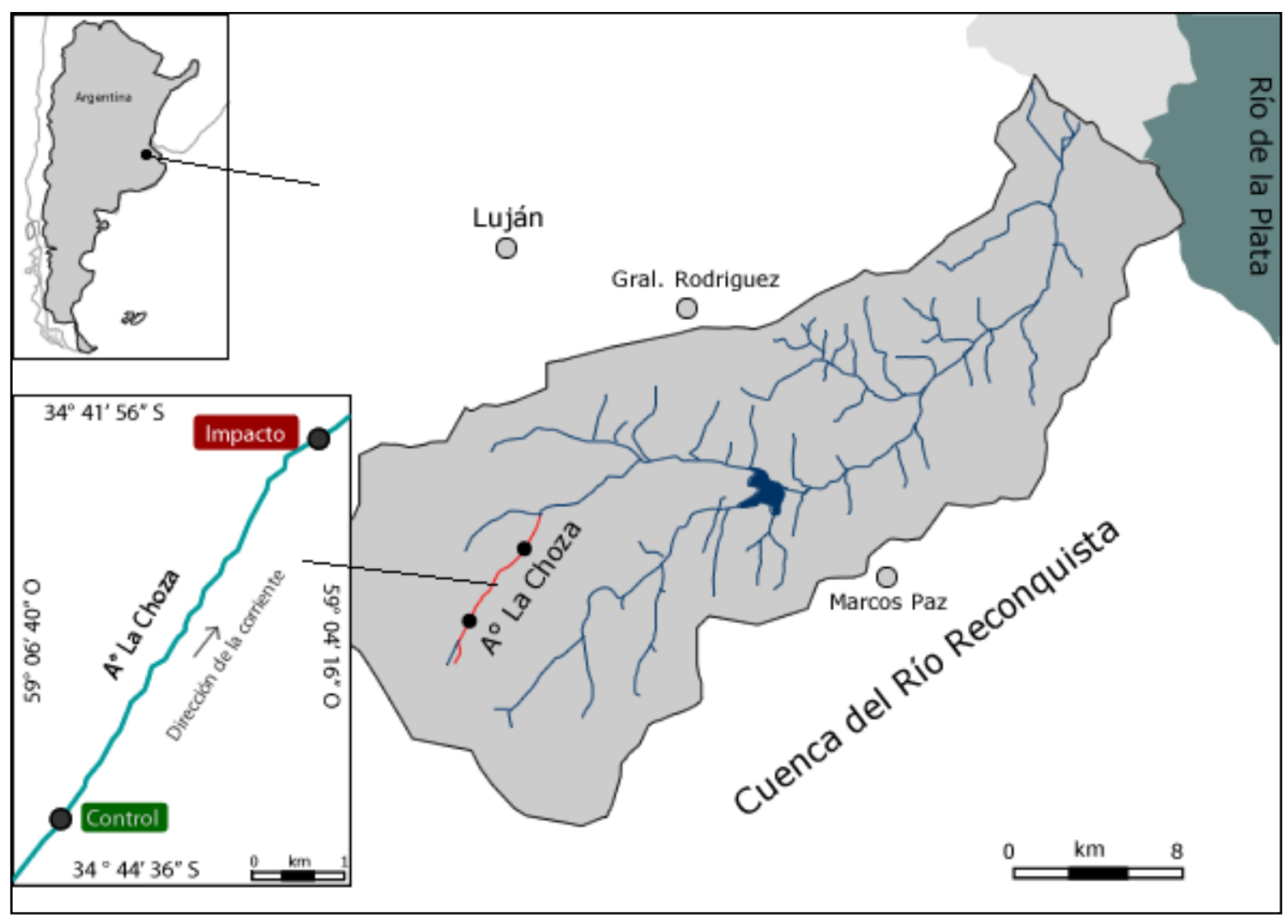

Figura 4.3. Localización de la cuenca del Río Reconquista y de los tramos Control e Impacto en el Arroyo "La Choza", cerca de la localidad de Luján, Argentina (Modificado de Vilches 2011). 

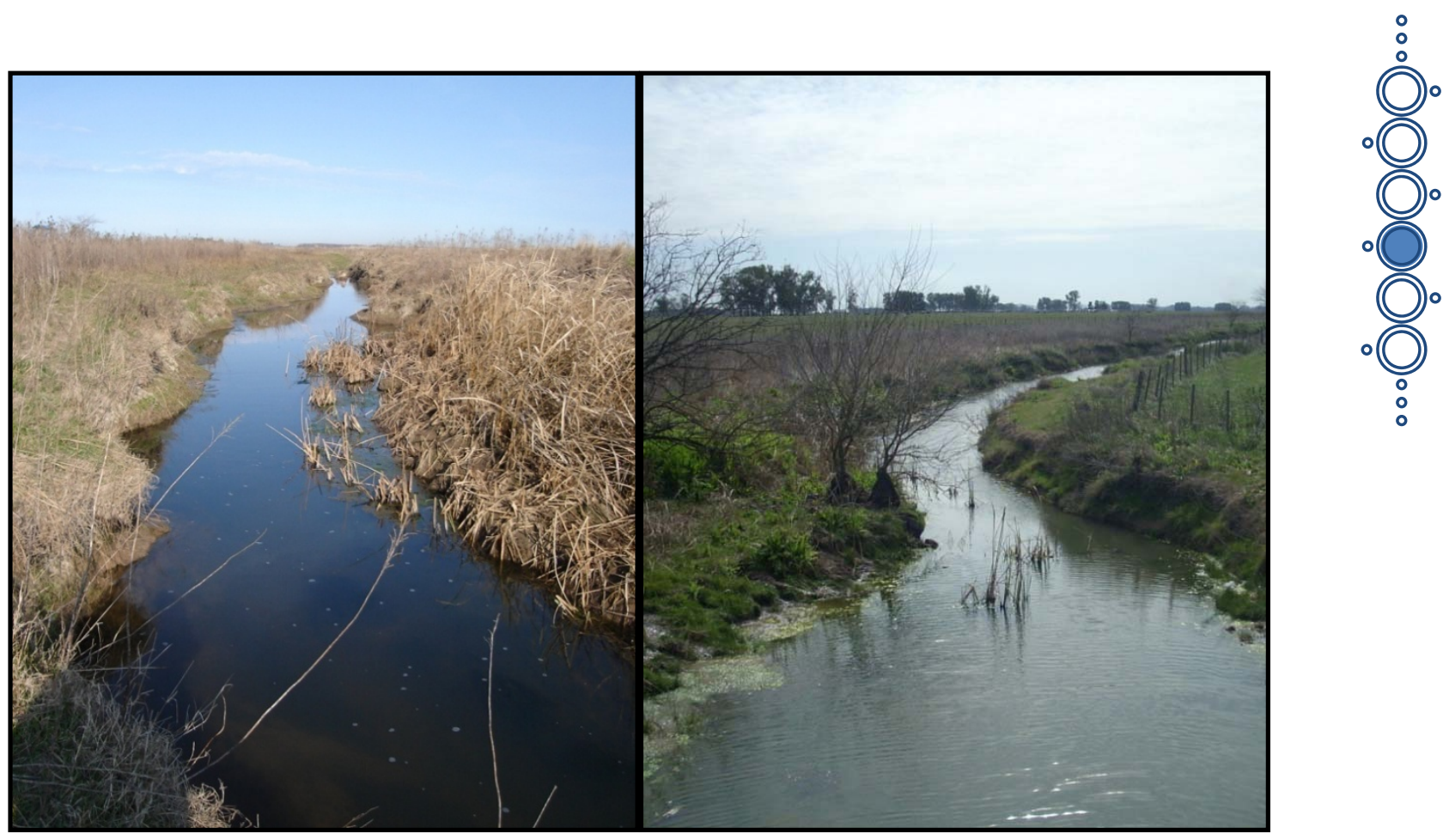

Figura 4.4. Tramos estudiados en el Arroyo "La Choza” en la experiencia de adición de nutrientes. Izquierda: Tramo Control; Derecha: Tramo Impacto

\subsubsection{Variables medidas}

Las variables medidas en el agua (parámetros físico-químicos excepto ganulometría) y en las muestras de biofilm (parámetros biológicos y granulometría) son resumidas en la Tabla 4.1. También se realizaron análisis de la granulometría de los sedimentos en ambos tramos para caracterizarlos. Para más detalles sobre cada metodología, ver Capítulo 3 - Metodologías. 


\begin{tabular}{|c|c|c|c|c|c|}
\hline & Variable & Técnica & Réplicas & $\mathbf{n}$ & Referencia \\
\hline \multirow{4}{*}{ 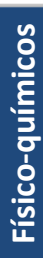 } & $\begin{array}{l}\text { pH, Oxígeno disuelto, } \\
\text { Temperatura, } \\
\text { Conductividad, Turbidez }\end{array}$ & $\begin{array}{c}\text { Sensor multiparamétrico } \\
\text { Horiba }\end{array}$ & 3 & 60 & \multirow{4}{*}{$\begin{array}{l}\text { SM (APHA } \\
1998)\end{array}$} \\
\hline & PAR & Sensor PAR LI-COR & 1 & 20 & \\
\hline & $\mathrm{NO}_{3}, \mathrm{NO}_{2}, \mathrm{NH}_{4}, \mathrm{PRS}$ & SM & 3 & 60 & \\
\hline & Granulometría & & 3 & 6 & \\
\hline \multirow{3}{*}{$\frac{\tilde{\delta}}{\frac{u}{00}}$} & Clorofila "a" & Espectrofotometría & 3 & 102 & $\begin{array}{c}\text { Strickland \& } \\
\text { Parsons } \\
\text { (1968) }\end{array}$ \\
\hline & Biomasa bacteriana & Epifluorescencia & 3 & 102 & $\begin{array}{l}\text { Porter \& Feig } \\
\text { (1980) }\end{array}$ \\
\hline & $\begin{array}{l}\text { Actividad enzimática } \\
\text { extracelular } \\
\text { ( } \beta \text {-glucosidasa, fosfatasa) }\end{array}$ & Espectrofluorometría & 5 & 90 & $\begin{array}{l}\text { Chróst } \\
\text { (1990) }\end{array}$ \\
\hline
\end{tabular}

Tabla 4.1. Variables medidas en el ensayo de campo en los sitios Control e Impacto, las réplicas analizadas en cada sitio en cada muestreo, el número total de datos de ambos sitios utilizados para los análisis estadísticos ( $\mathrm{n}$ ) y breve referencia de la metodología utilizada. Los parámetros biológicos fueron medidos en el biofilm al igual que la granulometría, mientras que el resto de los parámetros físico-químicos fueron medidos en el agua.

\subsubsection{Análisis estadísticos}

La homogeneidad de varianzas fue previamente comprobada por medio del test de Cochrane, y sólo invalidó el test ANOVA si la varianza de alguna muestra fue mucho mayor al resto de las varianzas. Para analizar estadísticamente los resultados obtenidos, se realizaron análisis de varianza (ANOVA) entre los tramos Control e Impacto. Los datos fueron previamente transformados a $\log _{10}+1$ (menos el $\mathrm{pH}$ ). Los ANOVA se realizaron utilizando tres factores:

1. Factor BA: Factor fijo, con dos niveles (Antes y Después)

2. Factor $\mathrm{Cl}$ : Factor fijo, con dos niveles (Control e Impacto)

3. Factor Tiempo(BA): Factor al azar, anidado dentro del factor BA, indica a qué fecha de muestreo pertenecen los valores obtenidos.

Como una medida del tamaño del efecto biológico se calculó Eta-cuadrado $\left(\eta^{2}\right)$. Por otro lado, para tratar de estudiar la relación entre las distintas variables, se realizaron análisis de correlación de Pearson entre los promedios obtenidos para cada muestreo. 
Los resultados de la granulometría mostraron que alrededor del 90\% de las partículas del sedimento que compone las muestras de biofilm tiene un diámetro menor o igual a $62 \mu \mathrm{m}$ (Figura 4.5), no difiriendo lo observado entre el Control y el Impacto.

Las variaciones en parámetros físico-químicos se muestran en la Figura 4.6. Los resultados del BACIPS no expresan diferencias significativas debidas a la fertilización en conductividad, temperatura, oxígeno disuelto o $\mathrm{pH}$ (Tabla 4.2, columna $\mathrm{Cl}{ }^{*} \mathrm{BA}$ ), aunque si evidencian la variación de dichas variables a lo largo del período de estudio (Tabla 4.2, columna $\mathrm{Cl}{ }^{*}$ Tiempo(BA)).

Los valores promedio de PRS reflejan una diferencia promedio entre el tramo Impacto y el tramo Control de 0,35 mg. $\mathrm{L}^{-1}$ en el período fertilizado (Figura 4.7). Las concentraciones de PRS variaron significativamente debido a la fertilización en el tramo Impacto (Tabla 4.2, columna $\left.\mathrm{Cl}{ }^{*} \mathrm{BA}\right)$.

Las concentraciones de NID reflejan una diferencia promedio entre el tramo Impacto y el tramo Control de $0,46 \mathrm{mg} \cdot \mathrm{L}^{-1}$ en el período fertilizado (Figura 4.7). El efecto de la fertilización fue significativo sobre esta variable (Tabla 4.2), y principalmente notorio en los dos primeros meses del período Después. Las concentraciones de NID exhiben diferencias significativas sólo dentro de cada período (Antes y Después).

La relación NID:SRP varió en el Impacto de 5,6 (Antes) a 1,9 (Después), y en el Control de 3,2 (Antes) a 4,6 (Después). Esto indica un desbalance hacia la limitación del nitrógeno en el tramo Impacto. 


\begin{tabular}{|c|c|c|c|c|c|c|}
\hline & & \multicolumn{5}{|c|}{ Fuentes de variación } \\
\hline & & $\mathrm{Cl}$ & BA & Tiempo(BA) & $\mathrm{Cl} * \mathrm{BA}$ & Cl*Tiempo(BA) \\
\hline \multirow[t]{2}{*}{ Conductividad } & $p$ & 0,000 & 0,079 & 0,000 & 0,644 & 0,000 \\
\hline & $\eta^{2}$ & 0,11 & 0,29 & 0,57 & 0,00 & 0,01 \\
\hline \multirow[t]{2}{*}{ Temperatura } & $p$ & 0,959 & 0,278 & 0,000 & 0,304 & 0,000 \\
\hline & $\eta^{2}$ & 0,00 & 0,14 & 0,83 & 0,00 & 0,02 \\
\hline \multirow{2}{*}{$\begin{array}{l}\text { Oxígeno } \\
\text { Disuelto }\end{array}$} & $p$ & 0,922 & 0,866 & 0,002 & 0,564 & 0,003 \\
\hline & $\eta^{2}$ & 0,00 & 0,03 & 0,79 & 0,00 & 0,08 \\
\hline \multirow[t]{2}{*}{ pH } & $p$ & 0,918 & 0,022 & 0,113 & 0,227 & 0,001 \\
\hline & $\eta^{2}$ & 0,00 & 0,34 & 0,34 & 0,03 & 0,14 \\
\hline \multirow[t]{2}{*}{ PRS } & $p$ & 0,004 & 0,748 & 0,318 & 0,027 & 0,005 \\
\hline & $\eta^{2}$ & 0,06 & 0,00 & 0,11 & 0,03 & 0,07 \\
\hline \multirow[t]{2}{*}{ NID } & $p$ & 0,026 & 0,639 & 0,001 & 0,093 & 0,000 \\
\hline & $\eta^{2}$ & 0,05 & 0,02 & 0,80 & 0,03 & 0,06 \\
\hline
\end{tabular}

Tabla 4.2. Resultados obtenidos en los BACIPS ANOVA para las variables físico-químicas. Las fuentes de variación representan los tres factores: $\mathrm{Cl}=$ Control-Impacto; $\mathrm{BA}=$ Before-After (Antes-Después); Tiempo=Fecha de muestreo
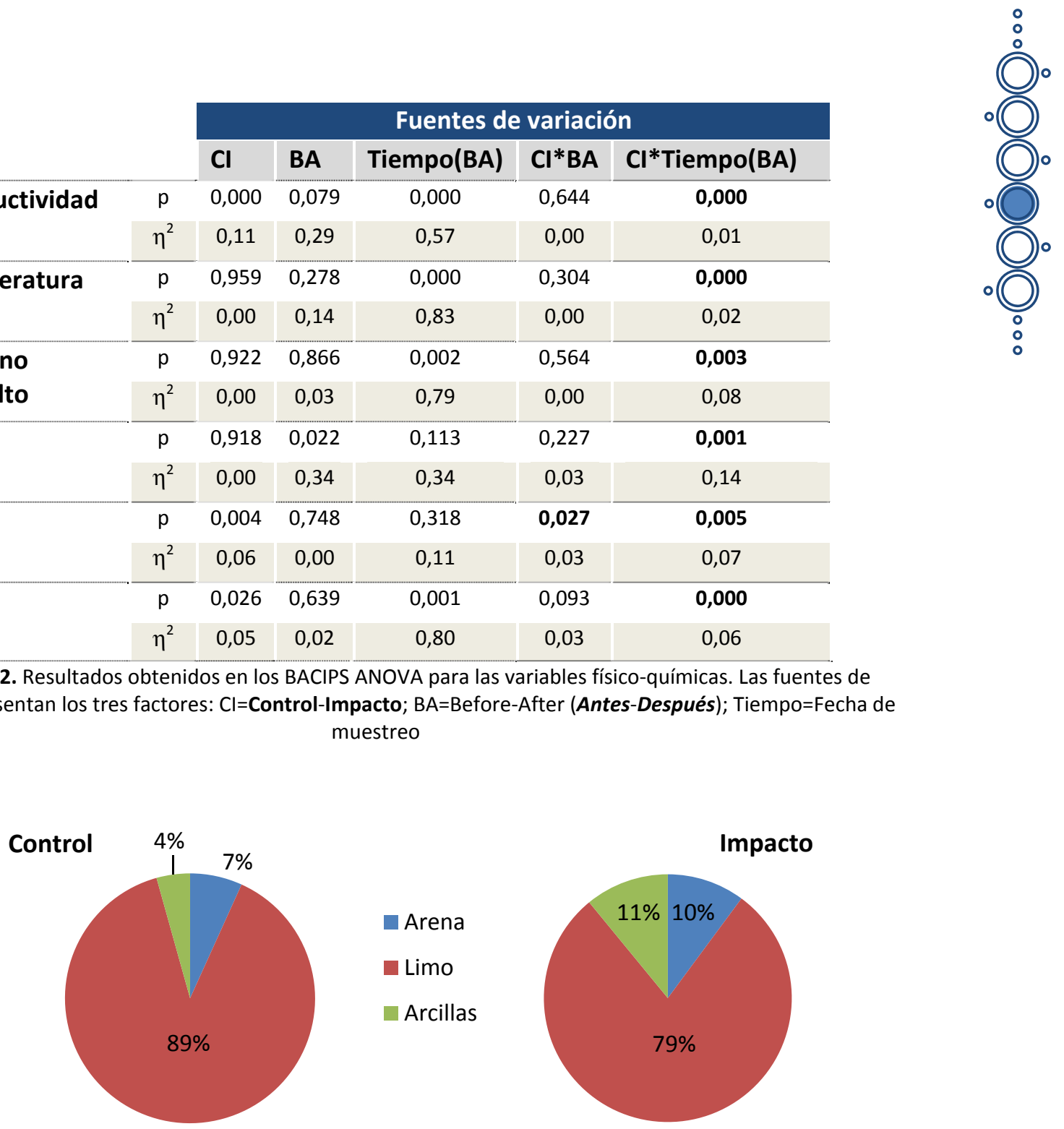

Figura 4.5. Datos promedio de la granulometría del tramo Control (derecha) y del tramo Impacto (izquierda). 

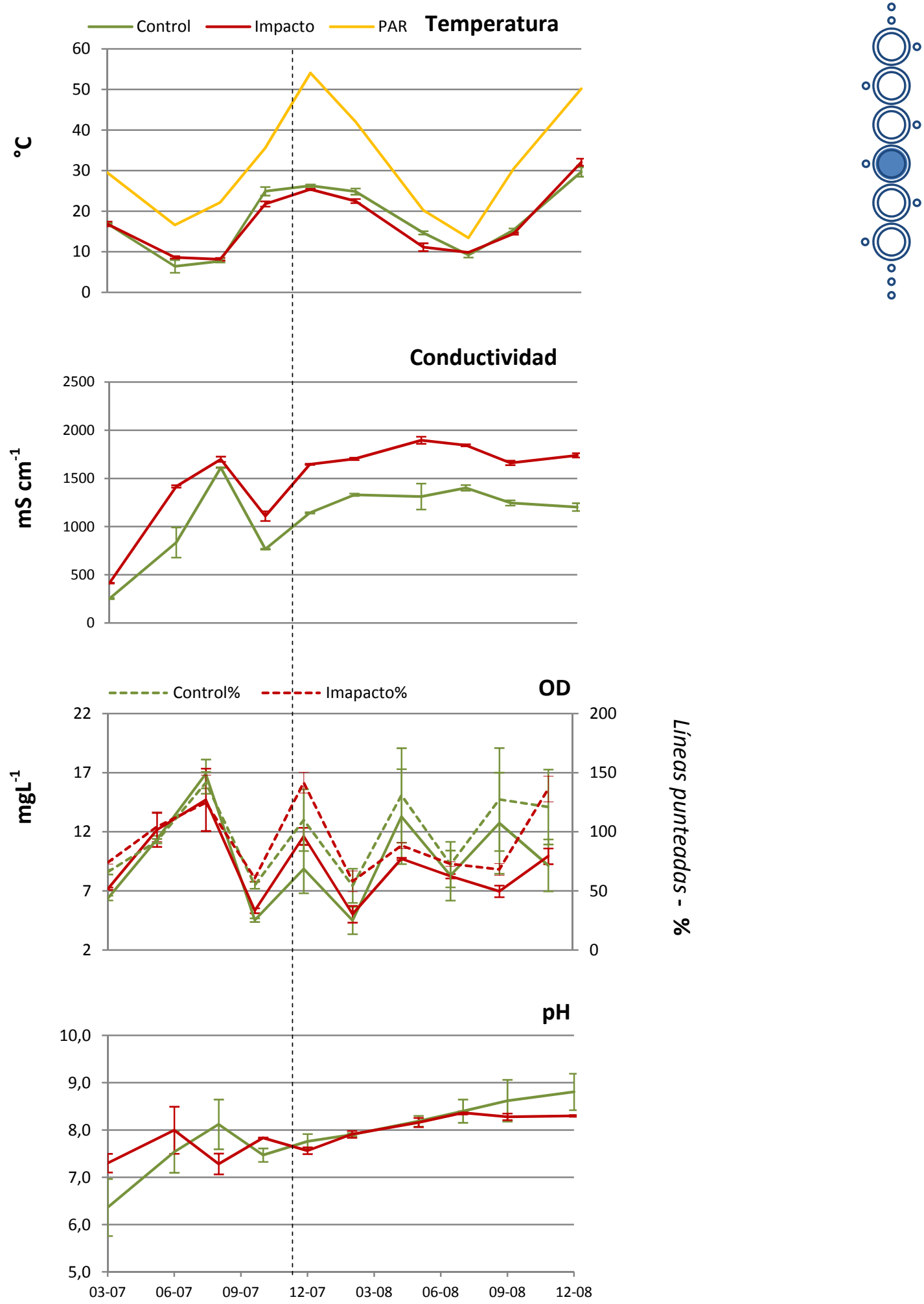

Figura 4.6. Variaciones de conductividad, temperatura, oxígeno disuelto y $\mathrm{pH}$ a lo largo de la experiencia en los tramos Control e Impacto. La línea punteada marca el comienzo de la adición experimental de nutrientes. 

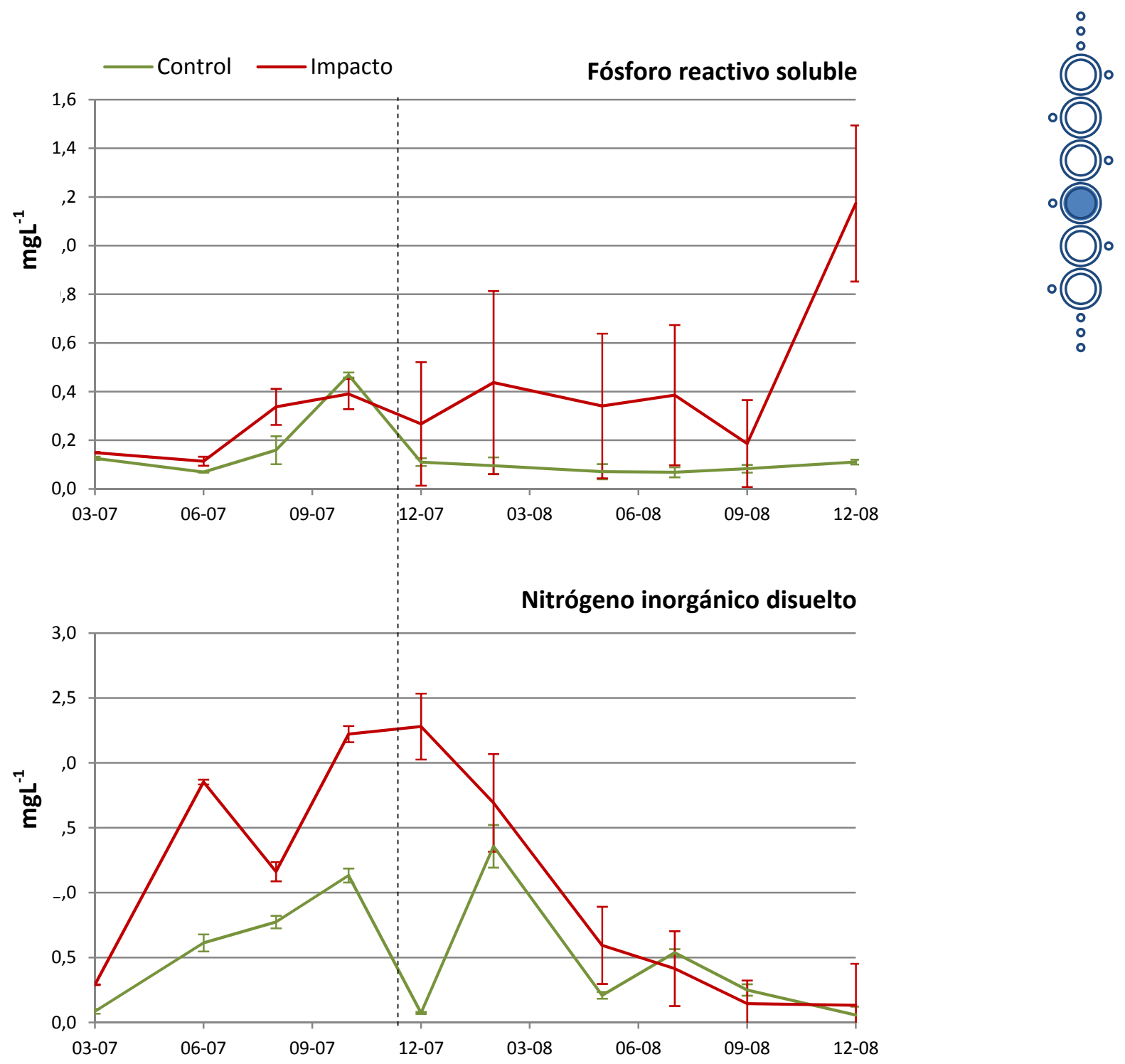

Figura 4.7. Concentraciones de PRS y NID durante la experiencia. La línea punteada marca el comienzo de la adición experimental de nutrientes 
La densidad y la biomasa bacteriana fueron similares en ambos tramos en el período Antes, mientras que en el período Después la diferencia entre ambos tramos fue mayor. Los valores mínimos de densidad bacteriana fueron reportados en invierno, tanto en el tramo Impacto como en el Control (Figura 4.8).

Los resultados del BACIPS ANOVA muestran un efecto de pulso en la comunidad bacteriana (Tabla 4.3, columna $\mathrm{Cl}^{*}$ Tiempo(BA)), resultando en un mayor desarrollo de la misma en el tramo Impacto y siendo mucho más notorio después de unos diez meses de comenzada la fertilización (Figura 4.8). La variación explicada por la interacción señalada es del $21 \%$, sugiriendo un efecto moderado de la fertilización sobre la biomasa bacteriana. Asimismo, el $68 \%$ de la variabilidad en los datos de biomasa fue contemplada en el factor temporal $\left(\eta^{2}=\right.$ $0,68)$, lo que evidencia una gran variación de este parámetro a lo largo de la experiencia.

Además, la biomasa bacteriana estuvo correlacionada positivamente con la concentración de PRS $(r=0,694 ; p<0,05)$ (Tabla 4.4).

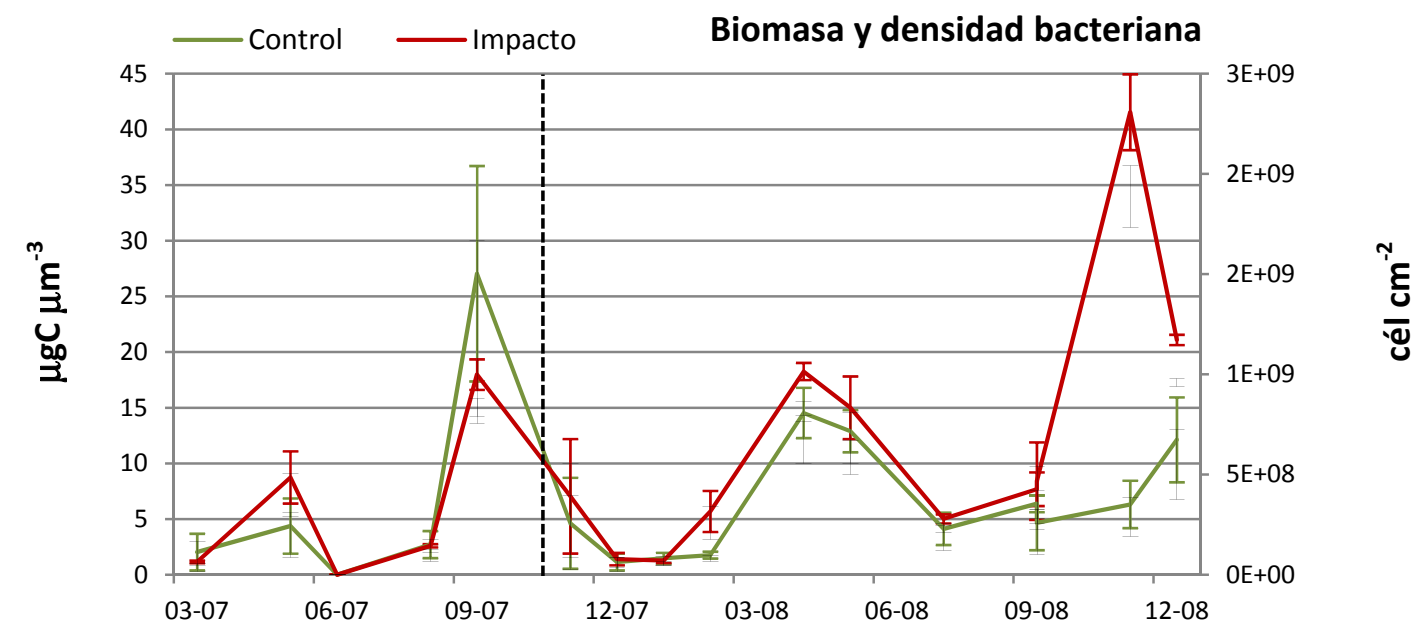

Figura 4.8. Promedios y desvíos de la densidad y biomasa bacteriana a lo largo de la experiencia. La línea punteada marca el comienzo de la adición experimental de nutrientes 
La concentración de clorofila "a" fue similar en ambos tramos en el período Antes, y mostró un aumento significativo en el tramo Impacto durante el período Después, principalmente por los incrementos en dic-2007 y nov-2009 (Figura 4.9). Aumentos de clorofila "a" fueron observados en otoño, verano y primavera.

Los resultados del BACIPS ANOVA muestran un efecto inmediato en la concentración de clorofila "a" (Tabla 4.3, columna Cl*BA). La variabilidad explicada por esa interacción es del 3\%, lo que sugiere que el efecto sobre la biomasa algal fue pequeño. Asimismo, el $78 \%$ de la variabilidad de los datos fue explicada por el tiempo $\left(\eta^{2}=0,78\right)$, lo que indica una gran variación del parámetro a lo largo de la experiencia.

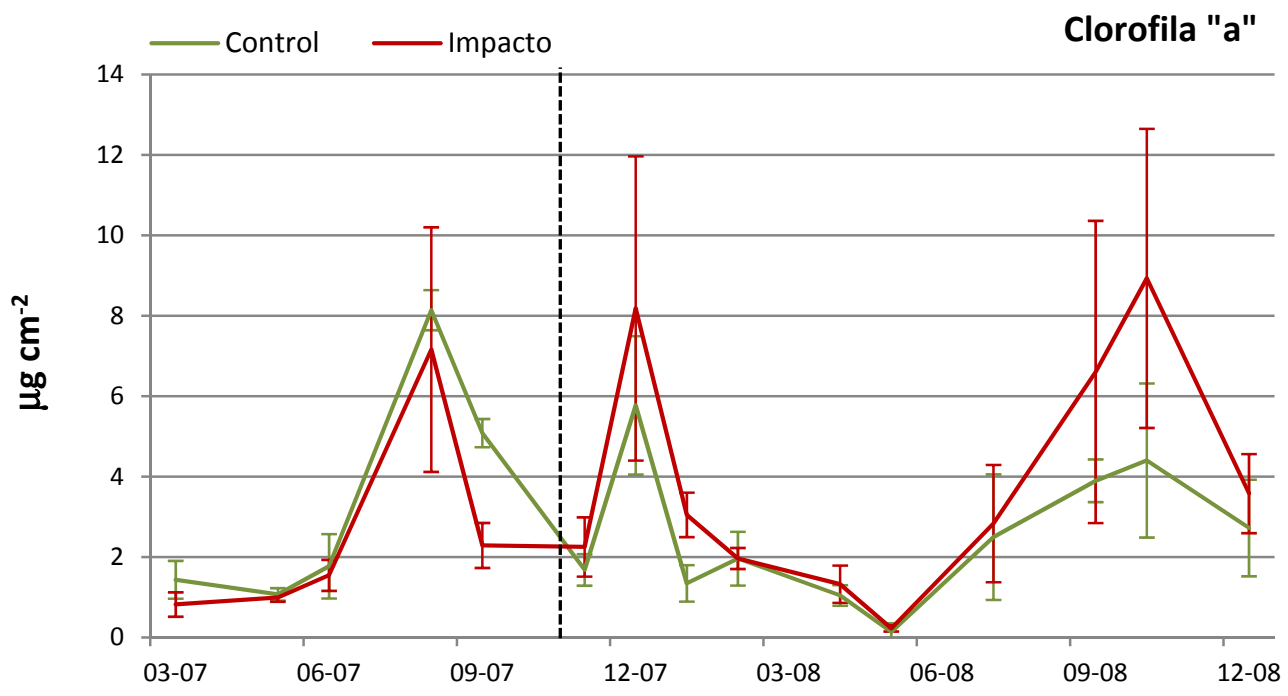

Figura 4.9. Promedios y desvíos de la clorofila "a" a lo largo de la experiencia. La línea punteada marca el comienzo de la adición experimental de nutrientes 
La $\beta$-glucosidasa exhibió un valor significativo en la interacción $\mathrm{Cl}$ *Tiempo(BA) en el BACIPS ANOVA (Tabla 4.3), que es explicada por la variabilidad entre los períodos y tramos. En el perído Antes hubo períodos donde fue mayor en el tramo Impacto, tendencia que se manturo en el comienzo del período Después, aunque hacia el final de la experiencia su actividad decrece en relación al Control (Figura 4.10). Asimismo, la variabilidad de las concentraciones de la enzima durante la experiencia fue muy amplia $\left(\eta^{2}=0,65\right)$ en ambos tramos.

La fosfatasa también exhibió valores significativos signficativas en la interacción CI*Tiempo(BA) en el BACIPS ANOVA (Tabla 4.3), resultado del incremento gradual en el tramo Control en el período fertilizado (Figura 4.11). Esta enzima tuvo una variabilidad temporal moderada en ambos tramos $\left(\eta^{2}=0,45\right)$.

La actividad de ambas enzimas estuvo correlacionada positivamente entre sí ( $r=0,737$; $\mathrm{p}<0,05)$, y la actividad de la $\beta$-glucosidasa se correlacionó con la concentración de clorofila "a" $(r=0,662 ; p<0,05)$ (Tabla 4.4).

La eficiencia de la $\beta$-glucosidasa, es decir, la cantidad de la enzima producida por unidad de biomasa bacteriana, fue calculada y expresada como nmol [MUF] $\mathrm{cm}^{-2} \mathrm{hr}^{-1} \mu \mathrm{gCbact}$. El desvío estándar fue calculado dividiendo cada valor obtenido para la $\beta$-glucosidasa sobre la biomasa bacteriana promedio para esa fecha. En el período Antes, sus valores eran menores en el tramo Control, mientras que en el período Después disminuyó en ambos tramos y se volvieron similares (Figura 4.12). A lo largo de la experiencia la variación de la eficiencia de esta enzima fue moderada $\left(\eta^{2}=0,46\right)$ en ambos tramos. 


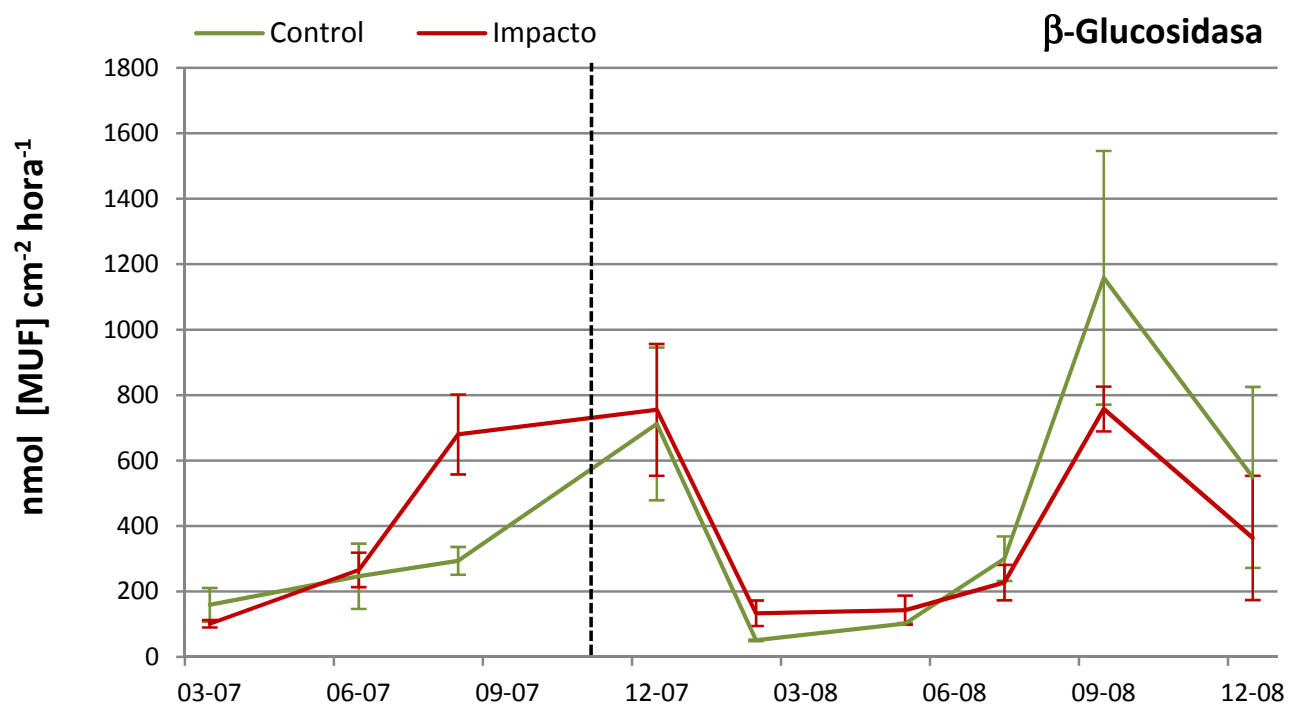

Figura 4.10. Promedios y desvíos de la actividad de la $\beta$-glucosidasa a lo largo de la experiencia. La línea punteada marca el comienzo de la adición experimental de nutrientes

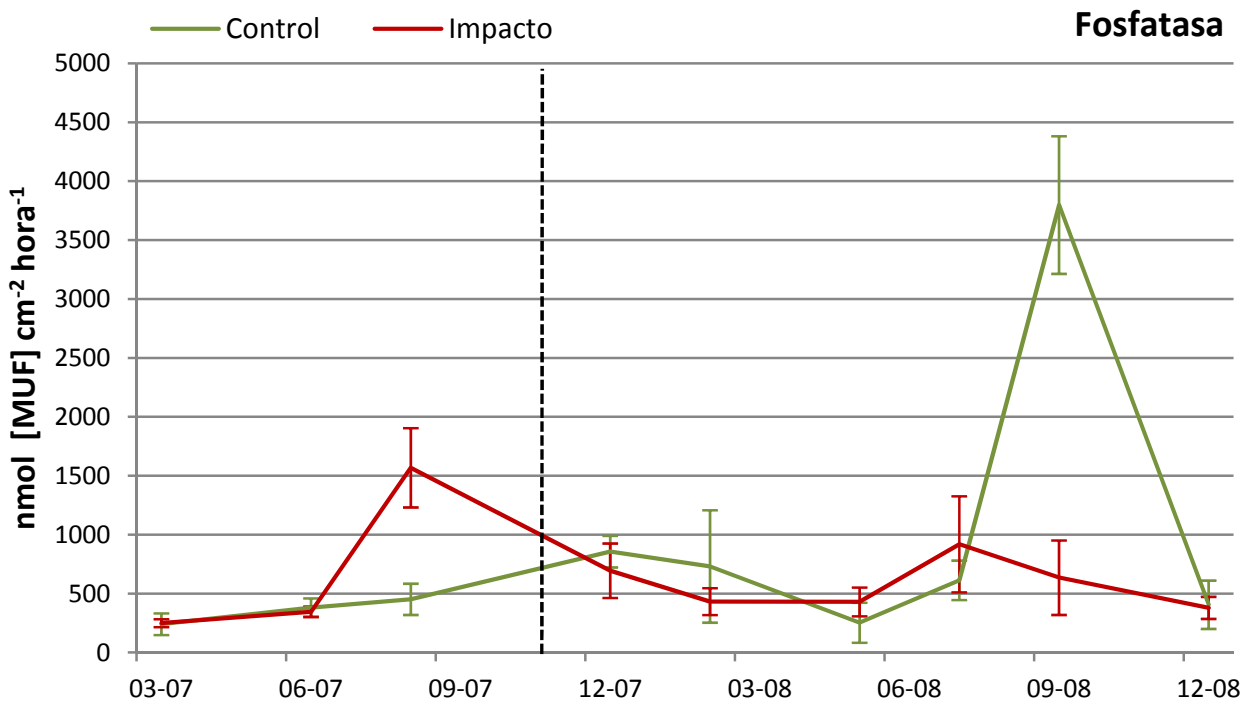

Figura 4.11. Promedios y desvíos de la actividad de la fosfatasa a lo largo de la experiencia. La línea punteada muestra el comienzo del período de fertilización. 


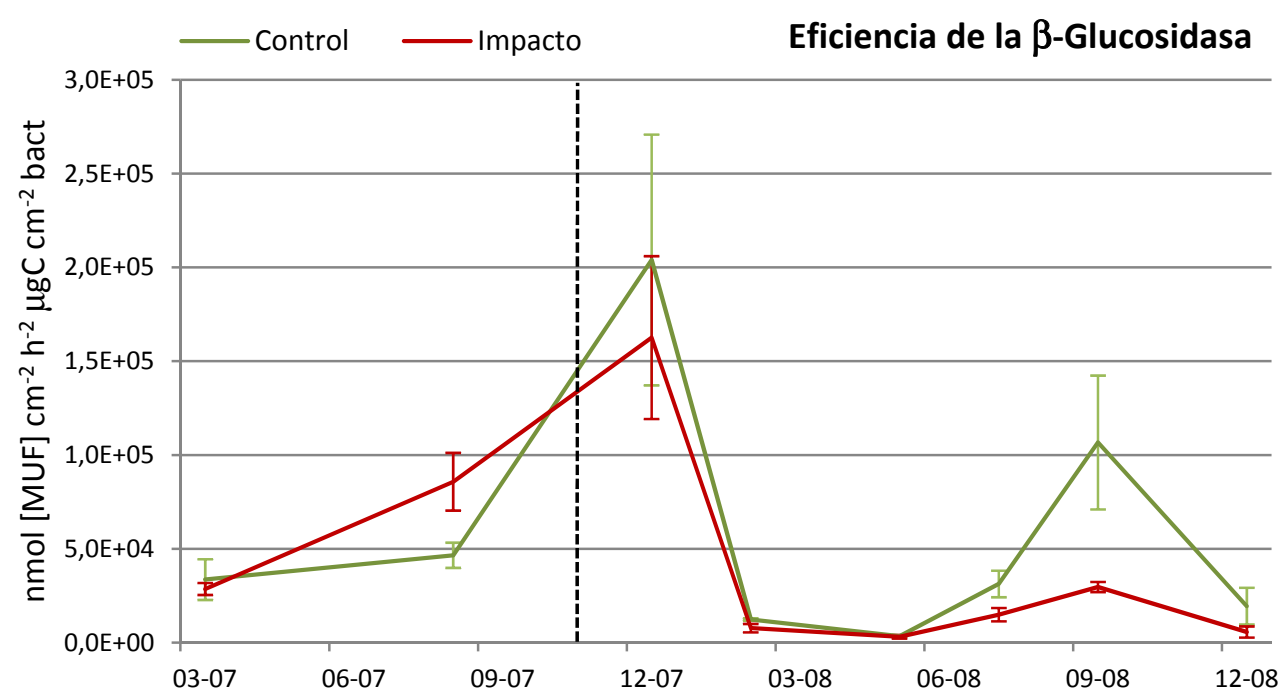

Figura 4.12. Eficiencia de la $\beta$-glucosidasa a lo largo de la experiencia. La línea punteada marca el comienzo de la adición experimental de nutrientes

\begin{tabular}{l|c|c|c|c|c|c|} 
& & \multicolumn{5}{c}{ Fuentes de variación } \\
\hline $\begin{array}{l}\text { Biomasa } \\
\text { bacteriana }\end{array}$ & $\mathrm{p}$ & 0,369 & 0,664 & 0,017 & 0,210 & $\mathbf{0 , 0 0 0}$ \\
& $\eta^{2}$ & 0,01 & 0,00 & 0,68 & 0,02 & 0,21 \\
\hline Clorofila "a" & $p$ & 0,896 & 0,983 & 0,000 & $\mathbf{0 , 0 0 3}$ & 0,546 \\
\hline B-glucosidasa & $\eta^{2}$ & 0,00 & 0,00 & 0,78 & 0,03 & 0,03 \\
\hline Fosfatasa & $p$ & 0,189 & 0,691 & 0,007 & 0,356 & $\mathbf{0 , 0 0 2}$ \\
\hline & $\eta^{2}$ & 0,03 & 0,02 & 0,65 & 0,01 & 0,08 \\
\hline Eficiencia $\beta$-GLU & $p$ & 0,309 & 0,398 & 0,191 & 0,251 & $\mathbf{0 , 0 0 0}$ \\
\hline & $\eta^{2}$ & 0,04 & 0,05 & 0,45 & 0,05 & 0,22 \\
\hline & $p$ & 0,202 & 0,184 & 0,187 & 0,184 & $\mathbf{0 , 0 0 0}$ \\
\hline
\end{tabular}

Tabla 4.3. Resultados obtenidos en los BACIPS ANOVA para las variables biológicas. Las fuentes de variación representan los tres factores: $\mathrm{Cl}=$ Control-Impacto; $\mathrm{BA}=$ Before-After; Tiempo=Fecha de muestreo, $\mathrm{y}$ los valores significativos son señalados en negrita. 


\begin{tabular}{|c|c|c|c|c|c|c|c|c|c|c|c|}
\hline & BACT & CL "A" & $\beta$-GLU & FOSF & COND & TEMP & OD & $\mathrm{pH}$ & PRS & NID & PAR \\
\hline BACT & --- & & & & & & & & & & \\
\hline$\overline{C L}$ "A" & -.26 & ---- & & & & & & & & & \\
\hline$\overline{\beta-G L U}$ & -.08 & $.78 *$ & ---- & & & & & & & & \\
\hline FOSF & -.20 & $.55 *$ & $.62 *$ & ---- & & & & & & & \\
\hline COND & .40 & .33 & .30 & .47 & ---- & & & & & & \\
\hline TEMP & .39 & .08 & .25 & -.16 & -.02 & ---- & & & & & \\
\hline OD & .03 & $.52 *$ & .40 & .22 & .30 & -.45 & ---- & & & & \\
\hline $\mathrm{pH}$ & $.52 *$ & -.06 & -.03 & -.08 & $.62 *$ & .14 & .12 & ---- & & & \\
\hline PRS & $.65 *$ & .12 & .18 & .16 & .46 & .40 & -.03 & .18 & ---- & & \\
\hline NID & -.41 & .31 & .27 & .28 & .39 & -.07 & .08 & -.09 & -.05 & ---- & \\
\hline PAR & .19 & .33 & .44 & -.04 & -.01 & $.94 *$ & -.31 & .01 & .31 & .08 & ---- \\
\hline
\end{tabular}

Tabla 4.4. Valores de correlaciones de Pearson obtenidas entre las variables biológicas (BACT=Biomasa bacteriana; $C L$ " $A$ " = Clorofila "a"; $\beta$-GLU= $\beta$-glucosidasa; FOSF=Fosfatasa) y las variables físico-químicas

(COND=Conductividad; TEMP=Temperatura; $\mathrm{OD}=$ Oxígeno Disuelto; $\mathrm{pH}=\mathrm{pH}$; $\mathrm{PRS}=$ Fósforo Reactivo Soluble;

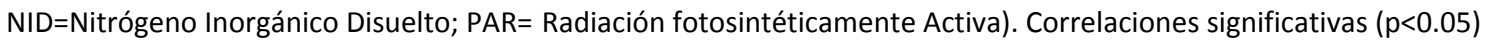
están marcadas con *. 
El metabolismo de los arroyos pampeanos en general es alimentado por producción primaria autóctona, que se desarrolla tanto en el epipelon como en el plancton y las macrófitas (Feijoó et al. 1999, Acuña et al. 2011). Estas características afectaron el experimento de adición de nutrientes en sí, y modularon la respuesta de la biomasa microbiana del biofilm epipélico y del metabolismo heterotrófico.

La adición de fósforo y nitrógeno al arroyo La Choza causó una concentración significativamente mayor de PRS en el tramo impactado como era esperado, pero no ocurrió lo mismo con el NID. El nitrógeno que fue agregado al arroyo puede haber sido rápidamente asimilado por las algas, macrófitas o bacterias, o pudo haber escapado del sistema por procesos de denitrificación causados por bacterias anaeróbicas en condiciones anóxicas. Al ser bajas las relaciones NID:PRS $(3,2-5,6)$ las comunidades biológicas pueden estar limitadas por nitrógeno (Stelzer \& Lamberti 2001), y la asimilación puede ser relevante. Sin embargo, se sugiere la denitrificación como proceso principal de pérdida de nitrógeno disuelto, ya que se han medido condiciones anóxicas en este arroyo tanto en el sedimento como en el agua durante la noche (Acuña et al. 2011), lo cual generaría un escenario propicio para que ocurran dichos procesos. Aún cuando los sedimentos sub-superficiales están bien oxigenados y tienen una concentración de nitrógeno relativamente baja, los procesos de denitrificación han sido observados en arroyos de climas más desérticos (Holmes et al. 1996).

Aún con las altas concentraciones basales de nutrientes en el arroyo La Choza, la adición de nutrientes causó un incremento significativo en la biomasa algal del epipelon, que mostró un primer pico de incremento en el verano (2-3 meses después del comienzo de la fertilización) y un segundo pico de incremento en primavera (unos 10 meses después del comienzo de la fertilización). Analizando los efectos tanto de luz como de nutrientes sobre la comunidad perifítica, von Schiller et al. (2007) concluyeron que la luz era el principal factor que afectaba al desarrollo de la biomasa algal en un arroyo Mediterráneo, y que un incremento en la disponibilidad de nutrientes no mejoraba su incremento ni en condiciones de alta ni de baja intensidad de luz. Sin embargo, este estudio sugiere que en un arroyo donde la disponibilidad de luz no es un factor limitante relevante, un incremento en la concentración de nutrientes aún incrementa la biomasa algal significativamente. Una interacción positiva entre la disponibilidad de nutrientes y de luz y los productores primarios también fue descripta en Ylla et al. (2007) para algas del sedimento y musgos. 
En los biofilms la relación entre productores primarios y la limitación potencial de fósforo puede ser deducida de los cambios en la actividad de la fosfatasa, ya que las algas son altamente responsables de las variaciones en esta actividad. En este experimento, la actividad de la fosfatasa se mantuvo entre valores de 1,67-26,50 nmol [MUF] $\mathrm{cm}^{-2} \mathrm{~h}^{-1}$, y más del $90 \%$ de los valores fueron menores a $10 \mathrm{nmol}[\mathrm{MUF}] \mathrm{cm}^{-2} \mathrm{~h}^{-1}$. Cuando se comparan estos resultados con los obtenidos en otros estudios, estos valores se encuentran entre los más bajos en biofilms de arroyos (Hill et al. 2012, Romaní et al. 2012). En los experimentos conducidos por Rier et al. (2007), por ejemplo, valores tan bajos sólo fueron medidos en biofilms con muy baja intensidad lumínica.

Aunque es esperable una disminución en la actividad de la fosfatasa en el sitio fertilizado debido a la mayor disponibilidad de fósforo (Romaní et al. 2004a), esto no fue observado en este estudio. Esto podría deberse a que la actividad de la fosfatasa no es inhibida por el enriquecimiento, y los valores medidos son los producidos por los organismos en su metabolismo basal. Sin embargo, en el tramo Control, un pico de incremento de fosfatasa fue medido en primavera, coincidiendo con el incremento en biomasa algal, que podría indicar una demanda de fósforo durante el desarrollo. Esta demanda no ocurría en el tramo fertilizado, ya que el fósforo inorgánico necesario para el desarrollo de los productores primarios estaba siendo provisto exógenamente.

La adición de nutrientes causó en el epipelon un efecto diferido en el desarrollo de la comunidad bacteriana, que no mostró su mayor efecto hasta primavera (unos 10 meses después del comienzo de la fertilización).

La respuesta bacteriana parece estar relacionado con la respuesta autotrófica ya que la biomasa bacteriana se incrementó después del primer pico de incremento en biomasa algal (verano) y más significativamente después del segundo pico de biomasa algal (primavera, 10 meses después del comienzo de la fertilización). Por lo contrario, en un arroyo mediterráneo de bajo orden, una fertilización a largo plazo causó una primera respuesta inmediata de las bacterias, independientemente de cualquier incremento en biomasa algal (Sabater et al. 2011), que es lo que se esperaría en un sistema basado en detritus (Chadwick \& Huryn 2003). Los incrementos en biomasa bacteriana en La Choza, ocurriendo siempre después de los incrementos en clorofila, sugieren que las bacterias en este microhábitat utilizan principalmente compuestos orgánicos autotróficos.

El metabolismo bacteriano del epipelon de estos arroyos con baja velocidad de corriente es similar al de los típicos biofilms epilíticos - altamente relacionados con la actividad

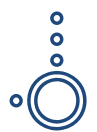


y biomasa algal - que a los biofilms episammicos donde los heterótrofos microbianos son más eficientes utilizando la materia orgánica alóctona (Romaní \& Sabater 2001).

Varios estudios en los biofilms epilíticos concluyeron que los exudados algales son una gran fuente de carbono para las bacterias (como Espeland et al. 2001, Romaní et al. 2004b, Francoeur et al. 2006, Rier et al. 2007). Estudios realizados sobre el biofilm epilítico evidencian que la acumulación de algas influencia el uso de materia orgánica incrementando la cantidad de sustrato orgánico disponible para las bacterias, aunque le confiere una respuesta más lenta a la comunidad microbiana que al desarrollo de la comunidad algal en sí (Romaní \& Sabater, 1999). Este modelo sería consistente con los resultados de este estudio, que muestran un incremento en la biomasa algal significativo con la adición de nutrientes, que también resultaría en un incremento bacteriano, aunque de manera más gradual.

Los efectos estimulantes de la biomasa algal sobre la actividad bacteriana en biofilms epilíticos han sido reportados en varios estudios (como en Murray et al. 1986, Chapell \& Goulder 1994, Romaní \& Sabater 1999). Carr et al. (2005) sugirieron que las algas y las bacterias coexisten en una asociación que ofrece el espacio y los recursos para sostener la producción de ambos grupos de organismos. Por otro lado, Rier \& Stevenson (2001) encontraron que sólo hay una relación positiva entre las algas y bacterias en el perifiton de arroyos cuando se incluyen en los análisis las concentraciones de clorofila "a" mayores a $5 \mu \mathrm{g}$ $\mathrm{cm}^{-2}$, y Rier \& Stevenson (2002) concluyen que las bacterias se asocian con las algas no como fuente de carbono, sino como sustrato para su colonización.

A pesar de la correlación positiva hallada en La Choza entre la concentración de $\beta$ glucosidasa y la biomasa algal, sus variaciones no estuvieron tan acopladas como en otros estudios (Somville 1984, Jones \& Lock 1993), que concluyeron que los polisacáridos liberados del componente autotrófico del biofilm aumentaron la actividad de la enzima.

Medidas de fosfatasa y de $\beta$-glucosidasa no han sido reportadas anteriormente en sedimentos de arroyos pampeanos, y son relativamente bajos comparados con arroyos de otros biomas (Romaní et al. 2004a, Rulík \& Spácil 2004, Hill et al. 2012). Diversos estudios muestran que las concentraciones de fosfatasa están inversamente correlacionadas con las concentraciones de fósforo en agua y sedimento (Hill et al. 2012, Findlay et al. 2001, Harbott \& Grace 2005, Sinsabaugh et al. 2010), y Hill et al. (2012) concluyeron que la escorrentía pobre en nutrientes en arroyos forestados estimula la producción extracelular enzimática para la adquisición de nitrógeno y fósforo. Por esto, en un arroyo rico en fósforo como La Choza, es 
consistente encontrar concentraciones más bajas de fosfatasa que en otros arroyos con niveles de nutrientes menores.

Las hipótesis planteadas en esta experiencia predecían un incremento en la $\beta$ glucosidasa con la adición de nutrientes, ya que el balance estequiométrico C:N:P hubiese sido disturbado cuando se agregaban sólo $\mathrm{N}$ y $\mathrm{P}$, lo que resultaría en una deficiencia de carbono para las bacterias y una mayor producción de la enzima relacionada con su adquisición. Sin embargo, la $\beta$-glucosidasa sólo se incrementó al final de la experiencia y después del incremento en biomasa algal en ambos tramos estudiados. La $\beta$-glucosidasa epipélica, entonces, parece estar más regulada por la disponibilidad del sustrato que por el desbalance de nutrientes.

Por otro lado, la variación en la eficiencia de la $\beta$-glucosidasa con la adición de nutrientes se traduce en una menor necesidad de las células bacterianas en producir la enzima, lo que es consistente con el incremento en biomasa algal en el tramo enriquecido, que les provee una fuente de carbono rápidamente incorporable. Esto sí es consistente con lo encontrado en otros estudios como el de Romaní \& Sabater 2000 que reportan que la eficiencia de los biofilms en producir enzimas fue menor en sitios con altas concentraciones de nutrientes.

En general, la respuesta del epipelon de un arroyo pampeano rico en nutrientes a la adición experimental produjo una respuesta lenta y retrasada en el incremento de biomasa algal que determinó un efecto diferido en el incremento de la densidad bacteriana. Estos cambios pueden ser los responsables de la ligera disminución en oxígeno disuelto y en el pH en el tramo fertilizado debido al aumento en actividad respiratoria.

Es de destacar que el análisis pormenorizado de la taxocenosis de diatomeas, realizado durante esta experiencia de fertilización por Gómez et al. (2011), demostró que el enriquecimiento realizado favoreció aquellas especies que prefieren un ambiente más eutrófico y que presentan un metabolismo que les permite disponer más facilmente del nitrógeno orgánico presente en el medio. Es así que especies como Nitzschia frustulum y Nitzschia incospicua incrementaron sus densidades poblacionales con la fertilización, como consecuencia del incremento de la materia orgánica, mientras que las densidades de especies como Nitzschia amphibia y Achnanthidium minutissimum decrecieron.

De acuerdo con Artigas et al. (2013) el efecto del enriquecimiento por nutrientes puede ser menos predecible en sistemas con altas concentraciones de nutrientes basales, 
como en los arroyos pampeanos, que se encuentran cerca de su saturación. Aunque los cambios son lentos, si algunos de ellos se vuelven crónicos, podrían afectar a todo el funcionamiento y servicios del ecosistema del arroyo.

El enriquecimiento por nutrientes en los ecosistemas acuáticos por el incremento en la escorrentía de tierras cultivadas es de gran preocupación. Los efectos que otras variables relacionadas a la escorrentía tienen sobre el biofilm también deben ser estudiados, ya que pueden afectar la manera en la que las comunidades responden al aumento de nutrientes. Por otro lado, es importante también destacar que serían necesarios estudios de enriquecimiento con nutrientes de mayor duración temporal para determinar los umbrales de resistencia de estas comunidades y su resiliencia hacia estados estables. 


\section{CAPÍTULO 5}

EL EFECTO SIMULTÁNEO DEL INCREMENTO DE

NUTRIENTES, TEMPERATURA, TURBIDEZ Y VELOCIDAD

DE LA CORRIENTE EN BIOFILMS. ENSAYOS DE

LABORATORIO.

"Si no concuerda con el experimento, está mal. En esta sencilla afirmación está la clave de la ciencia. No importa cuán hermosa sea su especulación. No importa cuán inteligente sea usted, quién hizo la especulación o cuál es su nombre. Si no concuerda con el experimento, está mal. Y eso es todo." Richard Feynman 
El desarrollo de los biofilms en los ecosistemas acuáticos está modulado por diversos factores, como fuera señalado en la introducción de esta tesis, y que fuera abordado en diferentes estudios (Capítulo 1. Introducción). Sin embargo son escasas las investigaciones que abordan el efecto de distintos factores de manera simultánea sobre el biofilm. Hay referencias que establecen, por ejemplo, la relación entre el desarrollo del biofilm en relación a la combinación de nutrientes y luz (Rosemond et al. 1993, Mosisch et al. 2001, von Schiller et al. 2007, entre otros), la relación entre el tipo de sustrato y los nutrientes (Romaní et al. 2004), o la relación entre la velocidad de la corriente, el sedimento en suspensión y la concentración de fósforo (Horner et al. 1990).

Por otra parte, la mayoría de estos estudios se han llevado a cabo sobre sustratos artificiales o en comunidades epilíticas, no existiendo antecedentes en sustratos blandos.

En este capítulo se abordarán las experiencias de laboratorio con el objetivo de demostrar los efectos del incremento simultáneo de nutrientes, la velocidad de la corriente, la turbidez y la temperatura sobre el biofilm. Para ello se emplearon mesocosmos que permitieron analizar las respuestas del biofilm bajo dos condiciones de calidad del agua (buena-moderada y mala), expuestos a dos tratamientos a una escala de tiempo corta (6 semanas). 
Los objetivos de los estudios expuestos en el presente capítulo fueron evaluar las modificaciones estructurales y funcionales en los biofilms cuando son expuestos a un aumento simultáneo de nutrientes inorgánicos (fósforo y nitrógeno), velocidad de la corriente, turbidez y temperatura. Además, fue de interés analizar las diferencias entre las respuestas de los biofilms a dichas variables en arroyos con distintos grados de calidad del agua.

La principal hipótesis planteada para las experiencias de manipulación en laboratorio fue que la estructura y función del biofilm epipélico de arroyos pampeanos es afectada por múltiples presiones simultáneas relacionadas a los cambios globales, tales como concentración de nutrientes, la temperatura, la velocidad de la corriente y la turbidez. También se hipotetizó que la manera en que el biofilm epipélico de arroyos pampeanos es afectado por dichas presiones depende de la calidad del agua donde se generan, siendo los impactos mayores en arroyos expuestos un menor impacto antropogénico.

Las predicciones asociadas a estas hipótesis fueron que

1) El incremento simultáneo de la concentración de nutrientes, la temperatura, la velocidad de la corriente y la turbidez, se manifestarán en el biofilm epipélico por:

a. Un aumento en la biomasa total y en la actividad metabólica heterotrófica (respiración).

b. Una disminución en la diversidad del biofilm y una disminución de la matriz (polisacáridos).

c. Una simplificación en la estructura comunitaria que favorecerá el predominio de la biomasa autotrófica sobre la heterotrófica.

2) Los efectos en los biofilms expuestos al aumento de dichas variables serán mayores en los biofilms provenientes de un arroyo con mejor calidad del agua. 
Se realizaron dos experiencias empleando canales artificiales en laboratorio: la primera se realizó utilizando inóculos de biofilms provenientes de un arroyo con un grado de impacto antropogénico bajo, con una buena a moderada calidad del agua. La segunda experiencia con biofilms de un arroyo altamente impactado, con una mala calidad del agua. El grado de impacto antropogénico fue definido en base a las concentraciones de nutrientes (NID y PRS), y oxígeno disuelto y sus demandas $\left(\mathrm{DBO}_{5}\right.$ y $\left.\mathrm{DQO}\right)$.

La elección de los sitios en los arroyos a estudiar se realizó en base a estudios previos (Licursi 2005, Sierra 2008), que detallan el grado de impacto antropogénico al cual están expuestos dichos sitios (Tabla 5.1). Previamente al comienzo de las experiencias se realizaron análisis físico-químicos (PRS, NID, $\mathrm{DBO}_{5}, \mathrm{DQO}, \mathrm{pH}$, conductividad, temperatura y $\mathrm{OD}, \mathrm{n}=3$ ) para confirmar la calidad del agua. Con los valores obtenidos se realizó un ANOVA, con el fin de demostrar la existencia de diferencias significativas entre ambos arroyos (Tabla 5.1).

Los valores indicadores de la calidad del agua, tales como el PRS, el NID, la $\mathrm{DBO}_{5}$ y la DQO, resultaron significativamente menores y el OD mayor, en el agua del Arroyo Martín comparado con el agua del Arroyo Rodríguez (Tabla 5.1). Por otro lado, la relación NID:SRP en ambos arroyos es muy baja, evidenciando una notable deficiencia de nitrógeno en relación al fósforo. 


\begin{tabular}{|c|c|c|c|}
\hline & $\begin{array}{c}A^{\circ} \text { con bajo impacto } \\
\text { Arroyo Martín }\end{array}$ & $\begin{array}{l}A^{\circ} \text { con alto impacto } \\
\text { Arroyo Rodríguez }\end{array}$ & $\mathbf{p}$ \\
\hline Latitud & $34^{\circ} 54^{\prime} 51^{\prime \prime} \mathrm{S}$ & $34^{\circ} 54^{\prime} 12^{\prime \prime} \mathrm{S}$ & NC \\
\hline Longitud & $58^{\circ} 04^{\prime} 39^{\prime \prime} \mathrm{O}$ & $58^{\circ} 03^{\prime} 47^{\prime \prime} \mathrm{O}$ & NC \\
\hline Orden & 2 & 2 & NC \\
\hline Usos del suelo & Agropecuario & $\begin{array}{c}\text { Agropecuario } \\
\text { Urbano } \\
\text { Industrial }\end{array}$ & NC \\
\hline PRS $\left(m g L^{-1}\right)$ & $0,37( \pm 0,00)$ & $2,24( \pm 0,26)$ & 0,00 \\
\hline NID $\left(m g L^{-1}\right)$ & $0,22( \pm 0,05)$ & $1,85( \pm 0,06)$ & 0,00 \\
\hline NID:SRP & $0,46( \pm 0,12)$ & $0,62( \pm 0,05)$ & 0,02 \\
\hline $\mathrm{DBO}_{5}\left(m g L^{-1}\right)$ & $6( \pm 0,11)$ & $46( \pm 3,05)$ & 0,00 \\
\hline $\mathrm{DQO}\left(m g L^{-1}\right)$ & $15( \pm 0,57)$ & $105( \pm 4,04)$ & 0,00 \\
\hline $\mathrm{pH}$ & $8,77( \pm 0,02)$ & $8,48( \pm 0,01)$ & 0,03 \\
\hline Conductividad $\left(\mu \mathrm{S} \mathrm{cm} \mathrm{cm}^{-1}\right)$ & $1536( \pm 412)$ & $1325( \pm 8,16$ & 0,42 \\
\hline Temperatura $\left({ }^{\circ} \mathrm{C}\right)$ & $23,43( \pm 0,68)$ & $28,73( \pm 0,58)$ & 0,01 \\
\hline$O D\left(m g L^{-1}\right)$ & $7,70( \pm 0,25)$ & $5,28( \pm 0,53)$ & 0,02 \\
\hline Caudal $\left(m^{3} s^{-1}\right)$ & 0,11 & 0,06 & B \\
\hline Velocidad de la corriente $\left(m^{1} s^{-1}\right)$ & 0,21 & 0,14 & B \\
\hline $\mathbf{N}^{\circ}$ de Froude & $\begin{array}{c}0,09 \\
\text { flujo lento }\end{array}$ & $\begin{array}{c}0,04 \\
\text { flujo lento }\end{array}$ & B \\
\hline $\mathbf{N}^{\circ}$ de Reynolds & $\begin{array}{c}240998 \\
\text { flujo turbulento }\end{array}$ & $\begin{array}{c}160665 \\
\text { flujo turbulento }\end{array}$ & B \\
\hline Turbulencia & $\begin{array}{c}3,4 \% \\
\text { baja turbulencia }\end{array}$ & $\begin{array}{c}3,5 \% \\
\text { baja turbulencia }\end{array}$ & B \\
\hline
\end{tabular}

Tabla 5.1. Sitios de muestreo seleccionados para realizar las experiencias y sus características. Las diferencias significativas (en negrita). NC=No Corresponde; B=Valor extraído de bibliografía (extraídos de Licursi 2005 y de Sierra 2008)

Para realizar la experiencia en un arroyo con bajo impacto antropogénico (Experiencia 1) se colectó biofilm cerca de la cabecera del arroyo Martín ( $\left.34^{\circ} 54^{\prime} 51^{\prime \prime} S ; 58^{\circ} 04^{\prime} 39^{\prime \prime} \mathrm{O}\right)$. El uso del suelo en este sitio es el predominante de tipo pecuario. La inoculación de los canales artificiales se realizó en noviembre 2009, y se utilizó agua de este arroyo para la experimentación en laboratorio.

Para realizar la experiencia en un arroyo con un alto impacto antropogénico (Experiencia 2) se colectó biofilm en el tramo medio del arroyo Rodríguez ( $34^{\circ} 54^{\prime} 12^{\prime \prime} \mathrm{S} ; 58^{\circ}$ $\left.03^{\prime} 47^{\prime \prime O}\right)$. Los usos del suelo predominantes en este sitio de muestreo incluyen la actividad agropecuaria, la urbana y actividad industrial. La inoculación de los canales artificiales se 
realizó en noviembre 2010, empleando también en este caso agua de dicho arroyo para la experimentación.

\subsubsection{Diseño experimental}

Se utilizaron en total nueve canales artificiales: tres que no fueron sometidos a ningún tratamiento, en los cuales sólo circuló agua del arroyo correspondiente según la experiencia, denominados canales Control (C); tres canales tratados con baja intensidad (TB) y tres canales tratados con alta intensidad (TA). Este diseño experimental corresponde a un diseño factorial ortogonal con dos factores:

1. Factor Tratamiento: Factor fijo, con tres niveles $(C, T B, T A)$.

2. Factor Fecha: Factor al azar, con seis niveles y medidas repetidas (semanas 1 a 6).

Las réplicas utilizadas para los análisis estadísticos estuvieron conformadas por el promedio de tres submuestras (o réplicas analíticas) de cada canal, para contemplar la posible heterogeneidad dentro de cada canal artificial.

Los nueve canales fueron dispuestos como se detalla en el Capítulo 3 ("Metodologías"), y la colonización de los sustratos fue lograda por inoculación del biofilm de cada uno de los arroyos elegidos.

La etapa de colonización duró seis semanas, siendo examinado regularmente el desarrollo del biofilm al microscopio óptico (Olympus BX-50) en cámara Sedgewick-Rafter de $1 \mathrm{~mL}$. Una vez asegurada la colonización de los sustratos, comenzó la manipulación de las variables físico-químicas de los canales tratamiento. Esta etapa de manipulación se mantuvo por 36 días, siendo monitoreados los parámetros físico-químicos cada dos días, y los parámetros biológicos cada siete. 
Cuatro variables fueron manipuladas simultáneamente en todos los canales: concentración de nutrientes (PRS y NID), turbidez, velocidad de la corriente y temperatura del agua.

Utilizando como referencia los incrementos pronosticados para la región pampeana en temperatura y precipitaciones (Hulme \& Sheard 1999) y la relación escorrentía-temperatura (Labat et al. 2004), se seleccionaron para los tratamientos TB y TA incrementos leves e incrementos altos de las cuatro variables a manipular (Tabla 5.2). Los incrementos en temperatura fueron de $1^{\circ} \mathrm{C}$ y de $4^{\circ} \mathrm{C}$ a partir de los observados en los $\mathrm{C}$; los incrementos en la velocidad de la corriente del $5 \%$ y $20 \%$ en relación a los observados en los C, y los incrementos en turbidez (sólidos suspendidos) del 15\% y 50\% en relación a los observados en los C. Para planificar los incrementos en nutrientes se consideraron como incremento leve del $50 \%$ y para el incremento alto el mismo incremento utilizado en la experiencia de campo (Capítulo 4), del $300 \%$. Las variables fueron manipuladas de la siguiente manera:

- Temperatura del agua: en cada canal se dispuso un termostato Atman de 70W con regulador automático, para alcanzar la temperatura del agua deseada. En los $\mathbf{C}$ se mantuvo una temperatura constante de $25^{\circ} \mathrm{C}$, y se aumentó $1{ }^{\circ} \mathrm{C}$ en los TB y $4{ }^{\circ} \mathrm{C}$ en los TA.

- Velocidad del agua: se utilizaron bombas de recirculación de agua (bombas Chosen ${ }^{\circledR}$ Champion CX-500), reguladas para mantener los C a una velocidad similar a la registrada en el campo, incrementando la de los TB un 5\% y la de los TA un 20\% más que la medida en los $\mathbf{C}$.

- Turbidez: se agregó sedimento esterilizado, para lo cual fueron autoclavados previamente, para incrementar la turbidez de los TB y TA. Los canales C mantuvieron la turbidez del agua del arroyo del cual provenían los biofilms, en los canales TB se incrementó $15 \%$, y en los canales TA un $50 \%$ más que la medida en $\operatorname{los} \mathbf{C}$.

- Nutrientes: Se agregó a los canales fertilizante de uso comercial (Nitrofoska Azul ${ }^{\circledR}$ ) con agregado de urea, buscando aumentar los niveles de NID y PRS de los canales TB en un $50 \%$ y en los canales TA un $300 \%$ con respecto a los canales $\mathbf{C}$. 
Los incrementos de las variables manipuladas en los canales tratamiento se consideraron como valor promedio a lo largo de toda la experiencia, y se permitió que pudiesen variar hasta un $20 \%$ del valor esperado según lo propuesto por Guasch \& Serra (2009).

\section{\begin{tabular}{l|l|l|l} 
Temperatura & Nutrientes & Turbidez & Velocidad
\end{tabular}}

\begin{tabular}{|c|c|c|c|c|}
\hline Control (C) & $25^{\circ} \mathrm{C}$ & - & - & - \\
\hline TB & $\begin{array}{c}+1^{\circ} \mathrm{C} \\
\left( \pm 0,2^{\circ} \mathrm{C}\right)\end{array}$ & $\begin{array}{c}+50 \% \\
( \pm 10 \%)\end{array}$ & $\begin{array}{l}+15 \% \\
( \pm 3 \%)\end{array}$ & $\begin{array}{c}+5 \% \\
( \pm 1 \%)\end{array}$ \\
\hline TA & $\begin{array}{c}+4^{\circ} \mathrm{C} \\
\left( \pm 0,8^{\circ} \mathrm{C}\right)\end{array}$ & $\begin{array}{l}+300 \% \\
( \pm 60 \%)\end{array}$ & $\begin{array}{c}+50 \% \\
( \pm 10 \%)\end{array}$ & $\begin{array}{l}+20 \% \\
( \pm 4 \%)\end{array}$ \\
\hline
\end{tabular}

Tabla 5.2. Variables a modificar en ambas experiencias en los dos tipos de tratamientos (TB y TA), en relación a los canales $\mathbf{C}$. 
Las variables estudiadas en las experiencias de laboratorio son resumidas en la Tabla 5.3. Para más detalle sobre las metodologías individuales, ver Capítulo 3 - Metodologías.

Previamente a la inoculación de los canales, se analizaron los nutrientes con la finalidad de conocer la disponibilidad de los mismos proveniente de los arroyos seleccionados. También se realizó un análisis granulométrico para caracterizar el sustrato blando de ambos arroyos.

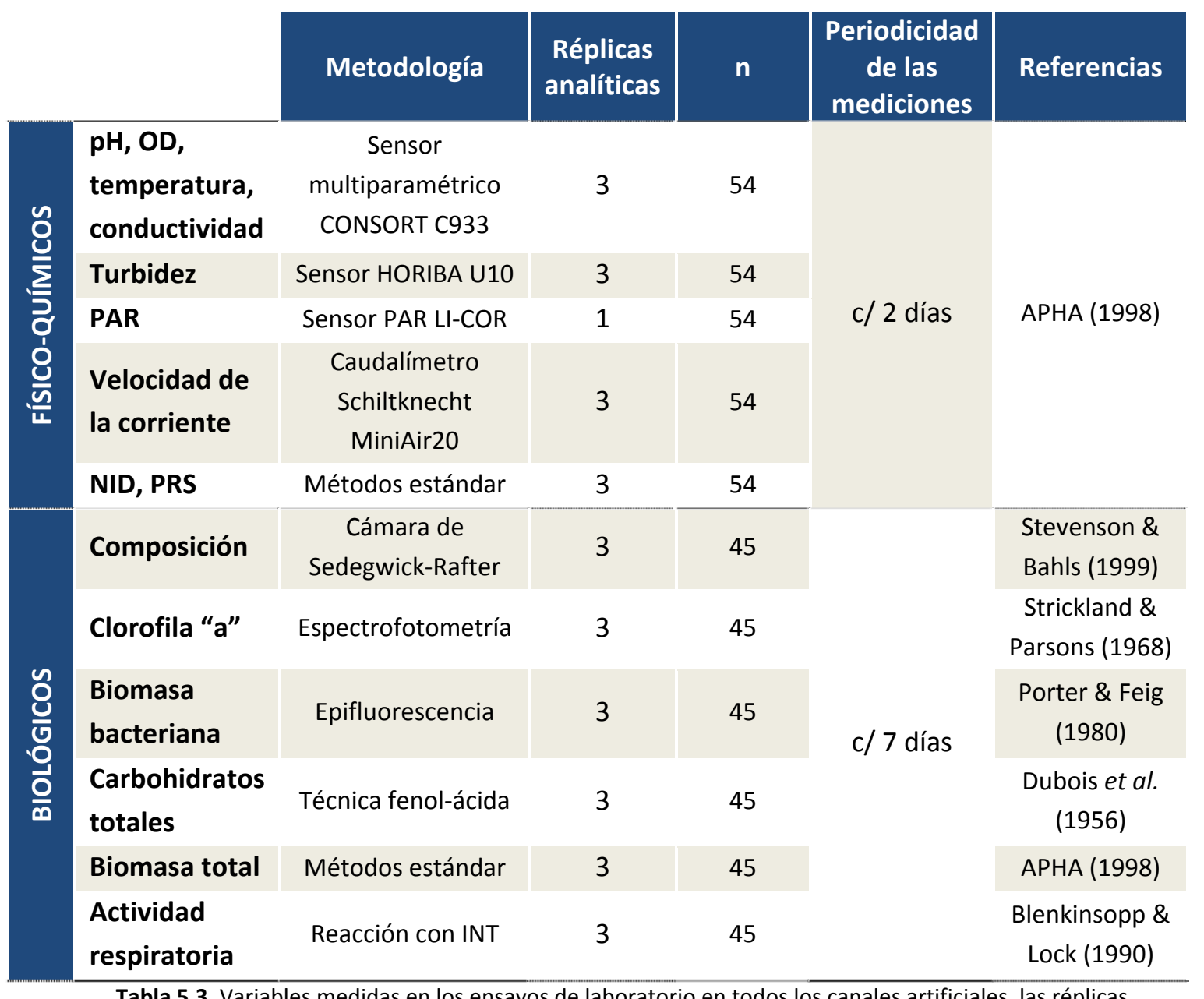

Tabla 5.3. Variables medidas en los ensayos de laboratorio en todos los canales artificiales, las réplicas analíticas tomadas de cada canal, el número total de datos de los nueve canales utilizados para los análisis estadísticos (n), la periodicidad aproximada para la colecta de muestras y breve referencia de la metodología utilizada. 
Para analizar los resultados obtenidos, se realizaron análisis de la varianza con medidas repetidas (RM ANOVA) entre los canales tratados y los canales control de cada experiencia (Winer, 1971). La esfericidad fue comprobada por el test de Mauchly, y se utilizó la corrección de Greenhouse-Geisser en el caso que no se cumpliese este supuesto (Greenhouse \& Geisser 1959).

En los casos que la interacción Tratamiento*Fecha resultó significativa $(p<0,05)$ se analizaron los resultados fecha por fecha con un ANOVA de un factor. Como medida estadística del efecto biológico se calculó Eta-cuadrado generalizado $\left(\eta_{\mathrm{G}}{ }^{2}\right)$.

Se controló periódicamente que las variables modificadas en los canales TB y TA estuvieran en los límites preestablecidos (Tabla 5.5), para lo cual se realizó un ANOVA de una vía entre los valores esperados y los obtenidos.

Para evaluar el cambio de la composición del biofilm en los distintos tratamientos se realizó un análisis de cluster utilizando las densidades de las especies presentes (productores primarios y consumidores) en los controles y tratamientos (C, TB y TA) durante las semanas de muestreo (1 a 6). El análisis se realizó con el software estadístico PAST ${ }^{\circledR}$, utilizando el método de la distancia mínima con la variable transformada a $L N(x+1)$, y la distancia Euclideana como medida de disimilitud.

Para conocer el porcentaje de disimilitud de las especies que conformaron los biofilms bajo las distintas condiciones experimentales, se realizaron análisis no paramétrico SIMPER (Similarity Percentage) con el software estadístico PAST $^{\circledR}$. Este análisis se basa en los porcentajes de disimilitud promedio calculada por el coeficiente Bray-Curtis y el aporte de cada especie a la segregación o no de un grupo en particular. La significancia global es evaluada por el test no paramétrico ANOSIM (Analysis of Similarity).

Para analizar cuáles de los taxones que conformaban el biofilm fueron los que aportaron el mayor porcentaje de disimilitud entre los distintos tratamientos, se realizaron análisis no paramétrico SIMPER (Similarity Percentage) con el software estadístico PAST ${ }^{\circledR}$. 


\subsection{RESULTADOS}

5.4.1 Parámetros físico-químicos

\section{Experiencia 1: Arroyo con bajo impacto antropogénico}

Los resultados de la granulometría mostraron que alrededor del 54\% de las partículas del sedimento sobre el que se desarrolló el biofilm tuvo un diámetro inferior o igual a $62 \mu \mathrm{m}$.

El pH varió entre 8,6 y 8,8 en los C, entre 8,5 y 8,8 en los TB, y entre 8,2 y 8,9 en los TA (Figura 5.1), y la significancia en la interacción Tratamiento*Fecha indica que el pH difirió entre los tratamientos y los controles (Tabla 5.4).

La conductividad varió entre 389,9 y $1152,2 \mu \mathrm{S} \mathrm{cm}^{-1}$ en los C, entre 474,6 y $1382,7 \mu \mathrm{S}$ $\mathrm{cm}^{-1}$ en los TB, y entre 826,9 y $2054,5 \mu \mathrm{S} \mathrm{cm}^{-1}$ en los TA (Figura 5.1). Los resultados muestran diferencias significativas entre los tratamientos y los controles, siendo mayores en ambos tratamientos en todas las fechas (Tabla 5.4, interacción Tratamiento*Fecha).

El oxígeno disuelto (OD) varió entre 7,7 y $7,8 \mathrm{mg} \mathrm{L}^{-1}$ en los $C$, entre 7,6 y $7,7 \mathrm{mg} \mathrm{L}^{-1}$ en los TB, y entre 7,6 y 7,7 mg L ${ }^{-1}$ en los TA (Figura 5.1). Los porcentajes de saturación tuvieron un mínimo de $89,8 \%$ (en los C) y un máximo de $103,4 \%$ (en los TA). Sólo excedieron el 100\% en los canales TA en las primeras semanas de la experiencia. El oxígeno disuelto fue significativamente diferente entre los tratamientos y los controles sólo en algunas fechas (Tabla 5.4, interacción Tratamiento*Fecha).

Los aumentos promedio en las variables manipuladas (Figura 5.2, 5.3) estuvieron dentro de los valores planificados para la experiencia ( $p>0,05$, Tabla 5.5). Es así que, con respecto a los canales $\mathrm{C}$, la temperatura en los canales TB y TA fue aumentada $1,1^{\circ} \mathrm{C}$ y $4,2^{\circ} \mathrm{C}$ respectivamente; la turbidez fue aumentada en los canales TB en un $16 \%$ y en los canales TA un 52\%; la velocidad del agua fue aumentada un $6 \%$ en los canales TB y un $24 \%$ en los canales TA; el PRS fue aumentado un 59\% en los canales TB y en los canales TA un 316\%; y el NID fue aumentado un $61 \%$ en los canales TB y un $282 \%$ en los canales TA. 
Los resultados de la granulometría mostraron que alrededor del $89 \%$ de las partículas del sedimento sobre el cual se desarrolló el biofilm en todos los canales tuvieron un diámetro promedio menor o igual a $62 \mu \mathrm{m}$.

El pH varió entre 8,8 y 9,4 en los C, entre 8,7 y 9,3 en los TB, y entre 8,2 y 9,2 en los TA (Figura 5.1). Los resultados del RM ANOVA muestran diferencias significativas entre los tratamientos y el control en algunas fechas (Tabla 5.4, interacción Tratamiento*Fecha).

La conductividad varió entre 1480,6 y $1806,7 \mu \mathrm{cm}^{-1}$ en los C, entre 1507,0 y $1888,7 \mu \mathrm{S} \mathrm{cm}^{-1}$ en los TB, y entre 1602,3 y $2256,3 \mu \mathrm{S} \mathrm{cm}^{-1}$ en los TA (Figura 5.1). Los resultados del ANOVA muestran diferencias significativas entre los tratamientos siendo mayores las conductividades en TB y TA que en los $\mathbf{C}$ en todas las fechas (Tabla 5.4, interacción Tratamiento*Fecha).

El oxígeno disuelto varió entre 5,5 y 6,0 $\mathrm{mg} \mathrm{L}^{-1}$ en los C, entre 5,5 y 5,8 $\mathrm{mg} \mathrm{L}^{-1}$ en los TB, y entre 5,4 y 5,9 $\mathrm{mg} \mathrm{L}^{-1}$ en los TA (Figura 5.1). El porcentaje de saturación de oxígeno varió entre $66,7 \%$ (en los C) hasta un máximo de 72,7\% (en los TA). En ningún caso el porcentaje de saturación alcanzó el 75\%. Los resultados del RM ANOVA muestran diferencias significativas en la concentración de oxígeno disuelto entre los tratamientos en algunas fechas (Tabla 5.4, interacción Tratamiento*Fecha).

Los aumentos promedio en las variables manipuladas (Figura 5.2, 5.3) estuvieron dentro de los valores planificados para la experiencia ( $p>0,05$, Tabla 5.5). Es así que, con respecto a los canales $\mathrm{C}$, la temperatura en los canales TB y TA fue aumentada $1,1^{\circ} \mathrm{C}$ y $6,2^{\circ} \mathrm{C}$ respectivamente; la turbidez fue aumentada en los canales TB en un $12 \%$ y en los canales TA un 61\%; la velocidad del agua fue aumentada un $9 \%$ en los canales TB y un $27 \%$ en los canales TA; el PRS fue aumentado un 43\% en los canales TB y en los canales TA un $286 \%$; y el NID fue aumentado un $53 \%$ en los canales TB y un $311 \%$ en los canales TA. 


\begin{tabular}{|c|c|c|c|c|c|c|}
\hline & & & & $\begin{array}{c}\text { M ANOV } \\
p\end{array}$ & & A posteriori \\
\hline & & & Tratamiento & Fecha & $\begin{array}{c}\text { Tratamiento } \\
\text { *Fecha }\end{array}$ & $\begin{array}{c}\text { SNK } \\
\text { Tratamiento }\end{array}$ \\
\hline & $\frac{\frac{1}{0}}{7}$ & $\mathrm{pH}$ & 0,00 & 0,03 & 0,00 & $\mathrm{C}>\mathrm{TB}>\mathrm{TA}$ \\
\hline$\stackrel{0}{ \pm}$ &.$\stackrel{\circ}{\underline{\Xi}}$ & Conductividad & 0,00 & 0,00 & 0,00 & $\mathrm{C}=\mathrm{TB}<\mathrm{TA}$ \\
\hline ֻั0 & 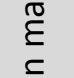 & OD & & & & \\
\hline .气 & $i 气$ & \% saturación & 0,79 & 0,02 & 0,00 & $\mathrm{C}=\mathrm{TB}=\mathrm{TA}$ \\
\hline$\stackrel{8}{\pi}$ & $\tilde{n}$ & Temperatura & 0,00 & 0,00 & 0,00 & $\mathrm{C}<\mathrm{TB}<\mathrm{TA}$ \\
\hline ธุ & $\begin{array}{l}\frac{\pi}{0} \\
\frac{\pi}{0}\end{array}$ & Turbidez & 0,38 & 0,00 & 0,00 & $\mathrm{C}=\mathrm{TB}<\mathrm{TA}$ \\
\hline 0 & $\overline{\bar{a}}$ & Velocidad & 0,00 & 0,04 & 0,00 & $\mathrm{C}<\mathrm{TB}<\mathrm{TA}$ \\
\hline & $\underset{\widetilde{c}}{\bar{c}}$ & PRS & 0,00 & 0,00 & 0,00 & $\mathrm{C}<\mathrm{TB}<\mathrm{TA}$ \\
\hline & & NID & 0,00 & 0,00 & 0,00 & $\mathrm{C}<\mathrm{TB}<\mathrm{TA}$ \\
\hline & $\bar{\sigma}$ & $\mathrm{pH}$ & 0,09 & 0,00 & 0,00 & $\mathrm{C}=\mathrm{TB}<\mathrm{TA}$ \\
\hline & $\frac{\pi}{3}$ & Conductividad & 0,00 & 0,00 & 0,00 & $\mathrm{C}=\mathrm{TB}<\mathrm{TA}$ \\
\hline 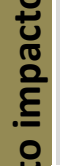 & 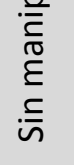 & $\begin{array}{l}\text { OD } \\
\text { \% saturación }\end{array}$ & 0,78 & 0,02 & 0,00 & $C>T B=T A$ \\
\hline$\frac{ \pm}{\pi}$ & $\tilde{n}$ & Temperatura & 0,00 & 0,00 & 0,00 & $\mathrm{C}<\mathrm{TB}<\mathrm{TA}$ \\
\hline ᄃิ & $\frac{\pi}{0}$ & PRS & 0,00 & 0,01 & 0,00 & $\mathrm{C}<\mathrm{TB}<\mathrm{TA}$ \\
\hline 0 & $\overline{\bar{a}}$ & NID & 0,03 & 0,22 & 0,00 & $\mathrm{C}<\mathrm{TB}<\mathrm{TA}$ \\
\hline & $\overline{\frac{\pi}{n}}$ & Turbidez & 0,01 & 0,01 & 0,00 & $\mathrm{C}<\mathrm{TB}<\mathrm{TA}$ \\
\hline & $\Sigma$ & Velocidad & 0,00 & 0,38 & 0,00 & $\mathrm{C}<\mathrm{TB}<\mathrm{TA}$ \\
\hline
\end{tabular}

Tabla 5.4. Tabla resumen del RM ANOVA para las variables físico-químicas de ambas experiencias. Se indican los valores de significancia para los factores Tratamiento, Fecha y su interacción. Los valores en negrita señalan las diferencias significativas, y el test $a$ posteriori Student-Neuman-Keuls en el factor Tratamiento. 


\begin{tabular}{|c|c|c|c|c|c|c|c|}
\hline & & \multirow{2}{*}{\multicolumn{3}{|c|}{ TB }} & \multirow{2}{*}{\multicolumn{3}{|c|}{ TA }} \\
\hline & & & & & & & \\
\hline & & Esperado & Obtenido & $p$ & Esperado & Obtenido & p \\
\hline \multirow{5}{*}{ 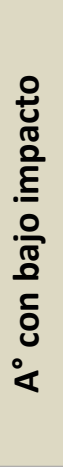 } & Temperatura $\left({ }^{\circ} \mathrm{C}\right)$ & $\begin{array}{c}+1^{\circ} \mathrm{C} \\
\left( \pm 0,2^{\circ} \mathrm{C}\right)\end{array}$ & $\begin{array}{l}+1,1^{\circ} \mathrm{C} \\
\left( \pm 1^{\circ} \mathrm{C}\right)\end{array}$ & 0,84 & $\begin{array}{c}+4^{\circ} \mathrm{C} \\
\left( \pm 0,8^{\circ} \mathrm{C}\right)\end{array}$ & $\begin{array}{l}+6,2^{\circ} \mathrm{C} \\
\left( \pm 2^{\circ} \mathrm{C}\right)\end{array}$ & 0,08 \\
\hline & Turbidez & $\begin{array}{l}+15 \% \\
( \pm 3 \%)\end{array}$ & $\begin{array}{c}+12,0 \% \\
( \pm 7 \%)\end{array}$ & 0,17 & $\begin{array}{c}+50 \% \\
( \pm 10 \%)\end{array}$ & $\begin{array}{l}+61 \% \\
( \pm 46 \%)\end{array}$ & 0,06 \\
\hline & Velocidad & $\begin{array}{l}+5 \% \\
( \pm 1 \%)\end{array}$ & $\begin{array}{c}+9 \% \\
( \pm 5,6 \%)\end{array}$ & 0,06 & $\begin{array}{l}+20 \% \\
( \pm 4 \%)\end{array}$ & $\begin{array}{c}+27 \% \\
( \pm 22 \%)\end{array}$ & 0,07 \\
\hline & PRS & $\begin{array}{l}+50 \% \\
( \pm 10 \%)\end{array}$ & $\begin{array}{c}+43 \% \\
( \pm 18 \%)\end{array}$ & 0,08 & $\begin{array}{l}+300 \% \\
( \pm 60 \%)\end{array}$ & $\begin{array}{l}+286 \% \\
( \pm 67 \%)\end{array}$ & 0,09 \\
\hline & NID & $\begin{array}{l}+50 \% \\
( \pm 10 \%)\end{array}$ & $\begin{array}{c}+53 \% \\
( \pm 26 \%)\end{array}$ & 0,43 & $\begin{array}{l}+300 \% \\
( \pm 60 \%)\end{array}$ & $\begin{array}{l}+311 \% \\
( \pm 51 \%)\end{array}$ & 0,14 \\
\hline \multirow{5}{*}{ 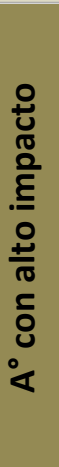 } & Temperatura $\left({ }^{\circ} \mathrm{C}\right)$ & $\begin{array}{c}+1^{\circ} \mathrm{C} \\
\left( \pm 0,2^{\circ} \mathrm{C}\right)\end{array}$ & $\begin{array}{l}+1,1^{\circ} \mathrm{C} \\
\left( \pm 1^{\circ} \mathrm{C}\right)\end{array}$ & 0,84 & $\begin{array}{c}+4^{\circ} \mathrm{C} \\
\left( \pm 0,8^{\circ} \mathrm{C}\right)\end{array}$ & $\begin{array}{l}+6,2^{\circ} \mathrm{C} \\
\left( \pm 2^{\circ} \mathrm{C}\right)\end{array}$ & 0,08 \\
\hline & Turbidez & $\begin{array}{l}+15 \% \\
( \pm 3 \%)\end{array}$ & $\begin{array}{c}+12,0 \% \\
( \pm 7 \%)\end{array}$ & 0,17 & $\begin{array}{c}+50 \% \\
( \pm 10 \%)\end{array}$ & $\begin{array}{c}+61 \% \\
( \pm 46 \%)\end{array}$ & 0,06 \\
\hline & Velocidad & $\begin{array}{l}+5 \% \\
( \pm 1 \%)\end{array}$ & $\begin{array}{c}+9 \% \\
( \pm 5,6 \%)\end{array}$ & 0,06 & $\begin{array}{l}+20 \% \\
( \pm 4 \%)\end{array}$ & $\begin{array}{l}+27 \% \\
( \pm 22 \%)\end{array}$ & 0,07 \\
\hline & PRS & $\begin{array}{l}+50 \% \\
( \pm 10 \%)\end{array}$ & $\begin{array}{l}+43 \% \\
( \pm 18 \%)\end{array}$ & 0,08 & $\begin{array}{l}+300 \% \\
( \pm 60 \%)\end{array}$ & $\begin{array}{l}+286 \% \\
( \pm 67 \%)\end{array}$ & 0,09 \\
\hline & NID & $\begin{array}{l}+50 \% \\
( \pm 10 \%)\end{array}$ & $\begin{array}{l}+53 \% \\
( \pm 26 \%)\end{array}$ & 0,43 & $\begin{array}{l}+300 \% \\
( \pm 60 \%)\end{array}$ & $\begin{array}{l}+311 \% \\
( \pm 51 \%)\end{array}$ & 0,14 \\
\hline
\end{tabular}

Tabla 5.5. Factores de incremento de las variables de los tratamientos en relación a los controles, y la significancia (p) del test ANOVA. 
En los canales artificiales se calcularon distintas variables hidrodinámicas para caracterizar el flujo en ambas experiencias (Tabla 5.6). El número de Froude indica un flujo subcrítico o lento en todos los canales, indicando una baja resistencia del diseño del canal artificial al pasaje del agua. De acuerdo al número de Reynolds el flujo fue turbulento, aunque la intensidad de dicha turbulencia es baja y cercana al $3 \%$.

\begin{tabular}{l|c|c|c|c|c|c|} 
& \multicolumn{3}{c|}{$\mathbf{A}^{\circ}$ con bajo impacto } & \multicolumn{3}{c|}{ A $^{\circ}$ con alto impacto } \\
\hline & C & TB & TA & C & TB & TA \\
\hline $\mathbf{N}^{\circ}$ de & 0,24 & 0,27 & 0,37 & 0,23 & 0,29 & 0,44 \\
Froude & $( \pm 0,00)$ & $( \pm 0,02)$ & $( \pm 0,02)$ & $( \pm 0,06)$ & $( \pm 0,07)$ & $( \pm 0,11)$ \\
& flujo lento & flujo lento & flujo lento & flujo lento & flujo lento & flujo lento \\
\hline \multirow{4}{*}{$\mathbf{N}^{\circ}$ de } & 397463 & 430888 & 539007 & 394382 & 432133 & 563540 \\
Reynolds & $( \pm 12686)$ & $( \pm 16471)$ & $( \pm 21318)$ & $( \pm 64027)$ & $( \pm 57116)$ & $( \pm 80056)$ \\
& flujo & flujo & flujo & flujo & flujo & flujo \\
& turbulento & turbulento & turbulento & turbulento & turbulento & turbulento \\
\hline Turbulencia & $3,2( \pm 0,00)$ & $3,1( \pm 0,00)$ & $3,1( \pm 0,00)$ & $3,2( \pm 0,00)$ & $3,1( \pm 0,00)$ & $3,0( \pm 0,00)$ \\
(\%) & baja & baja & baja & baja & baja & baja \\
& turbulencia & turbulencia & turbulencia & turbulencia & turbulencia & turbulencia \\
\hline
\end{tabular}

Tabla 5.6. Variables hidrodinámicas (promedio \pm DS) calculadas en los canales artificiales y su interpretación 


\section{$A^{\circ}$ con bajo impacto}

\section{$A^{\circ}$ con alto impacto}

$$
\text { - C TB - TA }
$$

pH

9,4
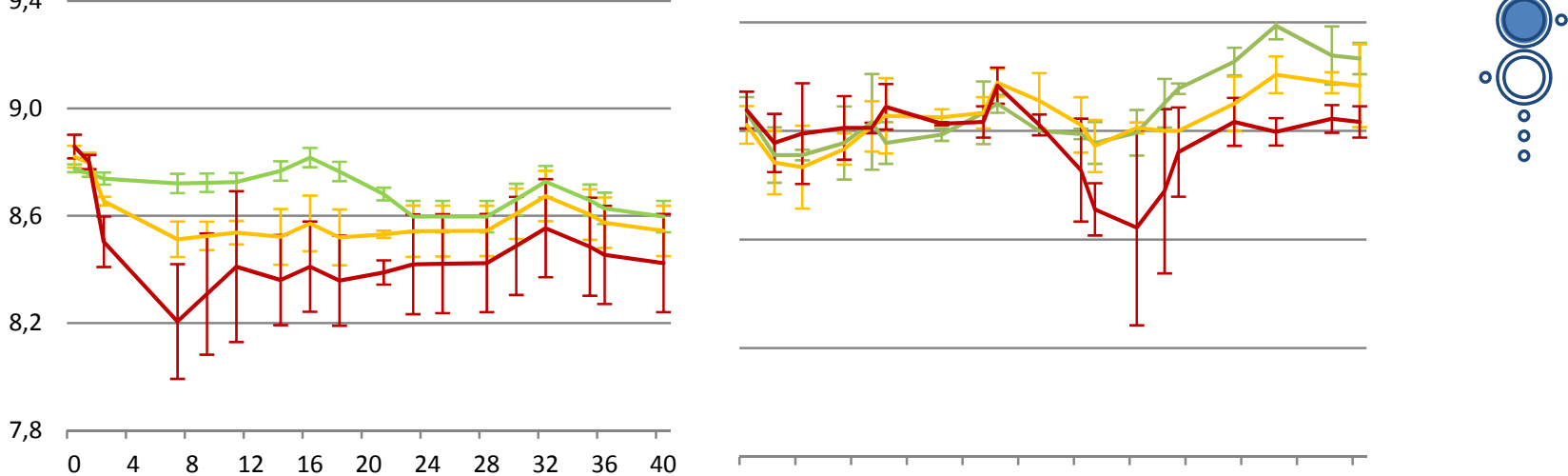

$\begin{array}{llllllllllll}0 & 4 & 8 & 12 & 16 & 20 & 24 & 28 & 32 & 36 & 40 & 44\end{array}$ CONDUCTIVIDAD
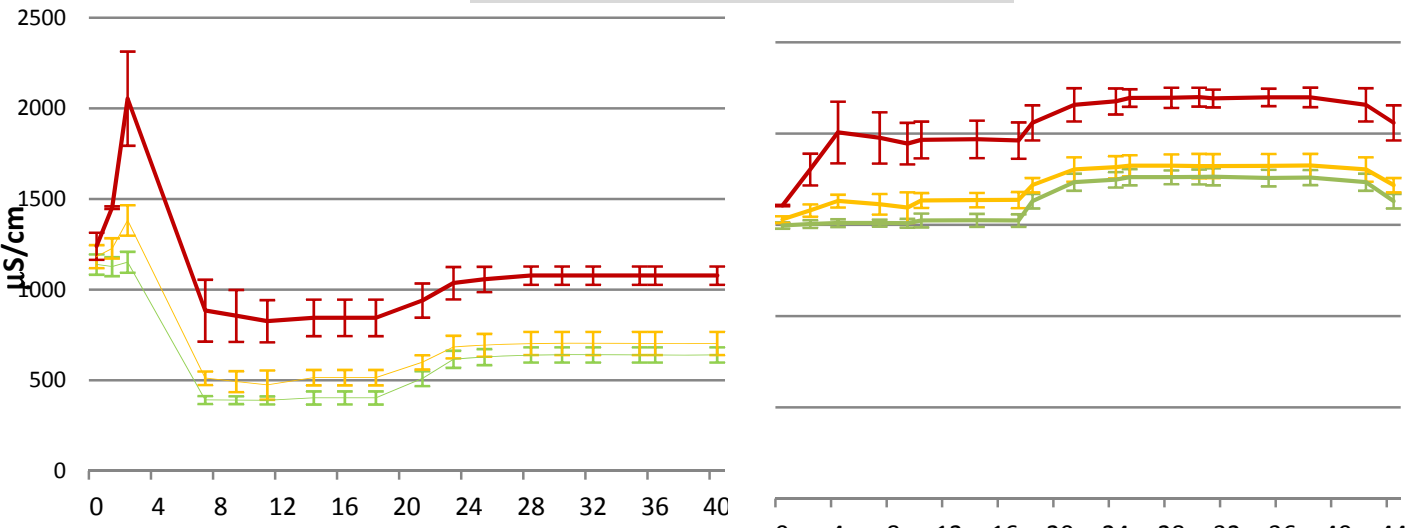

\section{CONCENTRACIÓN DE OXÍGENO DISUELTO}

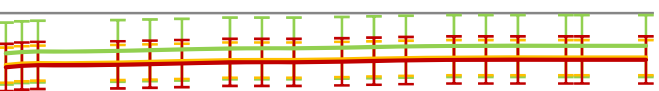

है

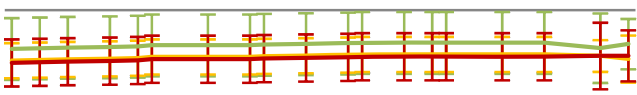

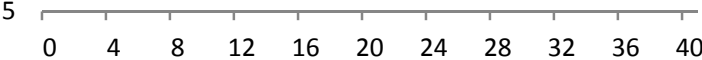

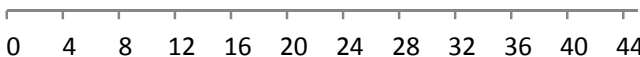

Figura 5.1. Variaciones en los parámetros físico-químicos de las variables no manipuladas durante las dos experiencias de laboratorio. Las barras verticales expresan desvío estándar. 


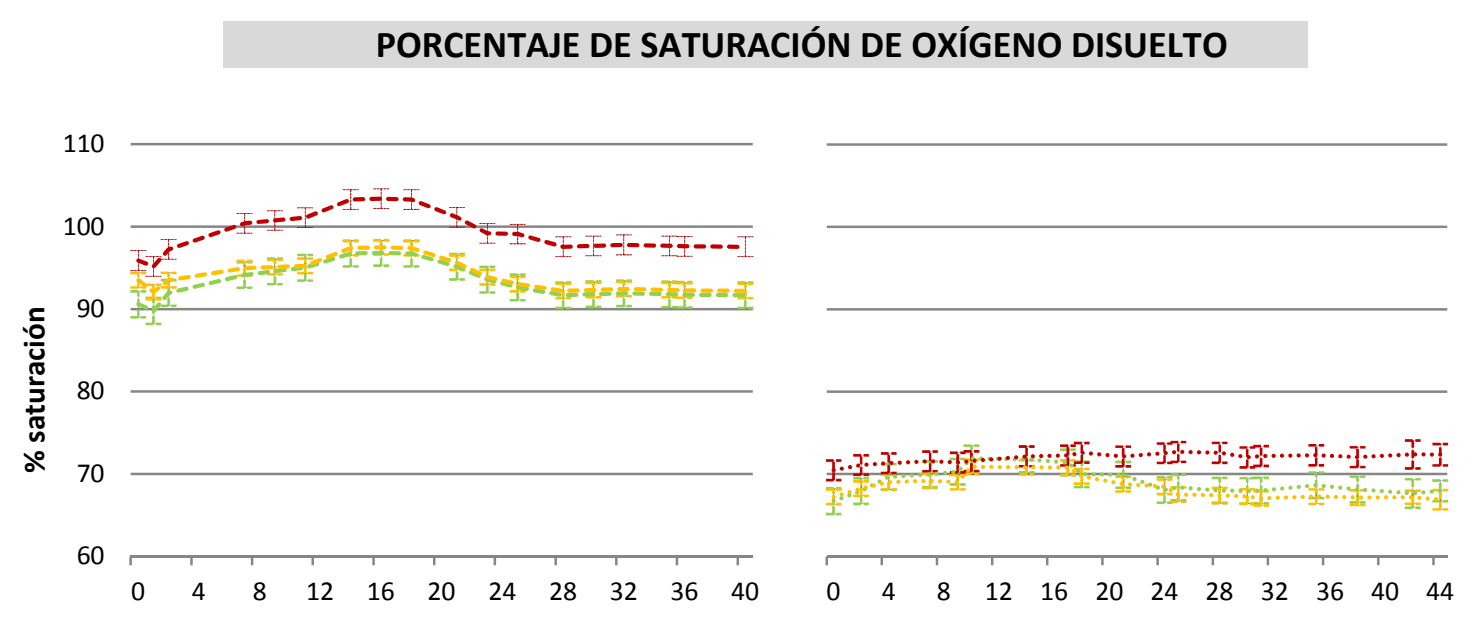

Figura 5.1 (Cont.). Variaciones en los parámetros físico-químicos de las variables no manipuladas durante las dos experiencias de laboratorio. Las barras verticales expresan desvío estándar. 


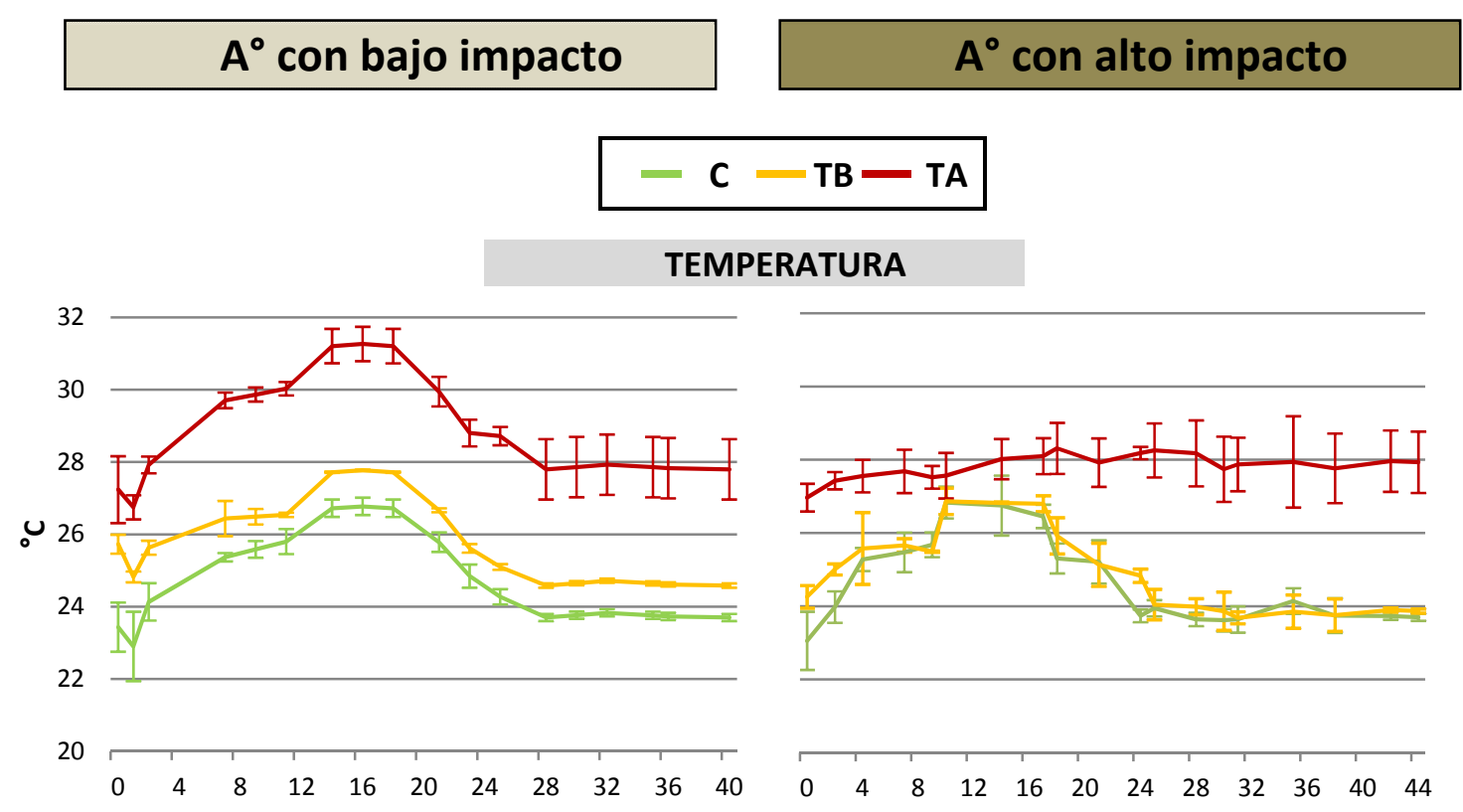

\section{TURBIDEZ}

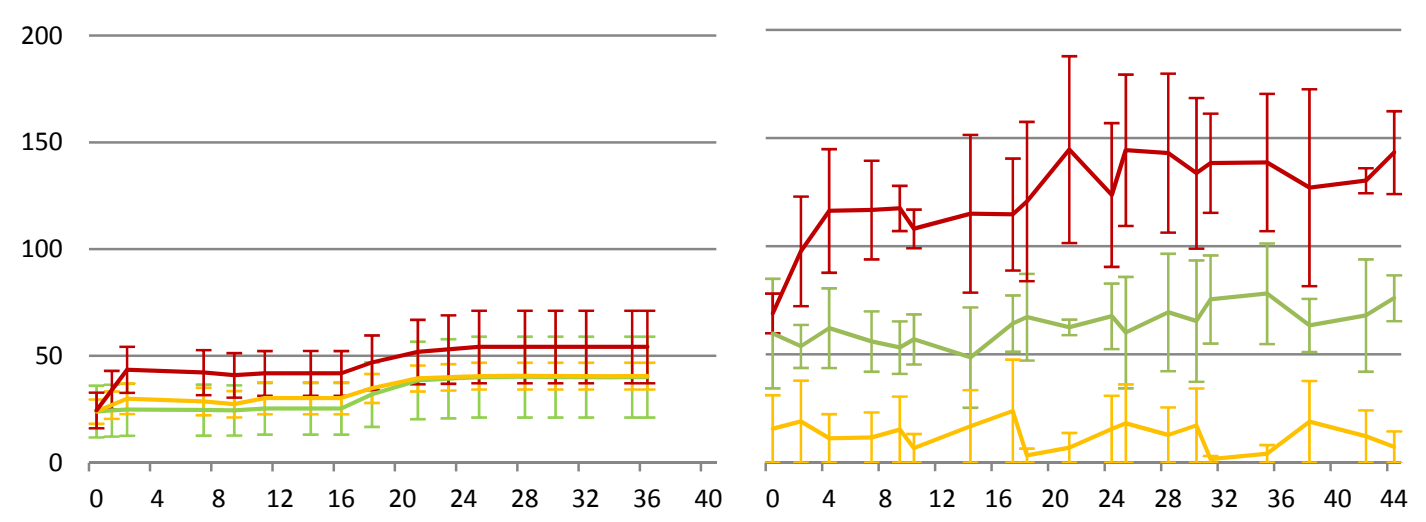

\section{VELOCIDAD DE AGUA}

0,65
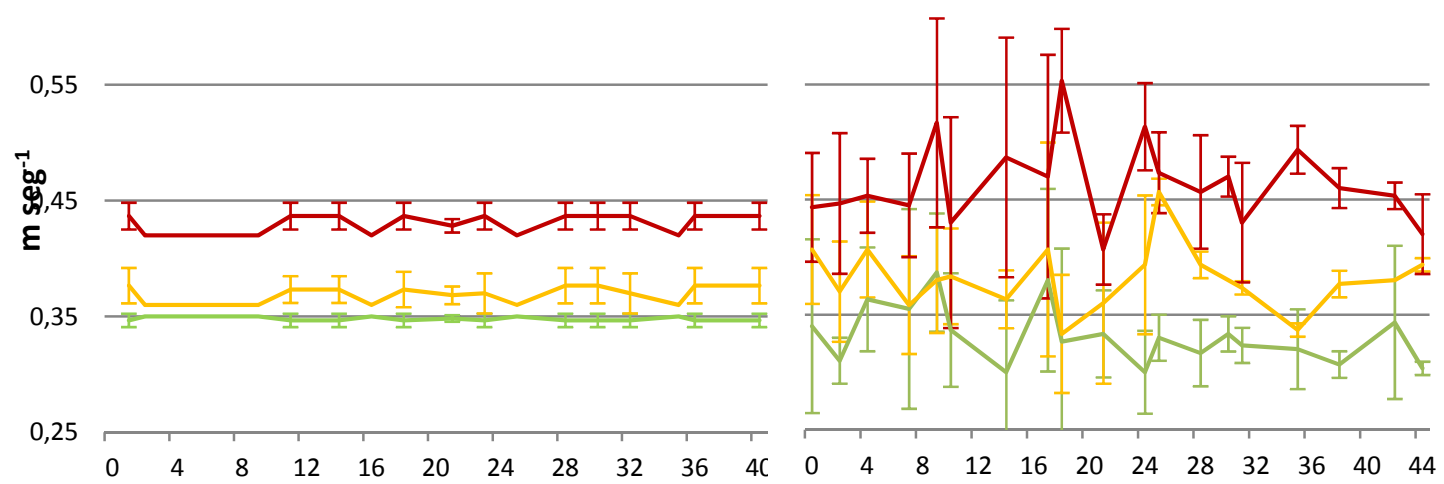

Figura 5.2. Variaciones en los parámetros físico-químicos de las variables manipuladas durante las dos experiencias de laboratorio. Las barras verticales expresan desvío estándar. 

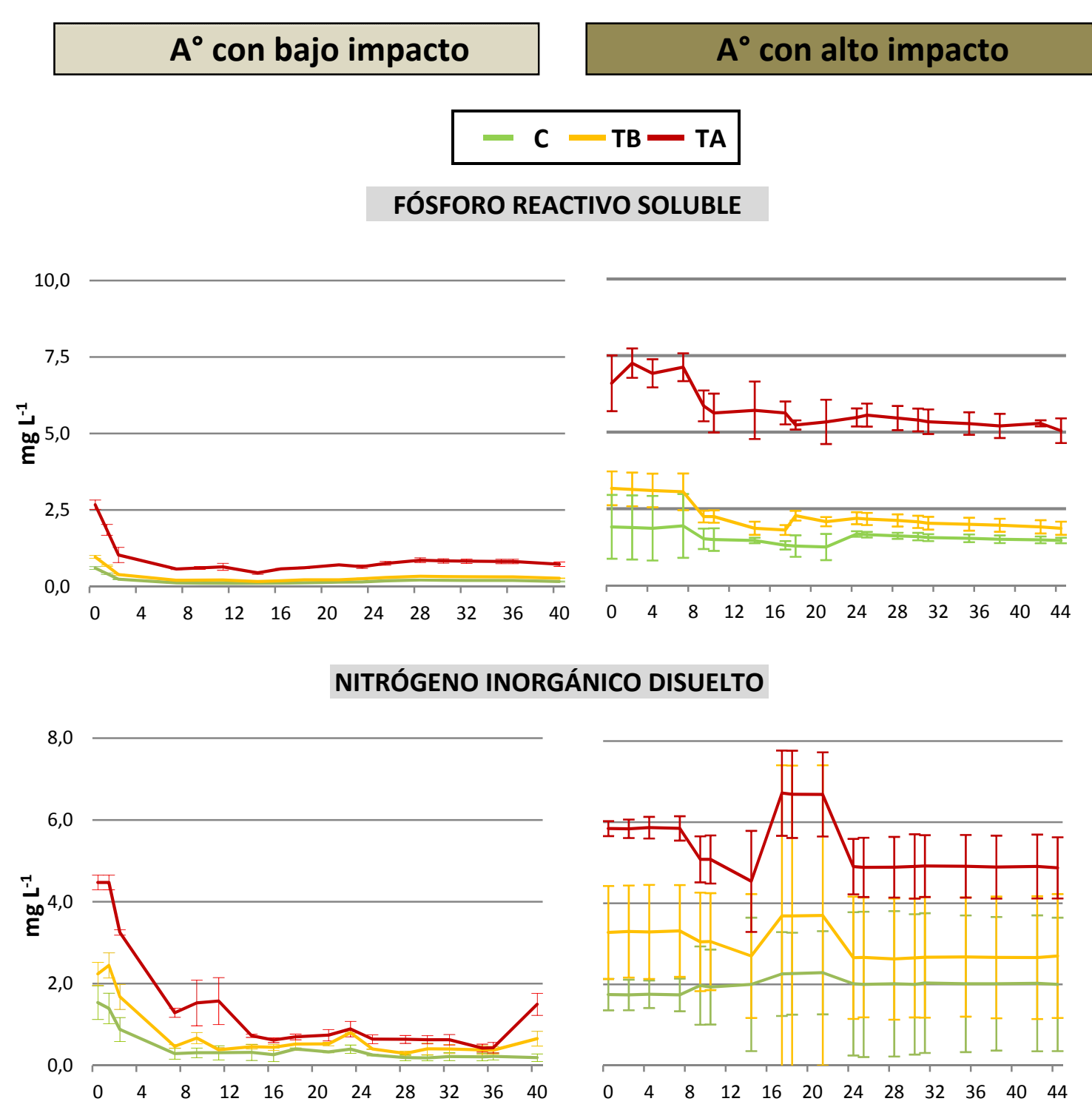

Figura 5.3. Variaciones en las concentraciones de nutrientes durante las dos experiencias de laboratorio. Las barras verticales expresan desvío estándar. 
En el biofilm del arroyo con bajo impacto antropogénico, la biomasa bacteriana varió poco hasta la cuarta semana, donde comenzó a aumentar significativamente en todos los canales, para luego disminuir hacia el final de la experiencia (Figura 5.4). Es de destacar que el incremento en la quinta semana fue registrada tanto en los tratamientos como en los controles (Tabla 5.9), y estuvo relacionada con un aumento del peso seco libre de cenizas. La variabilidad en la biomasa bacteriana no tuvo un fuerte efecto debido a los tratamientos $\left(\eta_{\mathrm{G}}{ }^{2}=\right.$ $0,01)$, aunque tuvo una variabilidad moderada entre las distintas fechas en todos los canales $\left(\eta_{\mathrm{G}}{ }^{2}=0,64\right)$.

En el biofilm del arroyo con alto impacto antropogénico, la biomasa bacteriana demostró una tendencia a aumentar desde el comienzo hasta el final de esta segunda experiencia en todos los canales (Figura 5.4), independientemente del tratamiento realizado (Tabla 5.9). Su variabilidad fue pequeña debida a los tratamientos aplicados $\left(\eta_{\mathrm{G}}{ }^{2}=0,05\right), \mathrm{y}$ exhibió una variación moderada entre las distintas fechas $\left(\eta_{\mathrm{G}}{ }^{2}=0,56\right)$. 

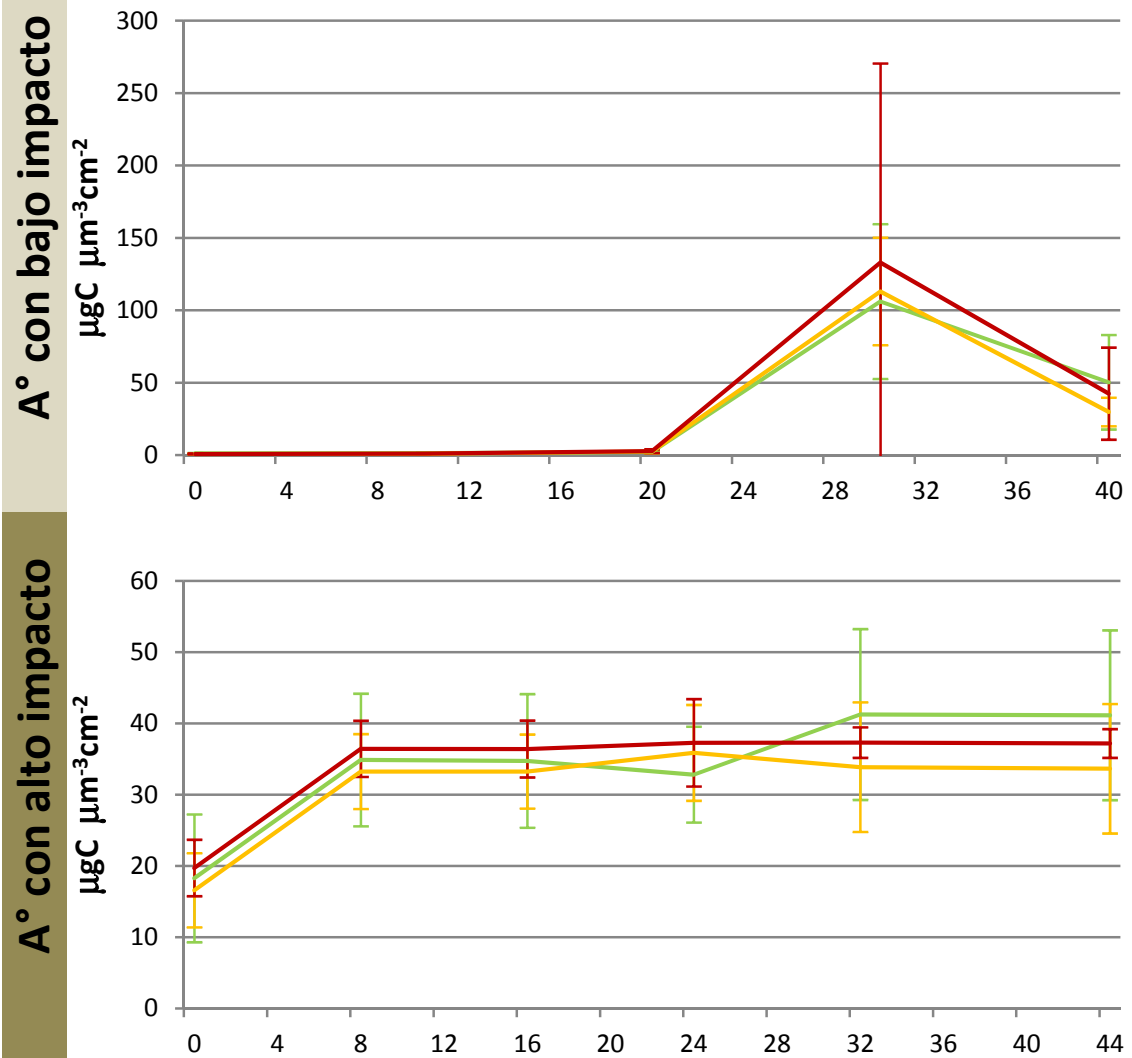

Figura 5.4. Promedios y desvíos estándar de la biomasa bacteriana en los tres tratamientos (C, TB y TA) durante las experiencias 
En el biofilm del arroyo con bajo impacto antropogénico, las variaciones de clorofila durante la experiencia fueron erráticas en todos los canales, no permitiendo establecer una tendencia clara entre los tratamientos (Figura 5.5, Tabla 5.9). Los tratamientos tuvieron un efecto biológico pequeño sobre la clorofila " $\mathrm{a}$ " $\left(\eta_{\mathrm{G}}{ }^{2}=0,09\right)$, que fue moderadamente variable entre las distintas fechas $\left(\eta_{\mathrm{G}}{ }^{2}=0,30\right)$.

Además, la concentración de clorofila "a" en los TB se correlacionó negativamente con la biomasa bacteriana $(-0,5482, p<0,05)$, y positivamente con la actividad respiratoria total $(r=0,5394 ; p<0,05)$.

En el biofilm del arroyo con alto impacto antropogénico, no fue posible establecer una tendencia de las variaciones de clorofila "a" entre los canales (Figura 5.5), aunque en los TA la concentración de clorofila "a" tuvo una correlación positiva con la de carbohidratos totales $(r=0,4802 ; p<0,05)$. En esta experiencia, la variabilidad en la clorofila "a" prácticamente no fue influenciada por los distintos tratamientos $\left(\eta_{G}{ }^{2}=0,01\right)$, mientras que su variabilidad a lo largo de la experiencia fue moderada $\left(\eta_{\mathrm{G}}{ }^{2}=0,24\right)$ (Tabla 5.9). 


$$
-\mathrm{C}-\mathrm{TB}-\mathrm{TA}
$$
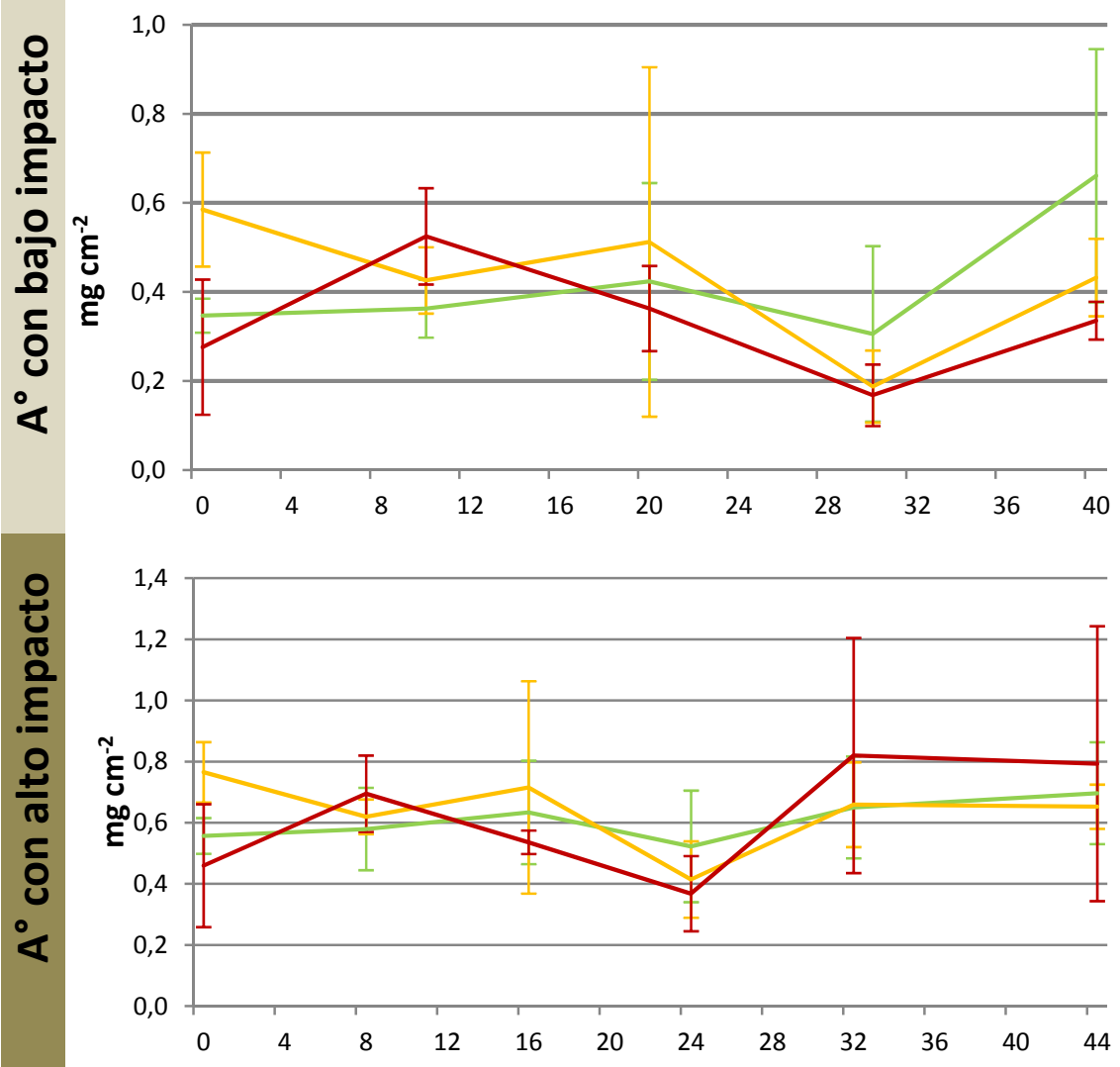

Figura 5.5. Promedios y desvíos estándar de la clorofila "a" obtenidos en los tres tratamientos (C, TB y TA) durante las experiencias. 
En el arroyo con bajo impacto antropogénico, se evidenció un importante aumento de la materia orgánica en la cuarta semana tanto en los TB como en los TA (Figura 5.6, Tabla 5.9), aunque no hubo diferencias significativas entre tratamientos en general. La variabilidad del PSCL fue pequeña debido a los tratamientos $\left(\eta_{\mathrm{G}}{ }^{2}=0,04\right)$, mientras que su variabilidad a lo largo de las distintas fechas fue moderada $\left(\eta_{\mathrm{G}}{ }^{2}=0,35\right)$.

En esta experiencia el peso seco libre de cenizas tuvo una correlación significativa con la biomasa bacteriana $(r=0,68 ; p<0,05)$. Ambas variables tuvieron un notable aumento en el día 30 en todos los canales.

En el arroyo con alto impacto antropogénico, el PSLC exhibió una disminución significativa de PSLC en todos los canales hacia el final de las experiencias (Figura 5.6, Tabla 5.9) Las variaciones del PSLC estuvieron relacionadas con los tratamientos de manera moderada $\left(\eta_{\mathrm{G}}{ }^{2}=0,07\right)$, al igual que su variabilidad a lo largo de la experiencia $\left(\eta_{\mathrm{G}}{ }^{2}=0,69\right)$ (Tabla 5.9). 

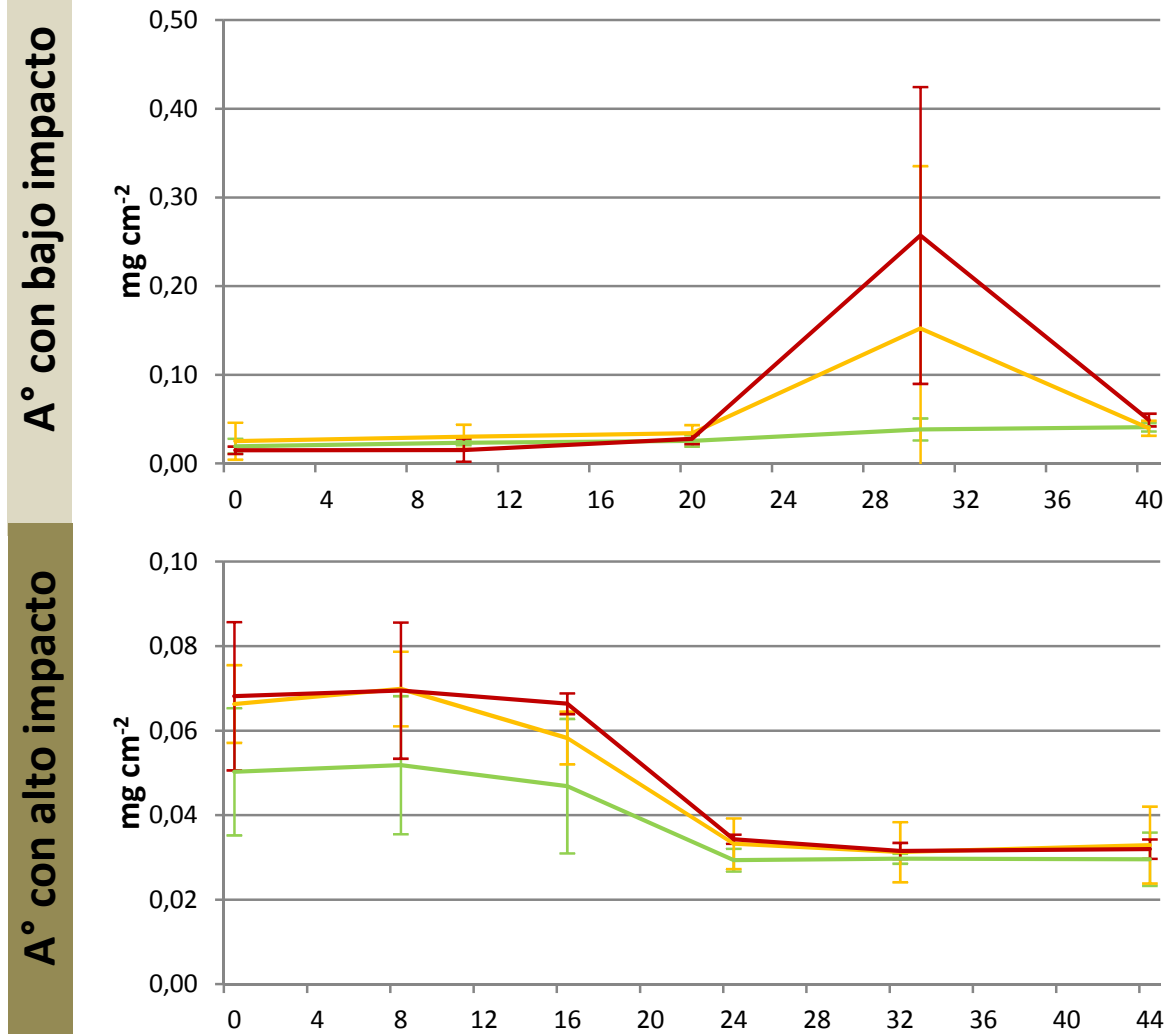

Figura 5.6. Promedios y desvíos estándar del peso seco libre de cenizas en los tres tratamientos (C, TB y TA) durante las experiencias 
En el arroyo con bajo impacto antropogénico, y al igual que el peso seco libre de cenizas, se evidenció un aumento del índice autotrófico en la cuarta semana de la experiencia en los TB y TA (Figura 5.7, Tabla 5.7). El análisis del RM ANOVA variable exhibe una interacción significativa (Tratamiento*Fecha), lo que indica que el índice autotrófico tuvo diferencias entre los tratamientos dependientes de la fecha. Los análisis a posteriori indican que en el día 30 los TA fueron significativamente mayores a C y TB (Tabla 5.7). La variabilidad del índice autotrófico debido a los tratamientos fue moderada $\left(\eta_{\mathrm{G}}{ }^{2}=0,22\right)$, mientras que tuvo una variabilidad alta entre las distintas fechas $\left(\eta_{\mathrm{G}}{ }^{2}=0,91\right)$.

En el arroyo con alto impacto antropogénico, a pesar de que no se encontraron diferencias significativas entre los tratamientos C, TB y TA (Figura 5.7, Tabla 5.9), tuvo una alta variación entre las distintas fechas $\left(\eta_{G}{ }^{2}=0,62\right)$, y esta variable fue menor en todos los tratamientos en los días 32 y 44 de la experiencia. 

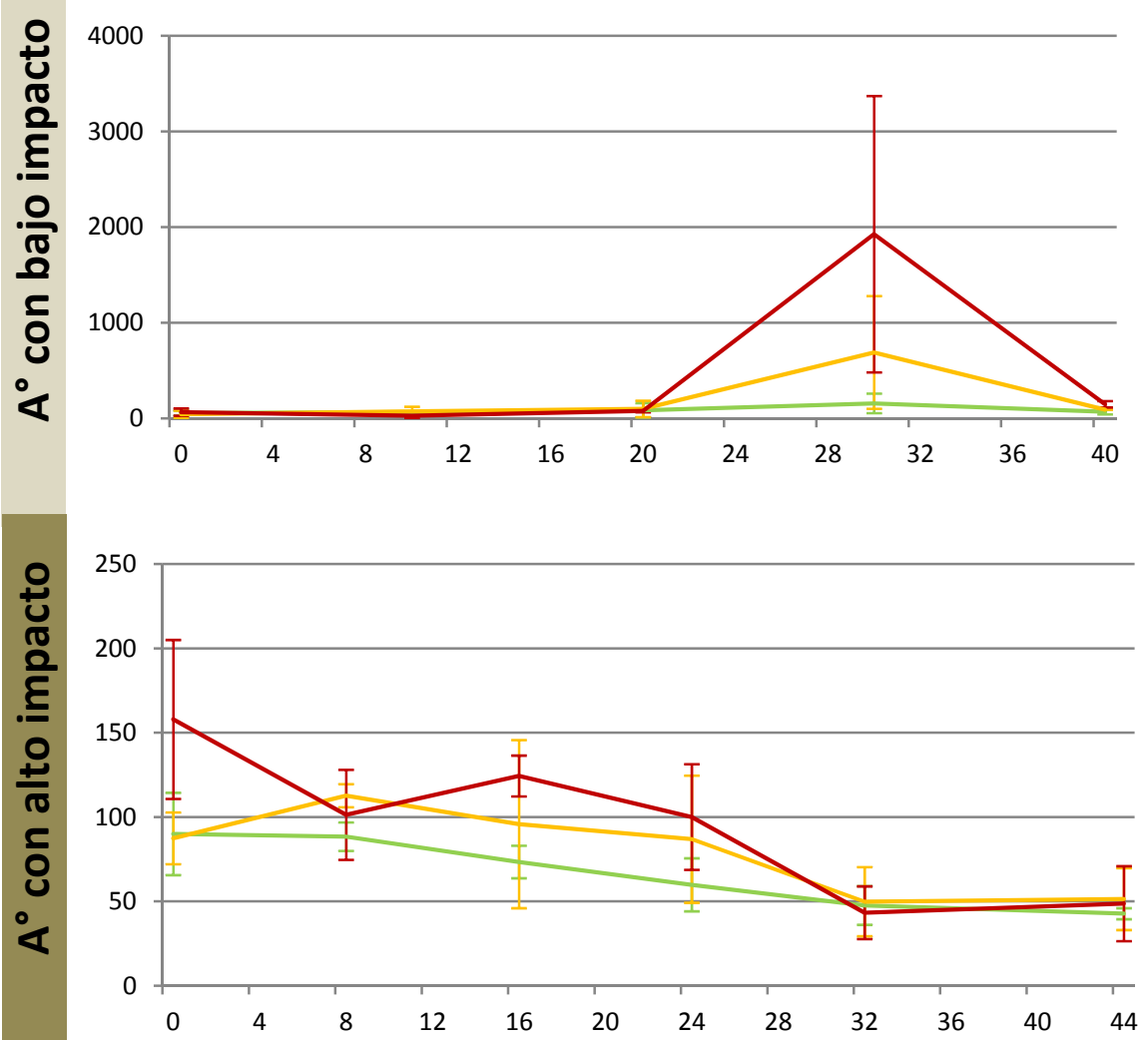

Figura 5.7. Promedios y desvíos estándar de la relación autótrofos/heterótrofos en los tres tratamientos (C, TB y TA) durante las experiencias

\begin{tabular}{c|ccc|c|c|} 
& \multicolumn{5}{|c}{ Análisis a posteriori } \\
& \multicolumn{5}{c}{ Tratamiento*Fecha } \\
\hline Día & $\mathbf{0}$ & $\mathbf{1 0}$ & $\mathbf{2 0}$ & $\mathbf{3 0}$ & $\mathbf{4 0}$ \\
C & $\mathrm{a}$ & $\mathrm{a}$ & $\mathrm{a}$ & $\mathrm{a}$ & $\mathrm{a}$ \\
TB & $\mathrm{a}$ & $\mathrm{a}$ & $\mathrm{a}$ & $\mathrm{a}$ & $\mathrm{a}$ \\
TA & $\mathrm{a}$ & $\mathrm{a}$ & $\mathrm{a}$ & $\mathrm{b}$ & $\mathrm{a}$ \\
\hline
\end{tabular}

Tabla 5.7. Resumen de los análisis a posteriori para la interacción Tratamiento*Fecha en el experimento del arroyo con bajo impacto. 
En el arroyo con bajo impacto antropogénico, la actividad respiratoria tuvo una tendencia menor en los TB y TA con respecto a los $\mathbf{C}$ al comienzo de la experiencia, que se revirtió a partir de la tercera semana de muestreo, con la disminución de dicha actividad en los C (Figura 5.8). El análisis del RM ANOVA variable exhibe una interacción significativa (Tratamiento*Fecha), por lo que la actividad respiratoria tuvo diferencias entre los tratamientos dependientes de la fecha. Los análisis a posteriori indican que en el día 10 los $\mathbf{C}$ fueron significativamente mayores a TB y TA, mientras que en el día 30 los C fueron menores a los tratamientos (Tabla 5.8).

El $\eta_{\mathrm{G}}{ }^{2}$ para esta variable indica una variabilidad moderada en la actividad respiratoria relacionada a los tratamientos $\left(\eta_{\mathrm{G}}{ }^{2}=0,18\right)$, al igual que la variación en el tiempo a lo largo de la experiencia $\left(\eta_{\mathrm{G}}{ }^{2}=0,30\right)$ (Tabla 5.9). Por otro lado la actividad respiratoria en los TB se correlacionó positivamente con la concentración de clorofila "a".

En el arroyo con alto impacto antropogénico, los canales TB y TA tuvieron una actividad respiratoria ligeramente inferior a los C (Figura 5.8), aunque no se encontraron diferencias significativas (Tabla 5.9). La variación en la actividad respiratoria estuvo poco influenciada por los tratamientos $\left(\eta_{\mathrm{G}}{ }^{2}=0,03\right)$, y por el factor fecha $\left(\eta_{\mathrm{G}}{ }^{2}=0,07\right)$. 

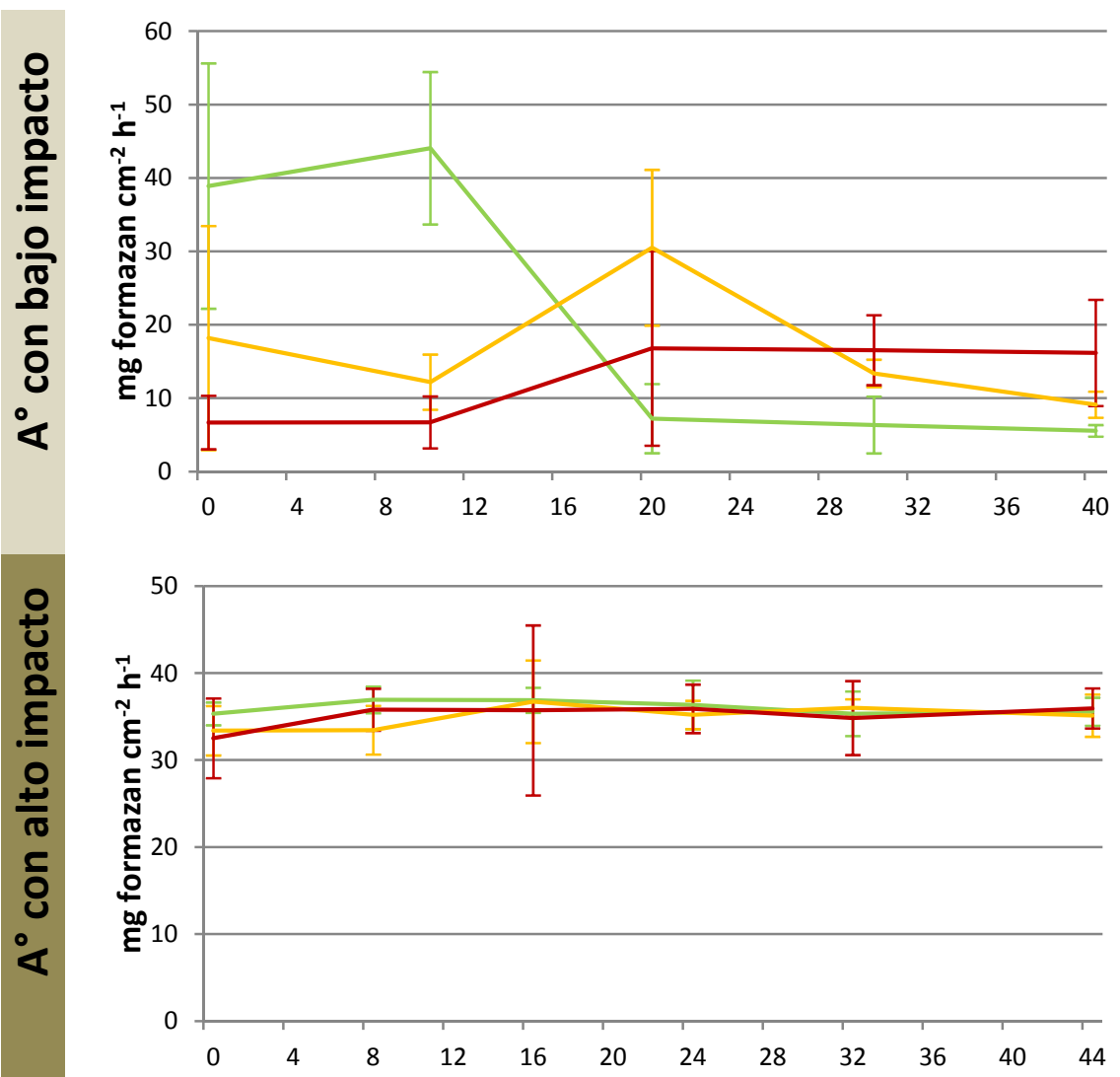

Figura 5.8. Promedios y desvíos estándar de la concentración de INT-formazan en los tres tratamientos (C, TB y TA) durante las experiencias

\section{Análisis a posteriori}

\begin{tabular}{c|ccccc} 
Día & $\mathbf{0}$ & $\mathbf{1 0}$ & $\mathbf{2 0}$ & $\mathbf{3 0}$ & $\mathbf{4 0}$ \\
$\mathrm{C}$ & $\mathrm{a}$ & $\mathrm{a}$ & $\mathrm{a}$ & $\mathrm{a}$ & $\mathrm{a}$ \\
TB & $\mathrm{ab}$ & $\mathrm{b}$ & $\mathrm{a}$ & $\mathrm{ab}$ & $\mathrm{a}$ \\
TA & $\mathrm{b}$ & $\mathrm{b}$ & $\mathrm{a}$ & $\mathrm{c}$ & $\mathrm{a}$
\end{tabular}

Tabla 5.8. Resumen de los análisis a posteriori para la interacción Tratamiento*Fecha en el experimento del arroyo con bajo impacto. 
En el arroyo con bajo impacto antropogénico, la concentración de carbohidratos totales aumentó en todos los canales a partir de la cuarta semana de muestreo (Figura 5.9), pero sin diferencias significativas entre los tratamientos y controles (Tabla 5.9).

El $\eta_{G}{ }^{2}$ indica que la variabilidad en los carbohidratos debida a los tratamientos es prácticamente inexistente $\left(\eta_{\mathrm{G}}{ }^{2}=0,01\right)$, aunque fue un parámetro que tuvo una gran variación en todos los canales en el factor Tiempo $\left(\eta_{\mathrm{G}}{ }^{2}=0,79\right)$.

En el arroyo con alto impacto antropogénico, la tendencia de los promedios en la concentración de carbohidratos totales fue en aumento hacia la finalización de la experiencia en todos los canales a la vez (Figura 5.9), aunque no hubo diferencias significativas entre los tratamientos y los controles, ni entre las distintas fechas de muestreo (Tabla 5.9).

Al igual que en la experiencia anterior, la variabilidad en este parámetro vinculada a los tratamientos fue muy baja $\left(\eta_{\mathrm{G}}{ }^{2}=0,01\right)$, y no fue muy variable a lo largo de toda la experiencia $\left(\eta_{\mathrm{G}}{ }^{2}=0,06\right)$. Además, en este caso la concentración de carbohidratos totales tuvo una correlación positiva con la de clorofila "a" $(r=-0,3398 ; p<0,05)$. 

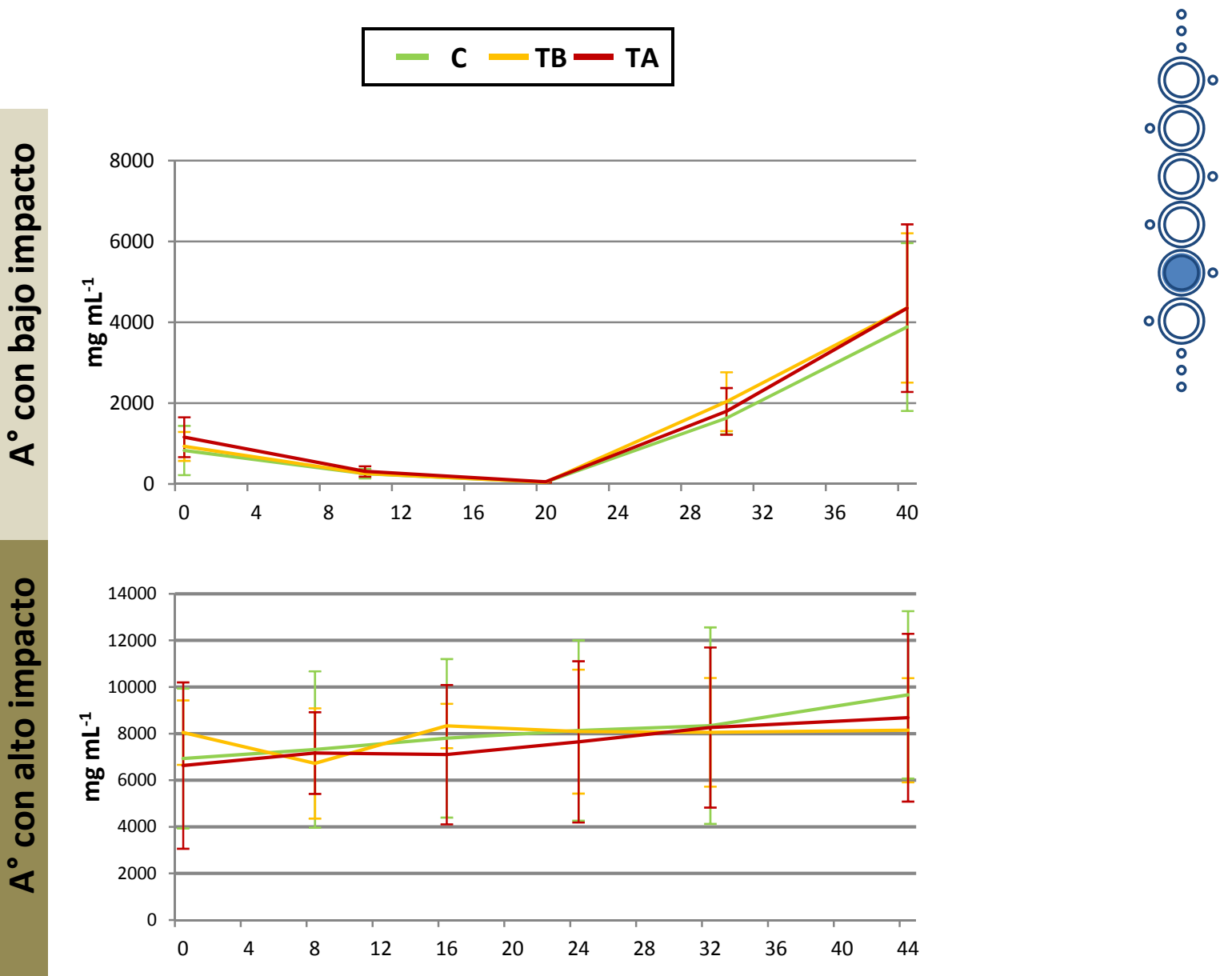

Figura 5.9. Promedios y desvíos estándar de la concentración de carbohidratos en los tres tratamientos (C, TB y TA) durante las experiencias. 


\begin{tabular}{|c|c|c|c|c|c|c|}
\hline & & & \multicolumn{3}{|c|}{ RM ANOVA } & \multirow[t]{2}{*}{$\begin{array}{c}\text { Tests a posteriori } \\
\text { SNK }\end{array}$} \\
\hline & & & $\mathbf{T}$ & $\mathbf{F}$ & $\mathbf{T}^{*} \mathbf{F}$ & \\
\hline \multirow{13}{*}{ 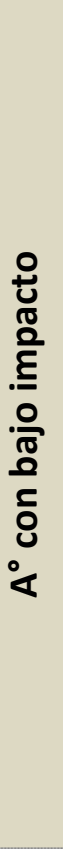 } & \multirow{2}{*}{ Clorofila “a” } & $p$ & 0,29 & 0,08 & 0,25 & \multirow[b]{2}{*}{--} \\
\hline & & $\eta_{G}{ }^{2}$ & 0,09 & 0,30 & 0,30 & \\
\hline & \multirow{2}{*}{ Biomasa bacteriana } & $p$ & 0,90 & 0,01 & 0,92 & \multirow[b]{2}{*}{$30>0=10=20=40$} \\
\hline & & $\eta_{G}{ }^{2}$ & 0,01 & 0,64 & 0,03 & \\
\hline & \multirow{2}{*}{ Peso seco libre de cenizas } & $\mathrm{p}$ & 0,27 & 0,04 & 0,25 & $\mathbf{F}$ \\
\hline & & $\eta_{G}{ }^{2}$ & 0,10 & 0,46 & 0,32 & $30>0=10=20=40$ \\
\hline & Índice autotrófico & $\mathrm{p}_{\eta^{2}}{ }^{2}$ & $\begin{array}{l}0,07 \\
0,22\end{array}$ & $\begin{array}{l}0,00 \\
0,91\end{array}$ & $\begin{array}{l}0,00 \\
0,90\end{array}$ & $\begin{array}{l}T^{*} \mathbf{F} \\
\begin{array}{l}\text { 0: } \mathrm{C}=\mathrm{TB}=\mathrm{TA} \\
\text { 10: } \mathrm{C}=\mathrm{TB}=\mathrm{TA} \\
\text { 20: } \mathrm{C}=\mathrm{TB}=\mathrm{TA} \\
\text { 30: } \mathrm{C}=\mathrm{TB}<\mathrm{TA} \\
\text { 40: } \mathrm{C}=\mathrm{TB}=\mathrm{TA}\end{array}\end{array}$ \\
\hline & \multirow{4}{*}{ Actividad respiratoria } & \multirow{4}{*}{$\begin{array}{c}\mathrm{p} \\
\eta_{G}{ }^{2}\end{array}$} & \multirow{4}{*}{$\begin{array}{l}0,30 \\
0,18\end{array}$} & \multirow{4}{*}{$\begin{array}{l}0,03 \\
0,30\end{array}$} & \multirow{4}{*}{$\begin{array}{l}0,00 \\
0,69\end{array}$} & $\mathrm{~T}^{*} \mathrm{~F}$ \\
\hline & & & & & & $\begin{array}{l}0: C=T B<T B=T A \\
10 \cdot C<T B=T A\end{array}$ \\
\hline & & & & & & 20: $C=T B=T A$ \\
\hline & & & & & & $\begin{array}{l}\text { 30: } C=T B<T B=T A \\
\text { 40: } C=T B=T A\end{array}$ \\
\hline & \multirow{2}{*}{ Carbohidratos totales } & $p$ & 0,90 & 0,00 & 0,94 & \multirow{2}{*}{$40>30>0=10=20$} \\
\hline & & $\eta_{G}{ }^{2}$ & 0,01 & 0,79 & 0,02 & \\
\hline \multirow{6}{*}{ 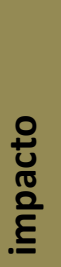 } & \multirow{2}{*}{ Clorofila “a" } & $p$ & 0,90 & 0,14 & 0,53 & \multirow{2}{*}{--- } \\
\hline & & $\eta_{G}{ }^{2}$ & 0,01 & 0,24 & 0,18 & \\
\hline & \multirow{2}{*}{ Biomasa bacteriana } & $p$ & 0,71 & 0,00 & 0,80 & \multirow[b]{2}{*}{$0<8=16=24=32=44$} \\
\hline & & $\eta_{G}{ }^{2}$ & 0,05 & 0,56 & 0,07 & \\
\hline & \multirow{2}{*}{ Peso seco libre de cenizas } & $p$ & 0,19 & 0,00 & 0,41 & \multirow{2}{*}{$\begin{array}{l}\text { F } \\
\quad 0=8=16>24=32=44\end{array}$} \\
\hline & & $\eta_{G}{ }^{2}$ & 0,25 & 0,77 & 0,16 & \\
\hline \multirow{6}{*}{ 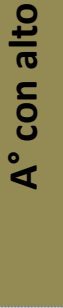 } & \multirow{2}{*}{ Índice autotrófico } & $p$ & 0,15 & 0,00 & 0,24 & $\mathbf{F}$ \\
\hline & & $\eta_{G}{ }^{2}$ & 0,26 & 0,62 & 0,30 & $0=8=16=24<32=44$ \\
\hline & Actividad respiratoria & $p$ & 0,63 & 0,60 & 0,94 & -- \\
\hline & Activiuad respiracorid & $\eta_{G}{ }^{2}$ & 0,03 & 0,07 & 0,06 & --- \\
\hline & Carbohidratos & $p$ & 0,97 & 0,41 & 0,87 & --- \\
\hline & 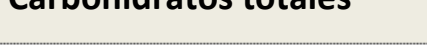 & $\eta_{G}{ }^{2}$ & 0,01 & 0,06 & 0,02 & - \\
\hline
\end{tabular}

Tabla 5.9. Valores de $p$ obtenidos del RM ANOVA con dos factores - Tratamiento (T) y Fecha (F), su interacción ( $\mathrm{T} * \mathrm{~F})$ para ambas experiencias, y las medidas de efecto biológico $\left(\eta_{\mathrm{G}}{ }^{2}\right)$. Se indican los resultados de los test a posteriori Student-Neuman-Keuls en casos con diferencias significativas $(p<0,05$, valores en negrita, los números representan días). 
En el biofilm del arroyo con bajo impacto antropogénico se reconocieron 108 taxones entre productores primarios y consumidores (Anexo, Tabla Extendida 9). El biofilm estuvo dominado numéricamente por diatomeas (Figura 5.10), siendo las más abundantes Surirella linearis, Denticula elegans, Navicula erifuga, Nitzschia frustulum, Placoneis clementis, Rhoicosphenia abbreviata y Surirella ovalis y por la cianobacteria Oscillatoria tenuissima. Entre los consumidores los grupos mejor representados fueron los protozoos como Arcella discoides y los copepoditos.

La riqueza específica, calculada utilizando las densidades tanto de las algas y los consumidores, varió entre 20 y 32 en los C, entre 18 y 31 en los TB y entre 10 y 36 en los TA. En los canales TA la riqueza disminuyó hacia el final de la experiencia $(p<0,05)$, mientras que fue similar en los demás canales. El índice de diversidad de Shannon $(H)$ varió entre 2,0 y 2,5 en los C, entre 1,7 y 2,2 en los TB, y entre 1,0 y 2,5 en los TA (Figura 5.11). Al igual que la riqueza específica, el índice disminuyó en los canales TA hacia el final de la experiencia $(p<0,05)$, mientras que en los demás canales se mantuvo sin mayores variaciones.

El resultado del análisis de cluster entre las densidades de los taxones (productores primarios y consumidores) en los distintos tratamientos (C, TB y TA) y entre las distintas fechas de muestreo (1 a 6) se exhibe en la Figura 5.12. Se evidencian tres grandes grupos: un grupo incluye las muestras de las semanas 1 y 2; otro grupo las semanas 3 y 4; y el último grupo las semanas 5 y 6 . Asimismo, dentro de cada uno de estos grupos, es en general mayor la similitud entre los TA y TB que con el C.

Por otro lado, los resultados del análisis (SIMPER) para la experiencia 1 evidenciaron un porcentaje de disimilitud entre los tratamientos con los controles del 50,3\%. Cabe destacar que el aporte individual de cada taxón nunca superó el 3,2\% (Tabla 5.10) y que el 50\% de la disimilitud total entre los tratamientos fue alcanzada con 21 taxones. Es así que, por ejemplo, Oscillatoria tenuissima, Nitzschia linearis, Diadesmis confervacea, Placoneis placentula, Sellaphora seminulum y Navicula arvensis contribuyen con el 17,5\% de las diferencias entre los tratamientos y los controles.

En el biofilm del arroyo con alto impacto antropogénico se reconocieron 62 taxones productores primarios y consumidores (Anexo, Tabla Extendida 10). La comunidad fue dominada numéricamente por cianobacterias (Figura 5.10), perteneciendo los taxones más abundantes a los géneros Oscillatoria y Lyngbya, y los consumidores más abundantes fueron 
los ciliados. También tuvieron una importante representación las clorofitas planctónicas, siendo sus especies más abundantes Eutetramorus sp., y Dictyosphaerium pulchellum.

La riqueza específica, calculada utilizando las densidades tanto de algas como de consumidores, varió entre 17 y 24 en los C, entre 13 y 22 en los TB y entre 16 y 22 en los TA. En general la riqueza se mantuvo constante a lo largo de la experiencia, y disminuyó levemente hacia el final de la misma en todos los canales. El índice de diversidad de Shannon (H) varió entre 1,46 y 1,54 en los C, entre 1,2 y 1,9 en los TB, y entre 1,3 y 1,8 en los TA (Figura 5.11). En todos los canales la diversidad se mantuvo invariante, y no se encontraron diferencias significativas a lo largo de la experiencia.

El resultado del análisis de clúster entre las densidades de los taxones (productores primarios y consumidores) en los distintos tratamientos (C, TB y TA) y entre las distintas semanas de muestreo ( 1 a 5 ) se exhibe en la Figura 5.13. En una primera instancia hay una separación de los datos obtenidos en la semana 1 con el resto de las semanas. Los TB y TA se diferenciaron de los $C$ en las semana 2 . En las semanas 3 y 4 los resultados son más homogéneos entre todos los canales, en tanto que en la semana 5 los tratamientos TB y TA se vuelven a diferenciar de los $\mathrm{C}$.

Los resultados del análisis SIMPER para la experiencia 2 evidenciaron un porcentaje de disimilitud entre los tratamientos del 32,8\%. Al igual que en la experiencia 1, la disimilitud ente los tratamientos y controles fue causada por numerosos taxones, y el $50 \%$ de la disimilitud total entre los grupos fue alcanzado con tan sólo 10 taxones (Tabla 5.10). Es así que, por ejemplo, Lyngbya sp., Oscillatoria sp., Nitzschia amphibia, Caloneis bacillum, Achnanthes exigua, Amphora montana y Achnanthes lanceolata contribuyen con el $27,9 \%$ de las diferencias entre los tratamientos y los controles. 

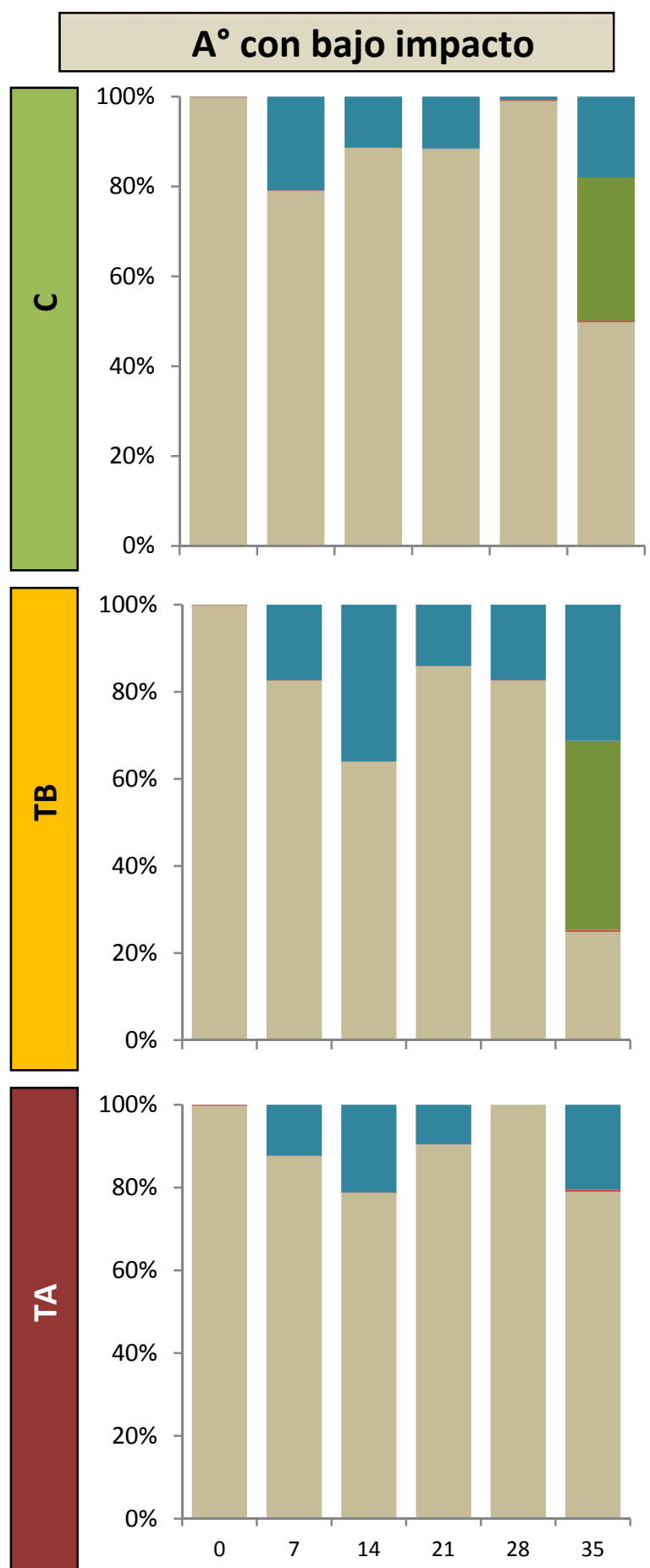

Diatomeas
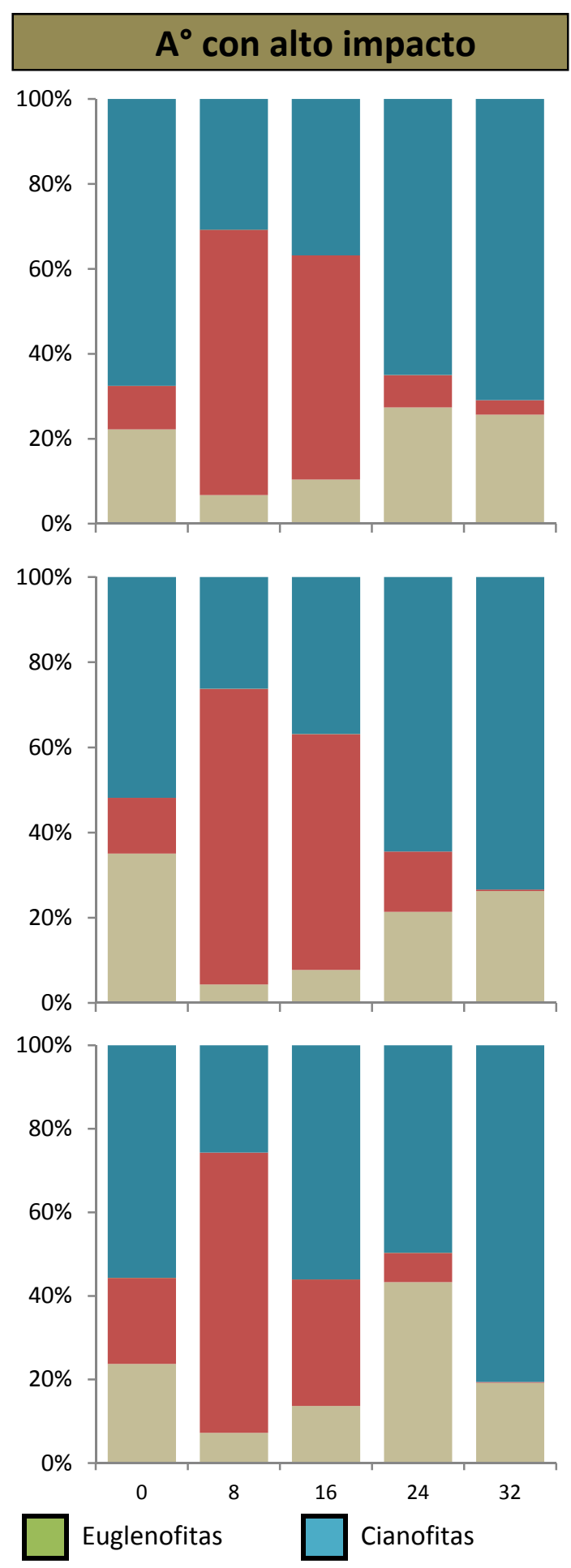

Figura 5.10. Porcentaje de abundancia de la composición algal del biofilm en las distintas fechas de muestreo en los tres tratamientos (C, TB y TA). 


$$
-\mathrm{C}-\mathrm{TB}-\mathrm{TA}
$$

\section{RIQUEZA ESPECÍFICA}
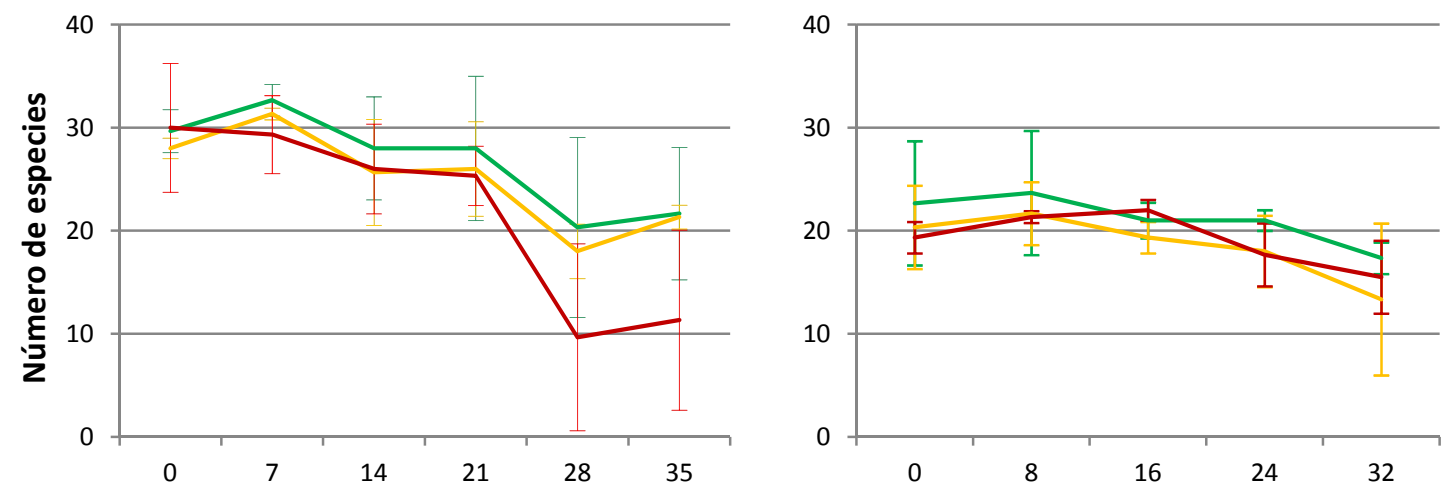

\section{DIVERSIDAD}

4 3
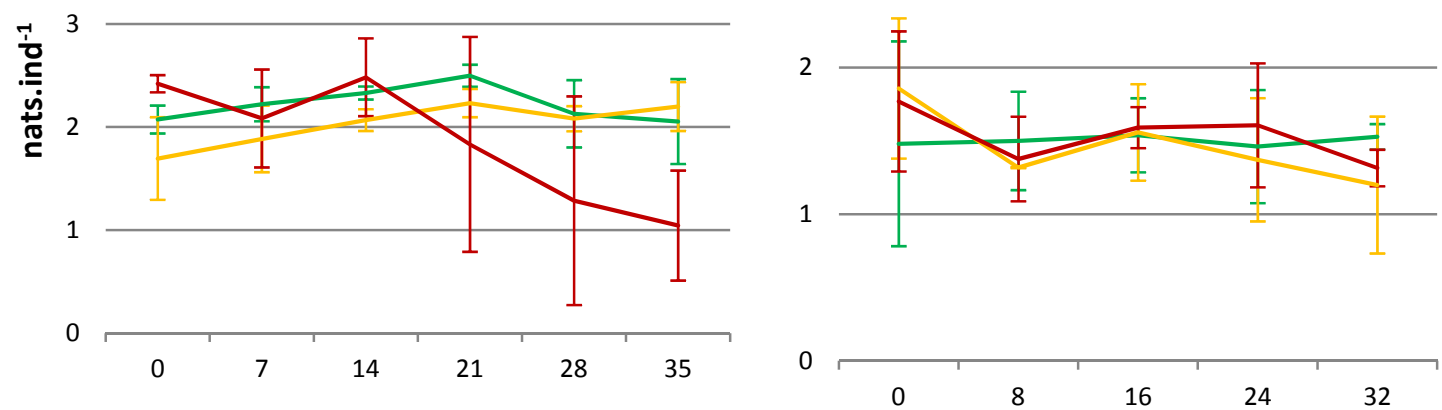

Figura 5.11. Variaciones en la riqueza específica y en el índice de Diversidad de Shannon $(H)$ de los autótrofos y consumidores identificados en el biofilm a lo largo de las experiencias. Las barras indican desvío estándar. 
Distancia

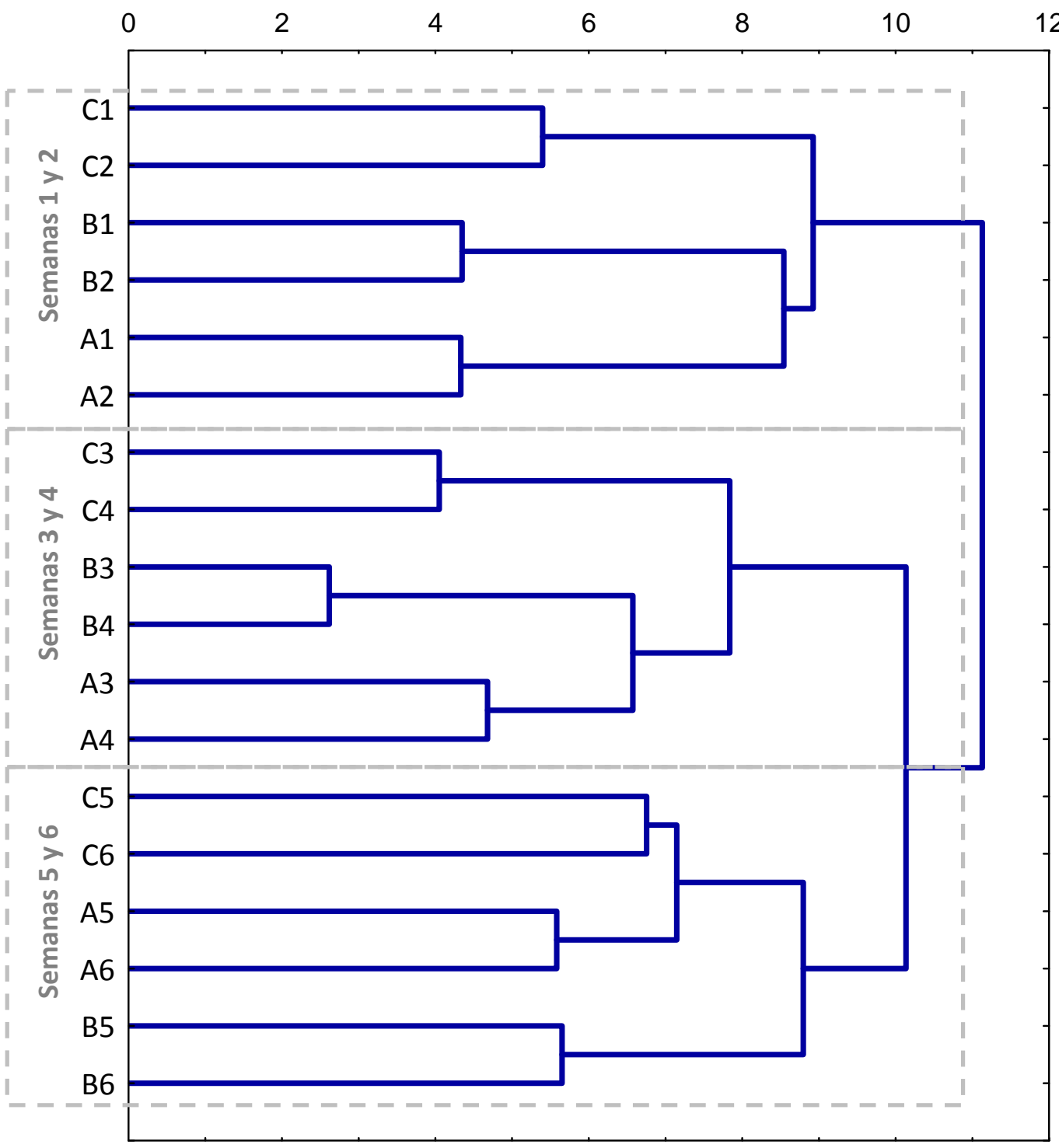

Figura 5.12. Análisis de clúster entre los tratamientos ( $C, T B, T A)$ en las distintas semanas de muestreo (1 a 6), calculado con las densidades de los autótrofos y consumidores identificados en el biofilm de la Experiencia 1. 
Distancia

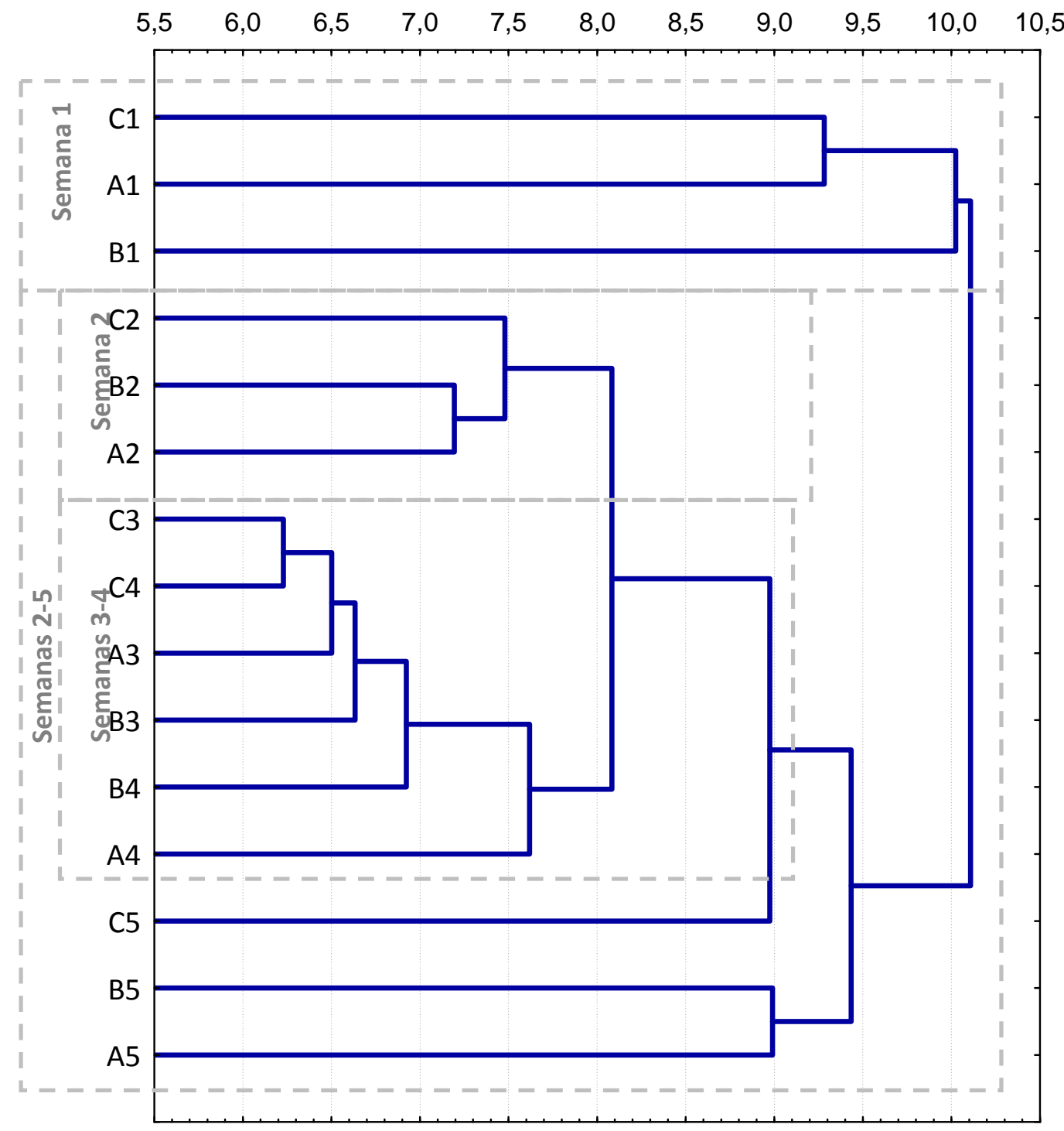

Figura 5.13. Análisis de clúster entre los tratamientos ( $C, T B, T A)$ en las distintas semanas de muestreo (1 a 5$)$, calculado con la densidades de los autótrofos y consumidores identificados en el biofilm de la Experiencia 2. 


\begin{tabular}{|c|c|c|c|}
\hline \multicolumn{2}{|c|}{$A^{\circ}$ con bajo impacto } & \multicolumn{2}{|c|}{$A^{\circ}$ con alto impacto } \\
\hline Taxones & \% Contribución & Taxones & \% Contribución \\
\hline Oscillatoria tenuissima & 3,27 & Lyngbya sp. & 5,38 \\
\hline Nitzschia linearis & 3,15 & Oscillatoria sp. & 5,08 \\
\hline Diadesmis confervacea & 3,01 & Nitzschia amphibia & 4,67 \\
\hline Placoneis placentula & 2,87 & Caloneis bacillum & 4,53 \\
\hline Sellaphora seminulum & 2,66 & Achnanthes exigua & 4,33 \\
\hline Navicula arvensis & 2,58 & Amphora montana & 3,98 \\
\hline Navicula erifuga & 2,39 & Achnanthes lanceolata & 3,51 \\
\hline Melosira varians & 2,37 & Navicula lanceolata & 3,44 \\
\hline Nitzschia levidensis & 2,32 & Luticola mutica & 3,43 \\
\hline Nitzschia amphibia & 2,26 & Diadesmis confervacea & 3,25 \\
\hline Diploneis puella & 2,23 & & \\
\hline Achnanthes lanceolata & 2,20 & & \\
\hline Eunotia bilunaris & 2,10 & & \\
\hline Navicula veneta & 2,10 & & \\
\hline Pinnularia microstauron & 2,03 & & \\
\hline Gomphonema minutum & 2,03 & & \\
\hline Gomphonema clavatum & 2,00 & & \\
\hline Gomphonema parvulum & 1,97 & & \\
\hline Caloneis bacillum & 1,92 & & \\
\hline Navicula minima & 1,91 & & \\
\hline Cymbella silesiaca & 1,90 & & \\
\hline $\begin{array}{l}\text { CONTRIBUCIÓN TOTAL } \\
\text { (21 taxones) }\end{array}$ & $49,25 \%$ & $\begin{array}{l}\text { CONTRIBUCIÓN TOTAL } \\
\text { (10 taxones) }\end{array}$ & $49,73 \%$ \\
\hline
\end{tabular}

Tabla 5.10. Taxones que explican hasta el 50\% de la disimilitud entre grupos, como resultado del análisis SIMPER, para ambas experiencias. En la Experiencia 1 fueron 21 especies, en la Experiencia 2 fueron 12 taxones. 


\subsection{3.h Análisis de las características ecológicas de diatomeas}

Considerando la representatividad de las diatomeas en los biofilms analizados y su reconocido valor como indicador de cambios ambientales, se realizó un análisis detallado de sus características ecológicas.

\subsection{3.h.i Metabolismo de consumo del nitrógeno}

En el arroyo con bajo impacto antropogénico los cambios en las proporciones de las especies revelaron que el porcentaje de diatomeas con un metabolismo de consumo de nitrógeno autotrófico aumenta hacia el final de la experiencia en detrimento de las heterotróficas (Figura 5.14). Sin embargo estas diferencias no fueron significativas entre los distintos tratamientos (Tabla 5.11).

En el arroyo con alto impacto antropogénico el biofilm estuvo dominado por diatomeas heterotróficas facultativos, y las autotróficas sensibles estuvieron muy poco representadas (Figura 5.14). Hacia el final de la experiencia, se advierte una dominancia de las especies heterotróficas facultativas y una disminución de las especies heterotróficas obligadas. Al igual que en la experiencia anterior no se encontraron diferencias significativas entre los tratamientos (Tabla 5.12). 

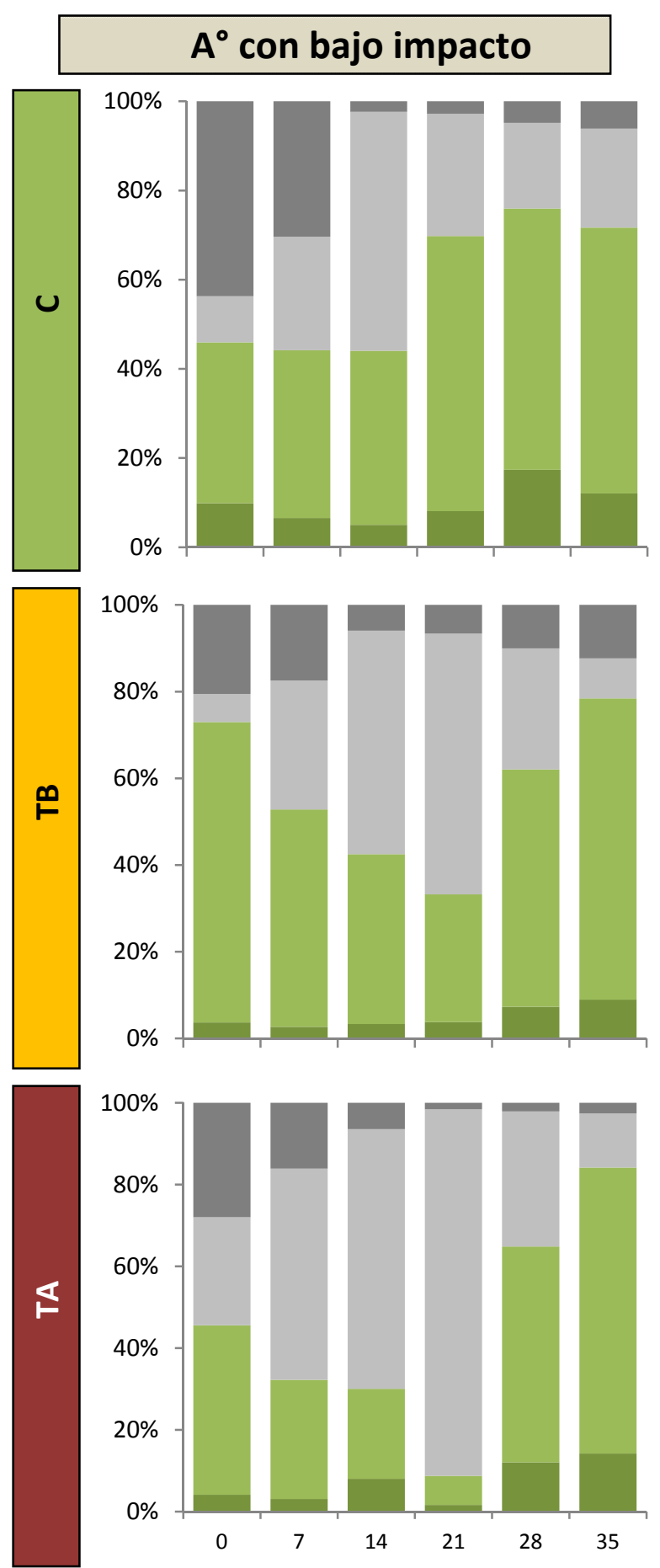

$\square$ Autótrofos sensibles

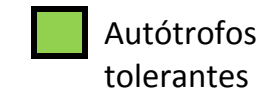

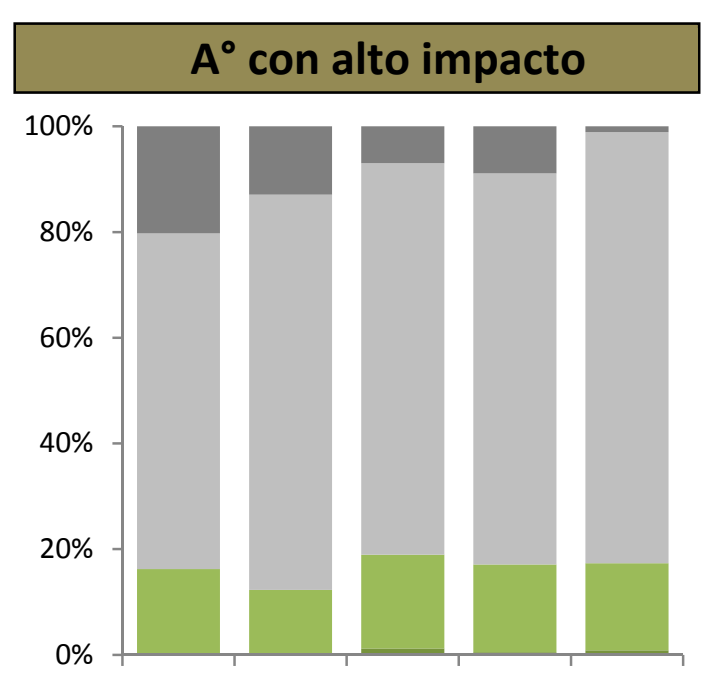
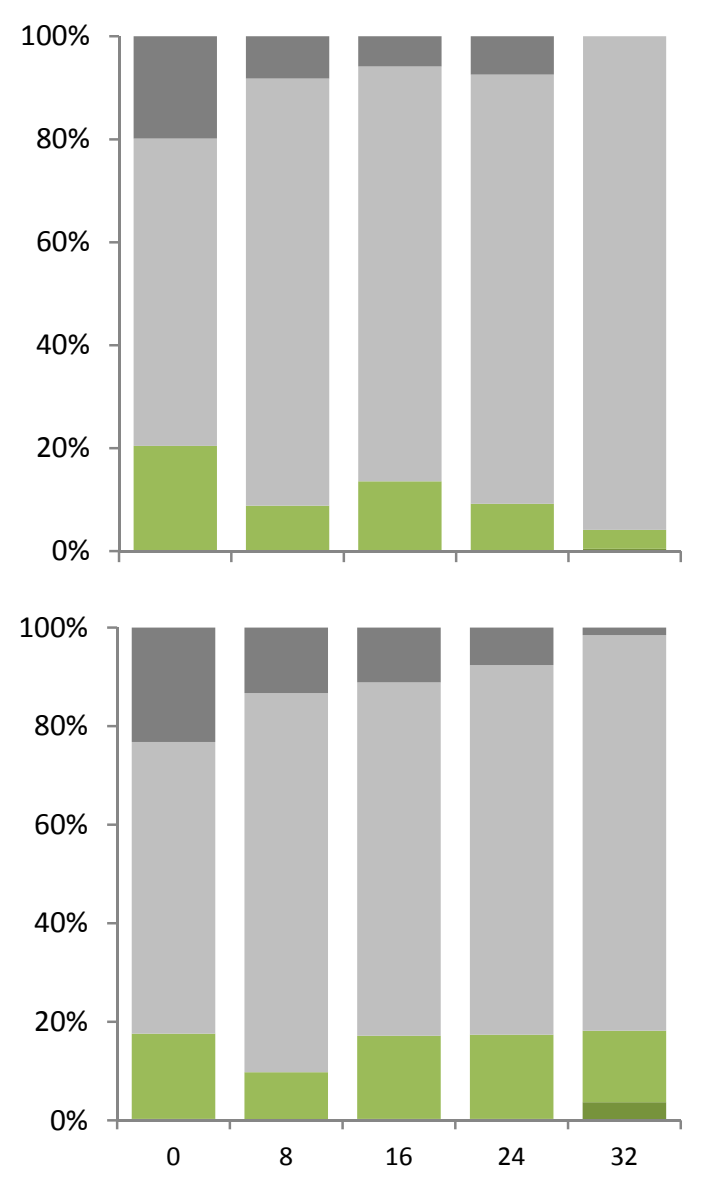

Heterotróficos facultativos

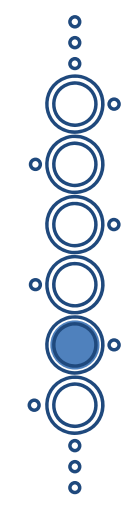

Figura 5.14. Proporción de diatomeas autotróficas (sensibles y tolerantes) y heterotróficas (facultativas y obligadas) en las distintas fechas de muestreo de ambas experiencias en los tres tratamientos (C, TB y TA) 
En el arroyo con bajo impacto antropogénico, las mayores densidades de las diatomeas encontradas fueron de ambientes $\alpha$-mesosapróbicos(Tabla 5.11). Cabe destacar que la baja proporción de especies oligosapróbicas tiende a casi desaparecer hacia el final de la experiencia en los tratamientos.En el arroyo con alto impacto antropogénico las mayores densidades de las especies de diatomeas encontradas también fueron especies $\alpha$ mesosapróbicas, pero en este caso no se encontraron especies oligosapróbicas en las muestras (Figura 5.15). En este caso, los organismos $\beta$-mesosapróbicos van disminuyendo significativamente hacia el final de la experiencia en todos los canales. (Tabla 5.12). 

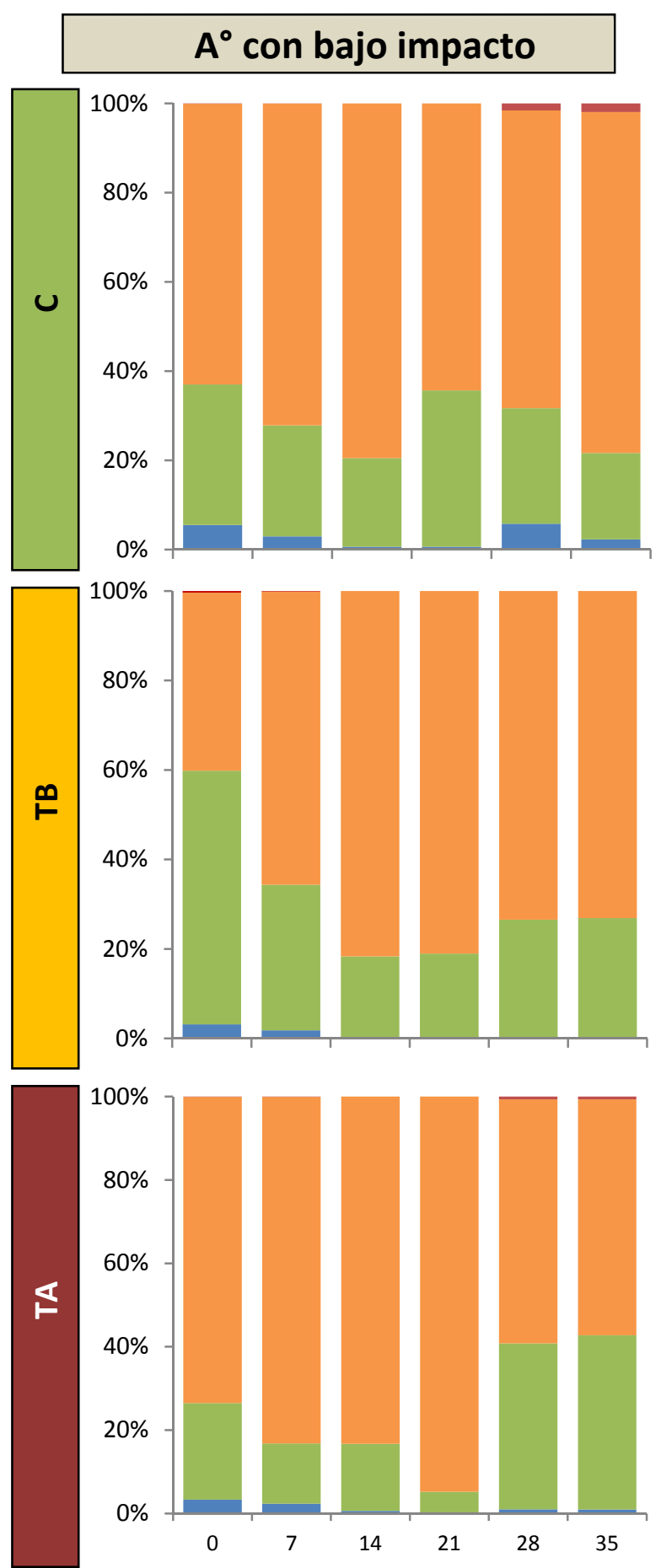
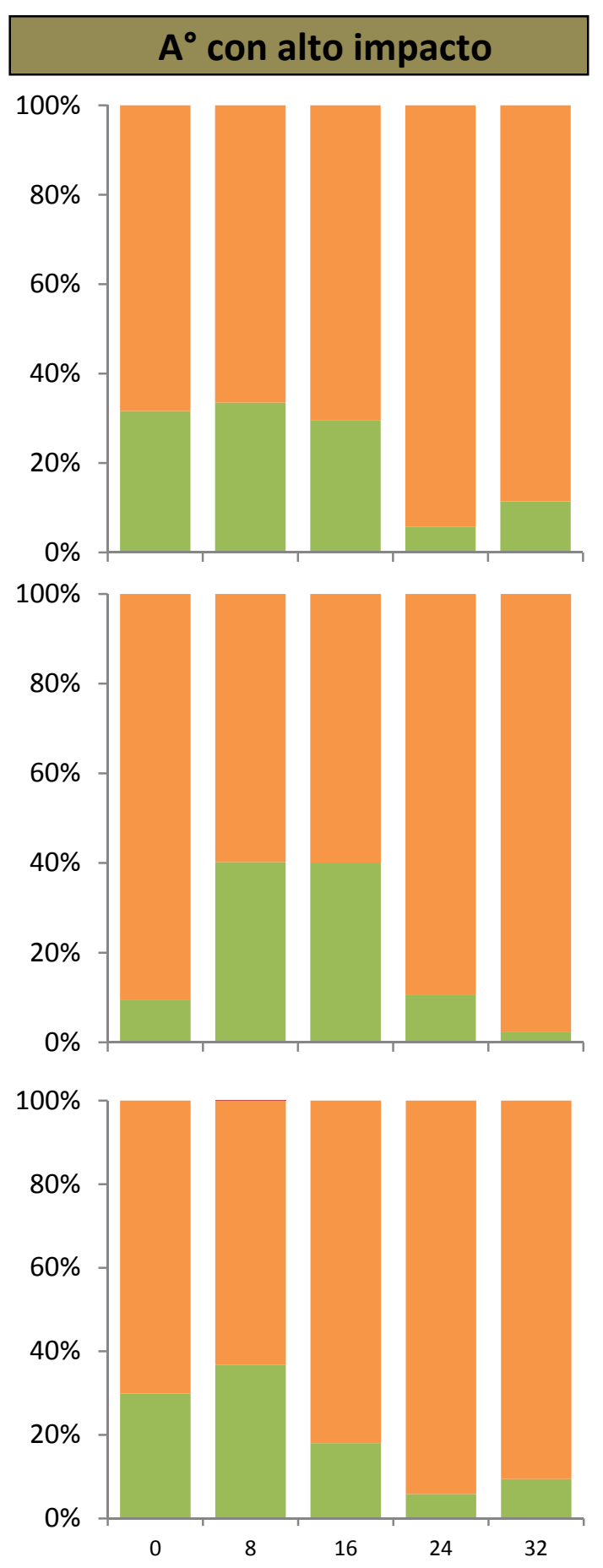

$\alpha$-mesosapr. $\square$ Polisapróbicas

Figura 5.15. Proporción de diatomeas oligosapróbicas, $\beta$-mesosapróbicas, $\alpha$-mesosapróbicas y polisapróbicas en las distintas fechas de muestreo en los tres tratamientos (C, TB y TA)
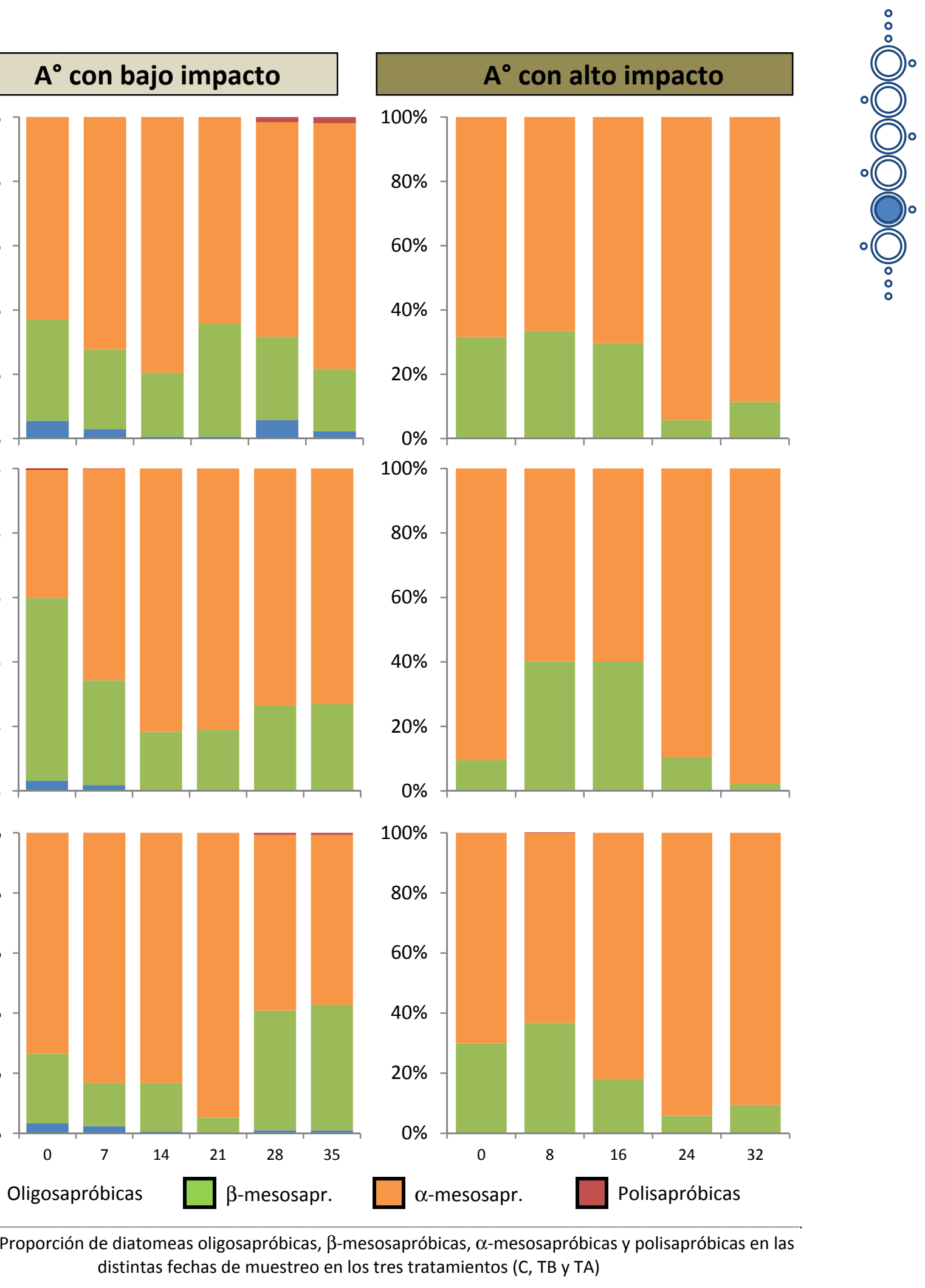
El análisis por la preferencia de los nutrientes revela que en el arroyo con bajo impacto antropogénico, la densidad de especies de diatomeas oligotróficas fue baja o inexistente en todos los tratamientos, siendo la mayoría de los individuos de ambientes eutróficos-hipereutróficos (Figura 5.16). Las pocas especies oligotróficas estuvieron presentes sólo en los canales C (, Tabla 5.11).

En el arroyo con alto impacto antropogénico no se encontraron especies oligotróficas, y la densidad de organismos fue ampliamente dominada por especies de diatomeas eutróficashipereutróficas (Figura 5.16). Hacia el final de la experiencia, el promedio de las especies mesotróficas disminuyeron, aunque dicha disminución no fue significativa estadísticamente (Tabla 5.12). 


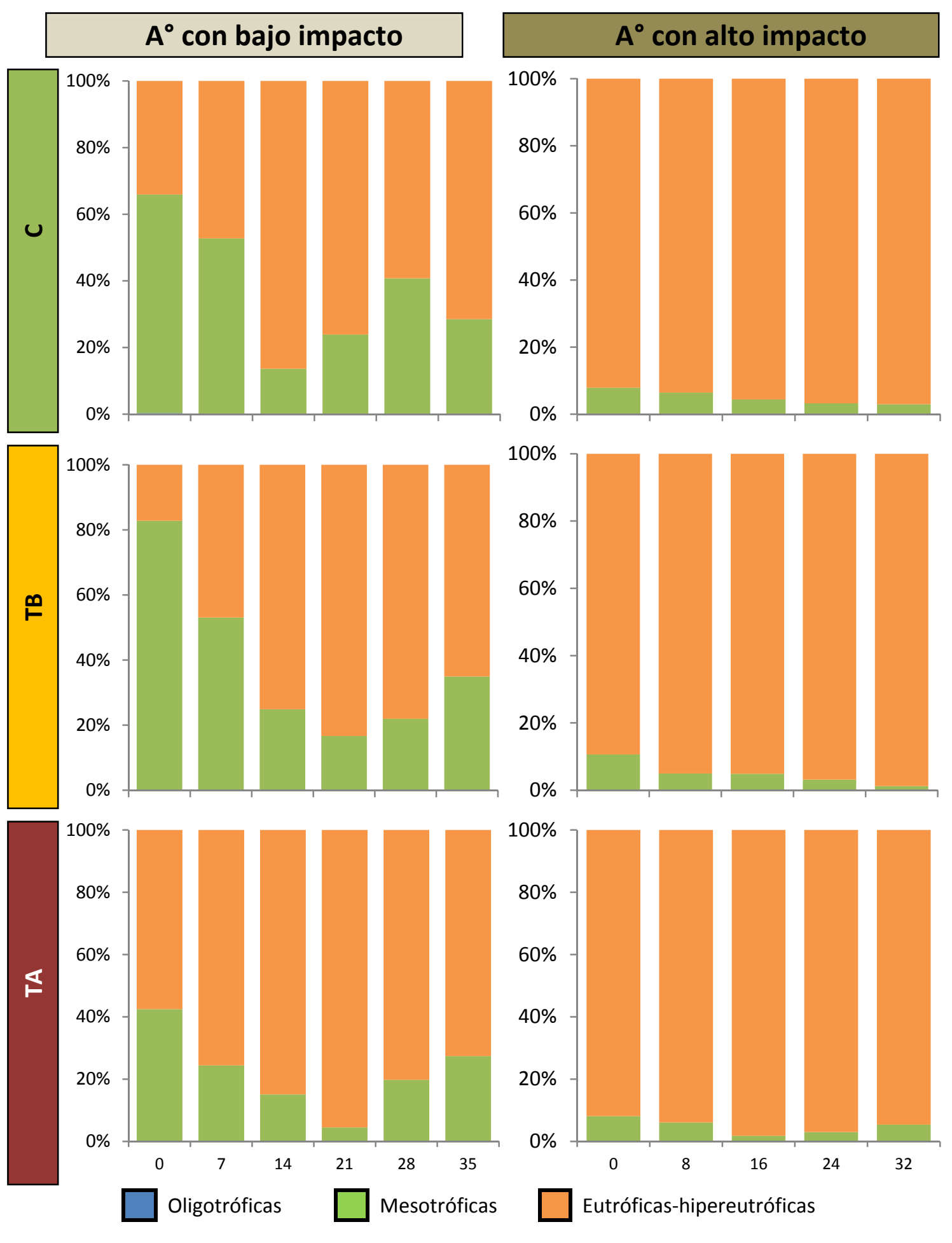

Figura 5.16. Proporción de diatomeas oligotróficas, mesotróficas, eutróficas-hipereutróficas en las distintas fechas de muestreo en los tres tratamientos (C, TB y TA) 

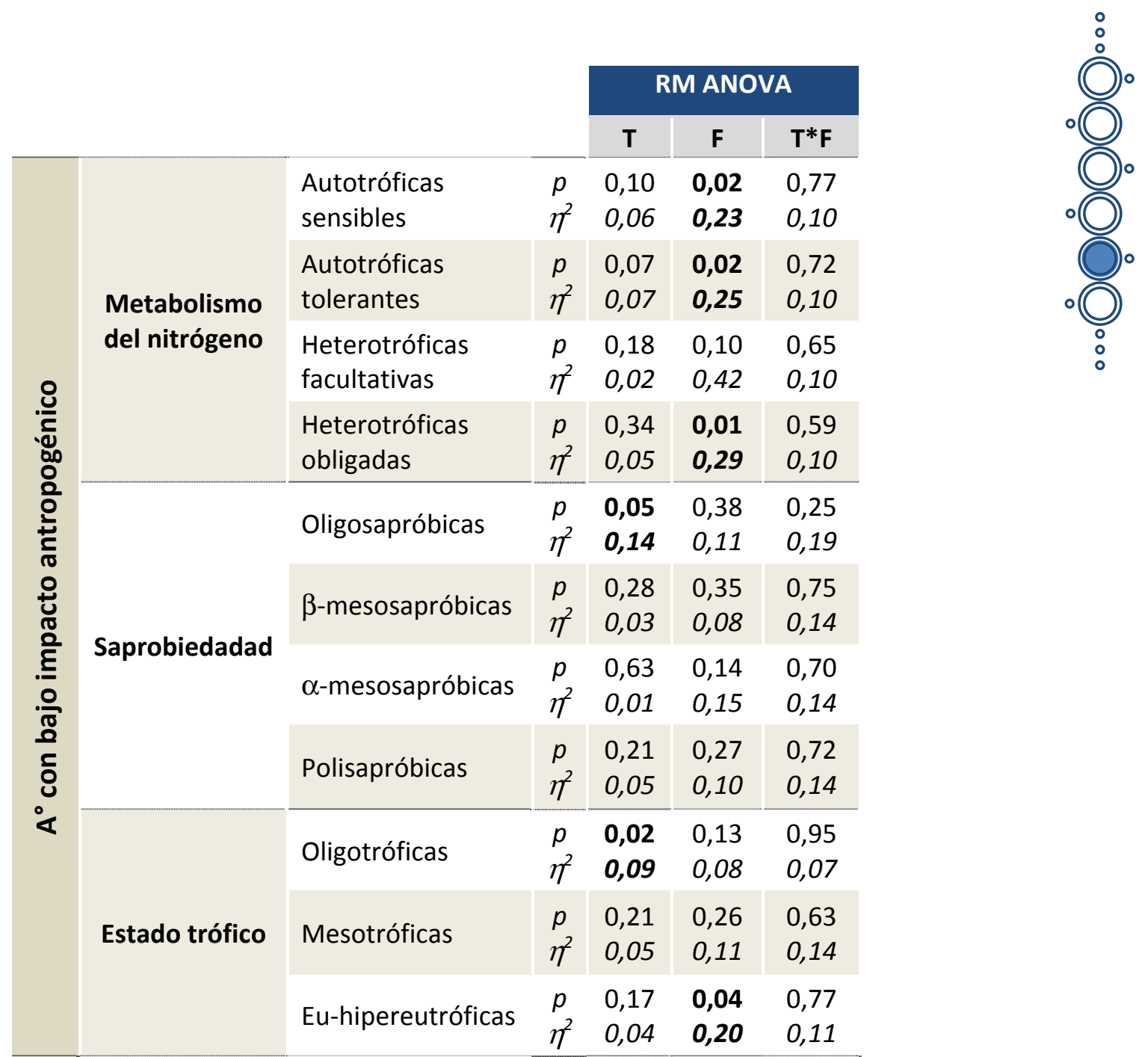

Tabla 5.11. Resultados del RM ANOVA entre los tratamientos (T) y las fechas de muestreo (F) de la experiencia del arroyo con bajo impacto antropogénico; se indican los valores de significancia ( $p$, diferencias significativas en negrita) y el tamaño del efecto biológico $\left(\eta_{\mathrm{G}}{ }^{2}\right)$ 


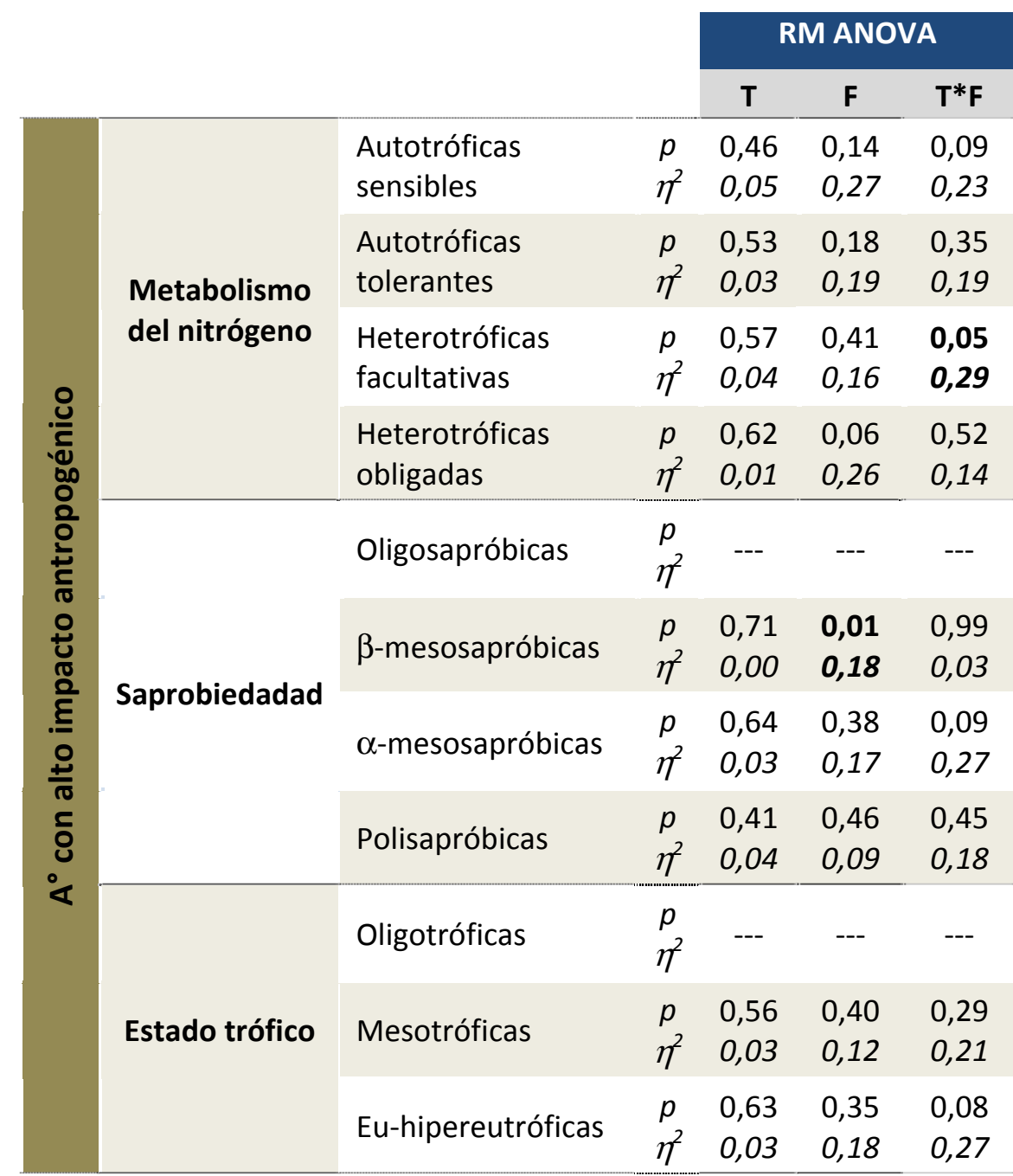

Tabla 5.12. Resultados del RM ANOVA entre los tratamientos $(T)$ y las fechas de muestreo (F) de la experiencia del arroyo con bajo impacto antropogénico; se indican los valores de significancia ( $p$, diferencias significativas en negrita) y el tamaño del efecto biológico $\left(\eta_{\mathrm{G}}{ }^{2}\right)$ 
Las experiencias de laboratorio aquí presentadas analizaron el efecto del aumento de cuatro variables simultáneamente (temperatura, nutrientes, turbidez y velocidad de la corriente), prediciendo un mayor desarrollo del biofilm, una mayor actividad en la comunidad biológica y una disminución en la diversidad y complejidad de la estructura comunitaria.

Los principales resultados evidencian que la composición de especies del biofilm es alterada cuando es expuesta a los efectos simultáneos de estos cuatro estresores asociados a los cambios globales en la llanura pampeana. La disminución de especies de diatomeas oligotróficas y oligosaprobicas en el experimento con biofilms del arroyo con bajo impacto antropogénico indica que el ensamble es afectado por los tratamientos. En esa misma experiencia, la diversidad y la riqueza específica disminuyeron en los tratamientos más intensos del experimento, sugiriendo que dicha comunidad es más sensible que la desarrollada en el experimento con biofilms del arroyo mas impactado.

Los resultados del análisis SIMPER en ambas experiencias muestra que los efectos de los tratamientos sobre la comunidad son evidenciados por cambios en la abundancia relativa de varias especies, más que en el desarrollo dominante de una única especie.

Sin embargo, otras variables estructurales y metabólicas que caracterizan el biofilm en general - tales como el contenido de clorofila "a", la biomasa bacteriana, los carbohidratos totales y el peso seco libre de cenizas- no evidenciaron diferencias significativas a causa de los estresores estudiados.

La concentración de clorofila "a" medida en los experimentos fue elevada en comparación con otros estudios realizados en canales artificiales (Fairchild et al. 1985, Horner et al. 1990, Navarro Rodríguez 1998, Muñoz et al. 2001, Ricart et al. 2009, entre otros) e incluso en relación a las concentraciones medidas en el arroyo "La Choza" en la experiencia de campo en esta misma tesis (ver Capítulo 4).

La disponibilidad de nutrientes es un factor regulador importante para el crecimiento y la producción algal y bacteriana y, generalmente, los enriquecimientos tienen un efecto positivo en estas comunidades (Fairchild et al. 1985, Sterner et al. 1992, Rosemond et al. 1993, Hepinstall \& Fuller 1994, Guasch et al. 1995, Hillebrand \& Sommer 1997, entre otros). Asimismo, la producción de la comunidad algal se ve fuertemente influenciada por la cantidad de luz que tienen disponible para la fotosíntesis, y la comunidad bacteriana responde 
diferencialmente a varios factores incluyendo a la biomasa algal. Es así que la biomasa bacteriana puede tener una relación positiva con la biomasa algal, utilizando el carbono orgánico disuelto que liberan (Espeland et al. 2001, Romaní et al. 2004b, Francoeur et al. 2006, Rier et al. 2007) o como sustrato (Rier \& Stevenson 2002); una relación de competición con las mismas, en las etapas iniciales del biofilm (Rhee 1972, Currie \& Kalff 1984, Guariento et al. 2011); o incluso pueden no estar vinculados sus desarrollos cuando hay suficiente carbono orgánico disuelto lábil en el ambiente, en situaciones ultraoligotróficas o de alta irradiancia (Sobczak 1996).

Es factible que la falta de respuesta en la biomasa algal y bacteriana a los tratamientos sea el resultado que ejercen las distintas variables cuando son manipuladas simultáneamente sobre el biofilm. El posible incremento en biomasa en la comunidad algal con el aumento de fósforo y nitrógeno está siendo compensado con la disminución en la penetración de la luz causada por el aumento en la turbidez y la materia orgánica.

Los valores obtenidos de la actividad respiratoria en nuestras experiencias fueron comparablemente altos con aquellos obtenidos en arroyos oligotróficos (Romaní \& Sabater 1999, 2001, Tien et al. 2009), respuesta esperable debido a la alta actividad del biofilm en arroyos ricos en nutrientes. El tamaño del efecto de esta variable indica efectos pequeños debido a los tratamientos, siendo ligeramente mayores en la experiencia 1 que en la experiencia 2.

En el biofilm proveniente del arroyo más impactado, la actividad respiratoria fue mayor a la obtenida en la primera experiencia, siendo consistente con una mayor biomasa algal y bacteriana. $Y$ hacia el final de esa experiencia el aumento en la actividad respiratoria fue consecuente con el aumento en la biomasa bacteriana. Este resultado se ha observado en estudios previos, donde la actividad respiratoria estuvo relacionada con la biomasa bacteriana (Jones \& Lock 1993, Romaní et al. 1998, Tien et al. 2009). Por otro lado, experiencias en laboratorio con biofilms autotróficos expuestos a altas y bajas irradiancias demostraron que en aquellos biofilms con un mayor desarrollo de la comunidad algal (expuestos a la luz), tuvieron una mayor actividad respiratoria total (Romaní \& Sabater 1999). Esto sugiere que la respuesta respiratoria es dependiente de ambas comunidades, tanto de la bacteriana como de la algal, siendo mejor expresada por el componente heterotrófico en nuestros estudios.

Entre las muchas funciones, la matriz extracelular de los biofilms ha sido propuesta como reserva de carbono y de protección ante la desecación y la erosión (Freeman \& Lock 1995, Flemming \& Windgender 2001, Branda et al. 2005, Ramasamy \& Zhang 2005). Cuando el 
biofilm es expuesto a aumentos pronunciados de velocidades de corriente, la producción de la matriz aumenta notablemente, aunque la misma retorna casi a sus valores originales cuando esos aumentos de corriente se mantienen por varios días (Ramasamy \& Zhang 2005). En este retorno a sus concentraciones originales la matriz se vuelve más compacta y densa. En nuestros resultados no se evidencian cambios significativos en la concentración de carbohidratos totales por efecto de los tratamientos, aunque la metodología utilizada para medir los azúcares no discrimina si los mismos son intra o extracelulares. Es por esto que un aumento o disminución en el desarrollo de la matriz extracelular podría estar compensado respectivamente por una disminución o aumento en el contenido de polisacáridos intracelulares. Sin embargo, el aumento en la velocidad de la corriente no fue suficiente como para aumentar la erosión del biofilm significativamente, ya que el peso seco libre de cenizas se mantuvo invariante entre los tratamientos.

Los biofilms en los arroyos pampeanos están dominados principalmente por diatomeas y cianobacterias (Solari et al. 1996, Gómez 1998,1999, Licursi \& Gómez 2003, Giorgi 2005) Al desarrollarse sobre sedimentos finos, los biofilms epipélicos suelen estar dominados por especies de diatomeas muy móviles (Underwood \& Kromkamp 1999), y el predomino de cianobacterias filamentosas se hace más evidente con los incrementos de nutrientes. Es así que en este estudio, en el biofilm del arroyo con un bajo impacto antropogénico hay una comunidad con mayor diversidad y dominada por diatomeas, mientras que en el biofilm del arroyo con alto impacto antropogénico la diversidad fue menor y dominada por cianobacterias.

Con respecto a la diversidad y la riqueza específica, disminuyeron en los tratamientos más intensos en el biofilm del arroyo con bajo impacto antropogénico, mientras que en biofilm del arroyo con alto impacto antropogénico se mantuvo invariante. Esto evidencia una mayor sensibilidad en la diversidad de arroyos expuestos a menores impactos, que puede ser alterada en mayor medida por las variables forzantes de los cambios globales. La disminución en la biodiversidad en los sistemas de agua dulce es una consecuencia esperada de los cambios globales (ej: Lake et al. 2000, Poff et al. 2002, Relyea 2005, Harley et al. 2006), y nuestros resultados parecen soportar esta predicción.

En las experiencias realizadas las mayores proporciones de diatomeas correspondieron a especies $\alpha$-mesosapróbicas y, de acuerdo con sus preferencias por los nutrientes, eutróficashipereutróficas. Las bajas proporciones de especies oligosapróbicas sólo se detectaron en el biofilm proveniente del arroyo con un bajo impacto antropogénico. Esto evidencia que los 
cambios en la comunidad favorecen el desarrollo de especies tolerantes a estados tróficos y sapróbicos más avanzados. A su vez, se evidencia una tendencia del biofilm de todos los canales, hacia un ensamble de diatomeas con rasgos más heterotróficos.

Numerosos estudios expresan el incremento de la biomasa del biofilm cuando son expuestos a un aumento en nutrientes (Guasch et al. 1995, Horner et al. 1990, Borchardt 1996) o de temperatura del agua (White et al. 1991, Romaní \& Sabater 2000). La relación inversa es obtenida con un incremento en la turbidez, que al disminuir la irradiancia que alcanza al biofilm causa una disminución en su biomasa (Horner et al. 1990, Tien et al. 2009). Por otro lado, un aumento en la velocidad de la corriente genera un aumento en la biomasa del biofilm, ya que permite una mayor difusión de nutrientes hacia el mismo, hasta un valor crítico de velocidad a partir del cual el agua empieza a erosionarlo más rápidamente que lo que éste se recupera.

Hay que considerar que las pequeñas variaciones debidas a los tratamientos pueden ser importantes para la escala de tiempo empleada, e incluso la estructura de las comunidades fue alterada hasta la significancia estadística. Por ejemplo, las proporciones de especies de diatomeas, al ser clasificadas por su consumo del nitrógeno, saprobiedad y estado trófico, sufrieron pequeñas modificaciones en el corto plazo de las experiencias. Estos cambios estructurales en estas comunidades fueron mayores en aquella que provenía de un arroyo con un menor impacto antropogénico, como es esperable a comunidades menos tolerantes.

Estos cambios parecen sutiles, pero resultan amplios si se considera la escala temporal y espacial utilizada. Los cambios globales ejercen sus efectos a escalas temporales y espaciales mucho mayores a las utilizadas en estos ensayos, y la cantidad de variables a considerar para su estudio apropiado es muy vasta. Pero es mediante el estudio a escalas pequeñas que se puede llegar a una mejor comprensión de la dinámica interna de esta microcomunidad y de los efectos que tienen las variables que influencian su desarrollo.

Según los reportes del IPCC (IPCC 2007), las mayores temperaturas y variaciones en la escorrentía probablemente produzcan efectos adversos sobre la calidad del agua, afectando la salud humana y la de los ecosistemas (Patz 2001, O’Reilly et al. 2003). Además, el incremento en nutrientes y sedimentos por escorrentía contribuirán con la degradación en la calidad del agua (Hamilton et al., 2001). Se espera que los aumentos de escorrentía movilicen fertilizantes y pesticidas hacia los cuerpos de agua en regiones donde hay poca vegetación de ribera (Soil and Water Conservation Society 2003), como es el caso de los arroyos pampeanos. Esto se minimizaría en aquellas áreas de la región Pampeana que aún conserven pastizales bien 
preservados, los cuales son capaces de retener gran parte de los elementos transportados por escorrentía (CITA Giaccio Gustavo)

Otras variables de importancia que modulan el desarrollo de estas comunidades, que no fueron consideradas en los ensayos de la presente tesis, deben ser incluidas y combinadas con los diversos factores para entender su aporte relativo a la dinámica de los biofilms. Entre estos se pueden destacar la herbivoría, que afecta directamente y en mayor medida al componente autotrófico del biofilm (Steinman 1996), y a los compuestos ecotoxicológicos, que ejercen efectos desde niveles celulares hasta ecosistémicos. 


\section{CONSIDERACIONES FINALES}

"La ciencia siempre está equivocada. Nunca soluciona un problema sin crear otros diez."

George Bernard Shaw 
Entre los diversos efectos que pueden tener los cambios globales, los relacionado s con los cambios del uso del suelo se ubican entre los principales, pudiendo impactar fuertemente en los arroyos y ríos. Si a estos se suman los atribuidos a los que acarrearan las modificaciones en los patrones de temperatura y precipitaciones, que a su vez modificarán los patrones de escorrentía, es esperable que los cursos de agua sufran cambios de distinta magnitud dependiendo el área del planeta que se analice. En el caso de la región pampeana estos incluirían de acuerdo con los pronósticos (Hulme \& Sheard 1999) aumentos en la escorrentía y temperatura que acarrearán aumentos de nutrientes, sólidos en suspensión y de la velocidad de la corriente.

De acuerdo con los descriptores analizados en las experiencias in situ y ex situ realizadas en esta tesis, fue posible comprobar algunos efectos, tales como los que causan el aumento de la temperatura, de nutrientes, de sólidos en suspensión y de velocidad de la corriente.

El enriquecimiento por nutrientes es una presión global para todos los tipos de ecosistemas acuáticos (UNEP 2007), ya que deriva en incrementos en los productores primarios y en cambios en las comunidades de los ecosistemas marinos y dulceacuícolas (Smith 2003). Es así que la experiencia de fertilización realizada en el arroyo La Choza demostró que aún con las altas concentraciones basales de nutrientes, la adición de los mismos causó un incremento significativo en la biomasa algal del epipelon. En fertilizaciones llevadas a cabo en arroyos mediterráneos y andinos también se observaron estos incrementos. En este arroyo, el período más propicio para el desarrollo de la biomasa algal es el comprendido entre finales del invierno y verano, coincidiendo con una menor descarga de los arroyos.

Sin embargo cabe señalar que esta respuesta no siempre es observada. Es así que en otros estudios de enriquecimiento con nutrientes realizados en otros arroyos no encontraron una relación entre la biomasa algal y las concentraciones de nutrientes, formulándose varias hipótesis para explicar estas respuestas. Una de ellas establece que los nutrientes exceden las concentraciones máximas para saturar el crecimiento algal (Munn et al. 1989). Aunque en la mayoría de las circunstancias, un número de factores tales como los regímenes hidrológicos (Welch et al. 1988, Biggs \& Close 1989, 1995), la disponibilidad de la luz (Lowe et al. 1986), la herbivoría (Rosemond et al. 1993 entre otros) y la interacción de estos factores (Hill et al. 1995, Hillebrand 2005) pueden contribuir a la falta de correlación entre la biomasa algal bentónica y las concentraciones de nutrientes.

Estudios realizados por otros grupos de investigación, llevados a cabo simultáneamente a los realizados en la presente tesis, han demostrado a través del análisis del 
contenido del tracto digestivo de macroinvertebrados que su principal fuente de alimento es aportada por diatomeas y detritus (López van Oosterom et al. 2013, Ocón et al 2013). Asimismo el estudio de los ensambles de oligoquetos revelaron cambios en la biomasa, abundancia, riqueza y diversidad taxonómica de los mismos relacionados al incremento de nutrientes (Armendariz et al. 2012). Estos cambios parecieron favorecer a las especies herbívoras y detritívoras, que ejercen un fuerte efecto sobre los biofilms. Por lo tanto la herbivoría constituye un factor de control a considerar en la interpretación de los efectos que produce el incremento de nutrientes.

En relación a la interacción de la luz y los nutrientes es necesario advertir que una mayor disponibilidad de luz o de nutrientes aisladamente no garantiza un incremento en biomasa. Por ejemplo, en un sistema limitado con nitrógeno un incremento en luz no aumentó la biomasa algal sin adiciones de nitrógeno (Taulbee et al. 2005). De manera similar varios estudios han encontrado que la adición de nutrientes por sí sola no estimula el incremento en biomasa algal a menos que la disponibilidad de luz se incremente también (Bernhardt \& Likens 2004, Mallory \& Richardson 2005). Estos resultados demuestran que para recursos esenciales como la luz y los nutrientes, la magnitud de la respuesta a los enriquecimientos depende en la disponibilidad relativa de otros factores. El experimento llevado a cabo en la presente tesis, en el arroyo "La Choza", sugiere que en un arroyo pampeano donde la disponibilidad de luz no es un factor limitante, un incremento en la concentración de nutrientes que aumente sus niveles basales aún es capaz de incrementar la biomasa algal significativamente.

Otro de los resultados obtenidos en esta tesis revela que la adición de nutrientes causó en el epipelon un efecto diferido en el desarrollo de la comunidad bacteriana. Esto indica que la dinámica bacteriana está ligada con la respuesta autotrófica. Los incrementos en biomasa bacteriana en La Choza, ocurriendo siempre después de los incrementos en la clorofila, sugieren que las bacterias en este microhábitat utilizan principalmente compuestos orgánicos autotróficos. Esto diferencia la dinámica de los sistemas pampeanos de otros en los cuales se han realizado fertilizaciones semejantes. Por ejemplo, en sistemas andinos se ha observado que la respuesta bacteriana fue inmediata e independiente de los cambios en la biomasa algal, demostrando que las bacterias utilizan directamente los nutrientes inorgánicos con cierta independencia de los compuestos orgánicos autotróficos (Artigas et al. 2013). En los sistemas mediterráneos, por otro lado, la respuesta bacteriana fue inmediata pero más extendida en el tiempo, lo que indica que en esos sistemas las bacterias también basan su consumo en detritus (Artigas et al. 2013). En otra experiencia realizada con epiliton de arroyos de tundra, la fertilización causó un aumento importante tanto en la biomasa algal como en el metabolismo bacteriano, directamente relacionados con el ingreso de nutrientes inorgánicos (Peterson et al.

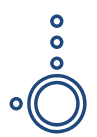


1993). Cabe señalar que los enriquecimientos con nutrientes además de incrementar la biomasa bacteriana favorecen el aumento de la respiración microbiana, la biomasa fúngicas y las tasas de descomposición (Gulis \& Suberkropp 2003).

En la experimentación in situ realizada en el arroyo La Choza no se observaron cambios en la fosfatasa alcalina. Esto podría deberse a que la actividad de la fosfatasa no es inhibida por el enriquecimiento, y los valores medidos son los producidos por los organismos en su metabolismo basal. Cuando se comparan las concentraciones obtenidas en el biofilm de los arroyos pampeanos con otros estudios, los valores son relativamente bajos (por ejemplo Hill et al. 2012, Romaní et al. 2012). En los experimentos conducidos por Rier et al. (2007), por ejemplo, valores tan bajos sólo fueron medidos en biofilms con muy baja intensidad lumínica.

La fosfatasa alcalina en la columna de agua y en el biofilm es un indicador de limitación por fósforo. En ensayos con cultivos, Healey \& Hendzel (1979) sugirieron que a niveles de fosfatasa de aproximadamente $0,003 \mu \mathrm{mol}$ por miligramo de clorofila por hora indican una limitación moderada de fósforo, mientras que niveles superiores a 0,005 $\mu$ moles por miligramo de clorofila por hora indican una limitación severa (Steinman \& Mulholland 1996). Los resultados obtenidos en el arroyo "La Choza" revelan niveles de fosfatasa en el orden de nanomoles por $\mathrm{cm}^{2}$ por hora, lo que indica que son valores muy inferiores a los límites encontrados por Healey \& Hendzel (1979). Esto evidenciaría que hay suficiente cantidad de fósforo en el medio para el desarrollo algal, y que no representa un elemento limitante.

Otros estudios respaldan que las concentraciones de fosfatasa están inversamente correlacionadas con las concentraciones de fósforo en agua y sedimento (Findlay et al. 2001, Harbott \& Grace 2005, Sinsabaugh et al. 2010), y Hill et al. (2012) concluyeron que la escorrentía pobre en nutrientes en arroyos forestados estimula la producción extracelular enzimática para la adquisición de nitrógeno y fósforo. Por esto, en un arroyo rico en fósforo como La Choza, es consistente encontrar concentraciones más bajas de fosfatasa que en otros arroyos con niveles de nutrientes menores. Cabe destacar que en el tramo control se midió un pico de incremento de fosfatasa en primavera, con el comienzo del período denominado como ventana de oportunidad, que coincide con el incremento en biomasa algal, lo cual podría indicar una demanda de fósforo durante el desarrollo. Esta demanda no ocurrió en el tramo fertilizado artificialmente, ya que el fósforo inorgánico necesario para el desarrollo de los productores primarios fue provisto de manera exógena.

Tampoco se observaron cambios en la $\beta$-glucosidasa en relación al enriquecimiento con nutrientes. Esta enzima sólo incrementó su actividad al final de la experiencia y después del incremento en biomasa algal. La $\beta$-glucosidasa epipélica, entonces, parece estar más 
regulada por la disponibilidad del sustrato que por el desbalance de nutrientes en el agua. Por otro lado, la variación en la eficiencia de la $\beta$-glucosidasa con la adición de nutrientes se traduce en una menor necesidad de las células bacterianas en producir la enzima, lo que es consistente con el incremento en biomasa algal en el tramo enriquecido, que les provee una fuente de carbono rápidamente asimilable. Esto sí es coincidente con lo encontrado en otros estudios como el de Romaní \& Sabater 2000 que reportan que la eficiencia de los biofilms en producir enzimas fue menor en sitios con altas concentraciones de nutrientes.

A pesar de la correlación positiva hallada en La Choza entre la concentración de $\beta$ glucosidasa y la biomasa algal, sus variaciones no estuvieron tan acopladas como en otros estudios (Somville 1984, Jones \& Lock 1993), que concluyeron que los productos liberados del componente autotrófico del biofilm aumentaron la actividad de esta enzima.

Es importante remarcar que el metabolismo bacteriano del epipelon de estos arroyos con baja velocidad de corriente se asemeja más al de los biofilms epilíticos -altamente relacionados con la densidad y actividad de las algas microbentónicas - que a de los biofilms episámicos, donde los heterótrofos microbianos son más eficientes utilizando la materia orgánica alóctona.

La composición algal cambia con los aumentos en las concentraciones de nutrientes (Stevenson 1996, Pan et al. 1996, Stevenson \& Smol 2001). Ya que los incrementos algales son generalmente asociados con los enriquecimientos por nutrientes, un cambio en la composición taxonómica en un arroyo puede demostrar los cambios a corto o largo plazo (Lowe \& Pan 1996). Por ello, la composición algal puede revelar las consecuencias de la contaminación por nutrientes.

La composición específica de los ensambles de diatomeas es reconocida como un indicador de las condiciones ambientales, especialmente en arroyos y ríos (Stevenson \& Pan 1999), debido a la sensibilidad de estos organismos a los enriquecimientos con nutrientes (van Dam et al. 1994, Kelly \& Whitton 1995, Kelly et al. 1998, Winter \& Duthie 2000, Gómez 1998, Gómez \& Licursi 2001, Gómez et al. 2011). Las respuestas relacionadas con los cambios en los ensambles de diatomeas fueron observadas en los estudios realizados, tanto en la experimentación ex situ como se señalo precedentemente, como in situ. En el caso de ésta última la fertilización produjo cambios en la abundancia relativa de las poblaciones de diatomeas favoreciendo aquellas que prefieren condiciones más eutróficas y con requerimientos metabólicos relacionados a mayores concentraciones de nitrógeno orgánico en el medio, como es el caso de Nitzschia frustulum y Nitzschia inconspicua (Gómez et al. 2011, Artigas et al. 2013). 
De acuerdo con los resultados expuestos, los enriquecimientos con nutrientes aceleran la producción autótrofa en los arroyos y en consecuencia cambian la estructura del ecosistema a partir de la modificación de los distintos niveles tróficos.

Carpenter et al. (1985) adaptaron el concepto de "cascada de efectos" desarrollado para redes tróficas marinas a los lagos y lo describieron como "interacciones tróficas en cascada". Postularon que cada nivel trófico está controlado tanto por predadores (control topdown) y recursos (control bottom-up). Es así que cambios en un nivel trófico alterarían el ciclo de materia y repercutirían en otros niveles tróficos en la red (Lamberti 1996, Biggs 2000). Es así que Huntsman (1948) reconoció que los fertilizantes estimulan el crecimiento algal y conducen a un incremento en densidades de insectos y peces. Desde entonces estudios más cuantitativos (Peterson et al. 1993, Slaney \& Ashley 1998) han demostrado que las adiciones de nutrientes incrementan la biomasa algal al menos al principio del enriquecimiento. Hacia el final de la fertilización los efectos de los predadores repercuten sobre la biomasa algal y compensan su incremento.

Los peces también se pueden beneficiar de los incrementos en la disponibilidad de alimento cuando las adiciones de nutrientes incrementan la producción primaria y secundaria. Estudios a largo plazo han reportado un aumento en el tamaño de los peces (Slaney \& Ward 1993, Slaney \& Ashley 1998) y de sus tasas de crecimiento (Deegan \& Peterson 1992, Slavik et al. 2004). Sin embargo, es difícil establecer cuánta producción primaria consecuencia de la adición de nutrientes repercute en este nivel trófico, y el efecto de la misma sobre los peces es muy impredecible. El impacto más obvio de las grandes cargas de nutrientes en los arroyos es la reducción en el oxígeno disuelto en el agua, lo que contribuiría a la eliminación de los taxones más sensibles.

En el arroyo "La Choza" se analizó la respuesta de los peces a la fertilización (Artigas et al. 2013), y, aunque no se encontró un aumento en biomasa, la condición de algunas especies (determinada como el peso/longitud) mejoraron, como fue el caso de Cnesterodon decenmaculatus. Esta mejora fue explicada por una mayor cantidad de materia orgánica autóctona (algas y macrófitas) y una mayor calidad relativa a los detritos alóctonos que permite a los peces sobrevivir a través de períodos poco favorables.

Según los reportes del IPCC (IPCC 2007), las mayores temperaturas y variaciones en la escorrentía probablemente produzcan efectos adversos sobre la calidad del agua, afectando la salud humana y la de los ecosistemas (Patz 2001, O’Reilly et al. 2003). Además, el incremento en nutrientes y sedimentos por escorrentía contribuirán con la degradación en la calidad del agua (Hamilton et al. 2001). Se espera que los aumentos de escorrentía movilicen fertilizantes 
y pesticidas hacia los cuerpos de agua en regiones donde hay poca vegetación de ribera (Soil and Water Conservation Society 2003), como es el caso de los arroyos pampeanos.

Los efectos combinados de varios factores también pueden producir respuestas de carácter sinérgico o antagónico. Las experiencias de laboratorio presentadas en esta tesis trataron de demostrar el efecto combinado del aumento de cuatro variables (velocidad de la corriente, nutrientes, turbidez y temperatura), prediciendo un mayor desarrollo del biofilm, una mayor actividad en la comunidad biológica y una disminución en la diversidad y complejidad de la estructura de la comunidad. Sin embargo, la mayoría de los resultados obtenidos no soportan estas hipótesis, evidenciado por la ausencia de diferencias significativas en los análisis (Figura 6.1).

Es así que la biomasa algal, la bacteriana y la actividad respiratoria total no evidenciaron cambios significativos debido a los tratamientos. En el biofilm del arroyo con un bajo impacto antropogénico se desarrolló una comunidad dominada por diatomeas, con una mayor diversidad que disminuyó hacia el final de la experiencia como resultado de un tratamiento alto. El biofilm del arroyo con alto impacto antropogénico, por otro lado, estuvo dominado por cianobacterias, y su diversidad no fue alterada por los tratamientos. Asimismo en las experiencias realizadas las mayores proporciones de diatomeas correspondieron a especies $\alpha$-mesosapróbicas $y$, de acuerdo con sus preferencias por los nutrientes fueron dominantes las eutróficas-hipereutróficas. En la experiencia 1 el biofilm de los tratamientos evidenció una respuesta más contundente demostrada por el incremento de los taxones que revelan un mayor estado trófico y sapróbico y una tendendencia hacia la heterotrofía de las especies de diatomeas en comparación con los controles. 
Figura 6.1. Resumen de los tratamientos utilizados en las experiencias de laboratorio (Alto y Bajo), las hipótesis establecidas para el estudio y resumen de los resultados obtenidos para las variables analizadas. Con símbolos + se indican aumentos significativos, con símbolos - se indican disminuciones significativas y con símbolos = se indica la ausencia de diferencias significativas.

Los efectos simultáneos de las variables estudiadas sobre el biofilm sugieren resultados no esperables cuando los efectos de variables son estudiados individualmente. Es posible que la falta de respuesta en la biomasa algal y bacteriana a los tratamientos sea el resultado de la interacción entre las distintas variables manipuladas. En tal sentido el incremento en la biomasa en la comunidad algal con el aumento de fósforo y nitrógeno sería compensado con la disminución en la penetración de la luz causada por el aumento en la turbidez.

Si bien las variaciones observadas entre los tratamientos y el control son pequeñas, las mismas pueden ser importantes si consideramos la escala de tiempo empleada. Si bien es reconocido que los cambios globales ejercen sus efectos a escalas temporales y espaciales mucho mayores a las utilizadas en estos ensayos, y que la cantidad de variables a considerar para su estudio es muy vasta, el empleo de escalas pequeñas puede brindar una mejor comprensión de la dinámica interna de los biofilms y de los efectos de las variables que modulan su desarrollo. 
De acuerdo con los resultados obtenidos en esta tesis es posible reconocer que los arroyos pampeanos demuestran una resistencia al cambio que se manifiesta a través de respuestas diferidas o de pequeños cambios visibles a diferentes escalas.

En síntesis, sólo algunas de las hipótesis planteadas en esta tesis no fueron rechazadas. Por lo cual el efecto de los enriquecimientos con nutrientes puede ser menos predecible en sistemas con altas concentraciones basales de nutrientes, como es el caso de los arroyos pampeanos, naturalmente enriquecidos. Estos muestran una red trófica muy compleja y compartimentalizada, y esa complejidad sería una de las causas que amortiguarían la transferencia potencial de los efectos de las adiciones de nutrientes.

Estos resultados indican que el amplio rango de medidas que pueden reducir los efectos de la eutrofización en arroyos debería incluir la planificación de los usos del suelo, particularmente el uso urbano y agrícola, reconocidos como las principales fuentes de nutrientes que pueden ingresar a los arroyos. 
Los arroyos pampeanos poseen características muy singulares en su hábitat y litología que los distinguen de los arroyos de montaña e incluso de la gran mayoría de los arroyos de llanura. La combinación de sus características naturales con un importante desarrollo sociodemográfico los convierte en un área de estudio de importancia para su desarrollo y manejo.

Las investigaciones realizadas sobre el biofilm de ríos y arroyos a nivel mundial son, en su amplia mayoría, sobre comunidades epiliticas o epifíticas (el tradicional perifiton), y casi no hay investigaciones sobre comunidades epipélicas.

Asimismo, los estudios realizados en laboratorio y en campo en esta tesis exhiben la importancia del análisis de múltiples variables forzantes sobre los sistemas lóticos, para tratar de entender como son afectados los distintos componentes y procesos del biofilm en simulaciones complejas. Los resultados obtenidos en este estudio podrían estar manifestando una "compensación" de los efectos de las variables sobre el biofilm, evidenciado por las respuestas graduales y muy leves.

Otras variables de importancia que modulan el desarrollo de estas comunidades, que no fueron consideradas en los ensayos de la presente tesis, como la herbivoría y los compuestos ecotoxicológicos, también deben ser incluidas y combinadas con los diversos factores para entender su aporte relativo a la dinámica de los biofilms. 


\section{BIBLIOGRAFÍA}

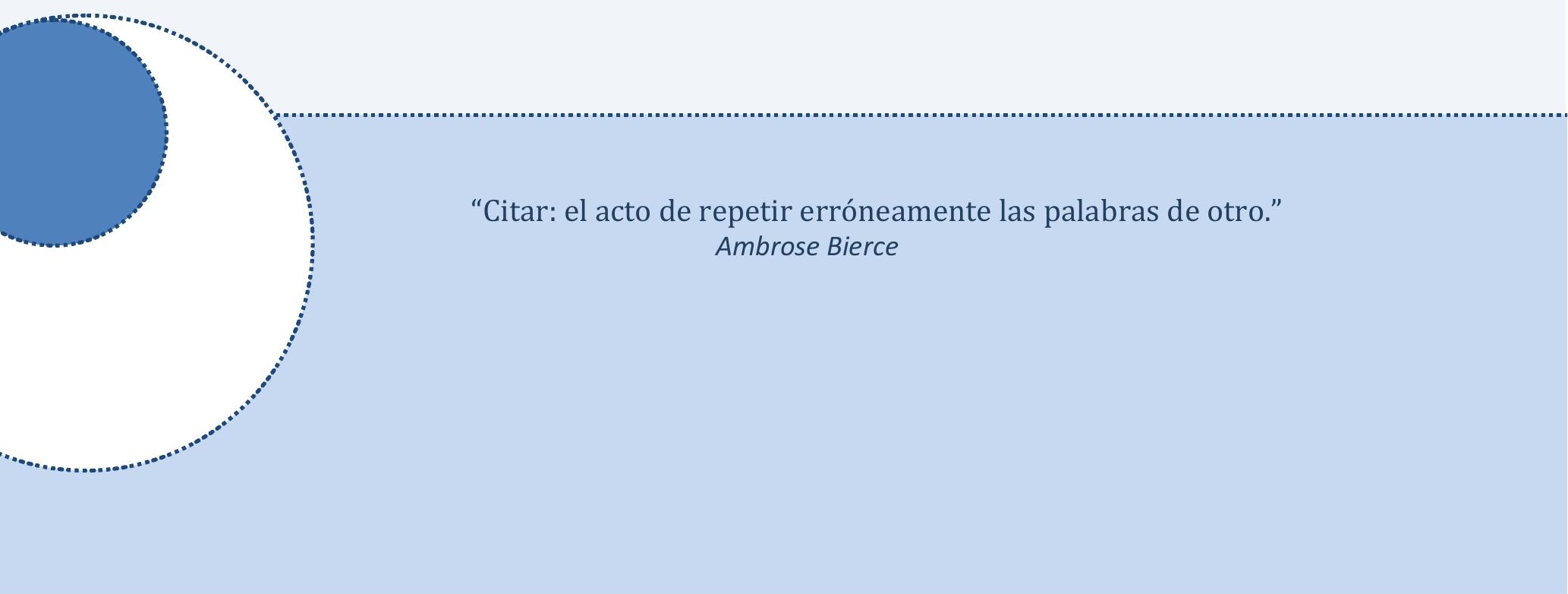


ACUÑA V, VILCHES C, GIORGI A. 2011. As productive and slow as a stream can be-the metabolism of a Pampean stream. Journal of the North American Benthological Society 30(1): 71-83.

ADMIRAAL W, BLANK H, BUCKERT-JONG MB, GUASCH H, IVORRA N, LEHMANN V, NYRSTRÖM M, PAULSSON M, SABATER S. 1999. Short-term toxicity of zinc to microbenthic algae and bacteria in a metal polluted stream. Water Research 33(9): 1989-1996.

ALEXANDER RB, SMITH RA, SCHWARZ GE. 2000. Effect of stream channel size on the delivery of nitrogen to the Gulf of Mexico. Nature 403: 758-761.

ALLAN JD, CASTILLO MA. 2007. Stream Ecology: Structure and Function of Running Waters, 2nd ed. Springer, The Netherlands. 400pp.

ALLISON DG, GILBERT P, LAPPIN-SCOTT HM, WILSON M (Eds). 2000. Community structure and co-operation in biofilms. Society for General microbiology Syposia. Cambridge University Press, Cambridge. 349pp.

ANTOINE SE, BENSON-EVANS K. 1982. The effects of current velocity on the rate of growth of benthic algal communities. Internationale Revue der Gesamten Hydrobiologie 67:575-83.

APHA. 1998. Standard methods for examination of water and wastewater 20th Edition. American Public Health Association, American Water Works Association and Water Pollution Control Federation, Washington. 1325pp.

ARMENDÁRIZ L, OCÓN C, RODRIGUES CAPÍTULO A. 2012. Potential responses of oligochaetes (Annelida, Clitellata) to global changes: Experimental fertilization in a lowland stream of Argentina (South America). Limnologica - Ecology and Management of Inland Waters 42(2): 118-126.

ARTIGAS J, GARCÍA-BERTHOU E, BAUER DE, CASTRO MI, COCHERO J, COLAUTTI D, CORTELEZZI A, DONATO JC, ELOSEGUI A, FEIJOÓ C, GIORGI A, GÓMEZ N, LEGGIERI L, MUÑOZ I, RODRIGUES-CAPÍTULO A, ROMANÍ AM, SABATER S. 2013. Global pressures, specific responses: effects of nutrient enrichment in streams from different biomes. Environmental Research Letters 8: 13pp.

ASNER GP, ELMORE AJ, OLANDER LP, MARTIN RE, HARRIS AT. 2004. Grazing systems, ecosystem responses, and global change. Annual Review of Environment and Resources 29: 261-299.

BAKEMAN R. 2005. Recommended effect size statistics for repeated measures designs. Behavior research methods 37(3): 379-384.

BALL RC, KEVERN NR, LINTON KJ. 1969. The Red Cedar River report. II, Bioecology. Publications of the Museum of Michigan State University, Biology Series 4:107-157.

BARLETT MS. 1947. The use of transformations. Biometrics 3: 39-52. 
BARRANGUET C, VAN BEUSEKOM SAM, VEUGER B, NEU TR, MANDERS EMM, SINKE JJ, ADMIRAAL W. 2004. Studying undisturbed autotrophic biofilms: still a technical challenge.. Aquatic Microbial Ecology 34: 1-9.

BATTIN TJ, KAPLAN LA, NEWBOLD JD, HANSEN CME. 2003. Contributions of microbial biofilms to ecosystem processes in stream mesocosms. Nature 426: 439-442.

BAUER DE. 2009. Ecología del fitoplancton de arroyos pampeanos y su valor como indicador de la calidad del agua. Tesis No 1039, UNLP, Argentina. 262pp.

BAUER DE, DONADELLI J, GÓMEZ N, LICURSI M. 2002a. Ecological status of the Pampean plain streams and rivers (Argentina). Verhandlungen des Internationalen Verein Limnologie 28: 259-262.

BAUER DE, CONDE ME, GOMEZ N. 2002b. Phytoplankton of a Small Lowland Stream Related to Water Quality and Hydraulic Discontinuities. Archiv Für Hydrobiologie 153(3): 421-441.

BERNHARDT ES, LIKENS GE. 2004. Controls on periphyton biomass in heterotrophic streams. Freshwater Biology 49(1): 14-27.

BIGGS BJF. 1995. The contribution of flood disturbance, catchment geology and land use to the habitat template of periphyton in stream ecosystems. Freshwater Biology 33:419438.

BIGGS BJF. 2000. Eutrophication of streams and rivers: dissolved nutrient-chlorophyll relationships for benthic algae. Journal of the North American Benthological Society 19:17-31.

BIGGS BJF, CLOSE ME. 1989. Periphyton biomass dynamics in gravel bed rivers: the relative effects of flows and nutrients. Freshwater Biology 22:209-231.

BINKLEY D, ICE GG, KAYE J, WILLIAMS CA. 2004. Nitrogen and phosphorus concentrations in forest streams of the United States. Journal of the American Water Resources Association 40: 1277-1291.

BITTON G, MARSHALL KC (Eds). 1980. Adsorption of microorganisms to surfaces. John Wiley \& Sons, Inc., New York. 452pp.

BLENKINSOPP SA, LOCK MA. 1990. The measurement of electron transport system activity in river biofilms. Water Research 24: 441-445.

BORCHARDT MA. 1996. Nutrients. In: STEVENSON RJ, BOTHWELL ML, LOWE RL (Eds). 1996. Algal Ecology. Academic Press, California. Pp. 183-227

BOTHWELL ML. 1985. Phosphorus limitation of lotic periphyton growth rates: an intersite comparison using continuous-flow troughs (Thompson river system, British Columbia). Limnology and Oceanography 30: 527-542. 
BOTT TL. 1975. Bacterial growth rates and temperature optima in a stream with a fluctuating thermal regime. Limnology and Oceanography 20(2): 191-197.

BOURRELLY P. 1972. Les algues d'eau douce. Initiation á la systématique. Tome I: Les Algues Vertes. Éditions N. Boubée \& Cie. Paris. 573pp.

BOX GEP. 1953. Non-normality and tests on variances. Biometrika 40: 318-335.

BOYLEN CW, BROCK TD. 1973. Bacterial decomposition processes in Lake Wingra sediments during winter. Limnology and Oceanography 18: 628-634.

BRANDA SS, VIK S, FRIEDMAN L, KOLTER R. 2005. Biofilms: the matrix revisited. Trends in microbiology 13(1): 20-6.

BRATBAK G, DUNDAS I. 1984. Bacterial Dry Matter Content and Biomass Estimations. Applied and Environmental Microbiology 48 (4): 755-7.

BRISOU J. 1995. Biofilms: Methods for enzymatic release of microorganisms. CRC Press. 204pp.

BROCKSEN RW, DAVIS GE, WARREN CE. 1968. Competition, food consumption, and production of sculpins and trout in laboratory stream com- munities. Journal of Wildlife Management 32: 51-75.

BRONMARCK CH. 1989. Interactions between epiphytes, macrophytes and freshwater snails: a review. Journal of Molluscan Studies 55: 299-311.

CABRERA AL, WILLINK A. 1980. Biogeografía de America Latina. Organization of American States, Washington. 122pp.

CAPERON J. 1967. Population Growth in Micro-Organisms Limited by Food Supply. Ecology 48: $715-722$

CAPERON J.1968. Population growth response of Isochsysis galbana to nitrate variation at limiting concentrations. Ecology 49: 866-872.

CARDINALE, BJ, PALMER MA, SWAN CM. 2002. The Influence of Substrate Heterogeneity on Biofilm Metabolism in a Stream Ecosystem. Ecology 83(2): 412-422.

CARPENTER SR, KITCHELL JF, HODGSON JR. 1985. Cascading trophic interactions and lake productivity. Bioscience 35: 634-639.

CARR GM, MORIN A, CHAMBERS PA. 2005. Bacteria and algae in stream periphyton along a nutrient gradient. Freshwater Biology 50(8): 1337-1350.

CHADWICK MA, HURYN AD. 2003. Effects of a whole- catchment $\mathrm{N}$ addition on stream detritus processing. Journal of the North American Benthological Society 22: 194-206.

CHAPELL KR, GOULDER R. 1994. Seasonal variation of extracellular enzyme activity in three diverse head-streams. Archiv für Hydrobiologie 130: 195-214. 
CHRÓST RJ. 1990. Microbial ectoenzymes in aquatic environments. In: OVERBECK J, CHRÓST RJ (Eds). 1990. Aquatic Microbial Ecology: Biochemical and Molecular Approaches. Springer-Verlag, New York. Pp. 47-78.

CHRÓST RJ. 1992. Significance of bacterial ectoenzymes in aquatic environments. Hydrobiologia 243-244(1): 61-70.

COCHRAN WG. 1947. Some consequences when the assumptions for the analysis of variance are not satisfied. Biometrics 3: 22-38

COELHO-BOTELHO MJ. 2003. Dinâmica da Comunidade Zooplanctônica e sua Relação com o Grau de Trofia em Reservatórios. V Simpósio e IV Reunião e Avaliação do Programa Biota/Fapesp. CETESB.

COHEN J. 1992. A power primer. Psychological Bulletin 112(1): 155-159.

CURRIE DJ, KALFF J. 1984. A comparison of the abilities of freshwater algae and bacteria to acquire and retain phosphorus. Limnology and Oceanography 29: 298-310.

DAHM CN. 1981. Pathways and mechanisms for removal of dissolved organic carbon from leaf leachate in streams. Canadian Journal of Fisheries and Aquatic Sciences 38: 68-76.

DAVIS GE, WARREN CE. 1965. Trophic relations of a sculpin in laboratory stream communities. Journal of Wildlife Management 29: 846-871.

DAY RW, QUINN GP. 1989. Comparisons of treatments after an analysis of variance. Ecological Monographs 59: 433-463.

DE PAGGI SJ. 2004. Diversidad de Rotíferos Monogononta en la cuenca del Bajo Paraná. Tesis doctoral No 0853. UNLP, Argentina.

DEEGAN LA, PETERSON BJ, GOLDEN H, MCIVOR CC, MILLER MC. 1997. Effects of fish density and river fertilization on al gal standing stocks, invertebrate communities, and fish production in an arctic river. Canadian Journal of Fisheries and Aquatic Sciences 54:269-283.

DESIKACHARY TV. 1959. Cyanophyta. Indian council of agricultural research, New Delhi. 685pp.

DODDS WK, BOUSKA WW, EITZMANN JL, PILGER TJ, PITTS KL, RILEY AJ, SCHLOESSER JT, THORNBRUGH DJ. 2009. Eutrophication of U.S. freshwaters: analysis of potential economic damages. Environmental Science and Technology 43: 12-19.

DONLAN RM. 2002. Biofilms: microbial life on surfaces. Emerging Infectious Diseases 8: 881890.

DONLAN RM, COSTERTON JW. 2002. Biofilms: survival mechanisms of clinically relevant microorganisms. Clinical Microbiology Reviews 15:167-193. 
DOU S. 2000. Hydrobios and Control of Eutrophication in Dongping Lake, Shandong Province. Acta Geologica Sinica 74 (2): 329-333.

DOWNES BJ, BARMUTA LA, FAIRWEATHER PG, FAITH DP, KEOUGH MJ, LAKE PS, MAPSTONE BD, QUINN GP. 2002. Monitoring Ecological Impacts: Concepts and Practice in Flowing Waters. Cambridge University Press, Cambridge. 452pp.

DROOP MR. 1961. Vitamin B12 and marine ecology: the response of Monochrysis lutheri. Journal of the Marine Biological Association 41: 689-733.

DROOP MR. 1968. Vitamin B12 and marine ecology. 4. The kinetics of uptake, growth, and inhibition in Monochrysis lutheri. Journal of the Marine Biological Association 48: 689-733.

DUBOIS M, GILLES KA, HAMILTON JK, REBERS PA, SMITH F. 1956. Colorimetric Method for Determination of Sugars and Related Substances. Analytical Chemistry 28(3): 350356.

DUGDALE RC. 1967. Nutrient limitation in the sea: Dynamics, identification, and significance. Limnology and Oceanography 12: 685-695.

EBERHARDT LL. 1976. Quantitative ecology and impact assessment. Journal of Environmental Management 4: 27-70.

EDWARDS RT. 1987. Sestonic bacteria as a food source for filtering invertebrates in two southeastern blackwater rivers. Limnology and Oceanography 32: 221-234

EDWARDS RT, MEYER JL. 1987. Bacteria as a food source for black fly larvae in a blackwater river. Journal of the North American Benthological Society 6: 241-250.

EISENHART C. 1947. The assumptions underlying the analysis of variance. Biometrics 3: 1-21.

ELWOOD JW, NEWBOLD JD, TRIMBLE AF, STARK RW. 1981. The limiting role of phosphorus in a woodland stream ecosystem: effects of P-enrichment on leaf decomposition and primary producers. Ecology 62: 146-158.

EPPLEY RW, COATSWORTH JL, SOLORZANO L. 1969. Studies of nitrate reductase in marine phytoplankton. Limnology and Oceanography 14: 194-205

ESPELAND EM, FRANCOEUR SN, WETZEL RG. 2001. Influence of algal photosynthesis on biofilm bacterial production and associated glucosidase and xylosidase activities. Microbial Ecology 42: 524-530.

FAIRCHILD GW, LOWE RL, RICHARDSON WB. 1985. Algal periphyton growth on nutrientdiffusing substrates: an in situ bioassay. Ecology 66:465-472.

FEIJOÓ CS, GIORGI A, GARCÍA ME, MOMO F. 1999. Temporal and spatial variability in streams of a pampean basin. Hydrobiología 394(0): 41-52. 
FEIJOÓ CS, LOMBARDO RJ. 2007. Baseline water quality and macrophyte assemblages in Pampean streams: a regional approach. Water research 41(7): 1399-410.

FINDLAY S, QUINNJM, HICKEY CW, BERRELL G, DOWNES M. 2001. Effects of land use and riparian flowpath on delivery of dissolved organic carbon to streams. Limnology and Oceanography 46: 345-355.

FIRTH P, FISHER SG (Eds). 1992. Global Climate Change and Freshwater Ecosystems. SpringerVerlag, New York. 321pp.

FLEMMING HC, WINGENDER J. 2001. Relevance of microbial extracellular polymeric substances (EPSs)--Part I: Structural and ecological aspects. Water science and technology 43(6): 1-8.

FOLEY JA, DEFRIES R, ASNER GP, BARFORD C, BONAN G, CARPENTER SR, CHAPIN FS, COE MT, DAILY GC, GIBBS HK, HELKOWSKI JH, HOLLOWAY T, HOWARD EA, KUCHARIK CJ, MONFREDA C, PATZ JA, PRENTICE IC, RAMANKUTTY N, SNYDER PK. 2005. Global consequences of land use. Science 309: 570-574.

FOLK RL. 1974. Petrology of Sedimentary Rocks. Hemphill Publishing Co., Austin. 182 pp.

FRANCOEUR SN, SCHAECHER M, NEELY RK, KUEHN KA. 2006. Periphytic photosynthetic stimulation of extracellular enzyme activity in aquatic microbial communities associated with decaying Typha litter. Microbial Ecology 52: 662-669.

FREEMAN C, LOCK MA. 1995. The biofilm polysaccharide matrix: A buffer against changing organic substrate supply?. Limnology and Oceanography 40(2): 273-278.

FUHS GW. 1969. Phosphorus content and the rate of growth in the diatoms Cyclotella nana and Thalassiosira fluviatilis. Journal of Phycology 5: 312-321.

GIORGI ADN. 1998. Factores reguladores del fitobentos de arroyos de llanura. Tesis doctoral No 711. UNLP, Argentina. 350pp.

GIORGI A, TIRABOSCHI B. 1999. Evaluación experimental del efecto de dos grupos de macroinvertebrados (anfípodos y gasterópodos) sobre algas epífitas. Ecología Austral 9: 35-44;

GIORGI A, FERREYRA G. 2000. Phytobenthos colonization in a lowland stream in Argentina. Journal of Freshwater Ecology 15(1): 39-46

GIORGI ADN, FEIJOÓ C, TELL G. 2005. Primary producers in a Pampean stream: temporal variation and structuring role. Biodiversity \& Conservation 14: 1699-1718.

GOERING JJ, NELSON DM, CARTER JA. 1973. Silicic acid uptake by natural populations of marine phytoplankton. Deep-Sea Research 20: 777-789. 
GOLD C, FEURTET-MAZEL A, COSTE M, BOUDOU A. 2003. Effects of cadmium stress on periphytic diatom communities in indoor artificial streams. Freshwater Biology 48(2): 316-328.

GÓMEZ N. 1998. Use of epipelic diatoms for evaluation of water quality in the MatanzaRiachuelo (Argentina), a Pampean plain river. Water Research 32 (7): 2029-2034.

GÓMEZ N. 1999. Epipelic diatom from the Matanza- Riachuelo river (Argentina), a highly polluted basin from the Pampean plain biotic indices and multivariate analysis. Aquatic Ecosystem Health and Management 2: 301-309.

GÓMEZ N, LICURSI M. 2001. The Pampean Diatom Index (IDP) for assessment of rivers and streams in Argentina. Aquatic Ecology (C): 173-181.

GÓMEZ N, SIERRA MV, CORTELEZZI A, RODRIGUES CAPÍTULO A. 2008. Effects of discharges from the textile industry on the biotic integrity of benthic assemblages. Ecotoxicology and environmental safety 69(3): 472-9.

GÓMEZ N, LICURSI M, COCHERO J. 2009. Seasonal and spatial distribution of the microbenthic communities of the Rio de la Plata estuary (Argentina) and possible environmental controls. Marine pollution bulletin 58(6): 878-87.

GÓMEZ N, SIERRA MV, COCHERO J, LICURSI M, BAUER DE. 2011. Epipelic biofilms as indicators of environmental changes in lowland fluvial systems. In: BAILEY WC. 2011. Biofilms: Formation, Development and Properties. Nova Science Publishers, Inc. Pp 259-290.

GREEN RH. 1979. Sampling design and statistical methods for environmental biologists. Wiley, Chichester. 272pp.

GREENHOUSE SW, GEISSER S. 1959. On methods in the analysis of profile data. Psychometrika 24: 95-112.

GREGORY SV. 1980. Effects of light, nutrients, and grazing on periphyton communities in streams. Tesis doctoral. Oregon State University, Corvallis.

GREGORY SV. 1983. Plant-herbivore interactions in stream systems. In: BARNES JR, MINSHALL GW (Eds).1983. Stream ecology. Application and testing of general ecological theory. Platinum press New York. Pp: 157-189.

GRIMM NB, FISHER SG. 1986a. Nitrogen limitation potential of Arizona streams and rivers. Journal of the Arizona-Nevada Academy of Science 21: 31-43.

GRIMM NB, FISHER SG. 1986b. Nitrogen limitation in a Sonoran Desert stream. Journal of the North American Benthological Society 5: 2-15 
GUARIENTO RD, CARNEIRO LS, CALIMAN A, BOZELLI RL, ESTEVES FA. 2011. How light and nutrients affect the relationship between autotrophic and heterotrophic biomass in a tropical black water periphyton community. Aquatic Ecology 45(4): 561-569.

GUASCH H, MARTÍ E, SABATER S. 1995. Nutrient enrichment effects on biofilm metabolism in a Mediterranean stream. Freshwater Biology 33: 373-383.

GUASCH H, NAVARRO E, SERRA A, SABATER S. 2004. Phosphate limitation influences the sensitivity to copper in periphytic algae. Freshwater biology 49: 463-73.

GUASCH H, SERRA A. 2009. Uso de ríos artificiales en ecología fluvial. In: ELOSEGUI A, SABATER $S$ (Eds). 2009. Conceptos y técnicas en ecología fluvial. Fundación BBVA, Bilbao. Pp: 387-395.

GULIS V, SUBERKROPP K. 2003. Leaf litter decomposition and microbial activity in nutrientenriched and unaltered reaches of a headwater stream. Freshwater Biology 48:123-134.

HAGLUND AL, HILLEBRAND H. 2005. The Effect of Grazing and Nutrient Supply on Periphyton Associated Bacteria. FEMS Microbiology Ecology 52 (1): 31-41.

HAMILTON WA. 1987. Biofilm: microbial interaction and metabolic activities. In: FLETCHER M, GRAY TRG, JONES JG (Eds). 1987. Ecology of microbial communities. Society for general microbiology symposium 41. Cambridge University Press, Cambridge, pp 361-387

HAMILTON S, CROOKSHANKAND N, LAM D. 2001. Hydrological and hydraulic routing and decision support in the Seymour Watershed .Final Report for the Greater Vancouver Regional District Watershed Management Branch. National Research Council and the Canadian Hydraulics Centre. 96pp.

HANSSON LA. 1988. Effects of competitive interactions on the biomass development of planktonic and periphytic algae in lakes. Limnology and Oceanography 33: 121128.

HARBOT EL, GRACE MR. 2005. Extracellular enzyme response to bioavailability of dissolved organic $C$ in streams of varying catchment urbanization. Journal of the North American Benthological Society 24: 588-601.

HEALEY FP, HENDZEL LL. 1979. Fluorometric measurement of alkaline phosphatase activity in algae. Freshwater Biology 9:429-439.

HECKY RE, KILHAM P. 1988. Nutrient limitation of phytoplankton in freshwater and marine envi- ronments: A review of recent evidence on the effects of enrichment.

Limnology and Oceanography 33:796-822 
HEPINSTALL JA, FULLER RL. 1994. Periphyton reactions to different light and nutrient levels and the response of bacteria to these manipulations. Archiv für Hydrobiologie 131: 161-173.

HILL WR. 1996. Effects of light. In: STEVENSON RJ, BOTHWELL ML, LOWE RL, THORP JH (Eds). 1996. Algal ecology: Freshwater benthic ecosystems. Academic press, San Diego. Pp: 121-149.

HILL WR, KNIGHT WR. 1988. Nutrient and light limitation of algae in two northern California streams. Journal of Phycology 24: 125-132.

HILL WR, RYON MG, SCHILLING EM. 1995. Light limitation in a stream ecosystem: Responses by primary producers and consumers. Ecology 76: 504-512.

HILL BH, ELONEN CM, SEIFERT LR, MAY AA, TARQUINIO E. 2012. Microbial enzyme stoichiometry and nutrient limitation in US streams and rivers. Ecological Indicators 18: 540-551.

HILLEBRAND H, SOMMER U. 1997. Response of epilithic microphytobenthos of the Western Baltic Sea to in situ experiments with nutrient enrichment. Marine EcologyProgress Series 160: 35-46.

HILLEBRAND H. 2005. Light regime and consumer control of autotrophic biomass. Journal of Ecology 93:758-769.

HOAGLAND KD, CARDER JP, SPAWN RL. 1996. Effects of organic toxic substances. In: STEVENSON RJ, BOTHWELL ML, LOWE RL, THORP JH (Eds). 1996. Algal ecology: Freshwater benthic ecosystems. Academic press, San Diego. Pp 469-496.

HOLMES RM, JONES JB Jr., FISHER SG, GRIMM NB. 1996. Denitrification in a nitrogen-limited stream ecosystem. Biogeochemistry 33: 125-146.

HOMER RR, WELCH EB. 1981. Stream periphyton development in relation to current velocity and nutrients. Canadian Journal of Fisheries and Aquatic Sciences 38: 449-457

HOPPE H. 1983. Significance of exoenzymatic activities in the ecology of brackish water: measurements by means of methylumbelliferyl-substrates. Marine Ecology Progress Series 11: 299-308.

HORNER RR, WELCH EB, VEENSTRA RB. 1983. Development of nuisance periphytic algae in laboratory streams in relation to enrichment and velocity. In: Wetzel RG (Ed). 1983. Periphyton of Freshwater Ecosystems. Dr. W. Junk Publishers, The Netherlands. Pp: 121-134

HORNER RR, WELCH EB, SEELEY MR, JACOBY JM. 1990. Responses of Periphyton to Changes in Current Velocity, Suspended Sediment and Phosphorus Concentration. Freshwater Biology 24 (2): 215-232. 
HULME M, SHEARD N. 1999. Climate Change Scenarios for Argentina. Climatic Research Unit, Norwich, UK. 6pp.

HUNTSMAN AG. 1948. Fertility and fertilization of streams. Journal of the Fisheries Research Board of Canada 7:248-253.

INDEC. 2010. Censo Nacional de Población, Hogares y Viviendas 2010. Instituto Nacional de Estadística y Censos. www.indec.gov.ar.

IPCC. 2007. Climate Change 2007: The Physical Science Basis. Contribution of Working Group I to the Fourth Assessment Report of the Intergovernmental Panel on Climate Change. SOLOMON S, QIN D, MANNING M, CHEN Z, MARQUIS M, AVERYT KB, TIGNOR M, MILLER HL (Eds.). Cambridge University Press, Cambridge, y New York, NY. 996 pp.

JANG A, KIM SM, KIM SY, LEE SG, KIM IS. 2001. Effect of Heavy Metals ( $\mathrm{Cu}, \mathrm{Pb}$, and Ni) on the Compositions of EPS in Biofilms. Water Science and Technology 43 (6): 41-8.

JASSBY AD, PLATT T. 1976. Mathematical formulation of the relationship between photosynthesis and light for phytoplankton. Limnology and Oceanography 21: 540-547.

JAVED M. 2006. Studies on Metal Contamination Levels in Plankton and Their Role as Biological Indicator of Water Pollution in the River Ravi. Pakistan Journal of Biological Sciences 9: 313-317.

JENKINSON HF, LAPPIN-SCOT H. 2001. Biofilms adhere to stay. Trends in Microbiology 9: 9-10.

JONES SE, LOCK MA. 1993. Seasonal determinations of extracellular hydrolytic activities in heterotrophic and mixed heterotrophic/autotrophic biofilms from two contrasting rivers. Hydrobiologia 257(1): 1-16.

JONES JI, JOHNSTONE O, YOUNG J, EATON W, MOSS B. 2002. The influence of nutrient loading, dissolved inorganic carbon and higher trophic levels on the interaction between submerged plants and periphyton. Journal of Ecology 90:12-24.

KAPLAN LA, BOTT TL. 1983. Microbial heterotrophic utilization of dissolved organic matter in a piedmont stream. Freshwater Biology 13:363-377.

KAPLAN LA, BOTT TL. 1989. Diel fluctuations in bacterial activity on streambed substrata during vernal algal blooms: effects of temperature, water chemistry, and habitat. Limnology and Oceanography 34:718-733

KEHDE PM, WILHM JL. 1972. The effects of grazing by snails on community structure of periphyton in laboratory streams. American Midland Naturalist 87:8-24.

KELLY MG, WHITTON BA. 1995. Trophic Diatom Index - a New Index for Monitoring Eutrophication in Rivers. Journal of Applied Phycology 7:433-444. 
KELLY MG, CAZAUBON A, CORING E, DELL'UOMO A, ECTOR L, GOLDSMITH B, GUASCH H, HÜRLIMANN J, JARLMAN A, KAWECKA B, KWANDRANS J, LAUGASTE R, LINDSTR ØM EA, LITAO M, MARVAN P, PADISÁK J, PIPP E, PRYGIEL J, ROTT E, SABATER S, VAN DAM H, VIZINET J. 1998. Recommendations for the routine sampling of diatoms for water quality assessments in Europe. Journal of Applied Phycology 10: 215-224.

KEVERN NR, BALL RC. 1965. Primary productivity and energy relationships in artificial streams. Limnology and Oceanography 10:74-87

KOETSIER P, MCARTHUR V, LEFF LG. 1997. Spatial and temporal response of stream bacteria to sources of dissolved organic carbon in a blackwater system. Freshwater Biology 37:79-89.

KOMÁREK J, PRAHA BF. 1983. Das Phytoplankton des SüBwasswassers, Systematik und Biologie. Schweizerbart, Stuttgart. 1044pp.

KOMAREK J, ANAGNOSTIDIS K. 1999. SüBwasswasserflora von Mitteleuropa, Cyanoprokaryota 1: Chroococcales. Gustav Fischer Verlag, Jena. 548 pp.

KOMAREK J, ANAGNOSTIDIS K. 2005. SüBwasswasserflora von Mitteleuropa, Cyanoprokaryota 2: Oscillatoriales. Elsevier GMHB, München. 759 pp

KORTE VL, BLINN DW. 1983. Diatom colonization on artificial substrata in pool and riffle zones studied by light and scanning electron microscopy. Journal of Phycology 19: 332341.

KRAMMER K, LANGE-BERTALOT H. 1986. SüBwasswasserflora von Mitteleuropa, Bacillariophyceae 1: Naviculaceae. Gustav Fischer Verlag, Stuttgart. 876 pp.

KRAMMER K, LANGE-BERTALOT H. 1988. SüBwasswasserflora von Mitteleuropa, Bacillariophyceae 2: Bacillariaceae, Epithemiaceae, Surirellaceae. Gustav Fischer Verlag, Stuttgart. $596 \mathrm{pp}$

KRAMMER K, LANGE-BERTALOT H. 1991a. SüBwasswasserflora von Mitteleuropa, Bacillariophyceae 3: Centrales, Fragilariaceae, Eunotiaceae. Gustav Fischer Verlag, Stuttgart. 576 pp.

KRAMMER K, LANGE-BERTALOT H. 1991b. SüBwasswasserflora von Mitteleuropa, Bacillariophyceae 4: Achnanthaceae, Literaturverzeichnis. Gustav Fischer Verlag Stuttgart. 437 pp.

KRAMMER K. 1992. Pinnularia: eine Monographie der europäischen Taxa. Bibliotheca Diatomologica 26: 1-353.

KRAMMER K. 2000. The genus Pinnularia. In: LANGE-BERTALOT H. (Ed). 2000. Diatoms of Europe, Vol 1. A.R.G. Gantner Verlag, Ruggell. 572pp. 
LABAT D, GODDÉRIS Y, PROBST JL, GUYOT JL. 2004. Evidence for global runoff increase related to climate warming. Advances in Water Resources 27(6): 631-642.

LAKE PS, PALMER MA, BIRO P, COLE J, COVICH AP, DAHM C, GIBERT J, GOEDKOOP W, MARTENS K, VERHOEVEN J. 2000. Global Change and the Biodiversity of Freshwater Ecosystems: Impacts on Linkages between Above-Sediment and Sediment Biota. BioScience 50(12): 9pp.

LAMBERTI GA. 1996. The role of periphyton in benthic food webs. In: STEVENSON RJ, BOTHWELL ML, LOWE RL, THORP JH (Eds). 1996. Algal ecology: Freshwater benthic ecosystems. Academic Press, San Diego.

LAMBERTI GA, ASHKENAS LR, GREGORY SV, STEINMAN AD. 1987. Effects of three herbivores on periphyton communities in laboratory streams. Journal of the North American Benthological Society 6:92-104.

LAMBERTI GA, STEINMAN AD. 1993. Research in Artificial Streams: Applications, Uses, and Abuses. Journal of the North American Benthological Society 12(4). 313pp.

LANGE-BERTALOT H. 1993. 85 new Taxa. Vol 2/1-4. J. Cramer, Berlin. 453pp.

LANGE-BERTALOT H, MOSER G. 1994. Brachysira, Monographie der Gattung. J. Cramer, Berlin. $211 \mathrm{pp}$.

LAUFF GH, CUMMINS KW. 1964. A model stream for studies in lotic ecology. Ecology 45: 188191.

LEFF LG. 2000. Longitudinal changes in microbial assemblages of the Ogeechee River. Freshwater Biology 43:605-615.

LEFF LG, BROWN BJ, LEMKE MJ. 1999. Spatial and temporal changes in bacterial assemblages of the Cuyahoga River. Ohio Journal of Science 99:44-48.

LEHTOLA MJ, LAXANDER M, MIETTINEN IT, HIRVONEN A, VARTIAINEN T, MARTIKAINEN PJ. 2006. The effects of changing water flow velocity on the formation of biofilms and water quality in pilot distribution system consisting of copper or polyethylene pipes. Water research 40(11): 2151-60.

LEU HG, OUYANG CF, SU JL. 1996. Effects of flow velocity changes on nitrogen transport and conversion in an open channel flow. Water Research 30(9): 2065-2071.

LICURSI M, GÓMEZ N. 2002. Benthic diatoms and some environmental conditions in three lowland streams. Annales de Limnologie - International Journal of Limnology 38(2): 109-118.

LICURSI M, GÓMEZ N. 2003. Aplicación de índices bióticos en la evaluación de la calidad del agua en sistemas lóticos de la llanura pampeana Argentina a partir del empleo de diatomeas. Biología Acuática 21: 31-49. 
LICURSI M. 2005. Efectos de las perturbaciones antropogénicas sobre la taxoncenosis de diatomeas bentónicas en sistemas lóticos pampeanos. Tesis doctoral No 859. UNLP, Argentina. 186pp.

LICURSI M, GÓMEZ N, DONADELLI J. 2010. Ecological optima and tolerances of coastal benthic diatoms in the freshwater-mixohaline zone of the Río de la Plata estuary. Marine Ecology Progress Series 418: 105-117.

LOCK MA. 1981. River epilithon. A light and organic energy reducer. In: LOCK MA, WILLIAMS DD (Eds). 1981. Perspectives in running water ecology. Plenum Press. Pp: 1-40.

LOCK MA. 1993. Attached microbial communities in rivers. In: LOCK MA (Ed). 1993. Aquatic microbiology: an ecological approach. Blackwell Scientific Publications, Oxford. Pp: 113-138.

LOCK MA, WALLACE RR, COSTERTON JW, VENTULLO RM, CHARLTON SE. 1984. River epilithon: toward a structural-functional model. Oikos 42: 10-22.

LÓPEZ VAN OOSTEROM MV, OCÓN CS, BRANCOLINI F, MAROÑAS ME, SENDRA ED, RODRIGUES CAPÍTULO A. 2013. Trophic relationships between macroinvertebrates and fish in a pampean lowland stream (Argentina). Iheringia - Série Zoologia. In press.

LOVELL CR, KONOPKA A. 1985. The effects of temperature on bacterial production in a dimictic eutrophic lake. FEMS Microbial Ecolology 31: 135-140.

LOWE RL, GOLLADAY SW, WEBSTER JR. 1986. Periphyton response to nutrient manipulation in streams draining clearcut and forested watersheds. Journal of the North American Benthological Society. 5:221-229

LOWE RL, PAN Y. 1996. Benthic algal communities and biological monitors. In: STEVENSON RJ, BOTHWELL ML, LOWE RL, THORP JH (Eds). 1996. Algal ecology: Freshwater benthic ecosystems. Academic Press, San Diego.

MALLORY MA, RICHARDSON JS. 2005. Complex interactions of light, nutrients and consumer density in a stream periphyton grazer (tailed frog tadpoles)system. Journal of Animal Ecology 74:1020-1028.

MARGALEF R. 1983. Limnología. Omega. Barcelona. 1010 pp

MARGALEF R. 1997. Our Biosphere. In: KINNE O. (Ed). 1997. Excellence in Ecology Series, book 10. Ecology Institute, Oldendorf. 176pp.

MCDIFFETT WF. 1970. The transformation of energy by a stream detritivore, Pteronarcys scotti (Plecoptera). Ecology 51: 976-988.

MCLNTIRE CD. 1968. Structural characteristics of benthic algal communities in laboratory streams. Ecology 49: 520-537 
MCINTIRE D, GARRISON RL, PHINNEY HK, WARREN CE. 1964. Primary production in laboratory streams. Limnology and Oceanography 9: 92-102.

MCNAMARA CJ, LEFF LG. 2004. Response of Biofilm Bacteria to Dissolved Organic Matter from Decomposing Maple Leaves. Microbial Ecology 48(3): 324-30.

MEYBECK M, HELMER R. 1989. The quality of rivers: from pristine stage to global pollution. Paleogeography, Paleoclimatology, Paleoecology 75: 283-309.

MONOD J. 1950. La technique de culture continue, theorie et applications. Annales de l'Institut Pasteur 79: 390-410.

MOSISCH TD. 2001. Effects of desiccation on stream epilithic algae. New Zealand Journal of Marine and Freshwater Research 35: 173-179.

MOSISCH TD, BUNN SE, DAVIES PM. 2001. The relative importance of shading and nutrients on algal production in subtropical streams. Freshwater Biology 46: 1269-1278.

MULHOLLAND PJ. 1996. Role in nutrient cycling in streams. In: STEVENSON RJ, BOTHWELL ML, LOWE RL, THORP JH (Eds). 1996. Algal ecology: Freshwater benthic ecosystems. Academic Press, San Diego. Pp 609-640.

MUNN MD, OSBORNE LL, WILEY MJ. 1989. Factors influencing periphyton growth in agricultural streams of central Illinois. Hydrobiologia 174:89-97.

MUÑOZ I, REAL M, GUASCH H, NAVARRO RODRIGUEZ E, SABATER S. 2001. Effects of Atrazine on Periphyton Under Grazing Pressure. Aquatic Toxicology 55 (3-4): 239-249.

MURRAY R, COOKSEY KE, PRISCU JC. 1986. Stimulation of bacterial DNA synthesis by algal exudates in attached algal-bacterial consortia. Applied and Environmental Microbiology 52: 1177-1182.

NAIMAN RJ, DÉCAMPS H. 1990. The ecology and management of aquatic-terrestrial ecotones. Man and Biosphere Series 4, UNESCO.

NAVARRO RODRIGUEZ E. 1998. Respuesta ecotoxicológica de comunidades microbentónicas de ríos mediterráneos. Tesis doctoral. Universidad de Barcelona, España.

NEALE PJ, RICHERSON PJ. 1987. Photoinhibition and the diurnal variation of phytoplankton photosynthesis-I. Development of a photosynthesis-irradiance model from studies of in situ responses. Journal Plankton Research 9 (1): 167-193.

NORLAND S. 1993. The relationship between biomass and volume of bacteria. In KEMP PF, SHERR BF, SHERR EB, COLE JJ (Eds.).1993. Handbook of methods in aquatic microbial ecology. Lewis Publishers, Boca Raton. Pp. 303-307. 
NOWELL RM, JUMARS PA. 1987. Flumes: theoretical and experimental considerations for simulation of benthic environments. Annual Review of Oceanography and Marine Biology 25: 91-112.

O'REILLY C, ALIN S, PLISNIER P, COHEN A, MCKEE B. 2003. Climate change decreases aquatic ecosystem productivity of Lake Tanganyika, Africa. Nature 424:766-768.

OCON CS, LÓPEZ van OOSTEROM MV, MUÑOZ MI, RODRIGUES-CAPÍTULO A. 2013. Macroinvertebrate trophic responses to nutrient addition in a temperate stream in South America. Archiv für Hydrobiologie 182(1): 17-30.

ODUM HT, HOSKIN CM. 1957. Metabolism of a laboratory stream microcosm. University of Texas Publications of the Institute of Marine Science 4:115-133.

ODUM EP, FINN JT, FRANZ EH. 1979. Perturbation theory and the subsidy- stress gradient. Bioscience 29: 349-352.

OLAPADE OA, LEFF LG. 2005. Seasonal Response of Stream Biofilm Communities to Dissolved Organic Matter and Nutrient Enrichments. Applied and Environmental Microbiology 71(5): 2278-2287.

OLEJNIK S, ALGINA J. 2003. Generalized eta and omega squared statistics: measures of effect size for some common research designs. Psychological methods 8(4): 434-47.

OLIVIER SR. 1965. Rotíferos Planctónicos de Argentina. Revista del Museo de la Plata (n.s.) 8 (63).

OSENBERG CW, BOLKER BM, WHITE J-SS, ST. MARY CM, SHIMA JS. 2006. Statistical issues and study design in ecological restorations: lessons learned from marine reserves. In: Falk DA, Palmer MA, Zedler JB (Eds). 2006. Foundations of Restoration Ecology. Island Press, Washington. Pp. 280-302.

PAASCHE E. 1973. Silicon and the ecology of marine plankton diatoms. Thalassiosira pseudonana (Cyclotella nana) grown in a chemostat with silicate as the limiting nutrient. Marine Biology 19: 117-126.

PAN Y, STEVENSON RJ, HILL BH, HERLIHY A, COLLINS GB. 1996. Using diatoms as indicators of ecological conditions in lotic systems: a regional assessment. Journal of the North American Benthological Society 15: 481-495.

PATRICK R. 1967. The effect of invasion rate, species, pool, and size of area on the structure of diatom community. Proceedings of the National Academy of Science 58: 13351342.

PATRICK R, REIMER CW. 1966. The Diatoms of the United States, exclusive of Alaska \& Hawaii, Vol. 1. Academy of Natural Sciences of Philadelphia Monographs 13 (1): 1-688. 
PATRICK R, REIMER CW. 1975. The Diatoms of the United States, exclusive of Alaska \& Hawaii, Vol. 2, Part 1. Academy of Natural Sciences of Philadelphia Monographs 13 (2/1): 1-213.

PATZ J. 2001. Public health risk assessment linked to climatic and ecological change. Human Ecology and Risk Assessment 7: 1317-1327.

PETERS GT, WEBSTER JR, BENFIELD EF. 1987. Microbial activity associated with seston in headwater streams: Effects of nitrogen, phosphorus and temperature. Freshwater Biology 18: 405-413.

PETERSON BJ, HOBBIE JE, CORLISS RL, FRIET K. 1983. A continuous-flow periphyton bioassay: tests of nutrient limitation in a tundra stream. Limnology and Oceanography 28: 583-59

PETERSON BJ, DEEGAN L, HELFRICH J, HOBBIE JE, HULLAR M, MOLLER B, FORD TE, HERSHEY A, HILTNER A, KIPPHUT G, LOCK MA, FIEBIG DM, MCKINLEY V, MILLER MC, VESTAL JR, VENTULLO R, VOLK G. 1993. Biological Responses of a Tundra River to Fertilization. Ecology 74:653-672.

PHINNEY K, MCINTIRE CD. 1965. Effects of temperature on metabolism of periphyton communities developed in laboratory streams. Limnology and Oceanography 10:341-344.

PLATT TC, GALLEGOS L, HARRISSON WG. 1980. Photoinhibition of photosynthesis in natural assemblages of marine phytoplankton. Journal of Marine Research 38: 687-701.

POFF NL, BRINSON MM, DAY JW. 2002. Aquatic ecosystems \& Global climate change. Pew Center on Global Climate Change, 17pp.

PORTER KG, FEIG YG. 1980. The use of DAPI for identifying and counting aquatic microflora. Limnology and Oceanography 41, 595-604.

PRINGLE C. 1987. Effects of water and substratum nutrient supplies on lotic periphyton growth: an integrated bioassay. Canadian Journal of Fisheries and Aquatic Sciences 44: 619-629.

PUSCH M, FIEBIG D, BRETTAR I, EISENMANN H, ELLIS BK, KAPLAN LA, LOCK MA, NAEGELI MW, TRAUNSPURGER W. 1998. The role of micro-organisms in the ecological connectivity of running waters. Freshwater biology 40: 453-495.

RAMANKUTTY N, FOLEY J. 1999. Estimating historical changes in global land cover: croplands from 1700 to 1992. Global Biogeochemical Cycles 13: 997-1028.

RAMASAMY P, ZHANG X. 2005. Effects of shear stress on the secretion of extracellular polymeric substances in biofilms. Water Science and Technology 52(7):217-23. 
REAL M, MUÑOZ I, GUASCH H, NAVARRO RODRÍGUEZ E, SABATER S. 2003. The effect of copper exposure on a simple aquatic food chain. Aquatic toxicology 63(3):283-91.

REDFIELD AC. 1958. The biological control of chemical factors in the environment. American Scientist 46:205-222

REESE MJ. 1937. The microflora of the non-calcareous streams Rheidol and Melindwr with special reference to water pollution from lead mines in Cardiganshire. Journal of Ecology 25: 385-407.

RELYEA RA. 2005. The impact of insecticides and herbicides on the biodiversity and productivity of aquatic communities. Ecological Applications 15: 618-627.

RHEE G. 1972. Competition between an alga and an aquatic bacterium for phosphate. Limnology and Oceanography 17(4): 505-514.

RHEE G. 1973. A continuous culture study of phosphate uptake, growth rate and polyphosphate in Scenedesmus sp. Journal of Phycology 9:495-506.

RICART M, BARCELÓ D, GEISZINGER A, GUASCH H, LÓPEZ DE ALDA M, ROMANÍ AM, VIDAL G, VILLAGRASA M, SABATER S. 2009. Effects of Low Concentrations of the Phenylurea Herbicide Diuron on Biofilm Algae and Bacteria. Chemosphere 76 (10): 1392-401.

RIER S, STEVENSON R. 2002. Effects of light, dissolved organic carbon, and inorganic nutrients on the relationship between algae and heterotrophic bacteria in stream periphyton. Hydrobiologia 489(1-3): 179-184.

RIER S, STEVENSON RJ. 2001. Relation of environmental factors to density of epilithic lotic bacteria in 2 ecoregions. Journal of the North American Benthological Society 20:520-532

RIER S, KUEHN K, FRANCOEUR S. 2007. Algal regulation of extracellular enzyme activity in stream microbial communities associated with inert substrata and detritus. Journal of the North American Benthological Society 26(3): 439-449.

RODGERS H JR, HARVEY RS. 1976. The effect of periphytic productivity as determined using ${ }^{14} \mathrm{C}$. Water Resources Bulletin 12: 1109-111

ROMANÍ AM, SABATER S. 1999. Effect of primary producers on the heterotrophic metabolism of a stream biofilm. Freshwater Biology 41(4): 729-736.

ROMANI AM, SABATER S. 2000. Influence of algal biomass on extracellular enzyme activity in river biofilms. Microbial Ecology 41(16): 16-24.

ROMANÍ AM, SABATER S. 2001. Structure and Activity of Rock and Sand Biofilms in a Mediterranean Stream. Ecology 82(11): 3232. 
ROMANÍ AM, BUTTURINI A, SABATER F, SABATER S. 1998. Heterotrophic metabolism in a forest stream sediment: surface versus subsurface zones. Aquatic Microbial Ecology 16: 143-151.

ROMANÍ AM, GIORGI A, ACUÑA V, SABATER S. 2004a. The influence of substratum type and nutrient supply on biofilm organic matter utilization in streams. Limnology and Oceanography 49(5): 1713-1721.

ROMANÍ AM, GUASCH H, MUÑOZ I, RUANA J, VILALTA E, SCHWARTZ T, EMTIAZI F, SABATER S.2004b. Biofilm structure and function and possible implications for riverine DOC dynamics. Microbial Ecology 47:316-328.

ROMANÍ AM, ARTIGAS J, CAMACHO A, GRAÇA MAS, PASCOAL C. 2009. La biota de los ríos: los microorganismos heterotróficos. In: ELOSEGUI A, SABATER S (Eds.) Conceptos y técnicas en ecología fluvial. Fundación BBVA, Bilbao. Pp: 169-218.

ROMANÍ AM, AMALFITANO S, ARTIGAS J, FAZI S, SABATER S, TIMONER X, YLLA I, ZOPPINI A. 2012. Microbial biofilm structure and organic matter use in mediterranean streams. Hydrobiologia DOI 10.1007/s10750-012-1302-y.

ROOT T L, SCHNEIDER SH. 2002. Ecology and climate: Research strategies and implications. Science 269 (5222): 334-341.

ROSE FL, MCINTIRE CD. 1970. Accumulation of dieldrin by benthic algae in laboratory streams. Hydrobiologia 35 (3-4): 481-493.

ROSEMOND AD, MULHOLLAND PJ, ELWOOD JW. 1993. Top-down and bottom-up control of stream periphyton: effects of nutrients and hervibores. Ecology 74: 1264-1280.

RULÍK M, SPÁCIL R. 2004. Extracellular enzyme activity within hyporheic sediments of a small lowland stream. Soil Biology and Biochemistry 36: 1653-1662.

SABATER S, SABATER F, ARMENGOL J. 1993. Ecología de los ríos mediterráneos. Investigación y Ciencia 203: 72-79.

SABATER S, GUASCH H, ROMANÍ A, MUÑOZ I. 2002. The effect of biological factors on the efficiency of river biofilms in improving water quality. Hydrobiologia 469 (1-3): 149-156.

SABATER S, BUTTURINI A, CLEMENT JC, BURT T, DOWRICK D, HEFTING M, MAÎTRE V, PINAY G, POSTOLACHE C, RZEPECKI M, SABATER F. 2003. Nitrogen removal by riparian buffers along a European climatic gradient: Patterns and factors of variation. Ecosystems 6(1): 20-30.

SABATER S, ELOSEGUI A. 2009. Presentación: importancia de los ríos. In: ELOSEGUI A, SABATER S. 2009. Conceptos y técnicas en ecología fluvial. Fundación BBVA, España. Pp:1521. 
SABATER S, ARTIGAS J, GAUDES A, MUÑOZ I, URREA G, ROMANÍ AM. 2011. Long-term moderate nutrient inputs enhance autotrophy in a forested Mediterranean stream. Freshwater Biology 56(7): 1266-1280.

SCHANZ F, JUON H. 1983. Two different methods of evaluating nutrient limitations of periphyton bioassays, using water from the River Rhine and eight of its tributaries. Hydrobiologia 102:187-195.

SCHEFFEÉ H. 1959. The analysis of variance. Wiley, New York. 477pp.

SCHILLER DV, MARTí E, RIERA JL, SABATER F. 2007. Effects of Nutrients and Light on Periphyton Biomass and Nitrogen Uptake in Mediterranean Streams with Contrasting Land Uses. Freshwater Biology 52 (5): 891-906.

SEABURG KG, PARKER BC, WHARTON RA, SIMMONS GM. 1981. Temperature-growth responses of algal isolates from Antartic oases. Journal of Phycology 17: 353-360.

SEIM WK. 1970. Influence of biologically stabilized kraft mill effluent on the food relations and pro- duction of juvenile chinook salmon in laboratory streams. Tesis M.S., Oregon State University, USA.

SHANNON CE, WEAVER W. 1949. The mathematical theory of communication. University of Illinois Press 19(7).

SHORER M, EISELE M. 1997. Accumulation of inorganic and organic pollutants by biofilms in the aquatic environment. Water, Air, and Soil Pollution 99: 651-659.

SIERRA MV. 2008. Microbentos de sistemas lóticos pampeanos y su relación con la calidad del agua: respuestas estructurales y funcionales. Tesis doctoral No 1014, UNLP, Argentina. 233pp.

SIERRA MV, GOMEZ N. 2007. Structural Characteristics and Oxygen Consumption of the Epipelic Biofilm in Three Lowland Streams Exposed to Different Land Uses. Water, Air, and Soil Pollution 186 (1-4): 115-127.

SIGEE DC (Ed). 2005. Freshwater microbiology. Biodiversity and Dynamic interactions of microorganisms in the aquatic environment. Wiley. England. 524pp.

SINSABAUGH RL, WEILAND T, LINKINS AE. 1991. Epilithon patch structure in a boreal river. Journal of the North American Benthological Society 10: 419-429.

SINSABAUGH RL, REPERT D, WEILAND T, GOLLADAY SW, LINKINS AE. 1991b. Exoenzyme accumulation in epilithic biofilms. Hydrobiologia 222:29-37.

SINSABAUGH RL, VAN HORN DJ, SHAH JJF, FINDLAY S. 2010. Ecoenzymatic stoichiometry in relation to productivity for freshwater biofilm and plankton communities. Microbial ecology 60(4): 885-93. 
SLADECEK V. 1973. System of water quality from the biological point of view. Archiv fuer Hydrobiologie 7: 1-218.

SLANEY PA, ASHLEY KI. 1998. Case studies of whole stream fertilization in British Columbia. In: STOCKNER JG, MILLBRINK G (Eds). Restoration of fisheries by enrichment of aquatic ecosystems. Uppsala University, Uppsala. Pp 83-97.

SLANEY PA, WARD BR. 1993. Experimental fertilization of nutrient deficient streams in British Columbia. In: SHOONER G., ASSELIN S. (Eds). Le développment du Saumon atlantique au Québec: connaître les règles du jeu pour réussir. Colloque international de la Fédération québécoise pour le saumon atlantique. Québec. p. 128-141

SLAVIK K, PETERSON BJ, DEEGAN LA, BOWDEN WB, HERSHEY AE, HOBBIE JE. 2004. Long-term responses of the Kuparuk River ecosystem to phosphorus fertilization. Ecology 85:939-954.

SMITH VH. 2003. Eutrophication of freshwater and coastal marine ecosystems. A global problem. Environmental Science and Pollution Research 10: 126-139.

SNEDECOR GW, COCHRAN WG. 1989. Statistical methods. University of lowa Press, Ames. $503 p p$.

SOBCZAK W. 1996. Epilithic bacteria responses to variations in algal biomass and labile dissolved organic carbon during biofilm colonization. Journal of the North American Benthological Society 15: 143-154.

SOIL AND WATER CONSERVATION SOCIETY.2003. Soil erosion and runoff from cropland. Reporte de la US Soil and Water Conservation Society. 63pp.

SOLARI LC, CLAPS MC. 1996. Planktonic and benthic algae of a Pampean river (Argentina): Comparative analysis. Annales de Limnologie 32(2): 89-95.

SOMVILLE M. 1984. Measurement and study of substrate specificity of exoglucosidase activity in eutrophic water. Applied Environmental Microbiology 48: 1181-1185.

STEINMAN AD. 1996. Effects of grazers on freshwater benthic algae In: STEVENSON RJ, BOTHWELL ML, LOWE RL, THORP JH (Eds). 1996. Algal ecology: Freshwater benthic ecosystems. Academic Press, San Diego. Pp: 341-373

STEINMAN AD, MULHOLLAND PJ. 1996. Phosphorus limitation, uptake, and turnover in stream algae. In: HAUER FR, LAMBERTI GA (Eds.). Methods in Stream Ecology. Academic Press, San Diego. Pp. 161-189.

STELZER RS, LAMBERTI GA. 2001. Effects of N: P ratio and total nutrient concentration on stream periphyton community structure, biomass, and elemental composition. Limnology and Oceanography 46: 356-367. 
STELZER RS, HEFFERNAN J, LIKENS GE. 2003. The influence of dissolved nutrients and particulate organic matter quality on microbial respiration and biomass in a forest stream. Freshwater Biology 48: 1925-1937.

STERNER RW, ELSER JJ, HESSEN DO. 1992. Stoichiometric relationships among producers, consumers and nutrient cycling in pelagic ecosystems. Biogeochemistry 17: 49-67.

STEVENSON RJ. 1983. Effects of current and conditions simulating autogenically changing microhabitats on benthic diatom immigration. Ecology 64(6): 1514-1524.

STEVENSON RJ. 1984. Epilithic and epipelic diatoms in the San-dusky River, with emphasis on species diversity and water pollution. Hydrobiologia 114: 114-161.

STEVENSON RJ. 1996. An introduction to algal ecology in freshwater benthic habitats In: STEVENSON RJ, BOTHWELL ML, LOWE RL, THORP JH (Eds). 1996. Algal ecology: Freshwater benthic ecosystems. Academic Press, San Diego. Pp: 3-30

STEVENSON RJ, BAHLS L. 1999. Periphyton protocols EPA 841-B-99-002. In: BARBOUR MT, GERRITSEN J, SNYDER BD, STRIBLING JB (Eds.). Rapid Bioassessment Protocols for Use in Streams and Wadeable Rivers: Periphyton, Benthic Macroinvertebrates and Fish. 2nd edition. U.S. Environmental Protection Agency, Washington. 326 pp.

STEVENSON RJ, PAN Y. 1999. Assessing environmental conditions in rivers and streams with diatoms. In: STOERMER EF, SMOL JP (Eds). The diatoms: Applications for the Environmental and Earth Sciences. Cambridge University Press, Cambridge. Pp 1140.

STEVENSON RJ, SMOL JP. 2001. Use of algae in environmental assessment. In: WEHR JD, SHEATH RG (Eds.). Freshwater Algae in North America: Classification and Ecology. Academic Press, San Diego.

STEVENSON RJ, SABATER S. 2010. Understanding Effects of Global Change on River Ecosystems: Science to Support Policy in a Changing World. Hydrobiologia 657 (1): 3-18.

STEWART-OATEN A, MUDOCH WM, PARKER KR. 1986. Environmental impact assessment: "pseudorreplication" in time? Ecology 67: 929-940.

STOCK MS, WARD AK. 1989. Establishment of a bedrock epilithic community in a small stream: microbial (algal and bacterial) metabolism and physical structure. Canadian Journal of Fisheries and Aquatic Sciences 46: 1874-1883.

STOCKNER JG, SHORTREED KRS. 1978. Enhancement of autotrophic production by nutrient addition in a coastal rainforest stream on Vancouver Island. Journal ofthe Fisheries Research Board of Canada 35: 28-34.

STREBLE H, KRAUTER D. 1987. Atlas de los Microorganismos de Agua Dulce. La vida en una gota de agua. Ediciones Omega, España. 336pp. 
STRICKLAND JDH, PARSONS TR. 1968. A practical handbook of seawater analysis. Pigment analysis. Bulletin of Fisheries Research Board of Canada 167.

TAULBEE WK, COOPER SD, MELACK JM. 2005. Effects of nutrient enrichment on algal biomass across a natural light gradient. Archiv Fur Hydrobiologie 164:449-464.

THIEL-NIELSEN J, S $\varnothing$ NDERGAARD M. 1998. Bacterial carbon biomass calculated from biovolumes. Archiv fuer Hydrobiologie 141(2):195-207.

TIEN CH-J, WUB W-H, CHUANG T-L, CHEN CS. 2009. Development of river biofilms on artificial substrates and their potential for biomonitoring water quality. Chemosphere 76 : 1288-95.

TILMAN D, FARGIONE J, WOLFF B, D'ANTONIO C, DOBSON A, HOWARTH R, SCHINDLER D, SCHLESINGER WH, SIMBERLOFF D, SWACKHAMER D. 2001. Forecasting agriculturally driven global environmental change. Science 292: 281-284.

TOLCACH E, GÓMEZ N. 2002. The effect of translocation of microbenthic communities in a polluted lowland stream. Verhandlungen des Internationalen Verein Limnologie 28: $254-258$.

UEHLINGER U. 1991. Spatial and temporal variability of the periphyton biomass in a pre-alpine river (Necker, Switzerland). Archiv fuer Hydrobiologie 123: 219-237.

UNDERWOOD AJ. 1991. Beyond BACl: experimental designs for detecting human environmental impacts on temporal variations in natural populations. Australian journal of Marine and Freshwater Research 42: 569-587.

UNDERWOOD AJ. 1992. Beyond BACI: the detection of environmental impact on populations in the real, but variable, world. Journal of Experimental Marine biology and Ecology 161: 145-178.

UNDERWOOD AJ. 1994. On Beyond $\mathrm{BACl}$ : sampling designs that might reliably detect environmental disturbances. Ecological Applications 4: 3-15.

UNDERWOOD AJ. 1996. Environmental design and analysis in marine environmental sampling. Manuals and Guides No. 34. UNESCO. 93pp.

UNDERWOOD AJ. 2007. Experiments in Ecology. Their logical design and interpretation using analysis of variance. Cambridge University Press, New York. 504pp.

UNDERWOOD GJC, Kromkamp J. 1999. Primary production by phytoplankton and microphytobenthos in estuaries. Advances in Ecology Research 29:93-153.

UNEP. 2007. Global environmental outlook 4. Environment for development. United Nations Environment Programme. Valletta, Malta. 
USEPA (US Environmental Protection agency). 1998. National strategy for the development of regional nutrient criteria. EPA-822-R-98-002. Office of Water. US Environmental Protection agency. Washington, USA.

van DAM H, MERTENS A, SINKELDAM J. 1994. A coded checklist and ecological indicator values of freshwater diatoms from The Netherlands. Netherlands of Journal of Aquatic Ecology 28 (1): 117-133.

VILCHES C. 2005. Comparación del metabolismo en productores del arroyo Las Flores. Tesis. UNLu, Argentina. 83pp.

VILCHES CS. 2011. Efectos de la contaminación difusa sobre el perifiton de arroyos. Tesis doctoral. UNLu, Argentina. 156pp.

VITOUSEK P. 1994. Beyond global warming: ecology and global change. Ecology 75(7): 18611876.

von SCHILLER D, MARTí E, RIERA JL, SABATER F. 2007. Effects of nutrients and light on periphyton biomass and nitrogen uptake in Mediterranean streams with contrasting land uses. Freshwater Biology 52(5): 891-906.

WARREN CE, DAVIS GE. 1971. Laboratory stream research: objectives, possibilities, and constraints. Annual Review of Ecology and Systematics 2:111-144.

WATSON RT, NOBLE IR, BOLIN B, RAVINDRANATH NH, VERARDO DJ, DOKKEN DJ. 2000. Land Use, Land-Use Change, and Forestry: A Special Report of the Intergovernmental Panel on Climate Change. Cambridge University Press, 388pp.

WELCH EB, JACOBY JM, HORNER RR, SEELEY MR. 1988. Nuisance biomass levels of periphytic algae in streams. Hydrobiologia 157:161-168.

WHITE DS, KALFF J, RASMUSSEN JB, GASOL JM. 1991. The effect of temperature and algal biomass on bacterial production and specific growth rate in freshwater and marine habitats. Microbial Ecology 21: 99-118.

WHITFORD LA, SCHUMACHER GH. 1964. Effect of current velocity on respiration and mineral uptake in Spirogyra and Oedogonium. Ecology. 45:168-170.

WHITFORD LA, DILLARD GE, SCHUMACHER GJ. 1964. An artificial stream apparatus for the study of lotic organisms. Limnology and Oceanography 9: 600-601.

WILLIAMS LG, MOUNT DI. 1965. Influence of zinc on periphytic communities. American Journal of Botany 52: 26-34.

WINER BJ. 1971. Statistical principles in experimental design. McGraw Hill. New York 907pp.

WINTER JG, DUTHIE HC. 2000. Epilithic diatoms as indicators of stream total $N$ and total $P$ concentration. Journal of the North American Benthological Society 19:32-49. 
YALLOP ML, PATERSON DM, WELLSBURY P. 2000. Interrelationships between rates of microbial production, exopolymer production, microbial biomass, and sediment stability in biofilms of intertidal sediments. Microbial Ecology 39: 116-127.

YLLA I, ROMANÍ AM, SABATER S. 2007. Differential effects of nutrients and light on the primary production of stream algae and mosses. Fundamental and Applied Limnology / Archiv für Hydrobiologie 170(1): 1-10. 


\section{ANEXO: TABLAS EXTENDIDAS}

\begin{tabular}{|c|c|c|c|c|c|c|c|c|c|c|c|}
\hline & \multirow{3}{*}{$\begin{array}{l}\text { Año } \\
\text { Período } \\
\text { Mes }\end{array}$} & \multicolumn{5}{|c|}{2007} & \multicolumn{5}{|c|}{2008} \\
\hline & & \multicolumn{4}{|c|}{ Antes de la adición } & \multicolumn{6}{|c|}{ Después de la adición } \\
\hline & & 3 & 6 & 8 & 10 & 12 & 2 & 5 & 7 & 9 & 12 \\
\hline \multirow[t]{2}{*}{$\begin{array}{l}\text { PRS } \\
\left(\mathrm{mg} \cdot \mathrm{L}^{-1}\right)\end{array}$} & Control & $\begin{array}{l}0,126 \\
( \pm 0,007)\end{array}$ & $\begin{array}{l}0,069 \\
( \pm 0,002)\end{array}$ & $\begin{array}{l}0,159 \\
( \pm 0,057)\end{array}$ & $\begin{array}{l}0,468 \\
( \pm 0,010)\end{array}$ & $\begin{array}{l}0,110 \\
( \pm 0,016)\end{array}$ & $\begin{array}{l}0,095 \\
( \pm 0,034)\end{array}$ & $\begin{array}{l}0,071 \\
( \pm 0,031)\end{array}$ & $\begin{array}{l}0,068 \\
( \pm 0,020)\end{array}$ & $\begin{array}{l}0,083 \\
( \pm 0,016)\end{array}$ & $\begin{array}{l}0,110 \\
( \pm 0,010)\end{array}$ \\
\hline & Impacto & $\begin{array}{l}0,149 \\
( \pm 0,003)\end{array}$ & $\begin{array}{l}0,114 \\
( \pm 0,019)\end{array}$ & $\begin{array}{l}0,337 \\
( \pm 0,074)\end{array}$ & $\begin{array}{l}0,390 \\
( \pm 0,062)\end{array}$ & $\begin{array}{l}0,267 \\
( \pm 0,254)\end{array}$ & $\begin{array}{l}0,437 \\
( \pm 0,376)\end{array}$ & $\begin{array}{l}0,341 \\
( \pm 0,297)\end{array}$ & $\begin{array}{l}0,385 \\
( \pm 0,288)\end{array}$ & $\begin{array}{l}0,186 \\
( \pm 0,179)\end{array}$ & $\begin{array}{l}1,173 \\
( \pm 0,321)\end{array}$ \\
\hline \multirow[t]{2}{*}{$\begin{array}{l}\text { NID } \\
\left(\mathrm{mg} \cdot \mathrm{L}^{-1}\right)\end{array}$} & Control & $\begin{array}{l}0,085 \\
( \pm 0,018)\end{array}$ & $\begin{array}{l}0,612 \\
( \pm 0,066)\end{array}$ & $\begin{array}{l}0,773 \\
( \pm 0,048)\end{array}$ & $\begin{array}{l}1,132 \\
( \pm 0,054)\end{array}$ & $\begin{array}{l}0,073 \\
( \pm 0,007)\end{array}$ & $\begin{array}{l}1,357 \\
( \pm 0,165)\end{array}$ & $\begin{array}{l}0,209 \\
( \pm 0,026)\end{array}$ & $\begin{array}{l}0,537 \\
( \pm 0,028)\end{array}$ & $\begin{array}{l}0,250 \\
( \pm 0,044)\end{array}$ & $\begin{array}{l}0,056 \\
( \pm 0,065)\end{array}$ \\
\hline & Impacto & $\begin{array}{l}0,291 \\
( \pm 0,011)\end{array}$ & $\begin{array}{l}1,853 \\
( \pm 0,166)\end{array}$ & $\begin{array}{l}1,162 \\
( \pm 0,088)\end{array}$ & $\begin{array}{l}2,222 \\
( \pm 0,120)\end{array}$ & $\begin{array}{l}2,280 \\
( \pm 0,075)\end{array}$ & $\begin{array}{l}1,692 \\
( \pm 0,050)\end{array}$ & $\begin{array}{l}0,594 \\
( \pm 0,034)\end{array}$ & $\begin{array}{l}0,414 \\
( \pm 0,025)\end{array}$ & $\begin{array}{l}0,145 \\
( \pm 0,003)\end{array}$ & $\begin{array}{l}0,132 \\
( \pm 0,014)\end{array}$ \\
\hline \multirow[t]{2}{*}{$\begin{array}{l}\text { Conductividad } \\
\left.(\text { (uS.cm })^{-1}\right)\end{array}$} & Control & $\begin{array}{l}253 \\
( \pm 6)\end{array}$ & $\begin{array}{l}835 \\
( \pm 157)\end{array}$ & $\begin{array}{l}1612 \\
( \pm 4)\end{array}$ & $\begin{array}{l}766 \\
( \pm 5)\end{array}$ & $\begin{array}{l}1143 \\
( \pm 7)\end{array}$ & $\begin{array}{l}1330 \\
( \pm 13)\end{array}$ & $\begin{array}{l}1312 \\
( \pm 135)\end{array}$ & $\begin{array}{l}1402 \\
( \pm 29)\end{array}$ & $\begin{array}{l}1246 \\
( \pm 27)\end{array}$ & $\begin{array}{l}1203 \\
( \pm 40)\end{array}$ \\
\hline & Impacto & $\begin{array}{l}413 \\
( \pm 4)\end{array}$ & $\begin{array}{l}1417 \\
( \pm 12)\end{array}$ & $\begin{array}{l}1699 \\
( \pm 27)\end{array}$ & $\begin{array}{l}1109 \\
( \pm 50)\end{array}$ & $\begin{array}{r}1647 \\
( \pm 6)\end{array}$ & $\begin{array}{l}1703 \\
( \pm 13)\end{array}$ & $\begin{array}{l}1896 \\
( \pm 37)\end{array}$ & $\begin{array}{l}1844 \\
( \pm 10)\end{array}$ & $\begin{array}{l}1661 \\
( \pm 23)\end{array}$ & $\begin{array}{l}1739 \\
( \pm 22)\end{array}$ \\
\hline \multirow[t]{2}{*}{$\begin{array}{l}\text { Temperatura } \\
\left({ }^{\circ} \mathrm{C}\right)\end{array}$} & Control & $\begin{array}{l}16,9 \\
( \pm 0,1)\end{array}$ & $\begin{array}{l}6,4 \\
( \pm 1,6)\end{array}$ & $\begin{array}{l}7,7 \\
( \pm 0,3)\end{array}$ & $\begin{array}{l}24,9 \\
( \pm 1,1)\end{array}$ & $\begin{array}{l}26,3 \\
( \pm 0,3)\end{array}$ & $\begin{array}{l}24,8 \\
( \pm 0,8)\end{array}$ & $\begin{array}{l}14,7 \\
( \pm 0,4)\end{array}$ & $\begin{array}{l}9,2 \\
( \pm 0,6)\end{array}$ & $\begin{array}{l}15,3 \\
( \pm 0,4)\end{array}$ & $\begin{array}{l}29,7 \\
( \pm 1,2)\end{array}$ \\
\hline & Impacto & $\begin{array}{l}16,9 \\
( \pm 0,6)\end{array}$ & $\begin{array}{l}8,6 \\
( \pm 0,3)\end{array}$ & $\begin{array}{l}8,1 \\
( \pm 0,4)\end{array}$ & $\begin{array}{l}21,8 \\
( \pm 0,6)\end{array}$ & $\begin{array}{l}25,4 \\
( \pm 0,2)\end{array}$ & $\begin{array}{l}22,5 \\
( \pm 0,5)\end{array}$ & $\begin{array}{l}11,1 \\
( \pm 1,0)\end{array}$ & $\begin{array}{l}9,8 \\
( \pm 0,2)\end{array}$ & $\begin{array}{l}14,4 \\
( \pm 0,2)\end{array}$ & $\begin{array}{l}32,1 \\
( \pm 0,9)\end{array}$ \\
\hline \multirow[t]{2}{*}{$\begin{array}{l}\text { OD } \\
\left(\mathrm{mg} \cdot \mathrm{L}^{-1}\right)\end{array}$} & Control & $\begin{array}{l}6,4 \\
( \pm 0,2)\end{array}$ & $\begin{array}{l}11,4 \\
( \pm 0,3)\end{array}$ & $\begin{array}{l}16,9 \\
( \pm 1,2)\end{array}$ & $\begin{array}{l}4,5 \\
( \pm 0,2)\end{array}$ & $\begin{array}{l}8,9 \\
( \pm 2,1)\end{array}$ & $\begin{array}{l}4,5 \\
( \pm 1,2)\end{array}$ & $\begin{array}{l}13,3 \\
( \pm 4,0)\end{array}$ & $\begin{array}{l}8,3 \\
( \pm 2,1)\end{array}$ & $\begin{array}{l}12,7 \\
( \pm 4,3)\end{array}$ & $\begin{array}{l}9,2 \\
( \pm 2,2)\end{array}$ \\
\hline & Impacto & $\begin{array}{l}7,2 \\
( \pm 0,1)\end{array}$ & $\begin{array}{l}12,2 \\
( \pm 1,4)\end{array}$ & $\begin{array}{l}14,7 \\
( \pm 2,6)\end{array}$ & $\begin{array}{l}5,3 \\
( \pm 0,2)\end{array}$ & $\begin{array}{l}11,6 \\
( \pm 0,7)\end{array}$ & $\begin{array}{l}5,0 \\
( \pm 0,7)\end{array}$ & $\begin{array}{l}9,7 \\
( \pm 0,1)\end{array}$ & $\begin{array}{l}8,3 \\
( \pm 0,2)\end{array}$ & $\begin{array}{l}7,0 \\
( \pm 0,5)\end{array}$ & $\begin{array}{l}9,9 \\
( \pm 0,7)\end{array}$ \\
\hline \multirow[t]{2}{*}{$\mathrm{pH}$} & Control & $\begin{array}{l}6,36 \\
( \pm 0,60)\end{array}$ & $\begin{array}{l}7,54 \\
( \pm 0,44)\end{array}$ & $\begin{array}{l}8,12 \\
( \pm 0,53)\end{array}$ & $\begin{array}{l}7,47 \\
( \pm 0,14)\end{array}$ & $\begin{array}{l}7,76 \\
( \pm 0,16)\end{array}$ & $\begin{array}{l}7,90 \\
( \pm 0,03)\end{array}$ & $\begin{array}{l}8,19 \\
( \pm 0,12)\end{array}$ & $\begin{array}{l}8,40 \\
( \pm 0,25)\end{array}$ & $\begin{array}{l}8,62 \\
( \pm 0,44)\end{array}$ & $\begin{array}{l}8,81 \\
( \pm 0,39)\end{array}$ \\
\hline & Impacto & $\begin{array}{l}7,30 \\
( \pm 0,20)\end{array}$ & $\begin{array}{l}8,00 \\
( \pm 0,50)\end{array}$ & $\begin{array}{l}7,28 \\
( \pm 0,22)\end{array}$ & $\begin{array}{l}7,83 \\
( \pm 0,01)\end{array}$ & $\begin{array}{l}7,56 \\
( \pm 0,07)\end{array}$ & $\begin{array}{l}7,91 \\
( \pm 0,07)\end{array}$ & $\begin{array}{l}8,16 \\
( \pm 0,10)\end{array}$ & $\begin{array}{l}8,36 \\
( \pm 0,03)\end{array}$ & $\begin{array}{l}8,28 \\
( \pm 0,07)\end{array}$ & $\begin{array}{l}8,30 \\
( \pm 0,02)\end{array}$ \\
\hline
\end{tabular}

Tabla Extendida 1. Parámetros físico-químicos del agua medidos en el Arroyo “La Choza” durante los períodos Antes y Después de la adición de nutrientes (Promedios \pm Desvío estándar). 


\begin{tabular}{|c|c|c|c|c|c|c|c|c|c|c|c|c|c|}
\hline & \multirow{3}{*}{$\begin{array}{l}\text { Año } \\
\text { Período } \\
\text { Mes }\end{array}$} & \multicolumn{6}{|c|}{2007} & \multicolumn{6}{|c|}{2008} \\
\hline & & \multicolumn{5}{|c|}{ Antes de la adición } & \multicolumn{7}{|c|}{ Después de la adición } \\
\hline & & 3 & 5 & 6 & 8 & 10 & 12 & 2 & 5 & 7 & 9 & 11 & 12 \\
\hline \multirow{2}{*}{$\begin{array}{l}\text { Densidad } \\
\text { bacteriana } \\
\left(\text { cél. } \mathrm{cm}^{-2}\right)\end{array}$} & Control & $\begin{array}{c}9,26 \mathrm{E}+7 \\
( \pm 7,48 \mathrm{E}+7)\end{array}$ & $\begin{array}{c}1,99 \mathrm{E}+8 \\
( \pm 1,13 \mathrm{E}+8)\end{array}$ & $\begin{array}{c}2,34 E+5 \\
( \pm 3,42 E+4)\end{array}$ & $\begin{array}{c}1,23 E+8 \\
( \pm 5,53 E+7)\end{array}$ & $\begin{array}{c}1,23 E+9 \\
( \pm 4,40 E+8)\end{array}$ & $\begin{array}{c}6,82 \mathrm{E}+7 \\
( \pm 3,41 \mathrm{E}+7)\end{array}$ & $\begin{array}{c}8,03 E+7 \\
( \pm 1,41 E+7)\end{array}$ & $\begin{array}{c}5,86 \mathrm{E}+8 \\
( \pm 8,61 \mathrm{E}+7)\end{array}$ & $\begin{array}{c}1,88 \mathrm{E}+8 \\
( \pm 6,61 \mathrm{E}+7)\end{array}$ & $\begin{array}{c}2,90 \mathrm{E}+8 \\
( \pm 3,42 \mathrm{E}+7)\end{array}$ & $\begin{array}{c}2,87 \mathrm{E}+8 \\
( \pm 9,68 \mathrm{E}+7)\end{array}$ & $\begin{array}{c}5,51 \mathrm{E}+8 \\
( \pm 1,73 \mathrm{E}+8)\end{array}$ \\
\hline & Impacto & $\begin{array}{c}5,31 \mathrm{E}+7 \\
( \pm 5,27 \mathrm{E}+6)\end{array}$ & $\begin{array}{c}3,97 \mathrm{E}+8 \\
( \pm 1,07 \mathrm{E}+8)\end{array}$ & $\begin{array}{c}5,74 E+4 \\
( \pm 2,39 E+4)\end{array}$ & $\begin{array}{c}1,19 \mathrm{E}+8 \\
( \pm 6,60 \mathrm{E}+6)\end{array}$ & $\begin{array}{c}8,17 \mathrm{E}+8 \\
( \pm 6,22 \mathrm{E}+7)\end{array}$ & $\begin{array}{c}6,95 \mathrm{E}+7 \\
( \pm 7,57 \mathrm{E}+6)\end{array}$ & $\begin{array}{c}2,59 \mathrm{E}+8 \\
( \pm 8,38 \mathrm{E}+7)\end{array}$ & $\begin{array}{c}6,82 \mathrm{E}+8 \\
( \pm 1,28 \mathrm{E}+8)\end{array}$ & $\begin{array}{c}2,28 \mathrm{E}+8 \\
( \pm 1,85 \mathrm{E}+7)\end{array}$ & $\begin{array}{c}3,82 \mathrm{E}+8 \\
( \pm 1,58 \mathrm{E}+8)\end{array}$ & $\begin{array}{c}1,89 \mathrm{E}+9 \\
( \pm 1,55 \mathrm{E}+8)\end{array}$ & $\begin{array}{c}9,59 \mathrm{E}+8 \\
( \pm 2,11 \mathrm{E}+7)\end{array}$ \\
\hline \multirow{2}{*}{$\begin{array}{l}\text { Biomasa } \\
\text { bacteriana } \\
\left(\mu \mathrm{gC} \mu \mathrm{m}^{-3} \mathrm{~cm}^{-2}\right)\end{array}$} & Control & $\begin{array}{c}2,036 \\
\pm 1,646)\end{array}$ & $\begin{array}{c}4,380 \\
\pm 2,480)\end{array}$ & $\begin{array}{c}0,005 \\
( \pm 0,001)\end{array}$ & $\begin{array}{c}2,711 \\
( \pm 1,217)\end{array}$ & $\begin{array}{c}27,041 \\
( \pm 9,676)\end{array}$ & $\begin{array}{c}1,147 \\
( \pm 0,750)\end{array}$ & $\begin{array}{c}1,767 \\
( \pm 0,310)\end{array}$ & $\begin{array}{c}12,901 \\
( \pm 1,894)\end{array}$ & $\begin{array}{c}4,129 \\
( \pm 1,454)\end{array}$ & $\begin{array}{c}6,376 \\
( \pm 0,753)\end{array}$ & $\begin{array}{c}6,318 \\
( \pm 2,130)\end{array}$ & $\begin{array}{c}12,124 \\
( \pm 3,811)\end{array}$ \\
\hline & Impacto & $\begin{array}{c}1,168 \\
( \pm 0,116)\end{array}$ & $\begin{array}{c}8,743 \\
( \pm 2,344)\end{array}$ & $\begin{array}{c}0,001 \\
( \pm 0,001)\end{array}$ & $\begin{array}{c}2,609 \\
( \pm 0,145)\end{array}$ & $\begin{array}{c}17,981 \\
( \pm 1,369)\end{array}$ & $\begin{array}{c}1,411 \\
( \pm 0,556)\end{array}$ & $\begin{array}{c}5,691 \\
( \pm 1,844)\end{array}$ & $\begin{array}{c}15,004 \\
( \pm 2,807)\end{array}$ & $\begin{array}{c}5,022 \\
( \pm 0,408)\end{array}$ & $\begin{array}{c}8,409 \\
( \pm 3,482)\end{array}$ & $\begin{array}{c}41,544 \\
( \pm 3,409)\end{array}$ & $\begin{array}{c}21,097 \\
( \pm 0,464)\end{array}$ \\
\hline \multirow[t]{2}{*}{$\begin{array}{l}\text { Clorofila "a" } \\
\left(\mathrm{mg} \mathrm{cm}^{-2}\right)\end{array}$} & Control & $\begin{array}{c}1,436 \\
\pm 0,470)\end{array}$ & $\begin{array}{c}1,072 \\
( \pm 0,154)\end{array}$ & $\begin{array}{c}1,771 \\
( \pm 0,800)\end{array}$ & $\begin{array}{c}8,133 \\
( \pm 0,513)\end{array}$ & $\begin{array}{c}5,100 \\
( \pm 0,361)\end{array}$ & $\begin{array}{c}5,800 \\
( \pm 1,732)\end{array}$ & $\begin{array}{c}1,967 \\
( \pm 0,709)\end{array}$ & $\begin{array}{c}0,137 \\
( \pm 0,211)\end{array}$ & $\begin{array}{c}2,493 \\
( \pm 1,559)\end{array}$ & $\begin{array}{c}3,900 \\
\pm 0,533)\end{array}$ & $\begin{array}{c}4,403 \\
\pm 1,918)\end{array}$ & $\begin{array}{c}2,723 \\
( \pm 1,198)\end{array}$ \\
\hline & Impacto & $\begin{array}{c}0,821 \\
( \pm 0,304)\end{array}$ & $\begin{array}{c}0,992 \\
( \pm 0,103)\end{array}$ & $\begin{array}{c}1,547 \\
( \pm 0,386)\end{array}$ & $\begin{array}{c}7,167 \\
( \pm 3,062)\end{array}$ & $\begin{array}{c}2,300 \\
( \pm 0,529)\end{array}$ & $\begin{array}{c}8,167 \\
( \pm 7,753)\end{array}$ & $\begin{array}{c}1,967 \\
( \pm 0,231)\end{array}$ & $\begin{array}{c}0,227 \\
( \pm 0,076)\end{array}$ & $\begin{array}{c}2,833 \\
( \pm 1,455)\end{array}$ & $\begin{array}{c}6,603 \\
( \pm 3,759)\end{array}$ & $\begin{array}{c}8,930 \\
( \pm 3,718)\end{array}$ & $\begin{array}{c}3,577 \\
( \pm 0,987)\end{array}$ \\
\hline \multirow{2}{*}{$\begin{array}{l}\text { b-Glucosidasa } \\
\text { (nmol[MUF]cm }{ }^{-2} \mathrm{hr}^{-} \\
\left.{ }^{\prime}\right)\end{array}$} & Control & $\begin{array}{c}1,111 \\
\pm 0,359)\end{array}$ & S/D & $\begin{array}{c}1,721 \\
( \pm 0,696)\end{array}$ & $\begin{array}{c}2,049 \\
( \pm 0,297)\end{array}$ & S/D & $\begin{array}{c}4,969 \\
( \pm 1,628\end{array}$ & $\begin{array}{c}0,355 \\
( \pm 0,017)\end{array}$ & $\begin{array}{c}0,711 \\
( \pm 0,017)\end{array}$ & $\begin{array}{c}2,096 \\
\pm 0,474)\end{array}$ & $\begin{array}{c}8,085 \\
\pm 2,704)\end{array}$ & $S / D$ & $\begin{array}{c}3,829 \\
( \pm 1,930)\end{array}$ \\
\hline & Impacto & $\begin{array}{c}0,924 \\
( \pm 0,103)\end{array}$ & $S / D$ & $\begin{array}{c}2,424 \\
( \pm 0,480)\end{array}$ & $\begin{array}{c}6,197 \\
( \pm 1,111)\end{array}$ & $S / D$ & $\begin{array}{c}6,881 \\
( \pm 1,836)\end{array}$ & $\begin{array}{c}1,217 \\
( \pm 0,356)\end{array}$ & $\begin{array}{c}1,304 \\
( \pm 0,405)\end{array}$ & $\begin{array}{c}2,072 \\
( \pm 0,493)\end{array}$ & $\begin{array}{c}5,525 \\
( \pm 3,135)\end{array}$ & $S / D$ & $\begin{array}{c}3,315 \\
( \pm 1,731)\end{array}$ \\
\hline \multirow{2}{*}{$\begin{array}{l}\text { Fosfatasa } \\
\text { Alcalina } \\
\text { (nmol[MUF] } \mathrm{cm}^{-2} \mathrm{hr}^{-} \\
\left.{ }^{1}\right)\end{array}$} & Control & $\begin{array}{c}1,677 \\
\pm 0,642)\end{array}$ & S/D & $\begin{array}{c}2,662 \\
( \pm 0,542)\end{array}$ & $\begin{array}{c}3,151 \\
( \pm 0,923)\end{array}$ & $S / D$ & $\begin{array}{c}5,973 \\
( \pm 0,933)\end{array}$ & $\begin{array}{c}5,096 \\
( \pm 3,329)\end{array}$ & $\begin{array}{c}1,764 \\
( \pm 1,186)\end{array}$ & $\begin{array}{c}4,276 \\
( \pm 1,171)\end{array}$ & $\begin{array}{l}26,503 \\
( \pm 4,077)\end{array}$ & $S / D$ & $\begin{array}{c}2,828 \\
( \pm 1,432)\end{array}$ \\
\hline & Impacto & $\begin{array}{c}2,270 \\
( \pm 0,307)\end{array}$ & $S / D$ & $\begin{array}{c}3,152 \\
( \pm 0,404)\end{array}$ & $\begin{array}{c}14,289 \\
( \pm 3,064)\end{array}$ & $S / D$ & $\begin{array}{c}6,325 \\
( \pm 2,109)\end{array}$ & $\begin{array}{c}3,938 \\
( \pm 1,039)\end{array}$ & $\begin{array}{c}3,916 \\
( \pm 1,112)\end{array}$ & $\begin{array}{c}8,370 \\
( \pm 3,715)\end{array}$ & $\begin{array}{c}5,788 \\
( \pm 2,882)\end{array}$ & $S / D$ & $\begin{array}{c}3,457 \\
( \pm 0,855)\end{array}$ \\
\hline
\end{tabular}

Tabla Extendida 2. Parámetros biológicos del biofilm medidos en el Arroyo “La Choza" durante los períodos Antes y Después de la adición de nutrientes (Promedios \pm Desvío estándar). 


\begin{tabular}{|c|c|c|c|c|c|c|c|c|c|c|c|c|c|c|c|c|c|c|c|}
\hline & Día & 0 & 1 & 2 & 7 & 9 & 11 & 14 & 16 & 18 & 21 & 23 & 25 & 28 & 30 & 32 & 35 & 36 & 40 \\
\hline \multirow{5}{*}{ I } & \multirow{2}{*}{ Control } & 8,78 & 8,76 & 8,74 & 8,72 & 8,72 & 8,73 & 8,77 & 8,82 & 8,76 & 8,68 & 8,60 & 8,60 & 8,60 & 8,66 & 8,73 & 8,66 & 8,63 & 8,60 \\
\hline & & $( \pm 0,01)$ & $( \pm 0,01)$ & $\pm 0,02)$ & $( \pm 0,04)$ & $( \pm 0,03)$ & $\pm 0,03)$ & $( \pm 0,04)$ & $( \pm 0,04)$ & $\pm 0,04)$ & $( \pm 0,02)$ & $( \pm 0,06)$ & $( \pm 0,06)$ & $( \pm 0,06)$ & $( \pm 0,06)$ & $\pm 0,06)$ & $( \pm 0,06)$ & $( \pm 0,06)$ & $( \pm 0,06)$ \\
\hline & Bajo & $\begin{array}{c}8,82 \\
( \pm 0,04)\end{array}$ & $\begin{array}{c}8,80 \\
( \pm 0,04)\end{array}$ & $\begin{array}{c}8,65 \\
\pm \pm 0,02)\end{array}$ & $\begin{array}{c}8,51 \\
\pm \pm 0,07)\end{array}$ & $\begin{array}{c}8,52 \\
( \pm 0,05)\end{array}$ & $\begin{array}{c}8,54 \\
( \pm 0,04)\end{array}$ & $\begin{array}{c}8,52 \\
\pm 0,10)\end{array}$ & $\begin{array}{c}8,57 \\
( \pm 0,10)\end{array}$ & $\begin{array}{c}8,52 \\
( \pm 0,10)\end{array}$ & $\begin{array}{c}8,53 \\
( \pm 0,01)\end{array}$ & $\begin{array}{c}8,54 \\
( \pm 0,10)\end{array}$ & $\begin{array}{c}8,54 \\
( \pm 0,09)\end{array}$ & $\begin{array}{c}8,54 \\
( \pm 0,09)\end{array}$ & $\begin{array}{c}8,61 \\
( \pm 0,09)\end{array}$ & $\begin{array}{c}8,67 \\
( \pm 0,09)\end{array}$ & $\begin{array}{c}8,60 \\
( \pm 0,09)\end{array}$ & $\begin{array}{c}8,57 \\
( \pm 0,09)\end{array}$ & $\begin{array}{c}8,54 \\
( \pm 0,09)\end{array}$ \\
\hline & \multirow[b]{2}{*}{ Alto } & 8,86 & 8,80 & 8,50 & 8,21 & 8,31 & 8,41 & 8,36 & 8,41 & 8,36 & 8,39 & 8,42 & 8,42 & 8,42 & 8,49 & 8,55 & 8,48 & 8,45 & 8,42 \\
\hline & & $( \pm 0,04)$ & $( \pm 0,03)$ & $( \pm 0,09)$ & $( \pm 0,21)$ & $( \pm 0,23)$ & $( \pm 0,28)$ & $( \pm 0,17)$ & $( \pm 0,17)$ & $( \pm 0,17)$ & $( \pm 0,05)$ & $( \pm 0,19)$ & $( \pm 0,18)$ & $( \pm 0,18)$ & $( \pm 0,18)$ & $( \pm 0,18)$ & $( \pm 0,18)$ & $( \pm 0,18)$ & $( \pm 0,18)$ \\
\hline \multirow{6}{*}{ 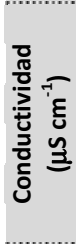 } & \multirow{2}{*}{ Control } & 1139,67 & 1128,00 & 1152,17 & 392,11 & 391,00 & 389,89 & 403,67 & 403,72 & 403,67 & 510,22 & 616,78 & 628,78 & 640,78 & 640,84 & 640,91 & 640,84 & 640,81 & 640,78 \\
\hline & & $( \pm 56,07)$ & $( \pm 52,72)$ & $( \pm 57,56)$ & $( \pm 21,92)$ & $( \pm 21,51)$ & $( \pm 22,20)$ & $( \pm 36,09)$ & $( \pm 36,09)$ & $( \pm 36,09)$ & $( \pm 41,15)$ & $( \pm 46,98)$ & $( \pm 44,39)$ & $( \pm 42,01)$ & $( \pm 42,01)$ & $( \pm 42,01)$ & $( \pm 42,01)$ & $( \pm 42,01)$ & $( \pm 42,01)$ \\
\hline & \multirow[b]{2}{*}{ Bajo } & 1183,00 & 1228,33 & 1382,67 & 512,33 & 493,44 & 474,56 & 515,44 & 515,50 & 515,44 & 599,83 & 684,22 & 694,11 & 704,00 & 704,06 & 704,13 & 704,06 & 704,03 & 704,00 \\
\hline & & $( \pm 63$, & $( \pm 56,08)$ & $( \pm 83,91)$ & $( \pm 37,29)$ & $( \pm 57,52)$ & $( \pm 80,67)$ & $( \pm 42,64)$ & $( \pm 42,64)$ & $( \pm 42,64)$ & $( \pm 39,56)$ & $( \pm 62,20)$ & $( \pm 62,92)$ & $( \pm 63,65)$ & $( \pm 63,65)$ & $( \pm 63,65)$ & $( \pm 63,65)$ & $( \pm 63,65)$ & $( \pm 63,65)$ \\
\hline & \multirow{2}{*}{ Alto } & 1240,33 & 1453,67 & 2054,50 & 885,11 & 856,00 & 826,89 & 845,44 & 845,50 & 845,44 & 940,94 & 1036,44 & 1057,28 & 1078,11 & 1078,18 & 1078,24 & 1078,17 & 1078,14 & 1078,11 \\
\hline & & $( \pm 74,78)$ & $( \pm 7,64)$ & $( \pm 259,7)$ & $( \pm 170,6)$ & $( \pm 143,5)$ & $( \pm 116,4)$ & $( \pm 100,8)$ & $( \pm 100,8)$ & $( \pm 100,8)$ & $( \pm 94,14)$ & $( \pm 89,46)$ & $( \pm 69,95)$ & $( \pm 50,45)$ & $( \pm 50,45)$ & $( \pm 50,45)$ & $( \pm 50,45)$ & $( \pm 50,45)$ & $( \pm 50,45)$ \\
\hline \multirow{5}{*}{ 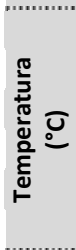 } & \multirow[b]{2}{*}{ Control } & 23,43 & 22,90 & 24,13 & 25,37 & 25,58 & 25,80 & 26,72 & 26,77 & 26,72 & 25,78 & 24,84 & 24,27 & 23,70 & 23,76 & 23,83 & 23,76 & 23,73 & 23,70 \\
\hline & & $( \pm 0,68)$ & $( \pm 0,96)$ & $( \pm 0,52)$ & $( \pm 0,12)$ & $( \pm 0,23)$ & $( \pm 0,35)$ & $( \pm 0,24)$ & $( \pm 0,24)$ & $( \pm 0,24)$ & $( \pm 0,27)$ & $( \pm 0,32)$ & $( \pm 0,21)$ & $( \pm 0,10)$ & $( \pm 0,10)$ & $( \pm 0,10)$ & $( \pm 0,10)$ & $( \pm 0,10)$ & $( \pm 0,10)$ \\
\hline & Bajo & $\begin{array}{c}25,73 \\
( \pm 0,26)\end{array}$ & $\begin{array}{c}24,82 \\
( \pm 0,15)\end{array}$ & $\begin{array}{c}25,63 \\
( \pm 0,19)\end{array}$ & $\begin{array}{c}26,44 \\
( \pm 0,49)\end{array}$ & $\begin{array}{c}26,49 \\
( \pm 0,21)\end{array}$ & $\begin{array}{c}26,54 \\
( \pm 0,06)\end{array}$ & $\begin{array}{c}27,72 \\
\pm 0,02)\end{array}$ & $\begin{array}{c}27,77 \\
( \pm 0,02)\end{array}$ & $\begin{array}{c}27,72 \\
\pm 0,02)\end{array}$ & $\begin{array}{c}26,67 \\
( \pm 0,06)\end{array}$ & $\begin{array}{c}25,61 \\
( \pm 0,12)\end{array}$ & $\begin{array}{c}25,10 \\
( \pm 0,08)\end{array}$ & $\begin{array}{c}24,58 \\
( \pm 0,06)\end{array}$ & $\begin{array}{c}24,65 \\
( \pm 0,06)\end{array}$ & $\begin{array}{c}24,72 \\
( \pm 0,06)\end{array}$ & $\begin{array}{c}24,65 \\
( \pm 0,06)\end{array}$ & $\begin{array}{c}24,61 \\
\pm 0,06)\end{array}$ & $\begin{array}{c}24,58 \\
( \pm 0,06)\end{array}$ \\
\hline & \multirow{2}{*}{ Alto } & 27,23 & 26,75 & 27,92 & 29,70 & 29,87 & 30,03 & 31,21 & 31,26 & 31,21 & 29,95 & 28,80 & 28,72 & 27,80 & 27,86 & 27,93 & 27,86 & 27,83 & 27,80 \\
\hline & & $( \pm 0,92)$ & $( \pm 0,33)$ & $( \pm 0,23)$ & $( \pm 0,22)$ & $( \pm 0,19)$ & $( \pm 0,19)$ & $( \pm 0,48)$ & $( \pm 0,48)$ & $( \pm 0,48)$ & $( \pm 0,41)$ & $( \pm 0,37)$ & $( \pm 0,25)$ & $( \pm 0,83)$ & $( \pm 0,83)$ & $( \pm 0,83)$ & $( \pm 0,83)$ & $( \pm 0,83)$ & $( \pm 0,83)$ \\
\hline \multirow{6}{*}{ 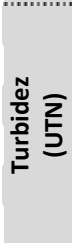 } & \multirow[b]{2}{*}{ Control } & 24,00 & 24,41 & 24,81 & 24,66 & 24,50 & 25,29 & 25,30 & 25,29 & 31,92 & 38,55 & 39,32 & 40,09 & 40,10 & 40,10 & 40,10 & 40,10 & 40,09 & $S / D$ \\
\hline & & $( \pm 12,12)$ & $( \pm 12,16)$ & $( \pm 12,19)$ & $( \pm 11,97)$ & $( \pm 11,74)$ & $( \pm 12,10)$ & $( \pm 12,10)$ & $( \pm 12,10)$ & $( \pm 15,13)$ & $( \pm 18,17)$ & $( \pm 18,55)$ & $( \pm 18,94)$ & $( \pm 18,94)$ & $( \pm 18,94)$ & $( \pm 18,94)$ & $( \pm 18,94)$ & $( \pm 18,94)$ & $S / D$ \\
\hline & & 23,95 & 26,95 & 29,95 & 28,68 & 27,41 & 30,18 & 30,18 & 30,18 & 34,81 & 39,44 & 40,01 & 40,58 & 40,58 & 40,59 & 40,58 & 40,58 & 40,58 & S/D \\
\hline & & $( \pm 5,69)$ & $( \pm 6,41)$ & $( \pm 7,16)$ & $( \pm 6,43)$ & $( \pm 6,19)$ & & $( \pm 7,50)$ & $( \pm 7,50)$ & $( \pm 6,78)$ & $( \pm 6,08)$ & $( \pm 6,17)$ & $( \pm 6,26)$ & $( \pm 6,26)$ & $( \pm 6,26)$ & $( \pm 6,26)$ & $( \pm 6,26)$ & $( \pm 6,26)$ & $S / D$ \\
\hline & & 24,50 & 34,01 & 43,52 & 42,23 & 40,93 & 41,87 & 41,87 & 41,87 & 46,86 & 51,86 & 53,04 & 54,22 & 54,22 & 54,22 & 54,22 & 54,22 & 54,22 & $S / D$ \\
\hline & Alto & $( \pm 8,35$ & $( \pm 9,02$ & $( \pm 10,80)$ & $( \pm 10,53)$ & $( \pm 10,42)$ & $( \pm 10,47)$ & $( \pm 10,47)$ & $( \pm 10,47)$ & $( \pm 12,78)$ & $( \pm 15,12)$ & $( \pm 16,02)$ & $( \pm 16,99)$ & $( \pm 16,99)$ & $( \pm 16,99)$ & $( \pm 16,99)$ & $( \pm 16,99)$ & $( \pm 16,99)$ & S/D \\
\hline
\end{tabular}

Tabla Extendida 3. Parámetros físico-químicos medidos en la experiencia con el biofilm proveniente del arroyo con bajo impacto antropogénico (Promedio \pm Desvío estándar) 


\begin{tabular}{|c|c|c|c|c|c|c|c|c|c|c|c|c|c|c|c|c|c|c|c|}
\hline \multirow{5}{*}{ 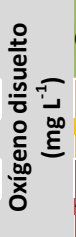 } & \multirow{3}{*}{$\begin{array}{l}\text { Control } \\
\text { Bajo } \\
\end{array}$} & $\begin{array}{c}7,71 \\
( \pm 0,23)\end{array}$ & $\begin{array}{c}7,72 \\
\pm 0,23)\end{array}$ & $\begin{array}{c}7,72 \\
\pm 0,23)\end{array}$ & $\begin{array}{c}7,73 \\
( \pm 0,23)\end{array}$ & $\begin{array}{c}7,73 \\
\pm 0,23)\end{array}$ & $\begin{array}{c}7,74 \\
( \pm 0,23)\end{array}$ & $\begin{array}{c}7,74 \\
\pm 0,23)\end{array}$ & $\begin{array}{c}7,74 \\
\pm 0,23)\end{array}$ & $\begin{array}{c}7,74 \\
( \pm 0,23)\end{array}$ & $\begin{array}{c}7,75 \\
\pm 0,23)\end{array}$ & $\begin{array}{c}7,75 \\
\pm 0,23)\end{array}$ & $\begin{array}{c}7,76 \\
( \pm 0,23)\end{array}$ & $\begin{array}{c}7,76 \\
( \pm 0,23)\end{array}$ & $\begin{array}{c}7,76 \\
\pm 0,23)\end{array}$ & $\begin{array}{c}7,76 \\
( \pm 0,23)\end{array}$ & $\begin{array}{c}7,76 \\
( \pm 0,23)\end{array}$ & $\begin{array}{c}7,76 \\
\pm 0,23)\end{array}$ & $\begin{array}{c}7,76 \\
\pm 0,23)\end{array}$ \\
\hline & & 7,62 & 7,63 & 7,64 & 7,64 & 7,65 & 7,65 & 7,66 & 7,66 & 7,66 & 7,66 & 7,67 & 7,67 & 7,68 & 7,68 & 7,68 & 7,68 & 7,68 & 7,68 \\
\hline & & $( \pm 0,13)$ & $( \pm 0,13)$ & $( \pm 0,13)$ & $( \pm 0,13)$ & $( \pm 0,13)$ & $( \pm 0,13)$ & $( \pm 0,13)$ & $( \pm 0,13)$ & $( \pm 0,13)$ & $( \pm 0,13)$ & $( \pm 0,13)$ & $( \pm 0,13)$ & $( \pm 0,13)$ & $( \pm 0,13)$ & $( \pm 0,13)$ & $( \pm 0,13)$ & $( \pm 0,13)$ & $( \pm 0,13)$ \\
\hline & \multirow[b]{2}{*}{ Alto } & 7,61 & 7,62 & 7,62 & 7,63 & 7,63 & 7,63 & 7,64 & 7,64 & 7,6 & 7,6 & 7,65 & 7,6 & 7,66 & 7,6 & 7,66 & 7,6 & 7,66 & 7,66 \\
\hline & & $( \pm 0,17)$ & $( \pm 0,17)$ & $0,17)$ & $( \pm 0,17)$ & $( \pm 0,17$ & $( \pm 0,17)$ & $( \pm 0,17)$ & $\pm 0,17)$ & $\pm 0,17)$ & $( \pm 0,17)$ & $\pm 0,17$ & $( \pm 0,17)$ & $( \pm 0,17)$ & $( \pm 0,17)$ & $( \pm 0,17)$ & $( \pm 0,17)$ & $\pm 0,17)$ & $\pm 0,17)$ \\
\hline \multirow{6}{*}{ 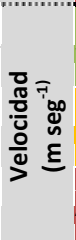 } & \multirow{2}{*}{ Control } & $S / D$ & 0,35 & 0,35 & 0,35 & 0,35 & 0,35 & 0,35 & 0,35 & 0,35 & 0,35 & 0,35 & 0,35 & 0,35 & 0,35 & 0,35 & 0,35 & 0,35 & 0,35 \\
\hline & & $S / D$ & $( \pm 0,01)$ & $( \pm 0,00)$ & $( \pm 0,00)$ & $( \pm 0,00)$ & $( \pm 0,01)$ & $( \pm 0,01)$ & $( \pm 0,00)$ & $( \pm 0,01)$ & $( \pm 0,00)$ & $( \pm 0,01)$ & $( \pm 0,00)$ & $( \pm 0,01)$ & $( \pm 0,01)$ & $( \pm 0,01)$ & $( \pm 0,00)$ & $( \pm 0,01)$ & $( \pm 0,01)$ \\
\hline & \multirow{2}{*}{ Bajo } & $S / D$ & 0,38 & 0,36 & 0,36 & 0,3 & 0,3 & 0,3 & 0,3 & 0 & 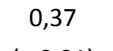 & 0,3 & 0 & 0,3 & 0 & 0 & 0,3 & 0,38 & 0,38 \\
\hline & & S/D & $( \pm 0,02)$ & $( \pm 0,00)$ & $( \pm 0,00)$ & $( \pm 0,00)$ & $( \pm 0,01)$ & $( \pm 0,01)$ & $( \pm 0,00)$ & $( \pm 0,02)$ & $( \pm 0,01)$ & $( \pm 0,02)$ & $( \pm 0,00)$ & $( \pm 0,02)$ & $( \pm 0,02)$ & $( \pm 0,02)$ & $( \pm 0,00)$ & $( \pm 0,02)$ & $\pm 0,02)$ \\
\hline & \multirow{2}{*}{ Alto } & S/D & 0,44 & 0,42 & 0,42 & 0,42 & 0,44 & 0,44 & 0,42 & 0,44 & 0,43 & 0,44 & 0,42 & 0,44 & 0,44 & 0,44 & 0,42 & 0,44 & 0,44 \\
\hline & & $S / D$ & $( \pm 0,01)$ & $( \pm 0,00)$ & $( \pm 0,00)$ & $( \pm 0,00)$ & $( \pm 0,01)$ & $( \pm 0,01)$ & $( \pm 0,00)$ & $( \pm 0,01)$ & $( \pm 0,01)$ & $( \pm 0,01)$ & $( \pm 0,00)$ & $( \pm 0,01)$ & $( \pm 0,01)$ & $( \pm 0,01)$ & $( \pm 0,00)$ & $( \pm 0,01)$ & $( \pm 0,01)$ \\
\hline
\end{tabular}

Tabla Extendida 3 (Cont.). Parámetros físico-químicos medidos en la experiencia con el biofilm proveniente del arroyo con bajo impacto antropogénico (Promedio \pm Desvío estándar)

\begin{tabular}{|c|c|c|c|c|c|c|c|c|c|c|c|c|c|c|c|c|c|c|c|}
\hline & Día & 0 & 1 & 2 & 7 & 9 & 11 & 14 & 16 & 18 & 21 & 23 & 25 & 28 & 30 & 32 & 35 & 36 & 40 \\
\hline \multirow{6}{*}{ 을 } & \multirow{2}{*}{ Control } & 1536,2 & 1393,6 & 878,4 & 286,0 & 308,4 & 308,1 & 316,6 & 259,6 & 399,0 & 327,3 & 398,3 & 253,0 & 189,3 & 183,2 & 216,1 & 206,5 & 220,8 & 190,3 \\
\hline & & $( \pm 412,4)$ & $( \pm 374,1)$ & $( \pm 294,2)$ & $( \pm 132,2)$ & $( \pm 117,3)$ & $( \pm 172,5)$ & $( \pm 194,5)$ & $( \pm 167,4)$ & $( \pm 28,9)$ & $( \pm 19,6)$ & $( \pm 100,6)$ & $( \pm 20,0)$ & $( \pm 72,1)$ & $( \pm 70,1)$ & $( \pm 94,9)$ & $( \pm 95,8)$ & $( \pm 86,2)$ & $( \pm 92,5)$ \\
\hline & \multirow{2}{*}{ Bajo } & 2237,0 & 2442,8 & 1676,5 & 466,2 & 668,2 & 383,3 & 458,3 & 442,9 & 521,2 & 524,1 & 798,8 & 399,5 & 290,0 & 402,8 & 400,1 & 377,1 & 371,5 & 652,8 \\
\hline & & $( \pm 282,1)$ & $( \pm 307,8)$ & $( \pm 306,6)$ & $( \pm 41,0)$ & $( \pm 136,2)$ & $( \pm 48,5)$ & $( \pm 60,7)$ & $( \pm 73,4)$ & $( \pm 157,6)$ & $( \pm 42,3)$ & $( \pm 15,5)$ & $( \pm 7,7)$ & $( \pm 56,4)$ & $( \pm 140,4)$ & $( \pm 110,9)$ & $( \pm 107,5)$ & $( \pm 95,5)$ & $( \pm 180,8)$ \\
\hline & \multirow[b]{2}{*}{ Alto } & 4472,1 & 4472,5 & 3250,6 & 1286,3 & 1527,3 & 1572,8 & 723,6 & 618,3 & 696,6 & 737,9 & 888,9 & 640,5 & 636,0 & 626,8 & 627,6 & 423,3 & 431,4 & 1493,4 \\
\hline & & $( \pm 178,4)$ & $( \pm 178,2)$ & $( \pm 66,6)$ & $( \pm 109,8)$ & $( \pm 557,8)$ & $( \pm 574,8)$ & $( \pm 40,3)$ & $( \pm 59,6)$ & $( \pm 69,8)$ & $( \pm 138,1)$ & $( \pm 189,5)$ & $( \pm 109,4)$ & $( \pm 96,0)$ & $( \pm 100,8)$ & $( \pm 128,5)$ & $( \pm 97,6)$ & $( \pm 128,4)$ & $( \pm 270,5)$ \\
\hline \multirow{4}{*}{ 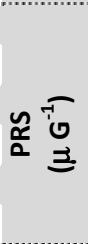 } & \multirow{2}{*}{ Control } & 603 & 421 & 238 & 119 & 109 & 113 & 100 & 116 & 126 & 146 & 151 & 183 & 214 & 206 & 202 & 198 & 198 & 166 \\
\hline & & $( \pm 46)$ & $( \pm 28)$ & $( \pm 11)$ & $( \pm 20)$ & $( \pm 11)$ & $( \pm 1)$ & $( \pm 28)$ & $( \pm 10)$ & $( \pm 15)$ & $( \pm 4)$ & $( \pm 6)$ & $( \pm 13)$ & $( \pm 21)$ & $( \pm 21)$ & $( \pm 21)$ & $( \pm 21)$ & $( \pm 21)$ & $( \pm 21)$ \\
\hline & Bajo & $\begin{array}{c}968 \\
( \pm 47)\end{array}$ & $\begin{array}{c}679 \\
( \pm 21)\end{array}$ & $\begin{array}{c}391 \\
( \pm 23)\end{array}$ & $\begin{array}{c}206 \\
( \pm 34)\end{array}$ & $\begin{array}{c}212 \\
( \pm 28)\end{array}$ & $\begin{array}{c}217 \\
( \pm 27)\end{array}$ & $\begin{array}{l}163 \\
( \pm 9)\end{array}$ & $\begin{array}{l}191 \\
( \pm 7)\end{array}$ & $\begin{array}{c}222 \\
( \pm 13)\end{array}$ & $\begin{array}{c}219 \\
( \pm 16)\end{array}$ & $\begin{array}{c}253 \\
( \pm 29)\end{array}$ & $\begin{array}{c}294 \\
( \pm 11)\end{array}$ & $\begin{array}{c}335 \\
( \pm 12)\end{array}$ & $\begin{array}{c}324 \\
( \pm 12)\end{array}$ & $\begin{array}{c}319 \\
( \pm 12)\end{array}$ & $\begin{array}{c}314 \\
( \pm 12)\end{array}$ & $\begin{array}{c}314 \\
( \pm 12)\end{array}$ & $\begin{array}{c}270 \\
( \pm 12)\end{array}$ \\
\hline & Alto & $\begin{array}{c}2672 \\
( \pm 151)\end{array}$ & $\begin{array}{c}1852 \\
( \pm 176)\end{array}$ & $\begin{array}{c}1031 \\
( \pm 247)\end{array}$ & $\begin{array}{c}575 \\
( \pm 24)\end{array}$ & $\begin{array}{c}610 \\
( \pm 50)\end{array}$ & $\begin{array}{c}645 \\
( \pm 116)\end{array}$ & $\begin{array}{c}448 \\
( \pm 45)\end{array}$ & $\begin{array}{c}578 \\
( \pm 16)\end{array}$ & $\begin{array}{c}614 \\
( \pm 25)\end{array}$ & $\begin{array}{c}708 \\
( \pm 17)\end{array}$ & $\begin{array}{c}650 \\
( \pm 60)\end{array}$ & $\begin{array}{c}755 \\
( \pm 63)\end{array}$ & $\begin{array}{c}860 \\
( \pm 73)\end{array}$ & $\begin{array}{c}839 \\
( \pm 73)\end{array}$ & $\begin{array}{c}828 \\
( \pm 73)\end{array}$ & $\begin{array}{c}817 \\
( \pm 73)\end{array}$ & $\begin{array}{c}817 \\
( \pm 73)\end{array}$ & $\begin{array}{c}729 \\
( \pm 73)\end{array}$ \\
\hline
\end{tabular}

Tabla Extendida 4. Nutrientes medidos en la experiencia con el biofilm proveniente del arroyo con bajo impacto antropogénico (Promedio \pm Desvío estándar) 


\begin{tabular}{|c|c|c|c|c|c|c|}
\hline & Día & 0 & 10 & 20 & 30 & 40 \\
\hline \multirow{6}{*}{$\begin{array}{l}\text { Clorofila "a" } \\
\left(\mathrm{mg} \cdot \mathrm{cm}^{-2}\right)\end{array}$} & \multirow{2}{*}{ Control } & 0,66 & 0,35 & 0,36 & 0,42 & 0,31 \\
\hline & & $( \pm 0,28)$ & $( \pm 0,04)$ & $( \pm 0,07)$ & $( \pm 0,22)$ & $( \pm 0,20)$ \\
\hline & \multirow{2}{*}{ Bajo } & 0,43 & 0,59 & 0,43 & 0,51 & 0,19 \\
\hline & & $( \pm 0,09)$ & $( \pm 0,13)$ & $( \pm 0,07)$ & $( \pm 0,39)$ & $( \pm 0,08)$ \\
\hline & \multirow{2}{*}{ Alto } & 0,34 & 0,28 & 0,52 & 0,36 & 0,17 \\
\hline & & $( \pm 0,04)$ & $( \pm 0,15)$ & $( \pm 0,11)$ & $( \pm 0,10)$ & $( \pm 0,07)$ \\
\hline \multirow{6}{*}{$\begin{array}{l}\text { Biomasa } \\
\text { bacteriana } \\
\left(\mu \mathrm{gC} \mu \mathrm{m}^{-3} \mathrm{~cm}^{-2}\right)\end{array}$} & \multirow{2}{*}{ Control } & 50,30 & 1,15 & 1,39 & 2,16 & 106,05 \\
\hline & & $( \pm 32,62)$ & $( \pm 0,38)$ & $( \pm 0,47)$ & $( \pm 0,89)$ & $( \pm 53,46)$ \\
\hline & \multirow{2}{*}{ Bajo } & 29,78 & 0,80 & 0,93 & 2,45 & 113,00 \\
\hline & & $( \pm 9,87)$ & $( \pm 0,09)$ & $( \pm 0,29)$ & $( \pm 1,20)$ & $( \pm 37,11)$ \\
\hline & \multirow{2}{*}{ Alto } & 42,45 & 0,83 & 0,98 & 2,72 & 132,97 \\
\hline & & $( \pm 31,78)$ & $( \pm 0,33)$ & $( \pm 0,62)$ & $( \pm 1,29)$ & $( \pm 137,48)$ \\
\hline \multirow{6}{*}{$\begin{array}{l}\text { Carbohidratos totales } \\
\left(\mathrm{mg} \mathrm{mL}^{-1}\right)\end{array}$} & \multirow{2}{*}{ Control } & 3884,34 & 830,03 & 258,05 & 45,89 & 1629,34 \\
\hline & & $( \pm 2075,81)$ & $( \pm 609,21)$ & $( \pm 116,35)$ & $( \pm 10,16)$ & $( \pm 393,05)$ \\
\hline & \multirow{2}{*}{ Bajo } & 4356,20 & 931,87 & 262,31 & 47,49 & 2037,11 \\
\hline & & $( \pm 1846,68)$ & $( \pm 357,31)$ & $( \pm 10,92)$ & $( \pm 1,09)$ & $( \pm 727,50)$ \\
\hline & \multirow{2}{*}{ Alto } & 4351,62 & 1159,94 & 313,13 & 55,61 & 1797,66 \\
\hline & & $( \pm 2072,04)$ & $( \pm 492,98)$ & $( \pm 127,94)$ & $( \pm 19,28)$ & $( \pm 577,44)$ \\
\hline \multirow{6}{*}{$\begin{array}{l}\text { Actividad respiratoria } \\
\text { total } \\
\left(\mu \mathrm{g} \text { formazan } \mathrm{cm}^{-2} \mathrm{~h}^{-1}\right)\end{array}$} & \multirow{2}{*}{ Control } & 0,06 & 0,39 & 0,44 & 0,07 & 0,06 \\
\hline & & $( \pm 0,01)$ & $( \pm 0,17)$ & $( \pm 0,10)$ & $( \pm 0,05)$ & $( \pm 0,04)$ \\
\hline & \multirow{2}{*}{ Bajo } & 0,09 & 0,18 & 0,12 & 0,31 & 0,13 \\
\hline & & $( \pm 0,02)$ & $( \pm 0,15)$ & $( \pm 0,04)$ & $( \pm 0,11)$ & $( \pm 0,02)$ \\
\hline & \multirow{2}{*}{ Alto } & 0,16 & 0,07 & 0,07 & 0,17 & 0,17 \\
\hline & & $( \pm 0,07)$ & $( \pm 0,04)$ & $( \pm 0,04)$ & $( \pm 0,13)$ & $( \pm 0,05)$ \\
\hline \multirow{6}{*}{$\begin{array}{l}\text { Peso seco libre de } \\
\text { cenizas } \\
\left(\mathrm{mg} \mathrm{cm}{ }^{-2}\right)\end{array}$} & \multirow{2}{*}{ Control } & 0,04 & 0,02 & 0,02 & 0,03 & 0,04 \\
\hline & & $( \pm 0,00)$ & $( \pm 0,01)$ & $( \pm 0,00)$ & $( \pm 0,01)$ & $( \pm 0,01)$ \\
\hline & \multirow{2}{*}{ Bajo } & 0,04 & 0,03 & 0,03 & 0,03 & 0,15 \\
\hline & & $( \pm 0,01)$ & $( \pm 0,02)$ & $( \pm 0,01)$ & $( \pm 0,01)$ & $( \pm 0,18)$ \\
\hline & \multirow{2}{*}{ Alto } & 0,05 & 0,01 & 0,02 & 0,03 & 0,26 \\
\hline & & $( \pm 0,01)$ & $( \pm 0,00)$ & $( \pm 0,01)$ & $( \pm 0,01)$ & $( \pm 0,17)$ \\
\hline
\end{tabular}

Tabla Extendida 5. Variable biológicas medidas en la experiencia con el biofilm proveniente del arroyo con bajo impacto antropogénico (Promedio \pm Desvío estándar) 


\begin{tabular}{|c|c|c|c|c|c|c|c|c|c|c|c|c|c|c|c|c|c|c|c|c|}
\hline & ía & 0 & 2 & 4 & 7 & 9 & 10 & 14 & 17 & 18 & 21 & 24 & 25 & 28 & 30 & 31 & 35 & 38 & 42 & 44 \\
\hline & \multirow{2}{*}{ Control } & 9, & 8,9 & 8,91 & 8,96 & 03 & 8,96 & 8,99 & 9,0 & 9,10 & 9,0 & & 8, & 8 & & & 26 & 9,39 & 9,28 & 9,27 \\
\hline & & $( \pm 0$ & & $( \pm 0$ & ) & 8) & $0,08)$ & 2) & $0,12)$ & & 0) & & 08) & 8) & & & 05) & $50,05)$ & 1) & 6) \\
\hline & \multirow{2}{*}{ Bajo } & 9,02 & 8,8 & 8,87 & 8,93 & 9,02 & 9,06 & 9,05 & 9,07 & & & & & & & & & 21 & 18 & 9 , \\
\hline & & $( \pm 0,07)$ & $( \pm 0,12)$ & 0,1 & $0,06)$ & 0,09 ) & $=0,14)$ & $\pm 0,03)$ & $( \pm 0,06)$ & $( \pm 0,05)$ & $( \pm 0,10)$ & $0,10)$ & $( \pm 0,10)$ & $\pm 0,02)$ & $( \pm 0,00)$ & $( \pm 0,00)$ & $( \pm 0,10)$ & $( \pm 0,07)$ & $( \pm 0,04)$ & $( \pm 0,15)$ \\
\hline & & 08 & 8 & 8,9 & 9,0 & & 9,0 & 03 & 9,0 & 9,1 & & 8, & & & & & & 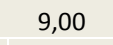 & 9,04 & 9,03 \\
\hline & & $( \pm 0,07)$ & $( \pm$ & $( \pm 0,19)$ & $( \pm 0,12)$ & $( \pm 0,02)$ & $0,08)$ & $0,01)$ & 0,06 & $( \pm 0,07)$ & $( \pm 0,04)$ & $( \pm 0,19)$ & $( \pm 0,10)$ & $( \pm 0,36)$ & $( \pm 0,30)$ & $( \pm 0,16)$ & $( \pm 0,09)$ & $( \pm 0,05)$ & $( \pm$ & 0 \\
\hline \multirow{6}{*}{ 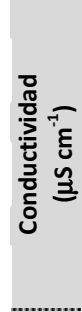 } & \multirow[b]{2}{*}{ Control } & 1496 , & 1504,83 & 10,00 & 10,00 & & 24,44 & 6 & 24,00 & & 34,33 & & 51,56 & 1,06 & 02 & & & & & 630,11 \\
\hline & & $( \pm 17$, & & & $\Leftrightarrow$ & $( \pm 23$ & $37,98)$ & 51) & 72) & $( \pm 39,59)$ & 58) & & 59) & 65) & 68) & 77) & 29) & & & $\begin{array}{c}( \pm \\
39,59)\end{array}$ \\
\hline & \multirow{2}{*}{ Bajo } & 1529, & 1578,67 & 89 & 1613,44 & 159 & 1634,11 & 27 & 44 & 83 & 39 & & 33 & 18 & & & & & & 17,83 \\
\hline & & $( \pm 18$, & & $( \pm 35,12)$ & $( \pm 56,41)$ & $( \pm 83,85)$ & $( \pm 40,74)$ & $=39,36)$ & :44,17) & $( \pm 39,27)$ & $( \pm 66,74)$ & $( \pm 6]$ & 5) & $( \pm 62$ & $( \pm 6$ & $( \pm 6$ & $( \pm 66,00)$ & $( \pm 6$ & $( \pm$ & ) 39,27 ) \\
\hline & \multirow[b]{2}{*}{ Altc } & 1606, & 1803,72 & $2006,44)$ & 1976,89 & 1945,67 & 1965,67 & 668,94 & 962,33 & 2059,06 & 2158,00 & 2176,72 & 195,44 & 2196,62 & 22 & 5 & 81 & ,78 & 21 & 2059,06 \\
\hline & & $( \pm 3, \varepsilon$ & $( \pm$ & & & & & & & & & & & & & & & & & (96,17) \\
\hline \multirow{6}{*}{ 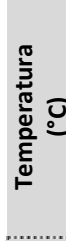 } & & 23,06 & 23,98 & 25,28 & 25,47 & 25,68 & 26,83 & 26,7 & 26,45 & 25,31 & 25,21 & 2 & 23 & 23,64 & 23 & 23 & 4 & 74 & 23,73 & 23,70 \\
\hline & & $( \pm 0,80)$ & $( \pm 0,43)$ & 32) & $( \pm 0$ & $( \pm 0,34)$ & $( \pm 0,44)$ & $( \pm 0,82)$ & $\pm 0,32)$ & $( \pm 0,41)$ & $( \pm 0,59)$ & 7) & $( \pm 0,22)$ & $( \pm c$ & $( \pm 0,31)$ & & & $( \pm 0,47)$ & & 1 \\
\hline & \multirow{2}{*}{$\mathrm{Ba}$} & 24,26 & 25,01 & 25,5 & 25,6 & 25,49 & 26,87 & 26,8 & 26,8 & 25,9 & 25 & 24 & 24, & 23, & 23, & 23 & 23, & 23,76 & 23,90 & 23, \\
\hline & & $( \pm 0,31)$ & $( \pm 0,15)$ & 98) & $( \pm 0,18)$ & $( \pm 0,02)$ & $\pm 0,36)$ & 0,03 & $\pm 0,22)$ & $( \pm 0,50)$ & $( \pm 0,59)$ & 8) & $( \pm 0,42)$ & $( \pm 0,22)$ & $( \pm 0,52)$ & $( \pm C$ & $( \pm 0,45)$ & $( \pm 0,44)$ & $( \pm 0,06)$ & $( \pm 0,06)$ \\
\hline & \multirow{2}{*}{ Alto } & 26,97 & 27,43 & 27,56 & 27,68 & 27,52 & 27,57 & 28,02 & 28,10 & 28,31 & 27,92 & 28,18 & 28,26 & 28 & 27,74 & 27,87 & 27,94 & 27,77 & 27,96 & 27,93 \\
\hline & & $( \pm 0,38)$ & $( \pm 0,24)$ & $( \pm 0,44)$ & $( \pm 0,59)$ & $( \pm 0,31)$ & $( \pm 0,62)$ & $( \pm 0,55)$ & $( \pm 0,49)$ & $( \pm 0,70)$ & $( \pm 0,66)$ & $( \pm 0,17)$ & $( \pm 0,74)$ & $( \pm 0,90)$ & $( \pm 0,89)$ & $( \pm 0,73)$ & $( \pm 1,25)$ & $( \pm 0,95)$ & $( \pm 0,84)$ & $( \pm 0,84)$ \\
\hline \multirow{6}{*}{$\begin{array}{l}\text { v } \\
\text { 을 } \\
\text { 놀 }\end{array}$} & \multirow[t]{2}{*}{ Control } & 59,67 & 537 & & 5599 & 17 & 56,96 & 48,5 & 64,2 & 6 & 62 & s & 60 & 69 & 65 & 7 & 10 & 63,43 & 68,00 & $\begin{array}{c}76,00 \\
( \pm\end{array}$ \\
\hline & & $( \pm 25,32)$ & $( \pm 9,9$ & $( \pm 18,44)$ & $( \pm 13,96)$ & $( \pm 12,12)$ & $( \pm 11,57)$ & $( \pm 23,20)$ & $( \pm 12,99)$ & $( \pm 2$ & $( \pm 3,60)$ & 6) & $( \pm 25,77)$ & $( \pm 27,14)$ & $( \pm 2$ & $( \pm 2$ & $( \pm 23,27)$ & $( \pm 12,27)$ & 98) & ) 10,58$)$ \\
\hline & \multirow{3}{*}{ Bajo } & 47,00 & 63,09 & 73,18 & 64,87 & 61,90 & 77,75 & 70,08 & 62,75 & 72,18 & 70,62 & 77,88 & 76,13 & 62,80 & 66,81 & 79,80 & 86,13 & 65,80 & 76,33 & 70,00 \\
\hline & & $( \pm 15,59)$ & $( \pm 18,95)$ & $( \pm 11,19)$ & $( \pm 11,60)$ & $( \pm 15,26)$ & $( \pm 6,61)$ & $( \pm 16,76)$ & $( \pm 23,82)$ & $( \pm 3,25)$ & $( \pm 6,86)$ & $( \pm 15,47)$ & $( \pm 18,09)$ & $( \pm 12,76)$ & $( \pm 17,15)$ & $( \pm 1,54)$ & $( \pm 4,05)$ & $( \pm 18,88)$ & $( \pm 12,10)$ & $( \pm 7,21)$ \\
\hline & & 69,00 & 97,69 & 116,38 & 116,79 & 117,53 & 108,06 & 115,07 & 114,73 & 120,72 & 144,71 & 123,74 & 144,44 & 143,11 & 133,78 & 138,44 & 138,77 & 127,10 & 130,33 & 143,33 \\
\hline & Alt & $( \pm 9,17)$ & $( \pm 25,33)$ & $( \pm 28,55)$ & $( \pm 22,80)$ & $(0,47)$ & $( \pm 8,94)$ & $36,47)$ & $( \pm 25,89)$ & $( \pm 36,84)$ & $( \pm 43,20)$ & $3,22)$ & $( \pm 35,01)$ & $( \pm 3$ & 4,83) & $( \pm 22,93)$ & $1,73)$ & $5,53)$ & $( \pm 5,77)$ & $\begin{array}{c}( \pm \\
19,14)\end{array}$ \\
\hline
\end{tabular}




\begin{tabular}{|c|c|c|c|c|c|c|c|c|c|c|c|c|c|c|c|c|c|c|c|c|}
\hline \multirow{4}{*}{ 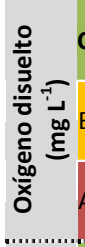 } & Control & $\begin{array}{c}\mathbf{5 , 7 2} \\
( \pm 0,23) \\
5,63\end{array}$ & $\begin{array}{c}5,72 \\
( \pm 0,23)\end{array}$ & $\begin{array}{c}5,73 \\
( \pm 0,23)\end{array}$ & $\begin{array}{c}5,73 \\
( \pm 0,23)\end{array}$ & $\begin{array}{c}5,74 \\
( \pm 0,23)\end{array}$ & $\begin{array}{c}5,74 \\
( \pm 0,23)\end{array}$ & $\begin{array}{c}5,74 \\
( \pm 0,23)\end{array}$ & $\begin{array}{c}5,74 \\
( \pm 0,23)\end{array}$ & $\begin{array}{c}5,75 \\
( \pm 0,23)\end{array}$ & $\begin{array}{c}5,75 \\
( \pm 0,23)\end{array}$ & $\begin{array}{c}5,76 \\
( \pm 0,23)\end{array}$ & $\begin{array}{c}5,76 \\
( \pm 0,23)\end{array}$ & $\begin{array}{c}5,76 \\
( \pm 0,23)\end{array}$ & $\begin{array}{c}5,76 \\
( \pm 0,23)\end{array}$ & $\begin{array}{c}5,76 \\
( \pm 0,23)\end{array}$ & $\begin{array}{c}5,76 \\
( \pm 0,23)\end{array}$ & $\begin{array}{c}5,76 \\
( \pm 0,23\end{array}$ & $\begin{array}{c}5,72 \\
\pm 0,25\end{array}$ & $\begin{array}{c}5,75 \\
( \pm 0,18)\end{array}$ \\
\hline & Bajo & $\begin{array}{c}5,63 \\
( \pm 0,13)\end{array}$ & $\begin{array}{c}5,64 \\
( \pm 0,13)\end{array}$ & $\begin{array}{c}5,64 \\
( \pm 0,13)\end{array}$ & $\begin{array}{c}5,65 \\
( \pm 0,13)\end{array}$ & $\begin{array}{c}5,65 \\
( \pm 0,13)\end{array}$ & $\begin{array}{c}5,66 \\
( \pm 0,13)\end{array}$ & $\begin{array}{c}5,66 \\
( \pm 0,13)\end{array}$ & $\begin{array}{c}5,66 \\
( \pm 0,13)\end{array}$ & $\begin{array}{c}5,66 \\
( \pm 0,13)\end{array}$ & $\begin{array}{c}5,67 \\
( \pm 0,13)\end{array}$ & $\begin{array}{c}5,67 \\
( \pm 0,13)\end{array}$ & $\begin{array}{c}5,68 \\
( \pm 0,13)\end{array}$ & $\begin{array}{c}5,68 \\
( \pm 0,13)\end{array}$ & $\begin{array}{c}5,68 \\
( \pm 0,13)\end{array}$ & $\begin{array}{c}5,68 \\
( \pm 0,13)\end{array}$ & $\begin{array}{c}5,68 \\
( \pm 0,13)\end{array}$ & $\begin{array}{c}5,68 \\
( \pm 0,13)\end{array}$ & $\begin{array}{c}5,67 \\
( \pm 0,12)\end{array}$ & $\begin{array}{c}5,64 \\
( \pm 0,17)\end{array}$ \\
\hline & \multirow{2}{*}{ Alto } & 5,62 & 5,62 & 5,63 & 5,63 & 5,63 & 5,64 & 5,64 & 5,64 & 5 , & 5 , & 5,66 & 5,66 & 5,66 & 5,66 & 5,66 & 5,66 & 5,66 & 5,67 & 5,67 \\
\hline & & $( \pm 0,17)$ & $( \pm 0,17)$ & $( \pm 0,17)$ & $( \pm 0,17)$ & $( \pm 0,17)$ & $( \pm 0,17)$ & $( \pm 0,17)$ & $( \pm 0,17)$ & $( \pm 0,17)$ & $( \pm 0,17)$ & $( \pm 0,17)$ & $( \pm 0,17)$ & $( \pm 0,17)$ & $( \pm 0,17)$ & $( \pm 0,17)$ & $( \pm 0,17)$ & $\pm 0,17$ & )$( \pm 0,24$ & $( \pm 0,19)$ \\
\hline \multirow{4}{*}{ 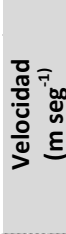 } & Control & $\begin{array}{c}0,34 \\
( \pm 0,08)\end{array}$ & $\begin{array}{c}0,31 \\
( \pm 0,02)\end{array}$ & $\begin{array}{c}0,36 \\
( \pm 0,05)\end{array}$ & 0,36 & $\begin{array}{c}0,39 \\
( \pm 0,05)\end{array}$ & $\begin{array}{c}0,34 \\
( \pm 0,05)\end{array}$ & $\begin{array}{c}0,30 \\
( \pm 0,06)\end{array}$ & $\begin{array}{c}0,38 \\
( \pm 0,08)\end{array}$ & $( \pm 0,08)$ & 0,33 & $\begin{array}{c}0,30 \\
( \pm 0,04)\end{array}$ & $\begin{array}{c}0,33 \\
( \pm 0,02)\end{array}$ & $\begin{array}{c}0,32 \\
( \pm 0,03)\end{array}$ & $\begin{array}{c}0,33 \\
( \pm 0,02)\end{array}$ & $\begin{array}{c}0,32 \\
( \pm 0,02)\end{array}$ & $\begin{array}{c}0,32 \\
( \pm 0,03)\end{array}$ & $\begin{array}{c}0,31 \\
( \pm 0,01)\end{array}$ & $\begin{array}{c}0,34 \\
( \pm 0,07)\end{array}$ & 0,30 \\
\hline & Bajo & $\begin{array}{c}0,41 \\
( \pm 0,05)\end{array}$ & $\begin{array}{c}0,37 \\
( \pm 0,04)\end{array}$ & $\begin{array}{c}0,41 \\
( \pm 0,04)\end{array}$ & $\begin{array}{c}0,36 \\
( \pm 0,04)\end{array}$ & $\begin{array}{c}0,38 \\
( \pm 0,05)\end{array}$ & $\begin{array}{c}0,38 \\
( \pm 0,04)\end{array}$ & $\begin{array}{c}0,36 \\
( \pm 0,03)\end{array}$ & $\begin{array}{c}0,41 \\
( \pm 0,09)\end{array}$ & $\begin{array}{c}0,33 \\
( \pm 0,05)\end{array}$ & $\begin{array}{c}0,36 \\
( \pm 0,07)\end{array}$ & $\begin{array}{c}0,39 \\
( \pm 0,06)\end{array}$ & $\begin{array}{c}0,46 \\
( \pm 0,01)\end{array}$ & $\begin{array}{c}0,39 \\
( \pm 0,01)\end{array}$ & $\begin{array}{c}0,38 \\
( \pm 0,00)\end{array}$ & $\begin{array}{c}0,37 \\
( \pm 0,01)\end{array}$ & $\begin{array}{c}0,34 \\
( \pm 0,01)\end{array}$ & $\begin{array}{c}0,38 \\
( \pm 0,01)\end{array}$ & $\begin{array}{c}0,38 \\
( \pm 0,00)\end{array}$ & $\begin{array}{c}0,39 \\
( \pm 0,01)\end{array}$ \\
\hline & \multirow{2}{*}{ Alto } & 0,44 & 0,45 & 0,45 & 0,45 & 0,52 & 0,43 & 0,49 & 0,47 & 0,55 & 0,41 & 0,51 & 0,47 & 0,46 & 0,47 & 0,43 & 0,49 & 0,46 & 0,45 & 0,42 \\
\hline & & $( \pm 0,05)$ & $( \pm 0,06)$ & $( \pm 0,03)$ & $( \pm 0,05)$ & $( \pm 0,09)$ & $( \pm 0,09)$ & $( \pm 0,10)$ & $( \pm 0,11)$ & $( \pm 0,05)$ & $( \pm 0,03)$ & $( \pm 0,04)$ & $( \pm 0,04)$ & $( \pm 0,05)$ & $( \pm 0,02)$ & $( \pm 0,05)$ & $( \pm 0,02)$ & $( \pm 0,02)$ & $( \pm 0,01)$ & $( \pm 0,03)$ \\
\hline
\end{tabular}
estándar)

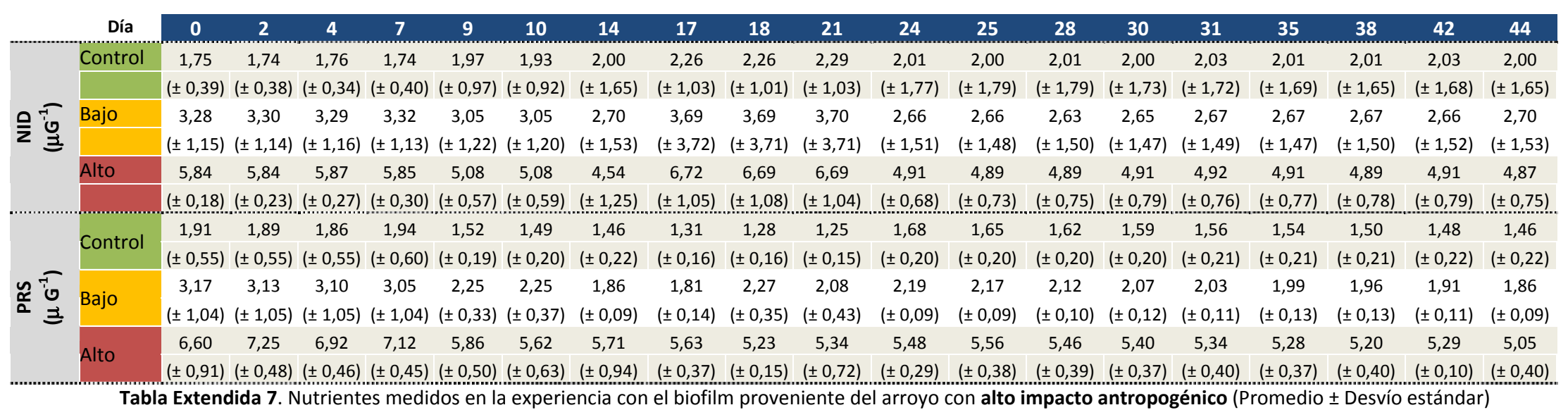




\begin{tabular}{|c|c|c|c|c|c|c|}
\hline & Día & 0 & 8 & 16 & 24 & 32 \\
\hline \multirow{6}{*}{$\begin{array}{l}\text { Clorofila "a" } \\
\left(\mathrm{mg} \cdot \mathrm{cm}^{-2}\right)\end{array}$} & \multirow{2}{*}{ Control } & 0,56 & 0,58 & 0,63 & 0,52 & 0,65 \\
\hline & & $( \pm 0,06)$ & $( \pm 0,13)$ & $( \pm 0,17)$ & $( \pm 0,18)$ & $( \pm 0,17)$ \\
\hline & \multirow{2}{*}{ Bajo } & 0,77 & 0,62 & 0,72 & 0,41 & 0,66 \\
\hline & & $( \pm 0,10)$ & $( \pm 0,06)$ & $( \pm 0,35)$ & $( \pm 0,12)$ & $( \pm 0,14)$ \\
\hline & \multirow{2}{*}{ Alto } & 0,46 & 0,69 & 0,54 & 0,37 & 0,82 \\
\hline & & $( \pm 0,20)$ & $( \pm 0,13)$ & $( \pm 0,04)$ & $( \pm 0,12)$ & $( \pm 0,38)$ \\
\hline \multirow{6}{*}{$\begin{array}{l}\text { Biomasa } \\
\text { bacteriana } \\
\left(\mu \mathrm{gC} \mu \mathrm{m}^{-3} \mathrm{~cm}^{-2}\right)\end{array}$} & \multirow[b]{2}{*}{ Control } & 18,26 & 34,87 & 34,73 & 32,82 & 41,25 \\
\hline & & $( \pm 8,97)$ & $( \pm 9,31)$ & $( \pm 9,38)$ & $( \pm 6,72)$ & $( \pm 11,99)$ \\
\hline & \multirow{2}{*}{ Bajo } & 16,59 & 33,24 & 33,25 & 35,87 & 33,87 \\
\hline & & $( \pm 5,20)$ & $( \pm 5,26)$ & $( \pm 5,20)$ & $( \pm 6,72)$ & $( \pm 9,09)$ \\
\hline & \multirow[b]{2}{*}{ Alto } & 19,72 & 36,43 & 36,40 & 37,28 & 37,31 \\
\hline & & $( \pm 3,96)$ & $( \pm 3,93)$ & $( \pm 3,99)$ & $( \pm 6,13)$ & $( \pm 2,14)$ \\
\hline \multirow{6}{*}{$\begin{array}{l}\text { Carbohidratos totales } \\
\left(\mathrm{mg} \mathrm{mL}^{-1}\right)\end{array}$} & \multirow{2}{*}{ Control } & 0,31 & 0,27 & 0,41 & 0,24 & 0,32 \\
\hline & & $( \pm 0,40)$ & $( \pm 0,30)$ & $( \pm 0,28)$ & $( \pm 0,15)$ & $( \pm 0,29)$ \\
\hline & \multirow{2}{*}{ Bajo } & 6,31 & 11,90 & 11,77 & 11,10 & 14,15 \\
\hline & & $( \pm 10,35)$ & $( \pm 19,90)$ & $( \pm 19,89)$ & $( \pm 18,80)$ & $( \pm 23,47)$ \\
\hline & \multirow{2}{*}{ Alto } & 10,25 & 15,94 & 15,94 & 16,44 & 18,31 \\
\hline & & $( \pm 5,80)$ & $( \pm 15,12)$ & $( \pm 15,13)$ & $( \pm 16,83)$ & $( \pm 13,55)$ \\
\hline \multirow{6}{*}{$\begin{array}{l}\text { Actividad respiratoria } \\
\text { total } \\
\left(\mu \mathrm{g} \text { formazan } \mathrm{cm}^{-2} \mathrm{~h}^{-1}\right)\end{array}$} & \multirow{2}{*}{ Control } & 35,32 & 36,93 & 36,88 & 36,35 & 35,33 \\
\hline & & $( \pm 1,31)$ & $( \pm 1,53)$ & $( \pm 1,44)$ & $( \pm 2,80)$ & $( \pm 2,57)$ \\
\hline & \multirow{2}{*}{ Bajo } & 33,38 & 33,44 & 36,72 & 35,20 & 36,00 \\
\hline & & $( \pm 2,84)$ & $( \pm 2,80)$ & $( \pm 4,75)$ & $( \pm 1,62)$ & $( \pm 1,00)$ \\
\hline & \multirow{2}{*}{ Alto } & 32,51 & 35,81 & 35,72 & 35,90 & 34,83 \\
\hline & & $( \pm 4,58)$ & $( \pm 2,40)$ & $( \pm 9,78)$ & $( \pm 2,78)$ & $( \pm 4,25)$ \\
\hline \multirow{6}{*}{$\begin{array}{l}\text { Peso seco libre de } \\
\text { cenizas } \\
\left.(\mathrm{mg} \mathrm{cm})^{-2}\right)\end{array}$} & \multirow{2}{*}{ Control } & 0,05 & 0,05 & 0,05 & 0,03 & 0,03 \\
\hline & & $( \pm 0,02)$ & $( \pm 0,02)$ & $( \pm 0,02)$ & $( \pm 0,00)$ & $( \pm 0,00)$ \\
\hline & \multirow{2}{*}{ Bajo } & 0,07 & 0,07 & 0,06 & 0,03 & 0,03 \\
\hline & & $( \pm 0,01)$ & $( \pm 0,01)$ & $( \pm 0,01)$ & $( \pm 0,01)$ & $( \pm 0,01)$ \\
\hline & \multirow{2}{*}{ Alto } & 0,07 & 0,07 & 0,07 & 0,03 & 0,03 \\
\hline & & $( \pm 0,02)$ & $( \pm 0,02)$ & $( \pm 0,00)$ & $( \pm 0,00)$ & $( \pm 0,00)$ \\
\hline
\end{tabular}

Tabla Extendida 8. Variable biológicas medidas en la experiencia con el biofilm proveniente del arroyo con alto impacto antropogénico (Promedio \pm Desvío estándar) 


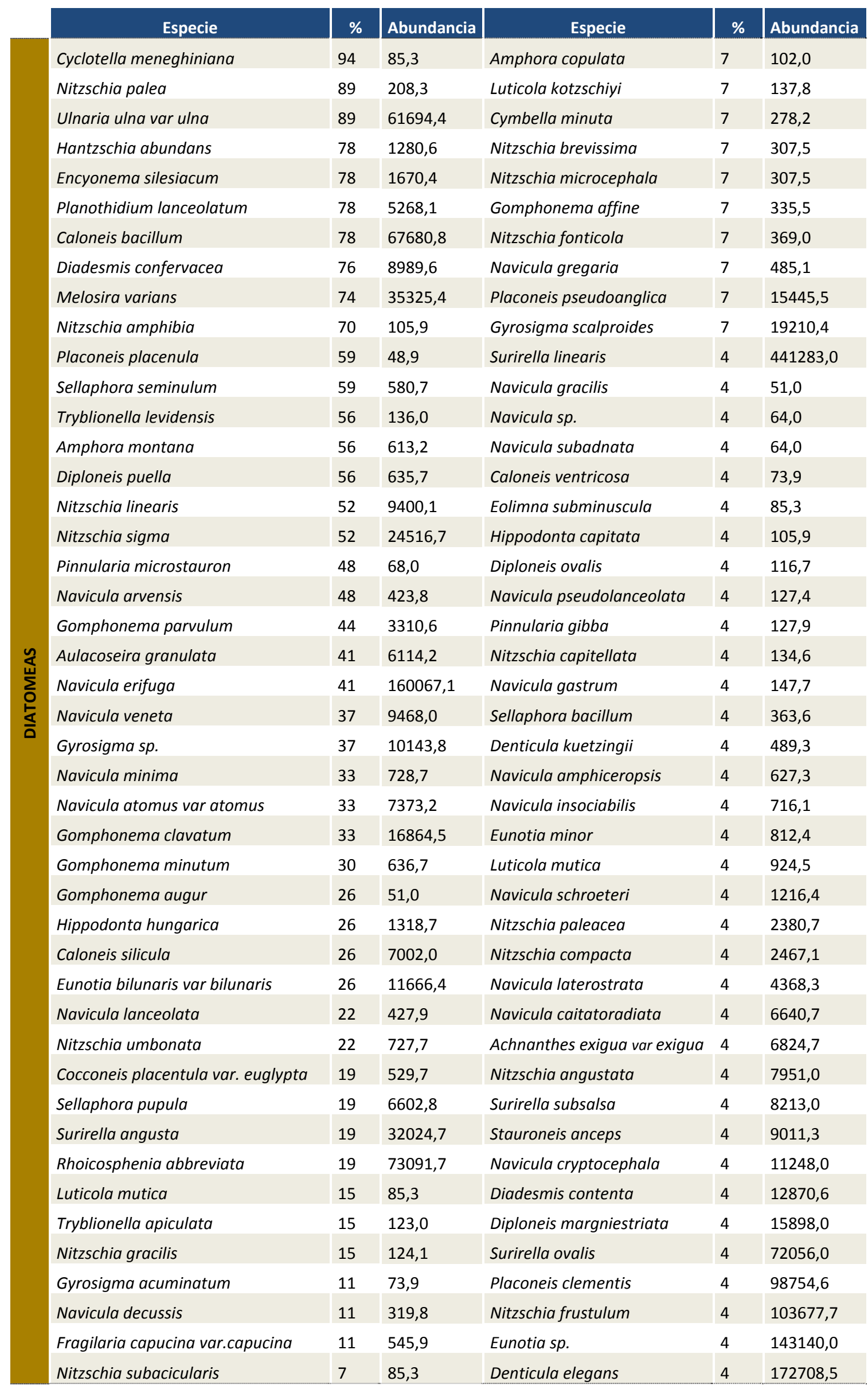




\begin{tabular}{|c|c|c|c|}
\hline & Especie & $\%$ & Abundancia \\
\hline CIANOBACTERIAS & Oscillatoria tenuissima & 63 & 350656,0 \\
\hline \multirow{2}{*}{ EUGLENOFITAS } & Phacus aff longicauda & 11 & 132380,0 \\
\hline & Euglena acus & 4 & 73,3 \\
\hline \multirow{5}{*}{ CLOROFITAS } & Scenedesmus opoliensis & 70 & 2793,3 \\
\hline & Closterium intermedium & 15 & 256,0 \\
\hline & Cosmarium sp. & 11 & 162,7 \\
\hline & Pediastrum duplex & 7 & 621,3 \\
\hline & Coelastrum microporum & 2 & 192,0 \\
\hline \multirow{3}{*}{ PROTOZOOS } & Ciliados & 22 & 660,7 \\
\hline & Arcella discoides & 19 & 415,3 \\
\hline & Centopyxis sp. & 6 & 144,0 \\
\hline \multirow{2}{*}{ ROTÍFEROS } & Trichocerca sp. & 4 & 554,7 \\
\hline & Cephallodella sp. & 9 & 232,0 \\
\hline BRANCHIOPODOS & Branchiopodos & 33 & 649,3 \\
\hline NEMATODES & Nematodes & 39 & 1029,3 \\
\hline COPEPODOS & Copepoditos & 2 & 26,7 \\
\hline
\end{tabular}

Tabla Extendida 9. Especies presentes en los biofilms del arroyo con bajo impacto antropogénico, con su frecuencia (\%) y abundancia relativa (cél. $\mathrm{mL}^{-1}$ ) promedio durante toda la experiencia. 


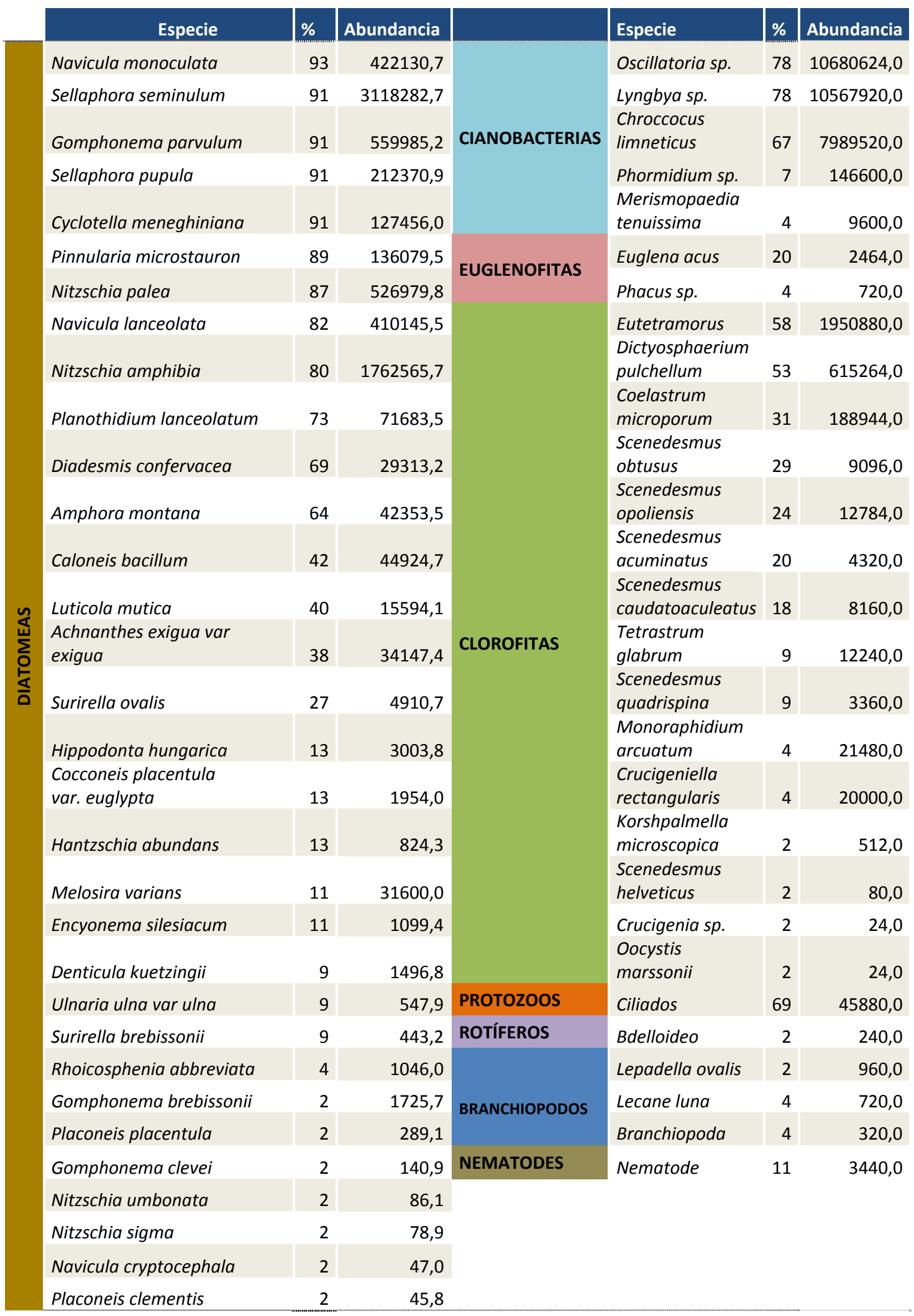

Tabla Extendida 10. Especies presentes en los biofilms del arroyo con alto impacto antropogénico, con su frecuencia (\%) y abundancia relativa (cél. $\mathrm{mL}^{-1}$ ) promedio durante toda la experiencia. 